Universidade de São Paulo

Instituto de Astronomia, Geofísica e Ciências Atmosféricas

Departamento de Geofísica

Daniele Cornellio de Paiva Caldeira Brandt

\title{
The use of giant Gaussian process models to study the paleomagnetic field of the Kiaman superchron
}

São Paulo 



\section{The use of giant Gaussian process models to study the paleomagnetic field of the Kiaman superchron}

Versão Corrigida. O original encontra-se disponível na Unidade.

Thesis presented to the Geophysical Department of the Institute of Astronomy, Geophysics and Atmospheric Sciences of the University of São Paulo as a partial requirement to obtain the title of Doctor of Science.

Concentration Area: Paleomagnetism Advisor: Profa. Dr. Marcia Ernesto

São Paulo

2020

Daniele C. P. C. Brandt 



\title{
O uso de modelos de processos Gaussianos gigantes para estudar o campo paleomagnético do superchron Kiaman
}

\author{
Tese apresentada ao Departamento \\ Geofísica do Instituto de Astronomia, \\ Geofísica e Ciências Atmosféricas da \\ Universidade de São Paulo como requisito \\ parcial para obtenção do título de Doutor em \\ Ciências.
}

Área de Concentração: Paleomagnetismo

Orientadora: Profa. Dra. Marcia Ernesto

São Paulo

2020

Daniele C. P. C. Brandt 

To my loves Guilherme and Plinio who are always with me, giving me love, strength, support, and coffee. 



\section{Acknowledgment}

I would not be able to do this work without all the human and material resources provided by the University of São Paulo and the Brazilian federal government. I also want to thank all the incredibly wonderful people who were around me in these years of work and fun, because doing science is also amusing.

I thank the advisor professor Marcia Ernesto, who respects my time and is the best person to talk about important decisions.

Professor Cathy Constable, who received me at the IGPP of the Scripps Institution of Oceanography, introduced me to her paleomagnetic group and dedicated me a lot of time.

Professor Ricardo Trindade, who is always presenting me with brilliant questions that make me grow.

Coordenação de Aperfeiçoamento de Pessoal de Nível Superior - Brasil (CAPES), for the financial support related to my internship at Scripps (San Diego, USA), code 88881.186997/2018-01.

Professor Lisa Tauxe, the paleomagnetic group at Scripps, and IGPP staff Iris and Paul.

The professors, staff, and colleagues of the Institute of Astronomy, Geophysics and Atmospheric Sciences of the University of São Paulo, especially Yara Marangoni, who masterfully coordinated the Geophysics program, Marcelo Bianchi and Victor Sacek, who allowed me to participate in the summer course of Python, and Carlos Alberto Mendonça for the discussions on inversion problems. Secretaries and friends Eliza and Luanah for their professional and emotional support. Rosa and the people from the library who helped me during the bibliographic research. The driver Leandro. The IT team: Edilson, Dennis and Marco. Luciana and Eduardo from the cafeteria. Special thanks to Rafael Monteiro da Silva, who, more than a friend, is my personal trainer in Python.

All the people from the USPMAG laboratory who were with me during this period enjoying our paleocafé or paleocerveja, in particular: Janine, who brings happiness to our group, Grasiane Mathias, who is my inspiration as a mother-scientist, Wilbor, Filipe Temporim, Filipe, Karine, Jhon, Kamilla, Aruã, Ualisson, Thiago, Franklin, Pedro Paiva, Marta, Caio, Letícia, Julia, Paul, Francesco, and Guilherme Begnini. Professors Elder Yokoyama, Jairo, Gelvam Hartman, Daniel Franco, Manoel D'Agrella, Eric Thover, Igor Pacca for following my development and Andrea Ustra for the mental guidance related to paper reviews and tips for mother scientists. Sonia Alonso for bringing happiness and cakes 
to our group. The lots of visiting researchers that passed by. I am very grateful for the essential support given by my colleague Giovanni Moreira when I was not available.

My friends who gave me emotional support Camila Nagamine, Priscilla Leão, Fátima Pesqueira, Vanessa Sicchiroli, Maria Carolina Rubinato, Juninho Mascarenhas, Marcos do Caxingui, Maíra Pippus, Maria Clara Sassaki, Aline Antonucci, Gabriel Martins, Talita Cristina, Mariane Temellis, my neighbors Fernanda and Juliana, the mothers of the Doyle school Hyeyoung, Zaure, Amy, Ishita, Natalia and Melissa, the mothers of the Vital Brazil school Clarissa, Mônica and Simone.

I am very grateful to Gabriela Gazeta and Alexandre Collepicolo, who gave the most important help when we arrived in San Diego and are very special friends of our family.

My sister, meteorologist and runner, Desirée, who showed me it was possible to enter the university, introduced me to the geophysics department and gives me a lot of emotional support. My architect brother Fellipe for cheering me on and giving me lots of parties. My brother-in-law Leonardo for preparing delicious foods and supporting me in the programming. My uncle Fernando, who challenged me with my first math problem to solve and helps me up to now, Aunt Celia, for teaching me English and helping me with the most difficult life decisions, my Aunt Jurema, my sister-in-law Isadora Toledo, my mother-in-law Magali, my godmother Mariana Rubinato, for supporting me. My cousin Débora, for inspiring me with the courage to live abroad, Beatriz, for her incredible sense of humor and memory, and Mariana for always being with me in all situations, maybe that's why I think she was born on the same day as I. My nephews Manuela, Paola, Guilherme and Gustavo for the happiness they give me.

My boyfriend, Plinio Jaqueto, who showed countless ways to give love and support. By my side or at six time-zones of distance, he helped me look after our family and remember where I came from.

My son, Guilherme, who is always with me, strengthens me and for being an incredibly brave boy, who faced the difficulties of living abroad during a period of great emotion that we were going through.

My mother Sandra, who always supports me, helps me raise my son and makes the best rice and beans in the world. And my father Alfredo, who encouraged me to look for the best, and never discouraged me because I am a woman. I would like to thank him, for sure he would be very proud of everything I have done so far, we would celebrate and, soon after, he would be curious about my next step. 
"Benditas coisas que eu não sei Os lugares onde não fui Os gostos que não provei Meus verdes ainda não maduros"

(Mart'nália e Zélia Duncan) 



\begin{abstract}
The assessment of the long-term paleosecular variation (PSV) of the geomagnetic field is frequently based on a class of statistical models known as giant Gaussian processes (GGP). The shape of the distributions of the paleomagnetic directions predicted by the most recent GGP model (TK03) calculated for the last $5 \mathrm{Ma}$, is used as a reference even for older ages. However, its validity was not confirmed for the Paleozoic Era. Particularly, during superchrons, there is evidence that the field has a steadier behavior with depleted PSV. In this work, the Kiaman Superchron field is approached by two different ways for testing the validity of the TK03 model and determining its directional PSV based on GGP models. First, a new paleomagnetic dataset from the rhythmites of the Paleozoic Mafra Formation (southern Brazil) was tested and compared to predictions of elongation $E$ of directions and dispersion $S_{F}$ of virtual geomagnetic poles (VGPs) from synthetic directions drawn from the TK03 model (a Monte Carlo procedure). Second, an extensive directional paleomagnetic database from the Kiaman magnetic interval (Kiaman database) was evaluated using a new approach based on the scale and shape of the distributions of directions compared to predictions given by numerical integration of directional probability density functions of GGP models. The Mafra's results (E = 2.08 $\left.{ }_{1.44}^{3.13} ; \mathrm{S}_{F}=10.9_{9.8}^{11.8}\right)$ revealed incompatible with the TK03 model. Simulations of different versions of GGP models producing reduced $\mathrm{S}_{F}$, also found in other studies, imply in distributions with a different shape than the TK03 model, mainly at the Equator. The latitudinal dependence of the proposed measures of PSV $\left(\sigma_{E}\right.$ and $\sigma_{N}$ ) provided useful diagnostics for testing the validity of a GGP model. For the Kiaman, the latitudinal dependence of $\sigma_{N}$ and $\sigma_{E}$ calculated for an extensive directional paleomagnetic database (Kiaman database) composed of 1419 paleomagnetic directions of igneous rocks, merged into paleolatitudinal bands showed two characteristics: (1) an elongated and more dispersed distribution near the Equator; (2) an almost constant behavior of more concentrated and circular distributions for latitudes greater than $10^{\circ}$. Two GGP models, with parameters $K R S_{m}=\left(\alpha, \beta, g_{1}^{0}\right)=(6.2 \mu T, 3.4,18 \mu T)$ and $K R S^{\prime}{ }_{m}=(3.6 \mu T, 6.6,18 \mu T)$, were found, including and excluding the equatorial band data, respectively. However, for both Kiaman models, the misfit is larger than the data uncertainties, indicating that simplified GGP models are not able to describe the Kiaman PSV, or the common experimental noise is overshadowing its suppressed PSV.
\end{abstract}

Keywords: Paleomagnetism, Mafra Formation, Kiaman superchron, giant Gaussian process, paleosecular variation, directional distributions, shape and scale directional analyses. 



\section{Resumo}

A determinação da variação paleossecular de longa escala de tempo ( 'paleosecular variation', PSV) do campo geomagnético é frequentemente baseada em uma classe de modelos estatísticos conhecidos como processos Gaussianos gigantes ( 'giant Gaussian process', GGP). O formato das distribuições das direções paleomagnéticas previstas pelo modelo GGP mais recente (TK03) calculado para os últimos $5 \mathrm{Ma}$, é usado como referência mesmo para idades mais antigas. No entanto, sua validade ainda não foi confirmada para a Era Paleozóica. Particularmente, durante os superchrons, há evidências de que o campo tem um comportamento mais estável com a PSV reduzida. Neste trabalho, o campo geomagnético do Superchron Kiaman é abordado de duas maneiras diferentes para se testar a validade do modelo TK03 e determinar sua PSV direcional, com base em modelos GGP. Primeiramente, um novo conjunto de dados paleomagnéticos dos ritmitos Paleozóicos da Formação Mafra (Bacia do Paraná, sul do Brasil) foi testado e comparado com as previsões de alongamento $E$ das direções e dispersão $S_{F}$ dos pólos geomagnéticos virtuais a partir de direções sintéticas extraídas do modelo TK03 (procedimento de Monte Carlo). A seguir, um extenso banco de dados paleomagnéticos direcionais do intervalo Kiaman (Kiaman database) foi avaliado, usando uma nova abordagem baseada na escala e forma das distribuições de direções, em comparação com previsões fornecidas pela integração numérica das funções de densidade de probabilidade direcional dos modelos GGP. Os resultados de $\left(\mathrm{E}=2.08_{1.44}^{3.13} ; \mathrm{S}_{F}=10.9_{9.8}^{11.8}\right)$ revelaram-se incompatíveis com o modelo TK03. Simulações de diferentes versões de modelos GGP que produzem $S_{F}$ reduzidas, também encontradas em outros estudos, implicam em distribuições de formato diferente do modelo TK03, principalmente no Equador. A dependência latitudinal das medidas propostas de PSV $\left(\sigma_{E}\right.$ e $\left.\sigma_{N}\right)$ são diagnósticos úteis para testar a validade de um modelo GGP. A dependência latitudinal de $\sigma_{E}$ e $\sigma_{N}$ calculada para o banco de dados do Kiaman, composto por 1419 direções paleomagnéticas de rochas ígneas e organizadas em bandas de paleolatitudes, mostrou duas características: (1) uma distribuição alongada e mais dispersa perto do Equador; (2) um comportamento quase constante de distribuições mais concentradas e circulares para latitudes

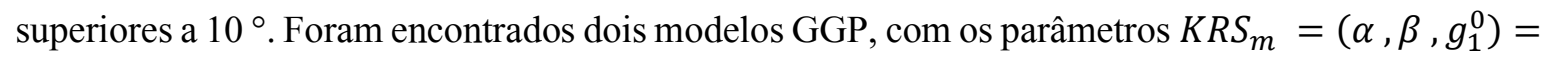
$(6.2 \mu T, 3.4,18 \mu T)$ and $K R S^{\prime}{ }_{m}=(3.6 \mu T, 6.6,18 \mu T)$, incluindo e excluindo os dados da banda equatorial, respectivamente. No entanto, para os dois modelos do Kiaman, as discrepâncias são maiores do que as incertezas dos dados, indicando que os modelos GGP simplificados não são capazes de descrever a PSV do Kiaman, ou então, o ruído experimental comumente encontrados em dados paleomagnéticos está ofuscando sua reduzida PSV.

Palavras-chave: Paleomagnetismo, Formação Mafra, Superchron Kiaman, processo Gaussiano gigante, variação paleo-secular, distribuições direcionais, análises direcionais de forma e escala. 



\section{Summary:}

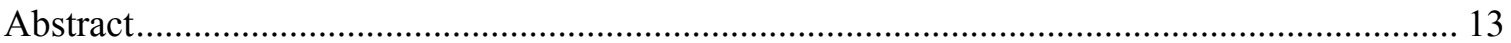

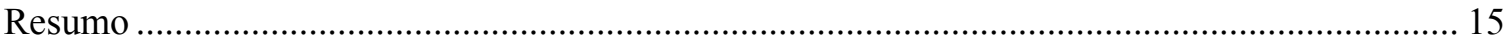

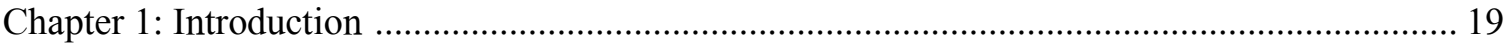

Chapter 2: Paleosecular variation models: theoretical background .............................................. 23

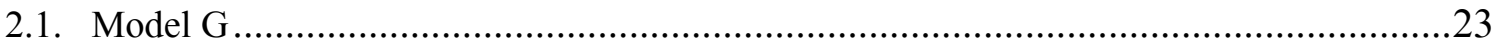

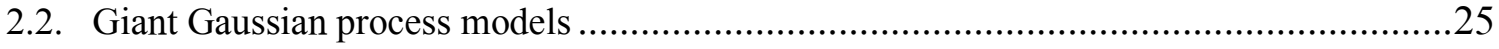

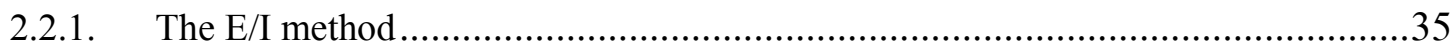

Chapter 3: Paleomagnetic results from Mafra Formation ............................................................ 37

New Late Pennsylvanian Paleomagnetic Results from Paraná Basin (Southern Brazil): Is the Recent

Giant Gaussian Process Model Valid for the Kiaman Superchron? (Article) ................................ 39

Chapter 4: Giant Gaussian process models of geomagnetic paleosecular variation: a directional

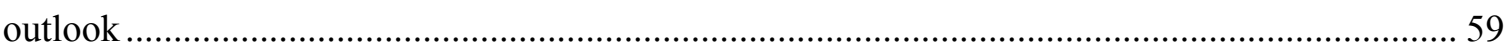

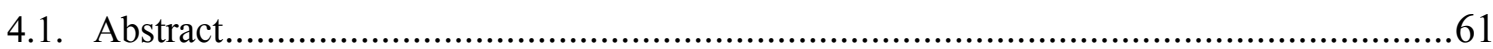

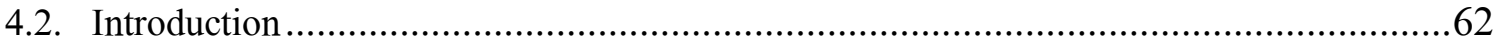

4.3. Predictions of PSV measurements for a simplified GGP model ...................................65

4.3.1. PSV measurements predictions of a simplified GGP model ................................68

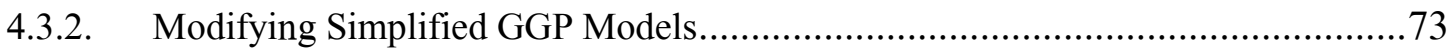

4.3.3. Assessing directional distributions from the last $10 \mathrm{Ma}$ : Real data.......................74

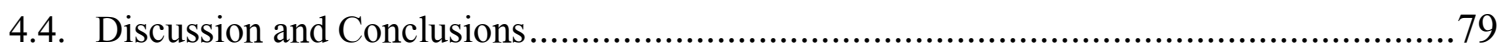

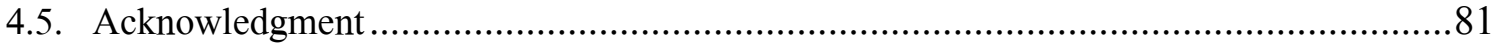

Chapter 5: Properties of the geomagnetic field during the Kiaman superchron: analysis of

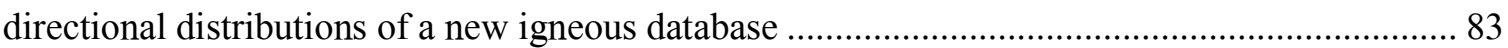

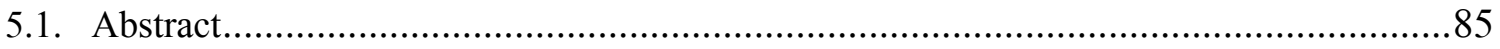

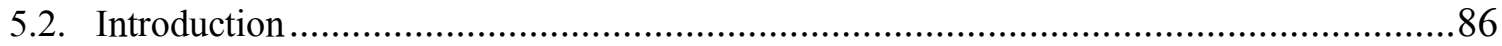

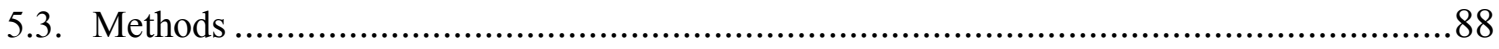

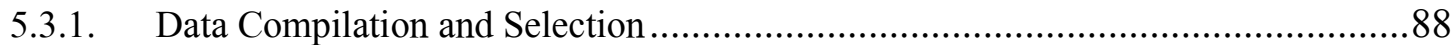

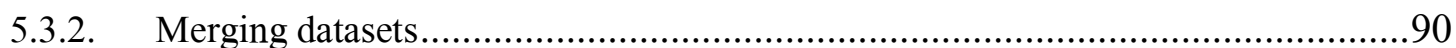

5.3.3. VGP Scatter and Model G-type PSV Analysis ....................................................91

5.3.4. Directional distributions - shape and scale of PSV .........................................92

5.4. The paleomagnetic database for the Kiaman times......................................................92

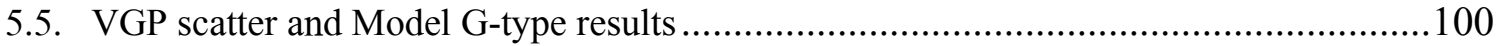

5.6. Shape and scale of directional PSV during Kiaman times..........................................102

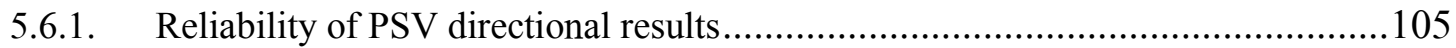


5.7. What was the geomagnetic field like during the Kiaman superchron?

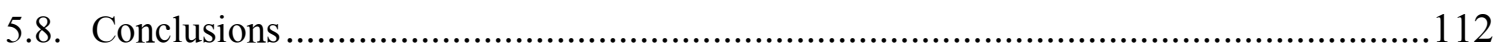

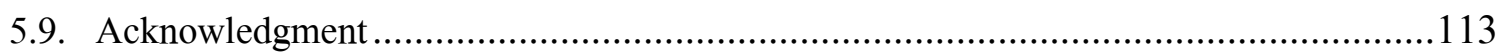

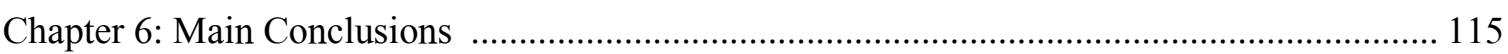

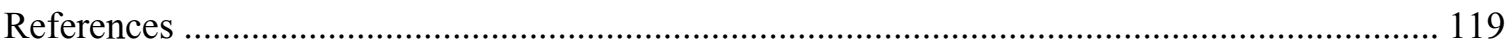




\section{Chapter 1:}

\section{Introduction}

The assessment of the geomagnetic field from the past gives us clues about the history of the deep Earth, based on the record of the geomagnetic field in rocks and archaeological artifacts. As we go back in time, the paleomagnetic record becomes scarcer geographically and temporarily. Thus, for studying the magnetic field throughout the Earth's history, simplifications are adopted: a mean-field generated by a geocentric axial dipole (GAD), and the use of the paleomagnetic record as spot readings of the temporal variations of the geomagnetic field. Even with these simplifications, we are able to investigate changes of the geomagnetic field throughout the geological time in terms of its mean strength (e.g. Tarduno et al., 2006), frequency of polarity reversals (e.g., Driscoll and Evans, 2016; Hounslow, 2016), the latitudinal dependence of the virtual geomagnetic poles (VGPs) scatter (e.g., McFadden et al., 1991; Biggin et al., 2008a; Biggin et al., 2008b; Smirnov et al., 2011; Oliveira et al., 2018; Doubrovine et al., 2019), and the shape of the distributions of the paleomagnetic directions (Tauxe and Kodama, 2009) through the statistical paleosecular variation (PSV) models.

The common paleomagnetic record considered for PSV studies are lavas, which can be considered as spot readings of the geomagnetic field, because of their fast cooling. The most used and latest PSV models are the G-model (McFadden et al., 1988) and the giant Gaussian process (GGP) type (Constable and Parker, 1988). The PSV models based on GGP are used to predict the distribution of directions at any point of the Earth (e.g. CP88, Constable and Parker, 1988; QC96, Quidelleur \& Courtillot, 1996; CJ99, Constable \& Johnson, 1999; TK03, Tauxe \& Kent, 2004). Available GGP models were determined using paleomagnetic directions from lava flows from the last $5 \mathrm{Ma}$. The most recent GGP model is the TK03, which was fitted to the most accurate dataset available at the time of publication (MM97, McElhinny and McFadden, 1997), and agrees with the latitudinal variation of VGPs dispersion found in MM97.

There is no GGP model that predicts the geomagnetic PSV from geological times older than the last $5 \mathrm{Ma}$, but analyses of some long records from igneous rocks confirmed that the elongation of directional distributions from Cretaceous and Proterozoic times (Tauxe et al., 2008; Tauxe and Kodama, 2009) are compatible to the predicted by the TK03 model. Also, the method of inclination shallowing correction, which relies on the elongation prediction 
from the TK03 model, named elongation/inclination (E/I) method (Tauxe and Kent, 2004), has been used for corrections of sedimentary data of any age. Shallowing correction has become a mandatory procedure for the late Paleozoic rocks since the majority of data of this age are derived from sedimentary rocks (Torsvik et al., 2012). Furthermore, the absence of inclination shallowing correction in the Paleozoic data has been pointed out as the cause of paleolatitudes overlapping error in Pangea reconstructions (Irving, 1977; Domeier et al., 2012).

The end of the Paleozoic Era is marked by the occurrence of a long superchron of reversed polarity which is called the Permo-Carboniferous Reversed Superchron ( $267-318$ Ma; Opdyke and Channell, 1996; Hounslow and Balabarov, 2018), and also known as the Kiaman Reverse Superchron. Superchrons are long time intervals (tens of million years) of a single polarity, and its cause has been linked to the deep mantle plume activity (Larson and Olson, 1991). The collapse of these superplumes causes a decrease in the core-mantle boundary heat flux and its lateral heterogeneity, resulting in the beginning of a superchron (Amit and Olson, 2015). The regrowth of the plume would again allow the possibility of field reversals.

Because of the long duration of the superchrons, they are expected to have a more stable mean dipole field with reduced angular dispersion of VGPs $\left(S_{F}\right)$, and higher intensities than periods of high reversal frequency (e.g., Tarduno et al., 2006). Some authors (McFadden et al., 1991; Biggin et al., 2008b; Oliveira et al., 2018;) have claimed stronger latitudinal dependence of $S_{F}$, and lower equatorial $S_{F}$ during superchrons. However, strong latitudinal dependence of $S_{F}$ is also observed for the last few million years and, therefore, this parameter is suspect of not being a reliable proxy for reversal frequency (Doubrovine et al., 2019).

Despite the pieces of evidence that behavior of the Kiaman field is considerably distinct from the last few million years, it became almost compulsory the use of the E/I method, and it has been applied to the Kiaman data by several authors (e.g., Brandt et al., 2009; Haldan et al., 2009; Franco et al., 2012; Lanci et al., 2013).This is so, because of the necessity of inclination shallowing correction of sedimentary Paleozoic rocks.

If the distribution of directions of a superchron is less scattered than the recent field but maintains the shape of the distribution with the same elongation for a given inclination, then the use of the TK03 model as a reference guide for superchrons is not incorrect, and the E/I method can be used. However, it is still not known whether this field model is valid for the Kiaman times. The longest paleomagnetic datasets from Kiaman igneous rocks presented 
smaller elongations than the TK03 model. However, the high uncertainties in the results made them inconclusive (Haldan et al., 2014; Bahzenov et al., 2016).

Apart from the knowledge about the shape of the distribution of the Kiaman directions, and the pertinence of using or not the inclination shallowing method for that time, the GGP model for past times (older than $5 \mathrm{Ma}$ ) is still not established. Therefore, this is a rich field of investigation and is what this thesis intends to explore.

During the development of this thesis, a new Kiaman sedimentary dataset (Brandt et al., 2019a) allowed the conclusion that the geomagnetic models based on recent data may not represent the Kiaman field behavior. Besides new paleomagnetic data, this work also contains a tentative of finding a GGP model for Kiaman times that could describe the VGPs scatter of this new dataset and the other two long series (Bahzenov et al., 2016; Haldan et al., 2014) using simulations of synthetic samples drawn from simplified GGP models. This study is an integrant part of this thesis and details are described in Chapter 3.

The keystone of this work is the proposition of a new methodology for describing de paleosecular variation from the distribution of directions using numerical determinations from directional probability density functions of simplified GGP models. This is presented in Chapter 4 in the format of a paper (Brandt et al., 2019b) already submitted to Geophysical Journal International, which is presently under revision. The evaluation of the suitability of using GGP models for describing the Kiaman field was tested by creating a comprehensive paleomagnetic directional database based only on igneous records. These results are described in a third paper (Chapter 5) which is ready but not yet submitted. 



\section{Chapter 2}

\section{Paleosecular variation models: theoretical background}

Two types of representations are commonly used to describe various aspects of the PSV: The model G (McFadden et al., 1988) and the GGP type model (Constable and Parker, 1988), hereafter described in more details.

\subsection{Model G}

Model $\mathrm{G}$ is based on the variation of the angular scatter ( $S$, Fisher's 1953 statistics) of the VGPs with the (paleo)latitude. McFadden et al. (1988) based on the idea that the magnetic field solutions for a spherical dynamo can be separated into two completely independent families (Roberts and Stix, 1972). Therefore, the contributions in VGP scatter given by dipolar $\left(S_{d}\right)$ and quadrupolar $\left(S_{q}\right)$ families are independent (Equation 2.1).

$$
S_{F}^{2}=S_{d}^{2}+S_{q}^{2}=(b \lambda)^{2}+a^{2}
$$

where $\lambda$ is the latitude, $S_{F}$ is the VGPs scatter associated with the paleosecular variation of the geomagnetic field, $a$ and $b$ are parameters associated with the quadrupolar and dipolar families.

The dipolar and quadrupolar families are also called by odd and even families, respectively. The parity of these families is found by the difference between $l$ and $m$ degree of the $g_{l}^{m}$ and $h_{l}^{m}$ coefficients of Gauss, which are used for describing with spherical harmonic functions a magnetic field produced by an internal source. Equation 2.2 shows the magnetic potential of a magnetic internal source described by an infinite sum of spherical harmonic functions:

$$
\Psi=r_{a} \sum_{l=1}^{\infty} \sum_{m=0}^{l}\left(\frac{r_{a}}{r}\right)^{l+1}\left(g_{l}^{m} \cos m \Phi+h_{l}^{m} \sin m \Phi\right) P_{l}^{m}(\cos \Theta)
$$

where $r_{a}$ is the Earth radius, $r, \Theta$, and $\Phi$ are the spherical coordinates, which are the distance from the center of the planet, co-latitude, and longitude, respectively. $P_{l}^{m}(\cos \Theta)$ are the partially normalized Schmidt functions, whose degree $l$ increases from 1 to infinity, depending on the complexity of the source. The degree $l$ cannot be zero because the simplest configuration of a magnetic source is a dipole $(l=1)$. The value of $m$ ranges from $m=0$ 
for a zonal magnetic source (invariant with longitude) to degree $m=l$. The magnetic field $\boldsymbol{B}$ is the gradient of the potential $\Psi$.

McFadden et al. (1988) analyzed the current geomagnetic field (given by IGRF65, Figure 2.1) and confirmed that the sum of the square of a quadrupolar and dipolar source of VGP scatter is compatible with the squared of total VGP scatter (Table 2 in McFadden et al., 1988). Moreover, simplified relationships between the VGP scatter caused by these independent sources were found; the dipolar family varies proportionally to the latitude $\left(S_{d}=b \lambda\right)$ while the quadrupolar families have no variation with latitude $\left(S_{q}=a\right)$. Thus, providing a model with parameters ( $a$ and $b$, Equation 2.1 ) that can be easily fitted to paleomagnetic data.

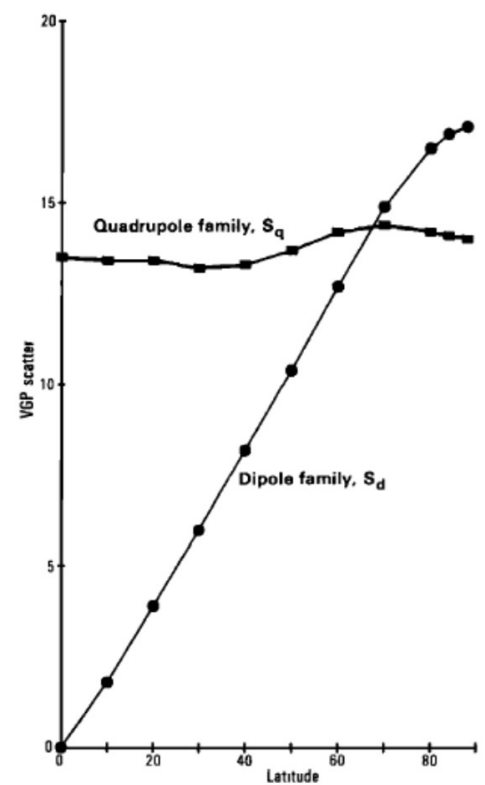

Figure 2.1. VGP scatter of IGRF65 with separated contributions: the quadrupole family (solid squares) and the dipole family (solid circles). Source: McFadden et al. (1988)

The application of the concept of the Model G throughout the geological past of the geomagnetic field, based on paleomagnetic records of older rocks was started with McFadden et al. (1991), modeling the geomagnetic field up to 200 Ma. An inverse relationship between the contribution of the two families was observed, when the dipolar family was more important, the quadrupolar family was less effective, and vice versa. The relative contribution of quadrupolar families was smaller during low-frequency rates, confirming a low contribution of quadrupolar components during the Cretaceous Normal Superchron (CNS). 
Biggin et al. (2008b) and Oliveira et al. (2018) also found that for superchrons the paleosecular variation evaluated by the model $\mathrm{G}$ was relatively suppressed for quadrupolar families and increased for dipolar families resulting in a higher ratio $b / a$ for these periods of stable polarity, when compared to the last $5 \mathrm{Ma}$ or Jurassic paleosecular results. The last paleosecular variation study for the CNS and pre-CNS times (Doubrovine et al., 2019), which was done using a new high-quality paleomagnetic database from lavas, found that the latitude dependence of $S_{F}$ is not a reliable proxy for reversal frequency, because compatible $b / a$ results are also found for the last $10 \mathrm{Ma}$.

The concept of Model G was also applied to paleomagnetic records of more than 2 billion years for studying the evolving conditions of the Earth's core (Biggin et al., 2008a; Smirnov et al., 2011). However, the use of model G to evaluate the past of the geomagnetic field is not out of criticism by the paleomagnetic community. Linder and Gilder (2012) have demonstrated that circular distribution of magnetic directions with the same precision parameter $\kappa$ (Fisher, 1953) along the globe result in an increasing VGP scatter with latitude, like the predictions of model $G$. This indicates that model $G$ is based on a mathematical artifact caused by the conversion from directions to poles, and for paleosecular variation studies the directional data should be analyzed instead of VGPs.

\subsection{Giant Gaussian process models}

The paleosecular variation model of the giant Gaussian process (GGP) type (first proposed by Constable and Parker, 1988) is able to predict the distribution of the magnetic field in any place on Earth's surface. It is based on the idea that the long-term variation of the geomagnetic field works as a natural statistical Gaussian process, which is described mathematically by normal distributions for each Gaussian coefficients $\left(g_{l}^{m}\right.$ and $\left.h_{l}^{m}\right)$. Then, a random instant $t_{i}$ of the past geomagnetic field is a random sample of the field $\boldsymbol{B}_{\boldsymbol{i}}$; this sample is described by a set of random samples of Gaussian coefficients $g_{l}^{m}$ and $h_{l}^{m}$ from distributions with mean values $\overline{g_{l}^{m}}$ and $\overline{h_{l}^{m}}$ and standard deviations $\sigma_{l}^{m}$. Because the degree $l$ varies up to infinite, an $l$ degree truncation is required for doing simulations of synthetic samples from GGP models, for example, a maximum degree $l=8$ was used for simulations done by Tauxe and Kent (2004).

The magnetic field $\boldsymbol{B}$ can be determined by the gradient of the potential $\Psi$, generated by an internal source, $\boldsymbol{B}=\left(B_{\Theta}, B_{\Phi}, B_{r}\right)=\left(-\frac{1}{r} \frac{\partial \Psi}{\partial \Theta},-\frac{1}{r \sin \Theta} \frac{\partial \Psi}{\partial \Phi},-\frac{\partial \Psi}{\partial r}\right)$. Using a more convenient mathematical representation of the field in terms of the fully normalized complex 
spherical harmonics with complex coefficients $b_{l}^{m}$, the magnetic potential is described by (equations following the appendix of Constable and Parker, 1988):

$$
\Psi=r_{a} \sum_{l=0}^{\infty} \sum_{m=-l}^{l}\left(\frac{r_{a}}{r}\right)^{l+1} b_{l}^{m} Y_{l}^{m}(\theta, \phi)
$$

where $r_{a}$ is the Earth radius,

$$
\begin{gathered}
b_{l}^{m}=\left\{\begin{array}{c}
(-1)^{m} \sqrt{\frac{2 \pi}{2 l+1}}\left[g_{l}^{m}-i h_{l}^{m}\right], m>0 \\
\sqrt{\frac{4 \pi}{2 l+1}} g_{l}^{0}, m=0 \\
(-1)^{m}\left(b_{l}^{m}\right)^{*}, m<0
\end{array}\right\} \\
Y_{l}^{m}(\theta, \phi)=\sqrt{\frac{2 l+1}{4 \pi} \frac{(l-m) !}{(l+m) !}} P_{l, m}(\cos \theta) e^{i m \phi} \\
Y_{l}^{m *}(\theta, \phi)=\sqrt{\frac{2 l+1}{4 \pi} \frac{(l-m) !}{(l+m) !}} P_{l, m}(\cos \theta) e^{-i m \phi}
\end{gathered}
$$

and the associated Legendre polynomials $P_{l, m}(\cos \theta)$ are:

$$
P_{l, m}(\cos \theta)=\frac{\sin ^{m} \theta}{2^{l}} \sum_{t=0}^{I n t\left(\frac{l-m}{2}\right)} \frac{(-1)^{t}(2 l-2 t) !}{t !(l-t) !(l-m-2 t) !} \cos ^{(l-m-2 t)} \theta
$$

The resulting orthogonal components are:

$$
\begin{gathered}
B_{r}=-\frac{\partial \Psi}{\partial r}=\sum_{l=0}^{\infty} \sum_{m=-l}^{l}(l+1)\left(\frac{r_{a}}{r}\right)^{l+2} b_{l}^{m} Y_{l}^{m}(\theta, \phi) \\
B_{\theta}=-\frac{1}{r} \frac{\partial \Psi}{\partial \theta}=-\sum_{l=0}^{\infty} \sum_{m=-l}^{l}\left(\frac{r_{a}}{r}\right)^{l+2} b_{l}^{m} \frac{d Y_{l}^{m}(\theta, \phi)}{d \theta} \\
B_{\phi}=-\frac{1}{r \sin \theta} \frac{\partial \Psi}{\partial \phi}=-\frac{r_{a}}{r \sin \theta} \sum_{l=0}^{\infty} \sum_{m=-l}^{l}\left(\frac{r_{a}}{r}\right)^{l+1} b_{l}^{m} \frac{d Y_{l}^{m}(\theta, \phi)}{d \phi}
\end{gathered}
$$

The resulting orthogonal components of $\boldsymbol{B}$ are linear combinations of $g_{l}^{m}$ and $h_{l}^{m}$, for a determined place. Because $g_{l}^{m}$ and $h_{l}^{m}$ are normally distributed in a GGP model, the orthogonal components are also distributed as normal gaussian distributions. Thus, the magnetic field $\boldsymbol{B}$ from a GGP model follows a 3D-gaussian probability distribution function (pdf).

For a zonal GGP model the coefficients $g_{l}^{m}$ and $h_{l}^{m}$ for the same $l, m$ degree vary with the same $\sigma_{l}^{m}$, then the covariances between $\Phi$ and $\Theta$, and $\Phi$ and $r$ are null $\left(\operatorname{Cov}\left(B_{\Theta}, B_{\Phi}\right)=\right.$ $\left.\operatorname{Cov}\left(B_{r}, B_{\Phi}\right)=0\right)$ and the other variances of $\boldsymbol{B}$ components are given by Equations 2.11 to 
2.14. The only non-zonal GGP model determined was the CJ98.nz proposed by Constable and Jhonson (1999), which has different $\sigma_{2}^{1}$ for $g_{2}^{1}$ and $h_{2}^{1}$ (see Table 2.1).

$$
\begin{gathered}
\sigma_{B_{\Theta}}^{2}=\sum_{l=1}^{\infty}\left[\sigma_{l}^{0^{2}}\left(\frac{d P_{l, 0}}{d \Theta}\right)^{2}+2 \sum_{m=1}^{l} \sigma_{l}^{m^{2}}\left(\frac{(l-m) !}{(l+m) !}\right)\left(\frac{d P_{l, m}}{d \Theta}\right)^{2}\right] \\
\sigma_{B_{\Phi}}^{2}=\frac{2}{\sin ^{2} \Theta} \sum_{l=0}^{\infty} \sum_{m=1}^{l} m^{2}{\sigma_{l}^{m}}^{2}\left(\frac{(l-m) !}{(l+m) !}\right) P_{l, m}(\cos \Theta)^{2} \\
\sigma_{B_{r}}^{2}=\sum_{l=0}^{\infty}(l+1)^{2}\left[\sigma_{l}^{0^{2}} P_{l, 0}(\cos \Theta)^{2}+2 \sum_{m=1}^{l} \sigma_{l}^{m^{2}}\left(\frac{(l-m) !}{(l+m) !}\right) P_{l, m}(\cos \Theta)^{2}\right] \\
\operatorname{Cov}\left(B_{r}, B_{\Theta}\right)=-\sum_{l=0}^{\infty}(l+1)\left(\frac{a}{r}\right)^{2 l+4}\left[\sigma_{l}^{0^{2}} P_{l, 0} \frac{d P_{l, 0}}{d \Theta}+2 \sum_{m=1}^{l} \sigma_{l}^{m^{2}} \frac{(l-m) !}{(l+m) !} P_{l, m} \frac{d P_{l, m}}{d \Theta}\right]
\end{gathered}
$$

A given instantaneous value $\boldsymbol{B}_{\boldsymbol{i}}$ of the field at a given location $(\Theta, \Phi)$ at the Earth's surface is a random sampling of a 3-D Gaussian pdf of random vectors $\boldsymbol{B}$, which its expected value $\boldsymbol{m}=E[\boldsymbol{B}]=E\left[\left(B_{\Theta}, B_{\Phi}, B_{r}\right)\right]$, is described by $\overline{g_{l}^{m}}$ and $\overline{h_{l}^{m}}$, and its covariance matrix $\operatorname{Cov}(\boldsymbol{B}, \boldsymbol{B})$ is described below:

$$
\operatorname{Cov}(\boldsymbol{B}, \boldsymbol{B})=\left[\begin{array}{ccc}
{\sigma_{B_{\Theta}}}^{2} & \operatorname{Cov}\left(B_{\Theta}, B_{\Phi}\right) & \operatorname{Cov}\left(B_{\Theta}, B_{r}\right) \\
\operatorname{Cov}\left(B_{\Theta}, B_{\Phi}\right) & \sigma_{B_{\Phi}}{ }^{2} & \operatorname{Cov}\left(B_{r}, B_{\Phi}\right) \\
\operatorname{Cov}\left(B_{\Theta}, B_{r}\right) & \operatorname{Cov}\left(B_{r}, B_{\Phi}\right) & {\sigma_{B_{\mathrm{r}}}}^{2}
\end{array}\right]
$$

Following Constable and Parker (1988) and using the equations presented by Khokhlov et al. (2006) the 3D-Gaussian pdf is given by:

$$
g(\boldsymbol{B})=\sqrt{\frac{\operatorname{det} \boldsymbol{\Lambda}}{(2 \pi)^{3}}} \exp \left[-\frac{1}{2}(\Lambda(\boldsymbol{B}-\boldsymbol{m}), \boldsymbol{B}-\boldsymbol{m})\right]
$$

where $\boldsymbol{\Lambda}=\operatorname{Cov}(\boldsymbol{B}, \boldsymbol{B})^{-1}$ is the inverse of the covariance matrix of the field at the location.

For unit vectors $(\boldsymbol{u})$ the pdf is given by integration across all values of the intensity $\rho$ of the paleomagnetic vectors (Constable and Parker, 1988; Khokhlov et al., 2001, equations are from Khokhlov et al., 2006). A pdf for the directional distribution is given by $s(\boldsymbol{u})$ :

$$
s(\boldsymbol{u})=\int_{0}^{\infty} g(\rho \boldsymbol{u}) d \rho
$$




$$
s(\boldsymbol{u})=e^{-\frac{1}{2} m^{2}} \cdot \frac{\sqrt{\operatorname{det} \Lambda}}{4 \pi|\boldsymbol{u}|_{\Lambda}^{3}}\left[z \sqrt{\frac{2}{\pi}}+e^{\frac{1}{2} z^{2}}\left(1+z^{2}\right)\left[1+\operatorname{Erf}\left(\frac{z}{\sqrt{2}}\right)\right]\right]
$$

where $\boldsymbol{u}$ is a unitary magnetic vector $\boldsymbol{u}=\boldsymbol{B} /|\boldsymbol{B}|$ and $\rho$ is the modulus of vector $\boldsymbol{B}$ in spherical coordinates; $|\boldsymbol{u}|_{\Lambda}=\sqrt{(\boldsymbol{u}, \boldsymbol{u})_{\Lambda}}=\sqrt{(\boldsymbol{\Lambda} \boldsymbol{u}, \boldsymbol{u})}$ is the $\boldsymbol{\Lambda}$-norm of $\boldsymbol{u}, z=\frac{(\boldsymbol{m}, \boldsymbol{u})_{\Lambda}}{|\boldsymbol{u}|_{\Lambda}}$, $(\boldsymbol{m}, \boldsymbol{u})_{\Lambda}$ is the $\boldsymbol{\Lambda}$-inner product $(\boldsymbol{m}, \boldsymbol{u})_{\Lambda}$, and $m=|\boldsymbol{m}|_{\Lambda}$. If the distribution is rotated to the origin (vertical), the covariance matrix is also rotated, and the expected field is given by: $\boldsymbol{m}_{\boldsymbol{r}}=(0,0,|\boldsymbol{m}|)$.

The 3D or directional (unit vectors) distribution from any GGP model is described by the model's covariance matrix $\operatorname{Cov}(\boldsymbol{B}, \boldsymbol{B})$ and the mean filed $\boldsymbol{m}$, which depend on the $\overline{g_{l}^{m}}$ or $\overline{h_{l}^{m}}$ and standard deviation $\sigma_{l}^{m}$. Table 2.1 shows the models CP88 (Constable and Parker, 1988), QC96 (Quidelleur \& Courtillot, 1996), CJ99 (Constable \& Johnson, 1999), and TK03 (Tauxe \& Kent, 2004) described by their $\overline{g_{l}^{m}}, \overline{h_{l}^{m}}$ and $\sigma_{l}^{m}$.

The first GGP model proposed for the last 5 million years was the CP88 (Constable and Parker, 1988), which has the same standard deviation $\sigma_{l}$ for an $l$ degree, independent of $m$, which were chosen individually up to $l=2$ (Table 2.1), and for the following $(l>2)$ they were determined by:

$$
\sigma_{l}^{2}=\frac{\left(c / r_{a}\right)^{2 l} \alpha^{2}}{(l+1)(2 l+1)}
$$

where $\alpha$ is a fitted parameter and $c / r_{a}=0.547$ is the ratio of the core radius to the Earth radius. Substituting $\sigma_{l}$ from Equation 2.15 to calculate the variances (Equations 2.11-14) allows the calculus for infinite $l$, using a converging series (see Appendix 2 in Constable and Parker, 1988). The only no-null mean Gaussians coefficients of CP88 are $\overline{g_{1}^{0}}$ and $\overline{g_{2}^{0}}$, which described a dipolar mean-field with a small contribution of quadrupolar zonal field.

After CP88, other more complex models (QC96, Quidelleur \& Courtillot, 1996; CJ99, Constable \& Johnson, 1999) were fitted to the paleomagnetic data from lavas of the last 5 million years, which was updated and changing with time, and follow the same type of building: choosing the $\sigma_{l}^{m}$ individually up to $l=2$ (Table 2.1), but in these cases, with different values depending also on the $m$ degree, and for $l>2$ the Equation 2.15 is also used, which allows the calculation of the variances in $\boldsymbol{B}$ without truncation of $l$. The intensity of $\overline{g_{1}^{0}}$ is the same and small quadrupolar components $\left(g_{2}^{0}\right)$ are also present in the mean-field of these models. 
Table 2.1. GGP model for the last 5Ma parameters: CP88 (Constable and Parker, 1988), QC96 (Quidelleur \& Courtillot, 1996), CJ99 (Constable \& Johnson, 1999), and TK03 (Tauxe \& Kent, 2004).

\begin{tabular}{cccccc}
\hline & CP88 & QC96 & CJ98 & CJ98.nz & TK03.GAD \\
\hline$\overline{g_{1}^{0}}$ & -30.0 & -30.0 & -30.0 & -30.0 & -18.0 \\
$\overline{g_{2}^{0}}$ & -1.8 & -1.2 & -1.5 & -1.5 & 0 \\
$\sigma_{1}^{0}$ & 3.0 & 3.0 & 11.72 & 11.72 & $\beta \sigma_{l}=6.4$ \\
$\sigma_{1}^{1}$ & 3.0 & 3.0 & 1.67 & 1.67 & $\sigma_{l}=1.7$ \\
$\sigma_{2}^{0}$ & $\sigma_{l}=2.14$ & 1.3 & 1.16 & 1.16 & $\sigma_{l}=0.6$ \\
$\sigma_{2}^{1}$ & $\sigma_{l}=2.14$ & 4.3 & 4.06 & $1.16(\mathrm{~g}), 8.12(\mathrm{~h})$ & $\beta \sigma_{l}=2.2$ \\
$\sigma_{2}^{2}$ & $\sigma_{l}=2.14$ & 1.3 & 1.16 & 1.16 & $\sigma_{l}=0.6$ \\
$\alpha$ & 27.7 & 27.7 & 15.0 & 15.0 & 7.5 \\
$\beta$ & & & & & 3.8 \\
\hline
\end{tabular}

Tauxe and Kent (2004) searched for a GGP model for the last $5 \mathrm{Ma}$ using the paleomagnetic database MM97 (McElhinny and McFadden, 1997). The time average field (TAF) of the TK03 model is a geocentric axial dipole (GAD), where the $\overline{g_{1}^{0}}$ is the only nonnull mean Gaussian coefficient. TK03 is the most simplified GGP model, and, instead of adjusting $\sigma_{l}^{m}$ individually, Tauxe and Kent (2004) based on the idea that the dipolar (odd) and quadrupolar (even) families are independent, then, just a factor $\beta$ (Equations 2.16 and 2.17), multiplied by the odd standard deviations would be necessary to differentiate the whole set of variances (see Table 2.1). Thus, the parameters that define the TK03 model are only three: $\overline{g_{1}^{0}}, \alpha$ and $\beta$.

$$
\begin{gathered}
\sigma_{l}^{m^{2}}=\frac{\left(c / r_{a}\right)^{2 l} \alpha^{2}}{(l+1)(2 l+1)} \text { for } l-m=\text { even }, \\
\sigma_{l}^{m^{2}}=\frac{\left(c / r_{a}\right)^{2 l} \alpha^{2} \beta^{2}}{(l+1)(2 l+1)} \text { for } l-m=\text { odd }
\end{gathered}
$$

Because of the insertion of $\beta$, the variances in $\mathrm{B}$ are not calculated for all infinite $l$, and truncation in $l$ is needed. Figure 2.2 shows the standard deviation $\sigma_{l}^{m}$ of the ordered coefficient $g_{l}^{m}$ and $h_{l}^{m}$ (order: $g_{1}^{0}, g_{1}^{1}, h_{1}^{1}, g_{2}^{0}, g_{2}^{1}, h_{2}^{1} \ldots$ ) of the zonal GGP models CP88, QC96, CJ98 and TK03. For degrees higher than 2 the models are too similar, even for TK03 that has the simplification of the inclusion of the $\beta$ parameter. All models have the highest variance in the axial-dipolar coefficient $\left(g_{1}^{0}\right)$, CJ98 has the greatest. The second degree $(l=$ 2) has the odd coefficients $\left(g_{2}^{1}\right.$ and $\left.h_{2}^{1}\right)$ with the highest variances in TK03, QC96 and CJ98 models. 


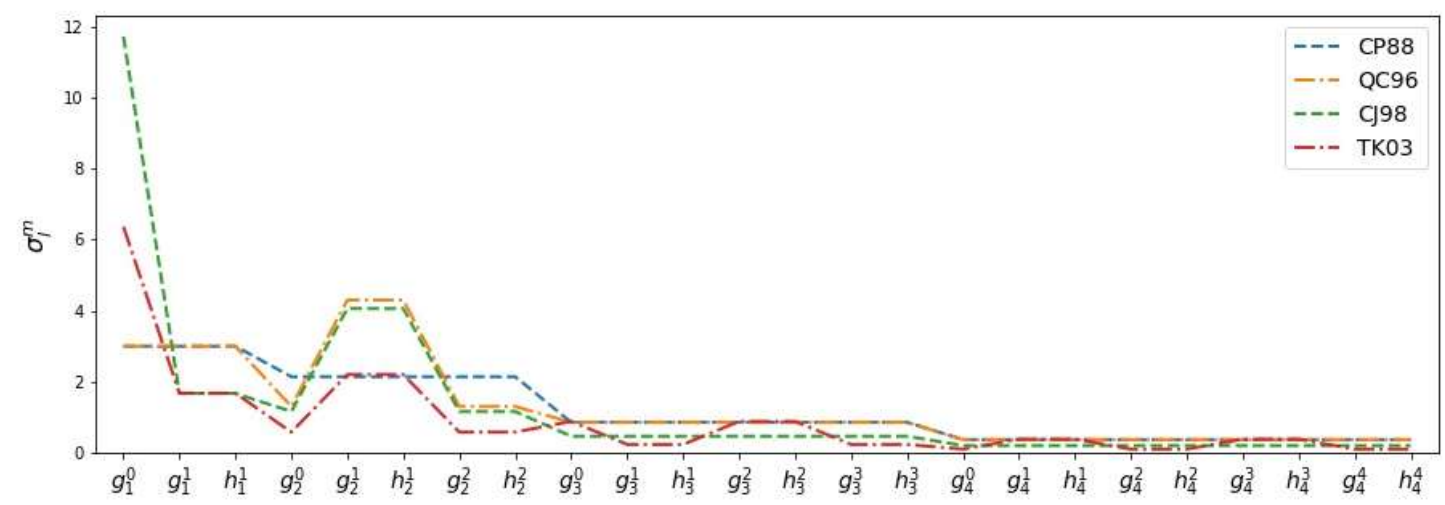

Figure 2.2. Standard deviations for each Gaussian coefficient of GGP models: CP88 (Constable and Parker, 1988), QC96 (Quidelleur \& Courtillot, 1996), CJ99 (Constable \& Johnson, 1999), and TK03 (Tauxe \& Kent, 2004).

Figure 2.3 shows the resulting variances of each model described above. Because of the simplifications, the CP88 model has resulting variances of B components constant with latitude and is called an isotropic model. However, this aspect does not mean that the distributions given by this model are the same for the whole Earth, neither that the distributions are circular around the expected field. This is because near the Equator the directional distribution around the expected horizontal field is more influenced by the vertical and east-west variances $\left(\sigma_{B_{r}}^{2}\right.$ and $\left.\sigma_{B_{\Phi}}^{2}\right)$, and near the poles, as the mean-field is almost vertical, the directional distribution is more influenced by the horizontal variances $\left(\sigma_{B_{\Theta}}^{2}\right.$ and $\left.\sigma_{B_{\Phi}}^{2}\right)$ which are equal $\left(\sigma_{B_{\theta}}=\sigma_{B_{\phi}}=5.39 \mu T\right.$, and $\left.\sigma_{B_{r}}=9.68 \mu T\right)$. At the poles, the distributions are circular around the mean and less dispersed; for lower latitudes, they are elongated and more dispersed (see the stereographic plots of Figure 2.4 of the pdf $s(u)$ isocurves and synthetic samples predicted by CP88).

The variances of TK03 and CJ98 models follow the same shape of latitudinal variation, but the variances of CJ98 are always greater than TK03. They also have elongated distributions near the Equator and are circular at the poles (see TK03 model predictions plots in Figure 2.5). 

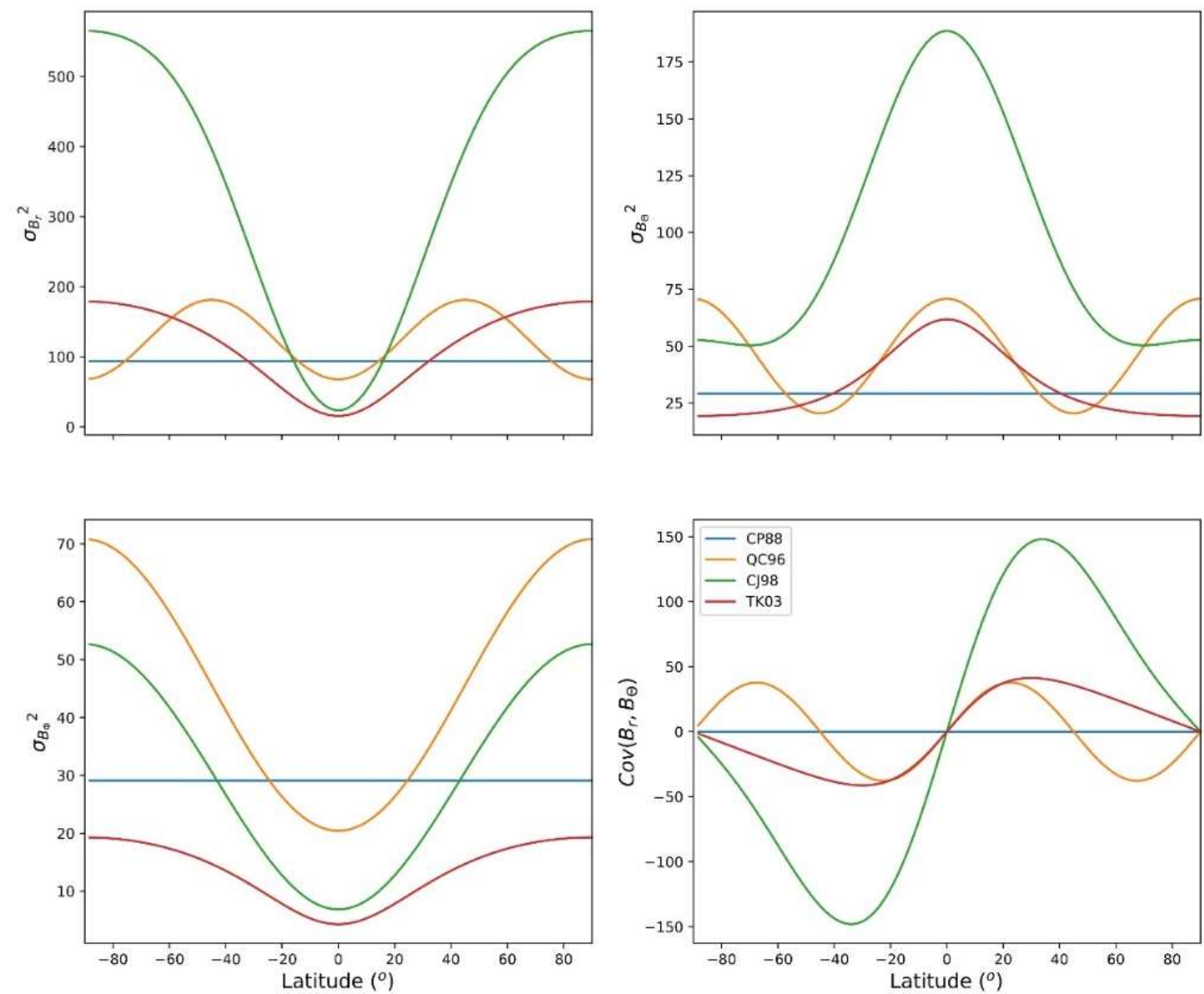

Figure 2.3. Latitudinal variation of B variances for models CP88, QC96, CP99 and TK03 (using $l$ truncation of 8 ). 


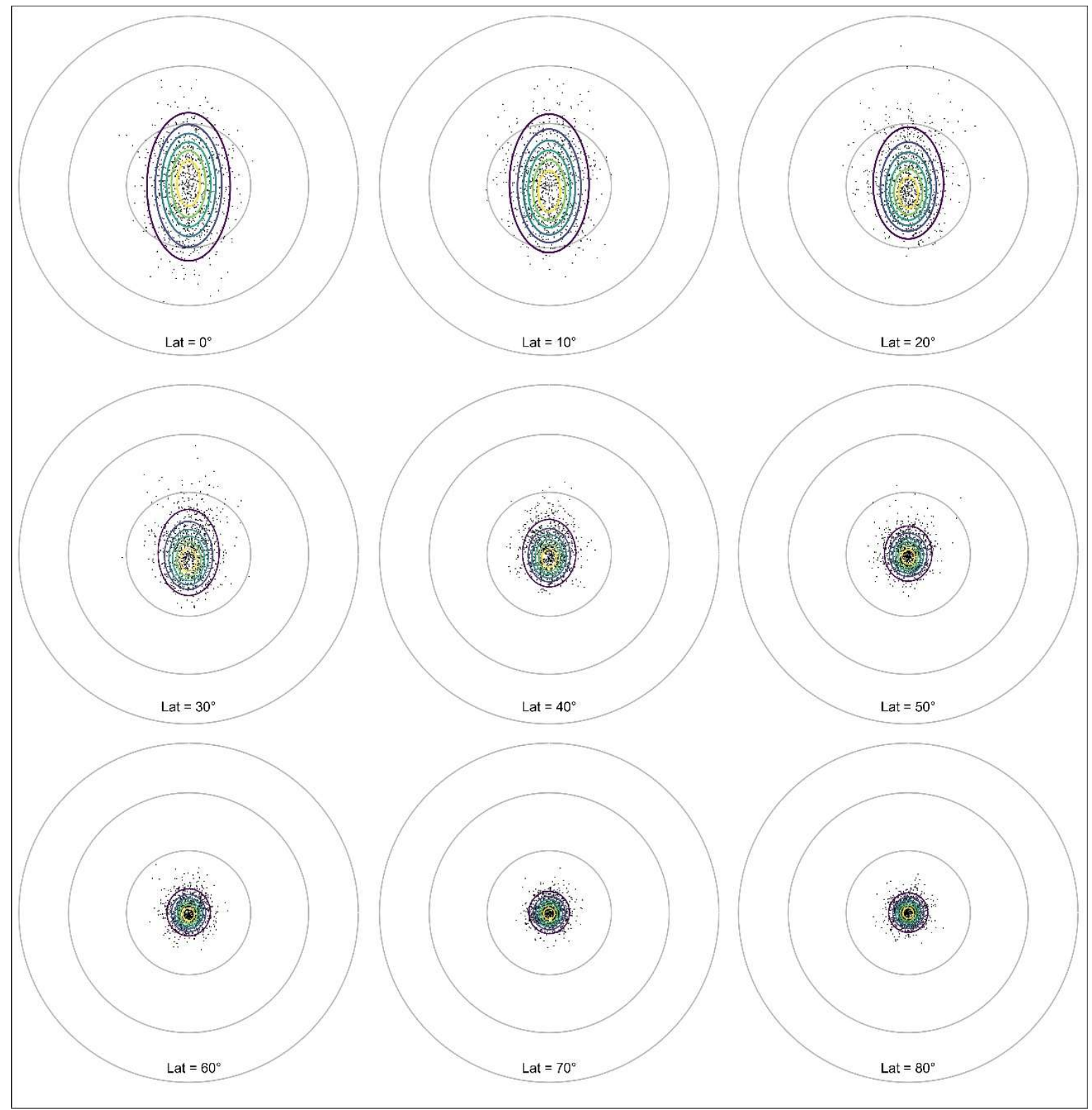

Figure 2.4. Pdf s(u) for CP88 model iso-value curves in stereographic projections. The color scale used for pdf iso-value curves is from purple (minimum) to yellow (maximum). Dots are simulations from the GGP model CP88 (using 1 truncation of 8). From top to bottom plots are from 0 to $80^{\circ} \mathrm{N}$ in latitude. 


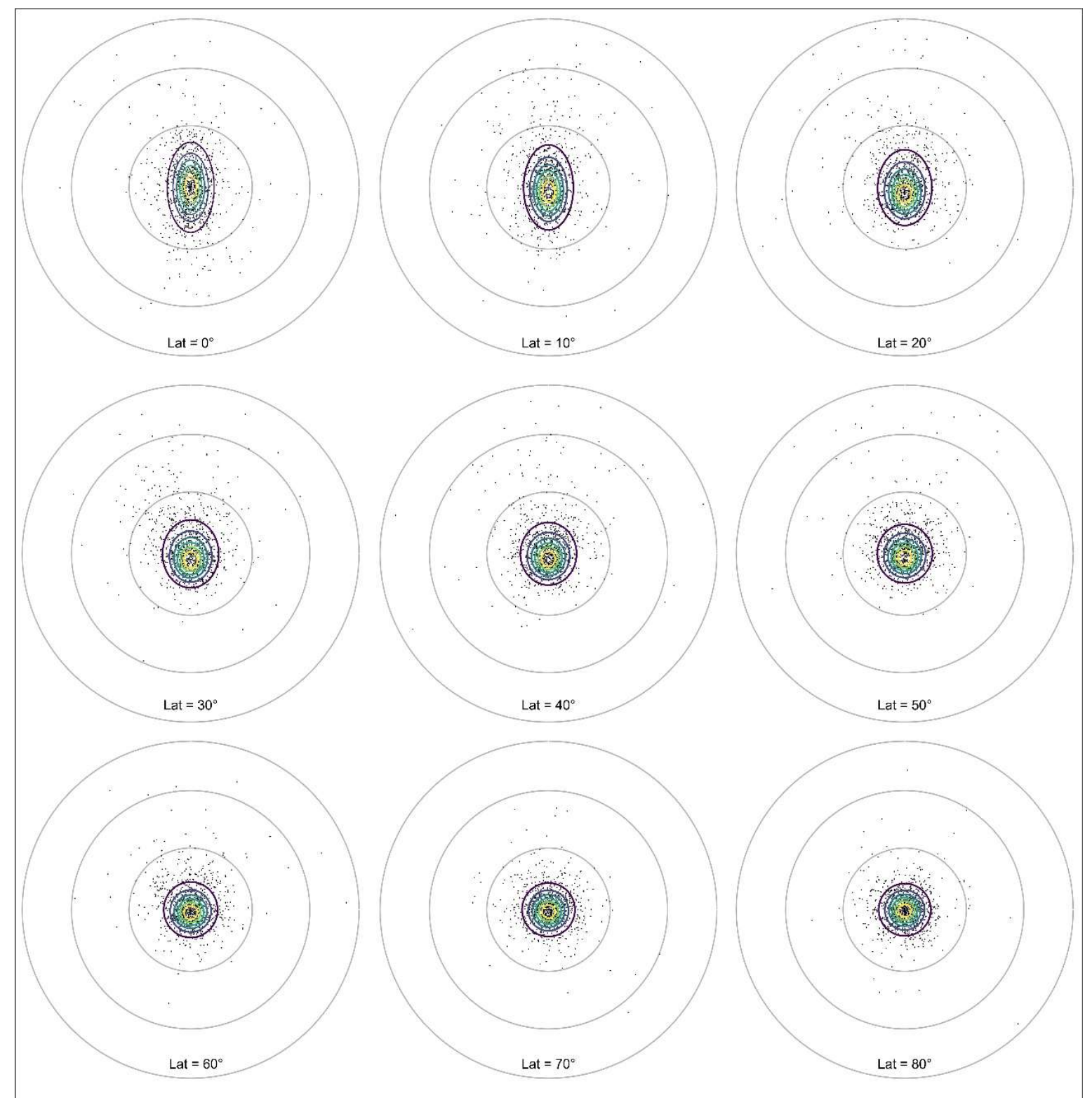

Figure 2.5. PDF s(u) for TK03 model iso-value curves in stereographic projections. The color scale is from purple (minimum) to yellow (maximum). Dots are simulations from the GGP model TK03 (using truncation of $\mathrm{l}=8$ ). From top to bottom the plots are from 0 to $80^{\circ} \mathrm{N}$ in latitude.

The TK03 model was determined as the GGP model in which the VGP scatter predictions, given by 10,000 simulations of synthetic samples using a maximum degree truncation at $l=8$, were compatible with the VGP scatter from MM97 database, the most recent database for the time. The intensity of the field was fitted considering the average virtual axial dipole moment (VADM) for the last five million years of approximately $46 \times 10^{21} \mathrm{Am}^{2}$ (Selkin and Tauxe, 2000). When compared to previous models, the TK03 is the best that describes the dispersion given by the MM97 database (Figure 2.6). Tauxe and Kent (2004) also compared the distributions of directions from MM97 to the model 
predictions $(10,000$ of synthetic samples results) using the elongation $E$ (Equation 2.18) of the distribution and got also good agreement:

$$
E=\tau_{1} / \tau_{3}
$$

where $\tau_{1}$ and $\tau_{3}$ are the maximum and minimum eigenvalues of the "orientation matrix" $\mathrm{T}$ (Scheidegger, 1965), which is defined as:

$$
T=\left[\begin{array}{lll}
\sum x_{i}{ }^{2} & \sum x_{i} y_{i} & \sum x_{i} z_{i} \\
\sum x_{i} y_{i} & \sum y_{i}^{2} & \sum y_{i} z_{i} \\
\sum x_{i} z_{i} & \sum y_{i} z_{i} & \sum z_{i}{ }^{2}
\end{array}\right]
$$

where $x_{i}, y_{i}$, and $z_{i}$ are the orthogonal components of the $i^{\text {th }}$ unit vector of the distribution.

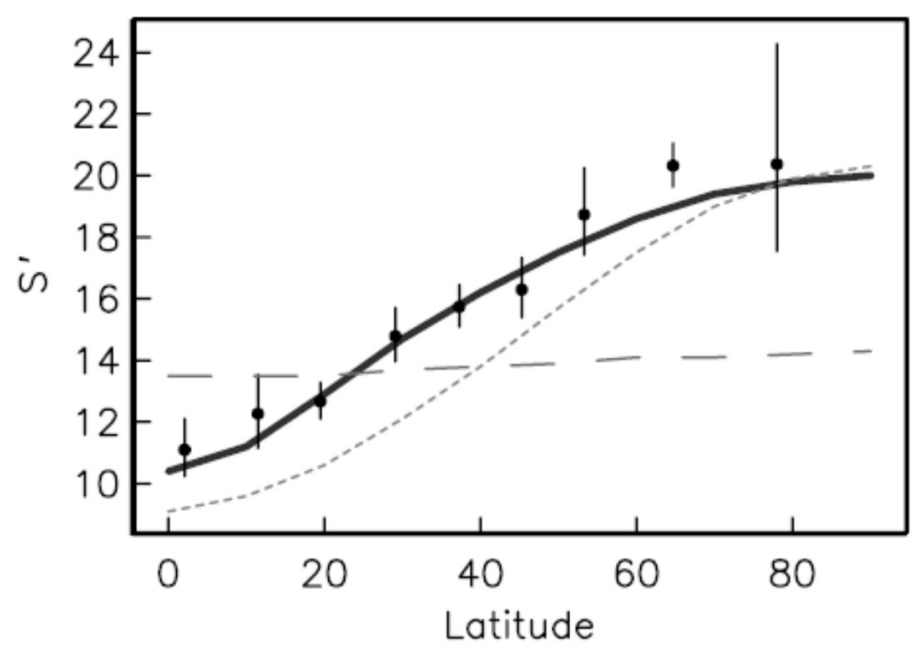

Figure 2.6. The estimated behavior of the VGP scatter from the data compilation of MM97 (circles). The dashed line is the predicted behavior from CP88 (GAD version), the dotted line is from CJ98 (GAD version) and the heavy solid line is from TK03. Source: Tauxe and Kent (2004)

The elongation predictions of TK03 decreases from the Equator up to the poles (Figure 2.5 and 2.7). A polynomial fit with the elongation results of 10,000 of synthetic samples simulations per inclination (given by the latitude, using GAD hypothesis) was determined. So, for a given inclination, an elongation is expected following the polynomial given by Tauxe et al. (2008):

$$
E(I)=2.895-\left(1.466 \times 10^{-2}\right) I-\left(3.525 \times 10^{-4}\right) I^{2}+\left(3.16 \times 10^{-6}\right) I^{3}
$$




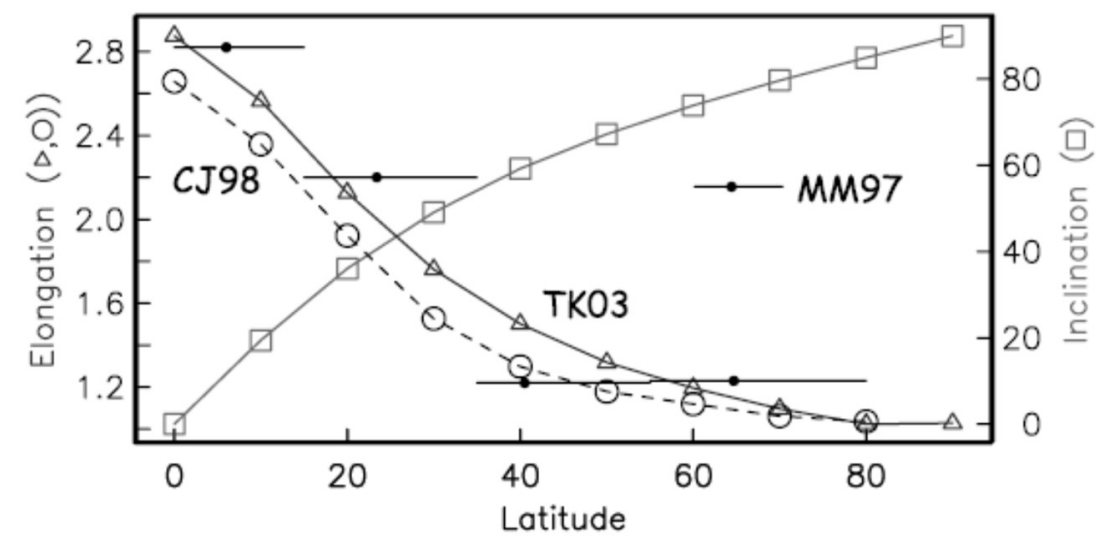

Figure 2.7. Variation of elongation and average inclination versus latitude for the TK03 model. Also shown is elongation from CJ98 (GAD version) and the selected directions from the MM97 database. Source: Tauxe and Kent (2004).

\subsubsection{The E/I method}

The elongation/inclination (E/I) method (Tauxe and Kent, 2004) is based on the distribution shape of unitary vectors predicted by the TK03 model. It is a method used for the detection and correction of paleomagnetic directions from sedimentary records that could suffer from inclination diminishing bias, an effect related to the compaction of sediments. According to this method, if a long section of sedimentary data has been affected by inclination shallowing, its distribution would be deformed, and the elongation that should be in the north-south direction would diminish until it becomes an East-West squeezed elongation. The $\mathrm{E} / \mathrm{I}$ method finds a flattening factor correction $f$ in which the pair $\mathrm{E} / \mathrm{I}$ is made compatible with that predicted by TK03.GAD model (polynomial of Equation 2.20). The $f$ factor can be described as $f=\tan I_{O} / \tan I_{f}$ (King, 1955), where $I_{f}$ is the real field and $I_{0}$ is the flattened observed inclination.

Figure 2.8 (Plate 2 from Tauxe and Kent, 2004) shows the application of the method E/I to 222 paleomagnetic directions from Oligo-Miocene redbeds from Asia (Gilder et al., 2001). The directions were originally E-W elongated and different flattening factors $f$ was applied successively to the directions. Plot b shows how the mean inclination increases with the diminishing of flattening factors from 1 to 0.3 . The elongation/inclination pair compatible with the TK03 model is achieved for an inclination of $64^{\circ}$ (Figure 2.8c), which is then the corrected inclination. 

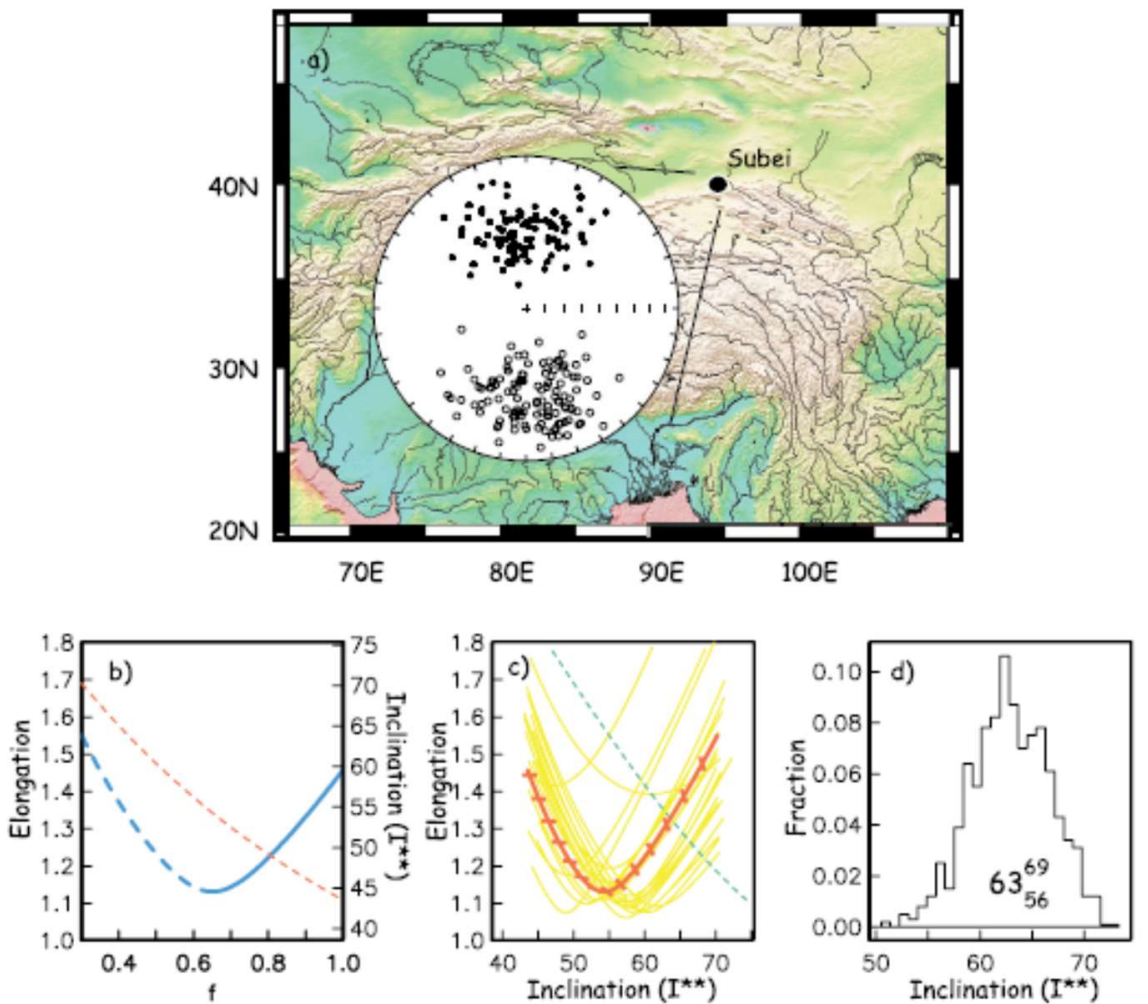

Figure 2.8. Plate 2 from Tauxe and Kent (2004). a) Paleomagnetic directions of Oligo-Miocene redbeds from Asia in equal-area projection. b) The plot of elongation (heavy solid and dashed line) and inclination (dashed) as a function of unflattening by the parameter $f$. Elongation is $\mathrm{E}-\mathrm{W}(\mathrm{N}-\mathrm{S})$ when the heavy line is solid (dashed) c) Plot of elongation versus inclination for the data in b) (solid) and for the TK03.GAD model (dashed). Also shown are results from 20 bootstrapped datasets. The crossing points represents the inclination/elongation pair most consistent with the TK03 model. d) Histogram of crossing points from 1000 bootstrapped datasets. Source: Tauxe and Kent (2004). 


\section{Chapter 3}

\section{Paleomagnetic results from Mafra Formation}

This chapter presents new and detailed paleomagnetic results from a Carboniferous (Kiaman) sedimentary section from the Mafra Formation belonging to the Itararé Group of the Paraná Basin, southern Brazil. These results are already published in the Journal of Geophysical Research (Brandt et al., 2019a), supplementary materials can be found at https://earthref.org/ERDA/2419/. This section is composed of rhythmites which proved to be very good and stable recorders of the geomagnetic field. The shallowing correction using the anisotropy of remanence was applied to the magnetic record and cyclostratigraphic analysis was used to infer if the elapsed time was sufficient to properly record the paleosecular variation of the geomagnetic field.

Apart from providing a reference paleomagnetic pole for South America, these results were the starting point for the development of the modeling presented in this thesis. The Mafra paleomagnetic data along with two other long igneous sections (Haldan et al., 2014; Bazhenov et al., 2016) from other areas and of approximately the same age were used for verifying the validity of TK03 model and the applicability of E/I method.

Although the elongation results did not help to define the shape of distribution delineated by the Kiaman PSV, the dispersion results, in spite of the different rock types, consistently revealed that the assumption that the TK03 model is valid for the Kiaman is mistaken. In addition, a GGP model with VGP scatter similar to those of the investigated sections predicts an elongation curve different from the TK03, mainly at Equatorial latitudes. This would imply that the inclination shallowing correction for sedimentary rocks of that age, assuming the TK03 as a valid model, is improper, especially for low paleolatitudes where the elongation is higher.

The directional distribution for the Kiaman remained an open question. One of the difficulties in solving this problem is that there are few Kiaman sections (mainly of igneous nature) long enough to perform the necessary tests. According to Tauxe et al. (2008), the minimum number of independent records to evaluate elongation is $100-150$, and datasets of this size are difficult to achieve. Therefore, other remaining questions are: How to improve the number of directional data instead of just looking for long sections? If the Kiaman PSV is not compatible with the recent GGP models, what is the GGP model that best describes it? And what is the better way to find a GGP model for the past? These questions will be addressed in Chapter 5, with the use of the new methodology presented in Chapter 4. 



\section{RESEARCH ARTICLE 10.1029/2018JB016968 \\ Key Points: \\ - We present a new Upper Carboniferous paleomagnetic pole for South American Plate, with inclination shallowing correction and time control \\ - The paleosecular variation results indicated that we should avoid the use of recent geomagnetic models as a reference for Kiaman superchron}

Supporting Information:

- Supporting Information S1

- Table S1

- Table S2

- Table S3

- Table S4

- Table S5

- Table S6

Correspondence to:

D. Brandt,

daniele.brandt@iag.usp.br

Citation:

Brandt, D., Ernesto, M., Constable, C., Franco, D. R., Carlos Weinschutz, L., de Oliveira Carvalho Rodrigues, P., et al. (2019). New late Pennsylvanian paleomagnetic results from Paraná Basin (southern Brazil): Is the recent Giant Gaussian Process model valid for the Kiaman superchron? Journal of Geophysical Research: Solid Earth, 124 https://doi.org/10.1029/2018JB016968

Received 1 NOV 2018

Accepted 18 JUN 2019

Accepted article online 24 JUN 2019

(C)2019. American Geophysical Union. All Rights Reserved.

\section{New Late Pennsylvanian Paleomagnetic Results From Paraná Basin (Southern Brazil): Is the Recent Giant Gaussian Process Model Valid for the Kiaman Superchron?}

\author{
Daniele Brandt $^{1}$ (D), Marcia Ernesto ${ }^{1}$ (D) Catherine Constable $^{2}$ (D), Daniel Ribeiro Franco ${ }^{3}$ (D), \\ Luiz Carlos Weinschutz ${ }^{4}$ (D), Pillar de Oliveira Carvalho Rodrigues ${ }^{3}$ (D), Linda Hinnov ${ }^{5}$, \\ Plinio Jaqueto $^{1}$ (D), Becky E. Strauss ${ }^{6,7}$ (D), Joshua Feinberg ${ }^{6}$ (D), \\ Pedro Vitor de Paiva Franco ${ }^{8}$ iD, and Xixi $\mathrm{Zhao}^{9}$ iD
}

${ }^{1}$ Instituto de Astronomia, Geofísica e Ciências Atmosféricas, Departamento de Geofísica, Universidade de São Paulo, São Paulo, SP, Brazil, ${ }^{2}$ Institute of Geophysics and Planetary Physics, Scripps Institution of Oceanography, University of California at San Diego, La Jolla, CA, USA, ${ }^{3}$ Coordenação de Geofísica, Observatório Nacional, Rio de Janeiro, RJ, Brazil, ${ }^{4}$ Centro Paleontológico da Universidade do Contestado, Universidade do Contestado, Mafra, Santa Catarina, Brazil, ${ }^{5}$ Department of Atmospheric, Oceanic, and Earth Sciences, George Mason University, Fairfax, VA, USA, ${ }^{6}$ Institute for Rock Magnetism, Department of Earth Sciences, University of Minnesota, Minneapolis, MN, USA, ${ }^{7}$ NIST: National Institute of Standards and Technology, Gaithersburg, MD, USA, ${ }^{8}$ Centro de Geociencias, Universidad Nacional Autónoma de México, Querétaro, México, ${ }^{9}$ State Key Laboratory of Marine Geology, Tongji University, Shanghai, China

\begin{abstract}
The most recent Giant Gaussian Process (GGP) model, based on the last $5 \mathrm{Ma}$, has been used as a reference for directional distribution of paleomagnetic record of older rocks as Cenozoic and Proterozoic. However, for Paleozoic times, its validity has not yet been tested. Here we evaluate the validity of this recent GGP model for the Kiaman superchron. We present new paleomagnetic results from a late Pennsylvanian section of glacial rhythmites (Mafra Formation) from southern Brazil. The 5-m section sampled spans more than $800 \mathrm{kyr}$, as evaluated by cyclostratigraphic analysis. Thermal demagnetization revealed a reversed characteristic component carried by single domain magnetite. Anisotropy of anhysteretic remanent magnetization indicated a small shallowing correction of $f=0.97$. The final paleomagnetic pole position is located at $51.9^{\circ} \mathrm{S}, 344.3^{\circ} \mathrm{E}\left(N=111, R=109.0, K=55.9, A_{95}=1.8^{\circ}\right)$, with a mean direction of Dec $=144.2^{\circ}$, Inc $=69.5^{\circ}\left(N=111, R=110.2, k=134.4, \alpha_{95}=1.2^{\circ}\right.$, Paleolat $\left.=53.2^{\circ} \mathrm{S}\right)$. The shape of the distribution of magnetization directions (elongation $\left.E=2.08_{1.44}^{3.13}\right)$ and the dispersion of virtual geomagnetic poles $\left(S_{V}=10.99 .8\right)$ are incompatible with the recent model. The reduced dispersion, also found in other studies, implies a different shape in directional distributions for any GGP model describing the Kiaman interval. This result alerts us that we should abandon the use of the recent GGP model as a reference for inclination shallowing correction of Carboniferous sedimentary data.
\end{abstract}

\section{Introduction}

Determination of the past configuration of supercontinents is possible because of the fundamental geocentric axial dipole (GAD) hypothesis of paleomagnetism. According to this hypothesis, the time-averaged geomagnetic field can be described as a magnetic dipole at the center of the Earth aligned to the rotation axis. The mean GAD with small contributions (less than 5\%) of persistent nondipolar components is confirmed by paleosecular studies in sediments and lavas from the last 10 million years (Cromwell et al., 2018; Johnson et al., 2008; Opdyke \& Henry, 1969).

Statistical paleosecular variation (PSV) models can describe this mean geomagnetic field and its long-term variations. The Giant Gaussian Process (GGP) type are PSV models that are capable of predicting a distribution of directions anywhere on the Earth (Constable \& Johnson, 1999; Constable \& Parker, 1988; Quidelleur \& Courtillot, 1996; Tauxe \& Kent, 2004). They are based on the concept that long-timescale variation of the geomagnetic field can be described by statistical fluctuation of the gauss coefficients around mean values $\left(g_{l}^{m}\right.$ and $\left.h_{l}^{m}\right)$ and standard deviations $\left(\sigma_{l}\right)$ that are a function of their degree, $l$, and proportional to a fitted parameter $\alpha$. Each gauss coefficient has a mean value corresponding to the description of the 
time-averaged field in terms of spherical harmonic functions, so if the model describes a mean GAD, all the coefficients have a null mean, except for $g_{1}^{0}$.

The most recent GGP model fitted for the recent field (0 to $5 \mathrm{Ma}$ ) is the TK03.GAD model (Tauxe \& Kent, 2004), which best describes the paleosecular variation recorded by recent lavas database of McElhinny and McFadden (1997). According to TK03.GAD, the distribution of directions should be elongated along the vertical and North-South plane, and this elongation should decay from almost three at the Equator to one (circular) at the poles. The elongation $E$, as described by Tauxe and Kent (2004), is determined by the ratio between intermediate and minimum eigenvalues $\left(\tau_{2} / \tau_{3}\right)$ from the "orientation matrix" $\mathrm{T}$ (Scheidegger, 1965). If a group of magnetic remanence directions accurately records the geomagnetic field, it should have a mean and distribution shape compatible with that predicted by the model. Tauxe et al. (2008) and Tauxe and Kodama (2009) tested the TK03.GAD model, proposed by Tauxe and Kent (2004), for rocks older than $5 \mathrm{Ma}$ and found good agreement for paleomagnetic data from Cenozoic and Proterozoic ages.

The TK03.GAD model has been used as a reference for correction of sedimentary data supposedly affected by inclination shallowing. The elongation/inclination (E/I) method (Tauxe \& Kent, 2004) was proposed to correct the difference in inclination produced by shallowing. According to this method, if a long section of sedimentary data has been affected by inclination shallowing, its distribution would be deformed, and the elongation that should be in the north-south direction would diminish until it becomes an East-West squeezed elongation. The E/I method finds a flattening factor correction $f$ in which the pair E/I is made compatible with that predicted by TK03.GAD model. The $f$ factor can be described as $f=\tan I_{\mathrm{O}} / \tan I_{f}$ (King, 1955), where $I_{f}$ is the real field and $I_{0}$ is the flattened observed inclination.

Shallowing correction has become a mandatory procedure for the late Paleozoic rocks, since the majority of data of this age are derived from sedimentary rocks (Torsvik et al., 2012), and because of the absence of inclination shallowing correction, these data have been pointed as the cause of paleolatitudes overlapping error in Pangea reconstruction (Domeier et al., 2012; Irving, 1977). There are two independent ways to do shallowing correction: by the use of anisotropy of anhysteretic remanent magnetization (AARM), first proposed by Jackson et al. (1991), and the E/I method. The former procedure is related to the magnetic fabric of the rocks and does not depend on any model of geomagnetic field. The E/I method depends on the geomagnetic record, and its validity has not been tested for Paleozoic times. Even so, it has been applied by some authors (e.g., Brandt et al., 2009; Franco, Ernesto, et al., 2012; Haldan et al., 2009; Lanci et al., 2013).

The end of the Paleozoic Era is marked by the occurrence of the longest Phanerozoic superchron, which is of reversed polarity and is called the Permo-Carboniferous Reversed superchron or Kiaman. Superchrons are long time intervals (tens of millions of years) when the geomagnetic field stayed in one stable polarity, and its secular variation was more suppressed. Dispersion of virtual geomagnetic poles (VGPs) of superchrons is smaller for low and medium latitudes and has a more prominent increase with latitude than is observed for the last 5-Ma field or other high-frequency reversal times (Biggin et al., 2008; de Oliveira et al., 2018; McFadden et al., 1991). However, Doubrovine et al. (2019) analyzed the paleosecular variation estimates for the CNS and the pre-CNS (198-126 Ma) using an updated volcanic database and, comparing to recent compilations for the last few million years (e.g., Cromwell et al., 2018), concluded that the differences in the latitude behavior of PSV during intervals of stable and high-variability field do not allow the use of this proxy to evaluate the geomagnetic field stability. That conclusion does not mean that the TK03.GAD gives similar VGP dispersion as a superchron because the TK03.GAD model was determined with a database [McElhinny \& McFadden, 1997] with larger VGP dispersion and with less variation in latitudes than a superchron. Therefore, it seems natural to us that if the Kiaman's dispersion of VGPs is so different from this model, then the directional distribution should also be different.

Attempts to test the validity of TK03.GAD for Kiaman times were done with two groups of paleomagnetic data from long sections of igneous records (Bazhenov et al., 2016; Haldan et al., 2014). Both results presented distributions with elongation smaller than that predicted by TK03.GAD model, but because of high values of uncertainty on elongation results, the analyses of those results on their own were not conclusive.

The present paper presents new and detailed paleomagnetic results from a Carboniferous sedimentary section from the Mafra Formation (Itararé Group, Paraná Basin, southern Brazil). We applied AARM 


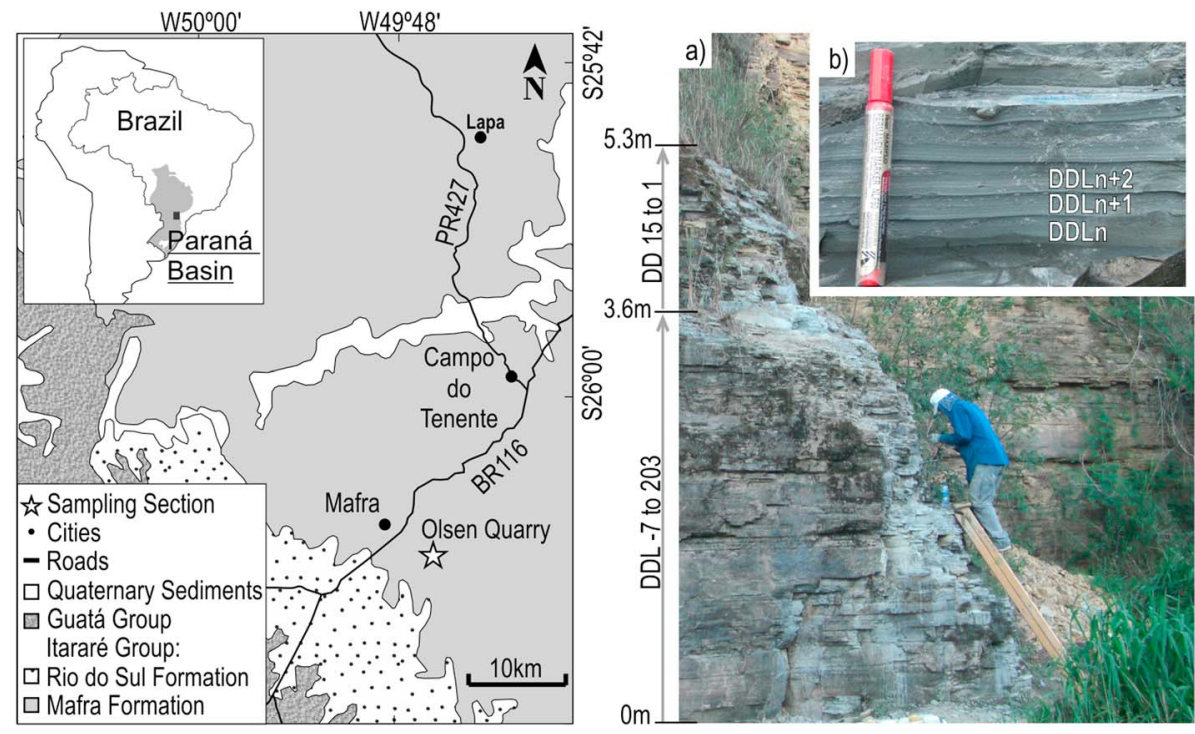

Figure 1. Location of sampling section (Olsen Quarry) at the geological map of the region. Dots are the Cities of Mafra, Campo do Tenente, and Lapa (Santa Catarina State). (a) Sampling section with the stratigraphic localization of DDL layers (samples to paleomagnetic and cyclostratigrafic analyses) and localization of DD layers (samples only for paleomagnetic analyses). (b) Detail of the rhythmites layers and the naming scheme of DDL part.

shallowing correction to the magnetic record and cyclostratigraphic analysis to infer if the elapsed time was sufficient to properly record the paleosecular variation of the geomagnetic field. This new data set is shown to be an accurate record of paleosecular variation, which allowed us to verify the applicability of E/I method for rocks of approximately the same age. We also run simulations of GGP models with lower values of dispersion of VGPs and higher latitudinal variation (as expected for a superchron) in order to find a GGP model that could explain the Mafra dispersion and elongation results.

\section{Geological Setting and Sampling}

Paraná Basin is an extensive intracratonic basin located in the center-eastern part of the South American plate. It covers the southern region of Brazil and parts of Uruguay, Argentina, and Paraguay. The subsidence and sedimentation of Paraná Basin started during Ordovician times (Milani, 1997). The glacial deposits of the Itararé Group are related to the third glacial cycle, which were the most extensive Gondwana glaciation of Phanerozoic. The best outcrops of this unit are at the eastern and northeastern border of Paraná Basin. Following Schneider et al. (1974), the sedimentation of Itararé Group begins with Campo do Tenente (Medium Carboniferous) and finishes with Rio do Sul formations (Early Permian). The Mafra Formation, whose rhythmites are the target of this work, is positioned between those two formations, and its deposition is attributed to the Late Pennsylvanian (Kasimovian to Gzhelian). This age was determined by palynostratigraphy, where the Late Carboniferous palynozone Crucisaccites monoletus were correlated to the middle portion of the Itararé Group (Holz et al., 2008).

The Mafra formation is composed of diamictites, sandstones, rhythmites, and mudstones. The sampled rhythmite section is located in an inactive quarry named Olsen $\left(26.14^{\circ} \mathrm{S}, 310.24^{\circ} \mathrm{E}\right.$, star in the geological map of Figure 1), near Mafra City. According to Weinschütz and Castro (2004), it is related to the middle portion of the Mafra Formation and is composed of pairs of light-colored siltites and fine layers of dark clay, with variable thickness of some millimeters up to $5 \mathrm{~cm}$ at maximum. These layers repeat all along the whole quarry, reaching a total thickness of a few tens of meters and hundreds of meters of lateral extension. The layers are flat and preserve the paleohorizontal plane.

The paleomagnetic sampling was performed through a 5-m-high wall comprising 216 of distinct layers. A total of 124 oriented blocks were collected and oriented by sun and magnetic compasses. The bottom part was sampled in detail: 201, from existing 211 pairs (layers), were sampled. This bottom part is $3.6 \mathrm{~m}$ of height, and its layers were named "DDL." Figure 1a shows the sampling section and stratigraphic 
location of DDL layers. Owing to difficulty of access, the top portion was not as comprehensively sampled; only 15 oriented hand samples were distributed along $1.7 \mathrm{~m}$. This top part was named DD and the layers range from DD1 to DD15. The whole section was considered for paleomagnetic analysis. However, only the detailed bottom part (DDL portion) was considered for cyclostratigraphic analyses.

\section{Materials and Methods}

Laboratory procedures and analysis in this study involved paleomagnetism, rock magnetism, anisotropy of anhysteretic remanence, and cyclostratigraphy.

\subsection{Paleomagnetic Procedures}

Cylinders of $2.5-\mathrm{cm}$ diameter and up to $2.1 \mathrm{~cm}$ high were cut from oriented hand samples in a core drill system in the Paleomagnetic Laboratory of the University of São Paulo (USPmag). Cylinders composed of more than one layer (light/dark pair) were sliced into separate layers. Layers thicker than $2.1 \mathrm{~cm}$ were sliced into two specimens. Demagnetization experiments were conducted in a magnetically shielded room with ambient field less than $500 \mathrm{nT}$. Remanent magnetization measurements were obtained using a superconducting rock magnetometer from $2 \mathrm{G}$ Enterprises. Thermal demagnetization was carried out in a thermal specimen demagnetizer from ASC (model TD48) with 9 to 35 heating steps from room temperature to $700{ }^{\circ} \mathrm{C}$. Bulk susceptibility was monitored during the thermal treatment using a Bartington MS2B. Detailed alternating field (AF) demagnetizations with 20 to 30 steps reached peak fields up to $160 \mathrm{mT}$ and were automatically performed in a set of coils coupled to a $2 \mathrm{G}$ magnetometer using random sequences of demagnetization axes to avoid systematic contribution of gyroremanent magnetization.

Principal component (Kirschvink, 1980) and great circle (Halls, 1976) analyses were conducted using the Remasoft software (Chadima \& Hrouda, 2006). Grouping of magnetic directions in each layer (stratigraphic level) was evaluated by the Fisher's (1953) statistics, and the combination of directions and planes followed the method of McFadden and McElhinny (1988) with specification of constraint arcs.

Inclination shallowing correction was performed using anisotropy of AARM measurements, following Jackson et al. (1991). The procedure of AARM acquisition was done using six different axes in the set of coils that are coupled to the $2 \mathrm{G}$ magnetometer, and tensorial analyses of AARM data were done using the Anisoft data browser 5 (Chadima \& Jelínek, 2008).

Calculation of VGPs, application of variable cutoff colatitude angles (Vandamme, 1994), calculation of dispersion of VGPs $(S)$, and elongation of the distribution of directions $(E)$ with bootstrap confidence limits followed the procedures described in Tauxe, Banerjee, et al. (2016). Simulations of GGP models were done using a modified mktk03 function from the PMAGPY package of Tauxe, Shaar, et al. (2016).

\subsection{Rock Magnetism}

Irregular first-order reversal curves (FORCs) were obtained at room temperature using a Princeton Vibrating Sample Magnetometer MicromagTM 3900. The measurement script, processing, and analyses were done using the xFORC software (Zhao et al., 2015). The diagnosis of magnetic domain structure using FORC diagrams followed the procedures of Hu et al. (2018) and Zhao et al. (2017).

Low-temperature magnetization curves of magnetic extracts were obtained at the Institute of Rock Magnetism with a Magnetic Property Measurement System by Quantum Design. Six samples distributed along the studied section were subjected to low-temperature rock magnetism experiments. The magnetic extraction of rock samples was made following Strauss et al. (2013) and Strehlau et al. (2014). Room temperature remanence measurements were made during thermal cycling, where the samples were first subjected to a saturation isothermal remanent magnetization at room temperature and then measured at every $5 \mathrm{~K}$ during cooling and heating. Field cooled (FC) and zero-field cooled (ZFC) experiments were also conducted. In these experiments, measurements were taken during heating from $1 \mathrm{~K}$ to room temperature. These two experiments differ in the way that the sample is magnetized. In the FC experiment, the sample is first cooled from room temperature to $10 \mathrm{~K}$ in the presence of a saturation field; then, the magnetic remanence is measured in steps of $5 \mathrm{~K}$ during the warming process. The ZFC experiment consists of cooling a sample in the absence of any magnetic field, inducing a saturation field in low temperatures, and then measuring the remanent magnetization during the warming process. 


\subsection{Cyclostratigraphic Analysis}

As discussed by some authors (e.g., Ellwood et al., 2000, 2012; Fang et al., 2017; Franco, Hinnov, \& Ernesto, 2012; Wu et al., 2012), variations in magnetic susceptibility $(\chi)$ due to changes in the detrital content of sediments have been widely used in cyclostratigraphic works because they can indicate climatically or eustatically controlled weathering inputs. However, the determination of the origin of $\chi$ variations can be tricky because several factors (e.g., grain size and shape, composition, and concentration) can alter $\chi$ values (Ellwood et al., 2000). Anhysteretic remanent magnetization (ARM) has been increasingly employed as an alternative method in cyclostratigraphic investigations (e.g., Fang et al., 2017; Kodama et al., 2010; Lanci et al., 2010), as it measures the low-coercivity, fine-grained $(<20 \mu \mathrm{m})$ ferromagnetic minerals (sensu stricto), for which is often easier to determine the provenance (Latta et al., 2006; Wu et al., 2012). For a better assessment and comparisons of the embedded quasiperiodic harmonic content, both $\chi$ and ARM data sets were considered in this study. This approach can also provide better estimates for the depositional time range related to these rocks.

$\chi$ and ARM data were determined along the entire DDL section for every sedimentary layer (201 layers). Susceptibility measurements were conducted using an MFK1-FA Kappabridge (AGICO), and ARM acquisition and measurements were done using the $2 \mathrm{G}$ magnetometer. The $\chi$ and ARM data sets were linearly interpolated and resampled every 1.75 and $1.80 \mathrm{~cm}$, the median spacings of the two series, respectively, and pre-whitened prior to spectral analysis by estimating and removing smoothed curve using MATLAB's smooth.m with the "loess" option and a running window that is $60 \%$ of the data length (Figures $7 \mathrm{a}$ and 7b). Spectral analysis was carried out with the prolate multitaper spectral estimator (Thomson, 1982), with hypothesis testing using a classical order 1 autoregressive red-noise null model (e.g., Mudelsee, 2014) using the MATLAB script classicredpad.m. The persistence and/or transience of frequencies along the series was evaluated with evolutionary fast Fourier transform (FFT) analysis using the MATLAB script evofft.m. These latter two scripts are available at http://mason.gmu.edu/ lhinnov/cyclostratigraphytools.html. The identification of potential astronomical frequencies was done by comparison of spectral peaks at frequencies that correspond to those of the Earth's orbital eccentricity, obliquity, and precession index predictions for the Upper Carboniferous-Lower Permian interval (298 Ma) by Berger and Loutre (1994).

\section{Remanent Magnetization of Mafra Rocks}

The thermal demagnetization data revealed the presence of two components in almost all demagnetized specimen, while the AF procedure mostly indicated the presence of more than one component, but did not discriminate the direction very well, and presented noisy behavior at the last few steps of demagnetization (which we eliminated from our directional analyses). A total of 528 specimens were subjected to the demagnetization process. AF demagnetization was applied to all 216 sampled layers (stratigraphic sites), which resulted in 366 AF demagnetized specimens. Thermal demagnetization was applied to 103 layers sparsely distributed along the section, which resulted in 162 thermally demagnetized specimens. Representative examples of thermal and AF demagnetization data are shown in Figure 2.

The thermal demagnetization efficiently removed all the remanent magnetization by $600{ }^{\circ} \mathrm{C}$ and revealed two components of magnetization: one (secondary) removed at temperatures below $350{ }^{\circ} \mathrm{C}$ and the other (characteristic) with high unblocking temperatures between 350 and $600{ }^{\circ} \mathrm{C}$. Specimens DD8A1B and DDL078B2B shown in Figure 2 are examples of thermal demagnetization that represent the typical behavior of Mafra specimens. DDL078B2B is an example of a pilot group of thermal demagnetization, containing more than 30 steps of demagnetization, and DD8A1B is an example of specimens that were subjected to a simpler protocol, with fewer demagnetization steps. Both specimens show good discrimination of the two components of magnetization, which are separated by a cusp elbow in the orthogonal plot. The final steps of demagnetization (between 350 and $600^{\circ} \mathrm{C}$ ) are well grouped in the stereographic projection and are distributed along a direction centered on the origin of the orthogonal plot. For temperatures higher than $600^{\circ} \mathrm{C}$, the remanence presents low values in the intensity plots and random behavior in the stereographic projection, and plots near the origin in the orthogonal plots, attesting to the complete demagnetization.

The decay of intensity of remanence was smooth for AF steps from 0 to $100 \mathrm{mT}$, but for the last steps (with about $10 \%$ of the intensity remaining), the behavior was unstable. The remanent magnetization data are distributed along a great circle between the first and last (by $10 \mathrm{mT}$ ) steps of demagnetization for almost all 


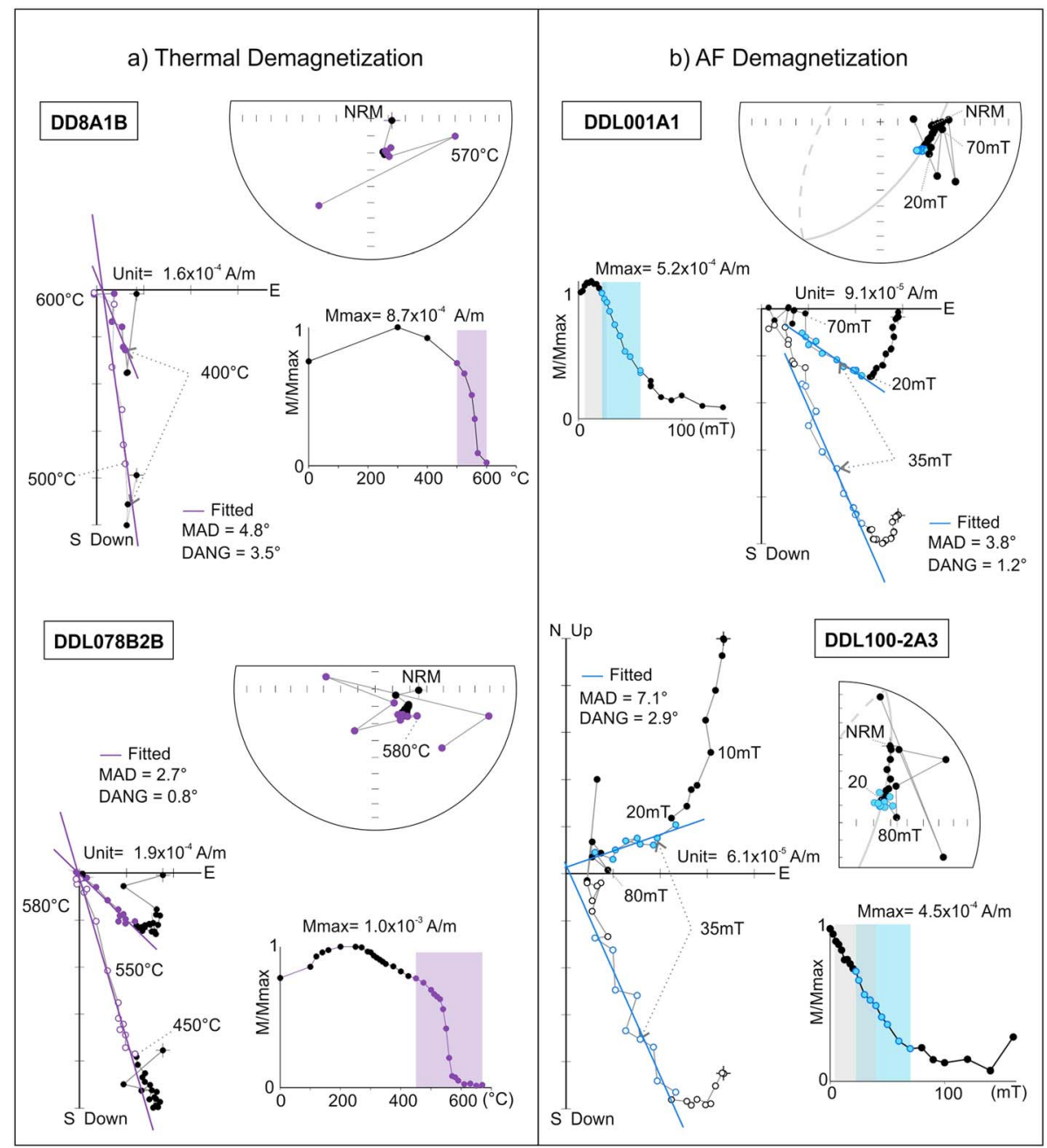

Figure 2. Intensity curves, orthogonal plots, and stereographic projections of four examples of Mafra demagnetized specimens. Alternating field (AF; thermal) demagnetizations are on the right (left). Orthogonal plots are composed of horizontal projection (filled circles) and vertical projection (empty circles). Filled circles in stereographic projections represent positive inclinations. The chosen steps for calculating the characteristic thermal and AF-C directions are colored in purple and blue, respectively, in the orthogonal, stereographic, and intensity plots. The great circles were fitted using the range shown in the grey area in the intensity plot. The great circles are shown in the stereographic plots. The maximum angular deviation (MAD) and the deviation angle between the center of mass and the fitted direction (DANG; Tauxe, Banerjee, et al., 2016) are also shown.

samples. This behavior is shown by stereographic projections of AF examples of Figure 2. The specimen DDL001A1 is an example that reveals the presence of two components, one of low coercivities up to $20 \mathrm{mT}$ and the other along the range from about 25 to $70 \mathrm{mT}$; above $70 \mathrm{mT}$ the data present a random behavior (intensity, orthogonal, and stereographic plots). The specimen DDL100-2A3 also shows the presence of two components, but it presents a smoother curve instead of two well-defined lines, and the same randomness toward the end of demagnetization. Excluding these noisy data at the end, the demagnetization for the more coercive range tends to go to the origin of orthogonal plot (see straight lines on Figure 2b).

Principal component analysis (Kirschvink, 1980) was used for fitting components of thermal and AF data. Part of the AF demagnetization data was also subjected to great circle adjustments (Halls, 1976). The secondary components were identified in the range of low coercivities ( 0 to $15 \mathrm{mT}$ ) and low temperatures (up to 350 ${ }^{\circ} \mathrm{C}$ ) for 314 (232 $\mathrm{AF}$ and 82 thermal) specimens. The maximum angular deviation (MAD) varied from $0.5^{\circ}$ to $26.3^{\circ}$. The high unblocking temperature characteristic component (Th-Ch) was fitted in the range of 350 to 
a)

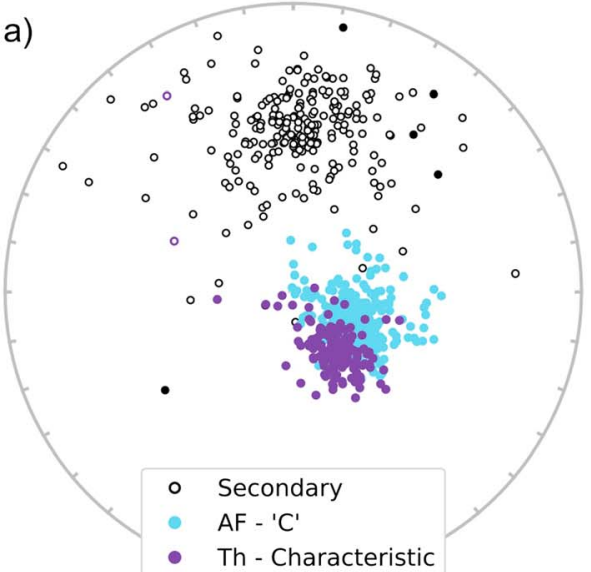

c)

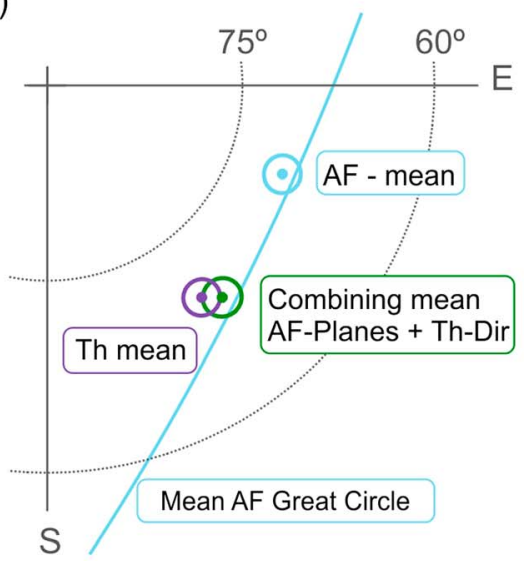

b)

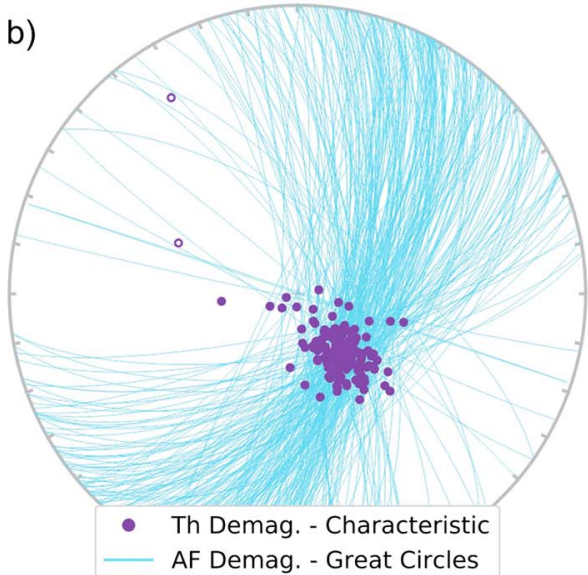

d)

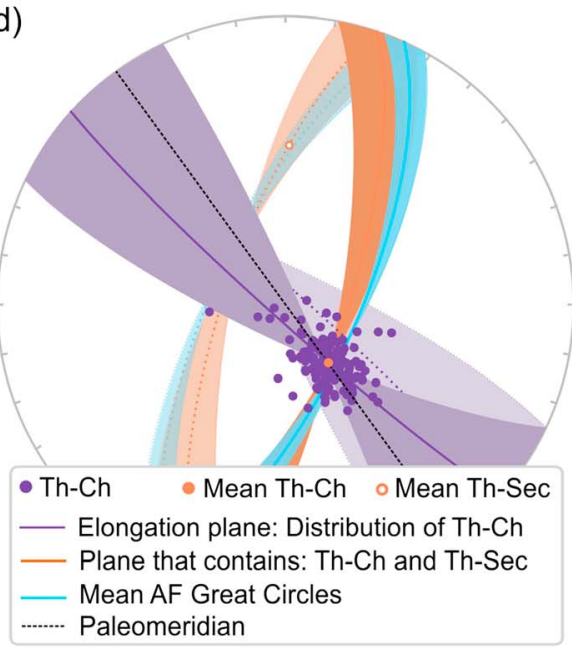

Figure 3. Directions and planes determined for demagnetized specimens from Mafra Formation. (a) Stereogram projection with secondary directions in black, characteristic component (thermal demagnetization data) in purple and $\mathrm{C}$ component (alternating field [AF] demagnetization data) in blue circles. Empty (full) circles are negative (positive) inclination. (b) Only lower projection of planes identified from AF demagnetization data (great circle analyses; Halls, 1976) and characteristic components determined by thermal demagnetization. (c) Global means using thermal data (purple), mean of $\mathrm{C}$ component, and mean of great circles from AF data (blue), and combining AF planes and Th directions (green). (c) The purple line represents the plane that contains the maximum and intermediate eigenvalues $\left(\tau_{1}\right.$ and $\left.\tau_{2}\right)$ from the "orientation matrix" $T$ (Scheidegger, 1965) from characteristic thermal data (Th-Ch). It indicates the plane of elongation. The orange plane is the plane that contains the mean thermal secondary (orange circle with negative inclination) and the mean characteristic thermal direction (orange circle with positive inclination). The blue plane is the mean great circle of AF data. The limits were defined by 1,000 bootstrap resamplings. The black dashed line is the direction of the paleomeridian given by the declination of thermal mean.

$600{ }^{\circ} \mathrm{C}$ for the majority of the specimens. Only four specimens (2.5\%) showed random behavior and gave no reliable components. The MAD of the Th-Ch components varied from $1.4^{\circ}$ to $25.4^{\circ}$. The high-coercivity characteristic component (AF-C) was identified in the range of 35 to $100 \mathrm{mT}$, excluding the noisy last steps. The values of MAD of AF-C components varied from $1.7^{\circ}$ to $32.1^{\circ}$. The AF great circles were determined in the range of 5 to $100 \mathrm{mT}$. A total of 322 planes were defined, and MAD values varied from $1.4^{\circ}$ to $31.4^{\circ}$. Directions or planes with MAD higher than $15^{\circ}$ were rejected for future analyses. This data cut represents about $11 \%$ of the total data set. All 954 components and planes with MAD $\leq 15^{\circ}$ from Mafra rocks are shown in Figure 3 and are listed in Table S1 (in the supporting information).

The secondary components form a relatively highly dispersed group pointing to the north with negative inclinations, which is compatible with the present geomagnetic field in the area. The AF-C and Th-Ch components point to the southeast and have high positive inclinations, excepting six results (two from thermal 


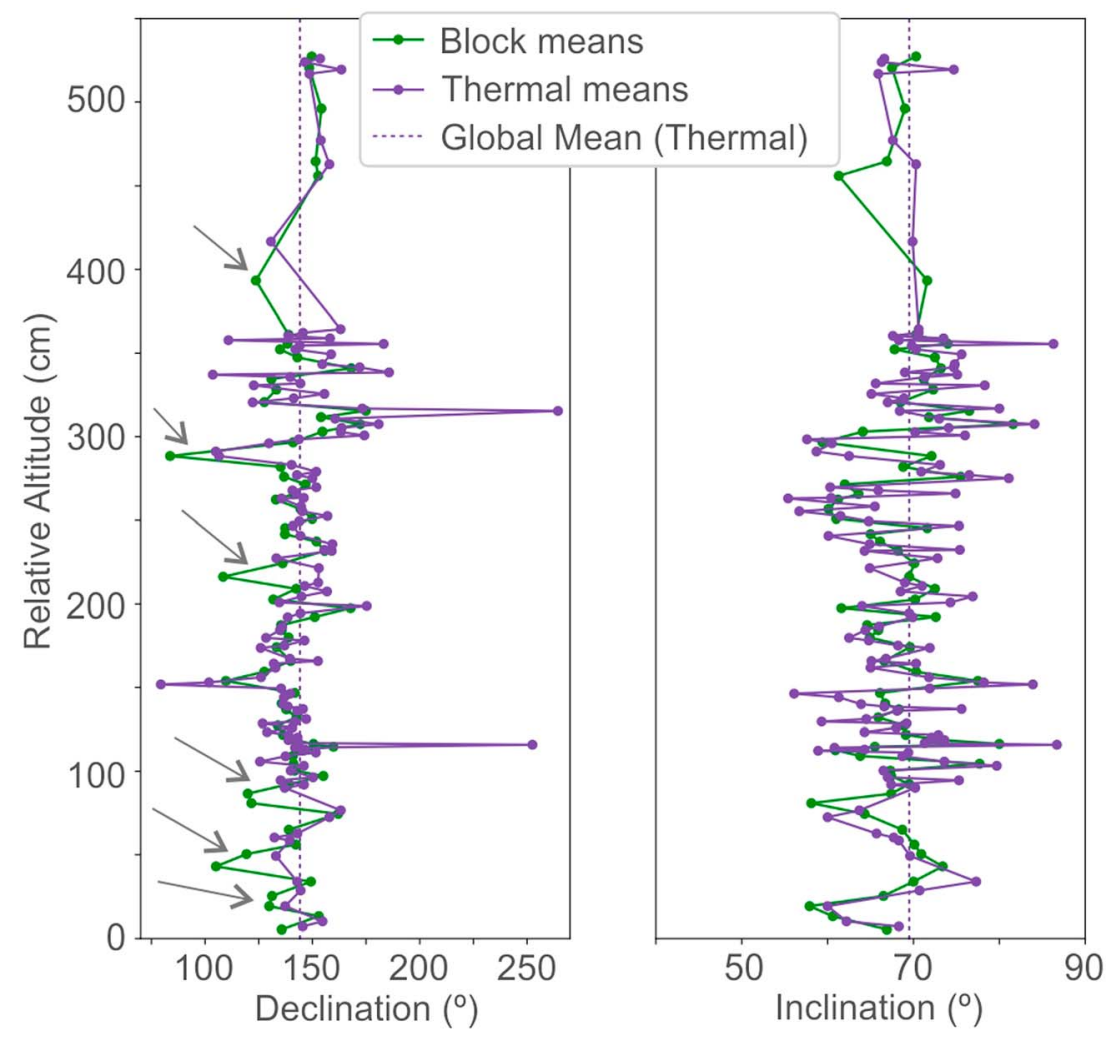

Figure 4. Declination and inclination of mean directions of groups of thermal directions and alternating field (AF) planes (green) and thermal mean directions per layer (purple). Arrows indicate the systematic differences of lower declination for block means (combining of AF-planes and Th-Ch).

and four from AF demagnetizations) with negative inclinations. These are spurious directions because they have no consistency with nearby samples.

Although the AF-C and Th-Ch point to a similar direction, they are systematically different from each other (Figure 3a); the AF-C directions present visibly lower declinations than Th-Ch. Figure 3c further shows that the global averages with only Th-Ch (purple) and only AF-C (blue) are quite different from each other, the angular cones of $95 \%$ confidence do not intercept and are small (both $1.4^{\circ}$ ) when compared to the angular distance between the vectors $\left(11^{\circ}\right)$. The mean AF-C plots in between the Th-Ch and the secondary means (Figure 3c), in the same remagnetization plane, therefore, indicating an incomplete removal of the secondary magnetization.

The fitted planes of AF demagnetization data (AF-planes) seem to be more consistent with thermal data because of the region in the stereographic projection where most of the intersections lie in the same region that is occupied by Th-Ch directions (Figure 3b). When they are grouped using the method of grouping planes and directions with constraints (McFadden \& McElhinny, 1988) using groups of at least five specimens along the stratigraphy, they present a global mean (green, in Figure 3c) that plots between the thermal mean and the mean remagnetization plane, with only a partial superposition of $\alpha_{95}$ (grouping global mean: $\operatorname{dec}=140.5^{\circ}$, inc $=68.8^{\circ}, \alpha_{95}=1.5^{\circ}, N=71$ groups; thermal global mean: dec $=143.9^{\circ}$, inc $=69.8^{\circ}, \alpha_{95}=$ $1.4^{\circ}, N=118$ layers). The differences appear more striking when we see the plot of both data sets along the relative elevation (Figure 4). At some levels, the declination of grouped directions (green) are very different from thermal directions (purple) and repeatedly tend to smaller declinations (indicated by arrows in Figure 4). Because of these systematic differences, the only partial overlapping of $\alpha_{95}$, and the positioning of the blocking mean between the remagnetization plane and the thermal mean, we consider it likely that even using only the analyses of AF data by the great circle fitting and grouping method will contaminate the results with incomplete removal of secondary directions. Thus, in the following, we considered only the thermal data set (Table S2) to avoid any contribution of secondary components in the final results. 

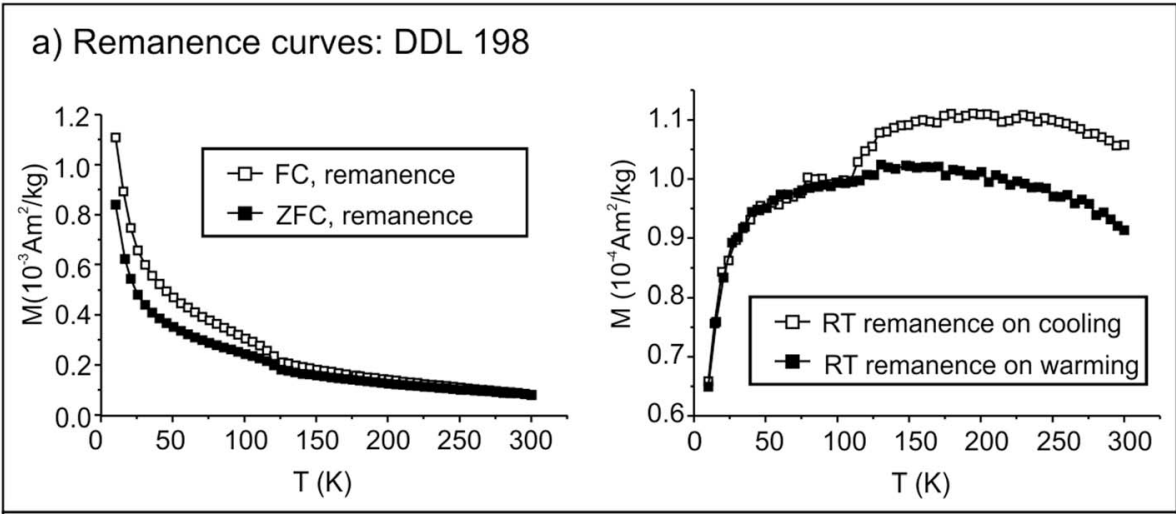

Hysteresis and FORC results: DDL025
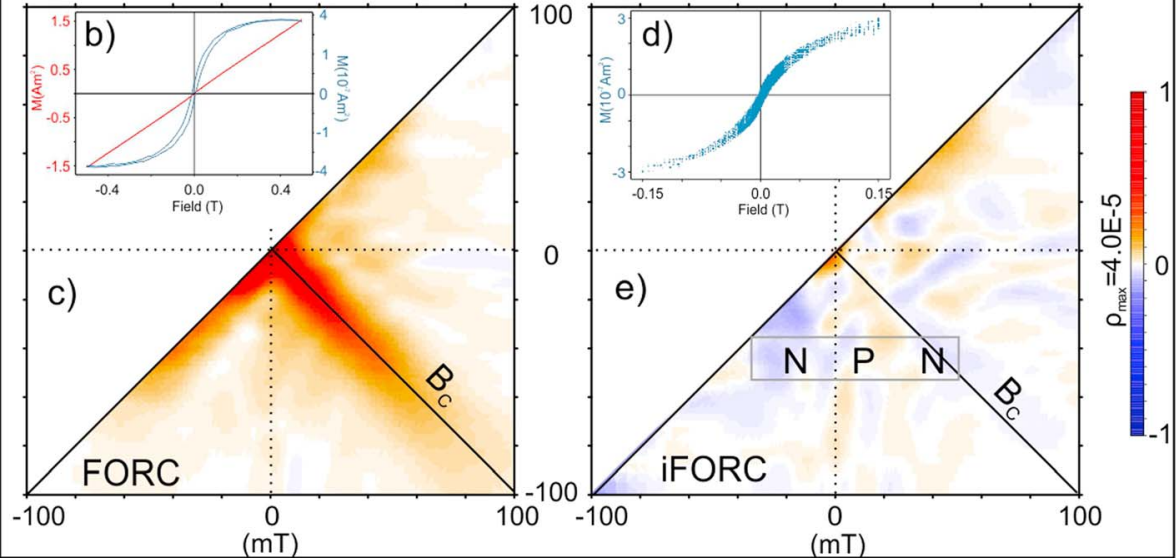

Figure 5. Rock magnetic results: (a) Remanence curves of sample DDL198: Field cooling (FC) and zero field cooling (ZFC) curves on left and room temperature (RT) curves on the right. Bottom: Irregular first-order reversal curves diagrams for sample DDL025. (b) A cycle of hysteresis with and without paramagnetic correction; (c) conventional first-order reversal curve (FORC) diagram; (d) corrected hysteresis cycles; (e) induced FORC diagram. The rectangle with $\mathrm{N}, \mathrm{P}$, and $\mathrm{N}$ is showing characteristic triple negative-positive-negative that is common for samples that contain single domain particles. Smoothing factor 5, 120 FORC curves were measured, with $300 \mathrm{~ms}$ of averaging time, maximum field of $300 \mathrm{mT}$ and saturation field of $300 \mathrm{mT}$.

Figure 3d shows the remagnetization planes defined by thermal data (orange) determined by the plane that contains the secondary and characteristic mean directions and by AF data (blue) determined by the mean great circle. The remagnetization planes determined by thermal and $\mathrm{AF}$ data are compatible with one another, and the elongation plane is totally different from them. As the elongated shape of the characteristic thermal directions (purple line at Figure 3d) is not compatible with the remagnetization planes, we can discard the hypothesis that this shape of distribution is due to incomplete removal of the secondary direction. Moreover, as the elongation plane is compatible with the plane that contains the paleomeridian and vertical, the elongated shape of the Mafra distribution is not related to inclination shallowing effect.

\section{Rock Magnetism and Flattening Factor $f$ Determination}

The samples presented a transition in room temperature remanence cooling curves at around $120 \mathrm{~K}$ and a partial recovery of the remanent magnetization during heating. This transition is called the Verwey transition (Dunlop \& Ozdemir, 1997) and indicates the presence of magnetite. FC remanence curves of all samples presented higher values than the ZFC remanence, which is indicative of the presence of single domain magnetite [following Bilardello \& Jackson, 2013]. Figure 5a shows one typical example of FC, ZFC, and room temperature remanence curves (sample DDL198).

Irregular FORCs at room temperature were performed on three selected samples from Olsen quarry to confirm the domain structure of the magnetic carrier. The conventional FORC diagram for all analyzed samples 


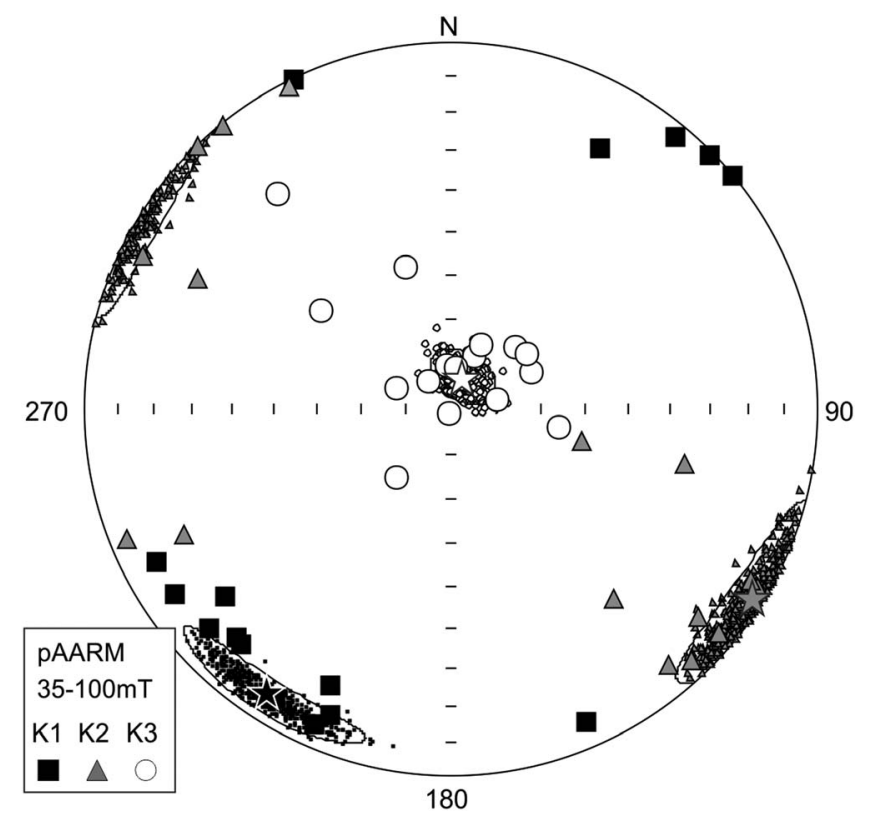

Figure 6. Equal-area projection of principal of anisotropy of partial anhysteretic remanent magnetization (pAARM) tensors axis: K3 (minimum, circle), K1 (maximum, square), and K2 (intermediate, triangle). Small symbols are 500 bootstrapped mean tensors axis, big symbols are the tensor for each sample, and stars are the mean tensor. The ellipses are $95 \%$ of bootstrapped confidence region. showed a positive distribution on the Bc axis (see DDL025 on Figure 5b). Induced FORC diagrams exhibited a characteristic triple negative-positive-negative that is common for samples that contain single domain particles, following $\mathrm{Hu}$ et al. (2018) and Zhao et al. (2017).

Sixteen specimens distributed along the sampling section were selected for AARM measurements to define a mean $K_{\mathrm{A}}$ tensor that represents the rock unit, following Kodama (2009). Partial AARM acquisition was conducted in the range 35 to $100 \mathrm{mT}$ of AF field with a bias field of 0.1 $\mathrm{mT}$. This range corresponds to the range of $\mathrm{AF}$ demagnetization that had the least influence on secondary magnetization (see Figure 2).

Results of AARM for each specimen, mean ellipsoid (with bootstrapped confidence ellipses), and 500 bootstrapped means are shown in Figure 6, where $K_{\mathrm{A} 1}, K_{\mathrm{A} 2}$, and $K_{\mathrm{A} 3}$ are the axes of the eigenvectors of, respectively, maximum, intermediate, and minimum eigenvalues of the $K_{\mathrm{A}}$ tensor. The results have approximately the same behavior, where the majority of maximum and intermediate directions $\left(K_{\mathrm{A} 1}\right.$ and $\left.K_{\mathrm{A} 2}\right)$ are near to the horizontal and minimum axes $\left(K_{\mathrm{A} 3}\right)$ are close to the vertical. The anisotropy degree of each specimen varied between $1.5 \%$ and $5.5 \%$. The mean ellipsoid (large symbols) presents an oblate shape and is positioned parallel to the horizontal. The normalized mean tensor $K_{\mathrm{A}}$ has eigenvalues of $K_{\mathrm{A} 1}=1.013, K_{\mathrm{A} 2}=1, K_{\mathrm{A} 3}=0.987$, with the directions $\operatorname{Dec}_{\mathrm{K} 1}=212.7$, $\mathrm{Inc}_{\mathrm{K} 1}=7.4, \mathrm{Dec}_{\mathrm{K} 2}=122.4, \mathrm{Inc}_{\mathrm{K} 2}=1.8, \mathrm{Dec}_{\mathrm{K} 3}=19.1, \mathrm{Inc}_{\mathrm{K} 3}=82.4$.

The AARM and rock magnetic results allowed us to determine the inclination shallowing correction factor (flattening factor, $f$ ). Magnetite can have particle anisotropy $a$ from 1 (isotropic particles) to infinite (elongated uniaxial). According to Dunlop and Ozdemir (1997), elongated particles should not exhibit the Verwey transition, which means that the Mafra's remanence curves are attesting to the presence of magnetite, but not the elongated particles. However, we can not discard the presence of elongated particles, because of the bulk remanence anisotropy, despite the low degree of anisotropy, agrees with the expected fabric for sedimentary rocks (horizontal oblate elipsoid on Figure 6). The flattening factor is determined by $f=K_{\mathrm{A} 3}(a$ $+2)-1 / K_{\mathrm{A} 1}(a+2)-1$ (Jackson et al., 1991), where $K_{\mathrm{A} 3}$ and $K_{\mathrm{A} 1}$ correspond to the minimum (vertical) and maximum (horizontal) axes from $K_{A}$ tensor and $a$ is the particle anisotropy that for natural magnetite has a typical value of $a=2$ (Kodama, 2012). Because the difference between the $K_{\mathrm{A} 3}$ and $K_{\mathrm{A} 1}$ from the mean Mafra tensor is small (1.013 and 0.987 , respectively), the flattening factor would vary between 0.96 and 0.97 for any value of $a$ between 1 and infinite. Therefore, for Mafra results, the particle anisotropy does not affect significantly the final flattening factor estimative. Anyway, considering the typical value of $a=2$, the resulting flattening factor for Mafra rocks is $f=0.97$, which means almost no correction.

\section{Cyclostratigraphic Results}

There are patterns strongly suggestive of astronomical signals in the $\chi$ and ARM series. A $\sim 60-\mathrm{cm}$ cycle occurs throughout both data series (Figures 7c and 7d, purple arcs); between 100 and $150 \mathrm{~cm}$, the cycle is shortened to $30 \mathrm{~cm}$ (down-pointing purple arrows). This cycle is prominent in the power spectra of both $\chi$ and ARM series (Figure 8); the spectral peak with a wavelength of $65 \mathrm{~cm}$ exceeds the $99 \%$ confidence level for red noise in the ARM spectrum. In Figures $7 \mathrm{c}$ and $7 \mathrm{~d}$, other shorter cycles occur within the $\sim 60$-cm cycles, preferentially at 23 and $10.6 \mathrm{~cm}$ in the $\chi$ spectrum and at $13 \mathrm{~cm}$ primarily in the ARM spectrum (Figures $8 \mathrm{c}$ and $8 \mathrm{~d}$ ). This overall pattern suggests that the $65-\mathrm{cm}$ cycle may represent the 100-kyr short orbital eccentricity cycle. The wavelength ratio $65: 23: 13: 10.6=6.13: 2.17: 1.23: 1$ is not far from the ratio of Late Carboniferous astronomical periodicities of Berger and Loutre (1994): 100:34.2:20.7:17.4 = 5.75:1.97:1.19:1. Moreover, the 60\% "loess" curves of the $\chi$ and ARM series have a cycle with a $~ 270-\mathrm{cm}$ wavelength (Figures $7 \mathrm{a}$ and $7 \mathrm{~b}$ ), that is, at a scale suggestive of the 405-kyr long orbital eccentricity cycle $(65 \mathrm{~cm} \times$ $4.05=263.25 \mathrm{~cm}$ ). The FFT spectrograms (Figure 8) show a sharp shift of frequencies to the right at $\sim 70-100$ to $150 \mathrm{~cm}$, suggesting a decrease in sedimentation rate in this stratigraphic interval and explaining the wide 
(A)

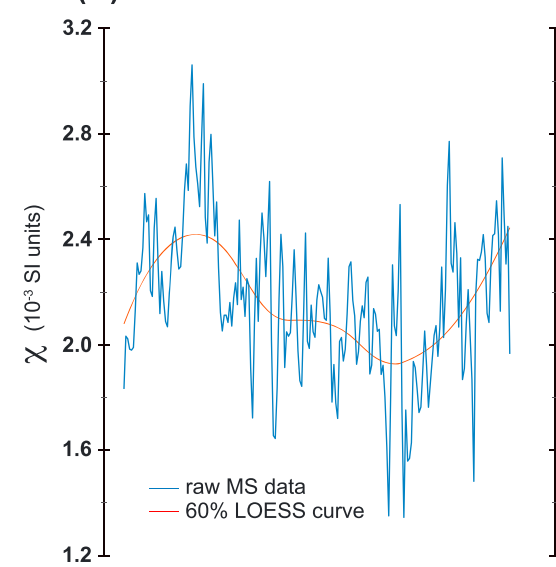

(B)

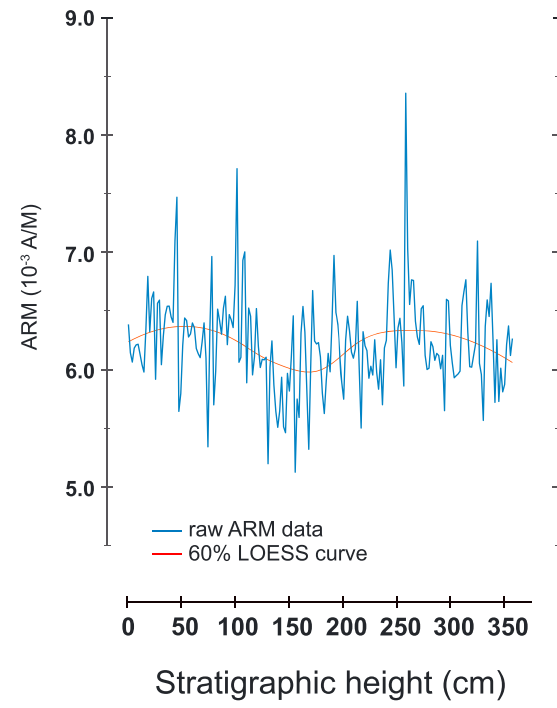

(C)

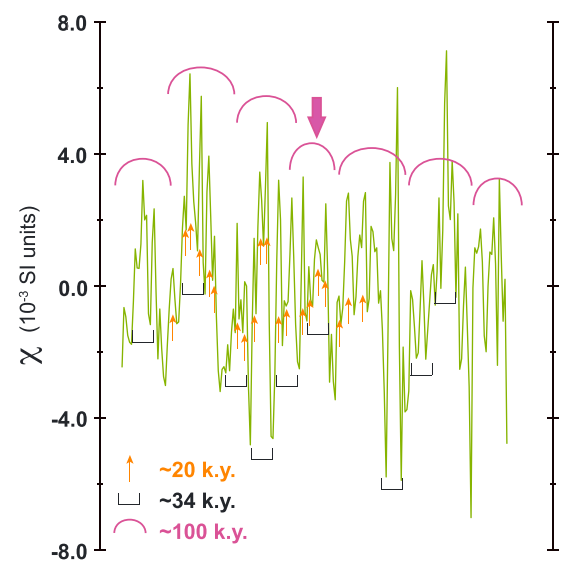

(D)

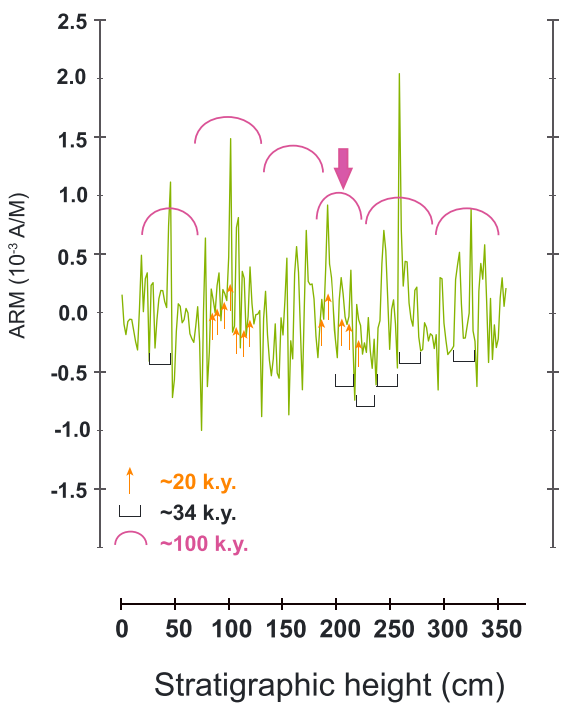

Figure 7. The cyclostratigraphic series. (a) Raw magnetic susceptibility $(\chi)$ and (b) raw anhysteretic remanent magnetization (ARM) data series after linear interpolation and resampling (blue) and their corresponding 60\% "loess" curves (red). (c) $\chi$ and (d) ARM data series after removal of the $60 \%$ loess curves. Purple arcs $=100$-kyr short orbital eccentricity cycles, black brackets $=34 \mathrm{kyr}$ obliquity cycles, and upward pointing orange arrows $=20 \mathrm{kyr}$ precession index cycles.

range of wavelengths presumably related to the precession index $(12.9,7.8$, and $6.2 \mathrm{~cm}$ in the ARM spectrum and 10.6, 7.3 , and $6.5 \mathrm{~cm}$ in the $\chi$ spectrum).

Assuming that the $65-\mathrm{cm}$ cycle is the main expression for the $\sim 100-\mathrm{kyr}$ short orbital eccentricity implies a sedimentation rate of $65 \mathrm{~cm} / 100 \mathrm{kyr}=0.65 \mathrm{~cm} / \mathrm{kyr}$ for the series. Thus, the $360-\mathrm{cm}$ series length may represent a duration of $360 \mathrm{~cm} /(0.65 \mathrm{~cm} / \mathrm{kyr})=553,846$ years, and a 1 -cm-thick specimen would be expected to average over $1.5 \mathrm{kyr}$. As the total section of paleomagnetic sampling comprises $5.3 \mathrm{~m}$, the complete sampled DDL section may correspond to a duration of $\sim 530 \mathrm{~cm} /(0.65 \mathrm{~cm} / \mathrm{kyr})=815,385$ years.

\section{Mafra and Other South American Paleomagnetic Poles}

The remanent magnetization of the Mafra rocks has high positive inclination and is carried mainly by single domain magnetite as revealed by thermal demagnetization. No other magnetic carrier was identified, but this does not exclude the possibility of a small contribution of a secondary mineral carrying the secondary direction, although not detected. The weak anisotropy indicates only a very small correction for inclination shallowing effect (flattening factor $f=0.97$ ), which changes the final mean inclination by $0.5^{\circ}$. The 118 


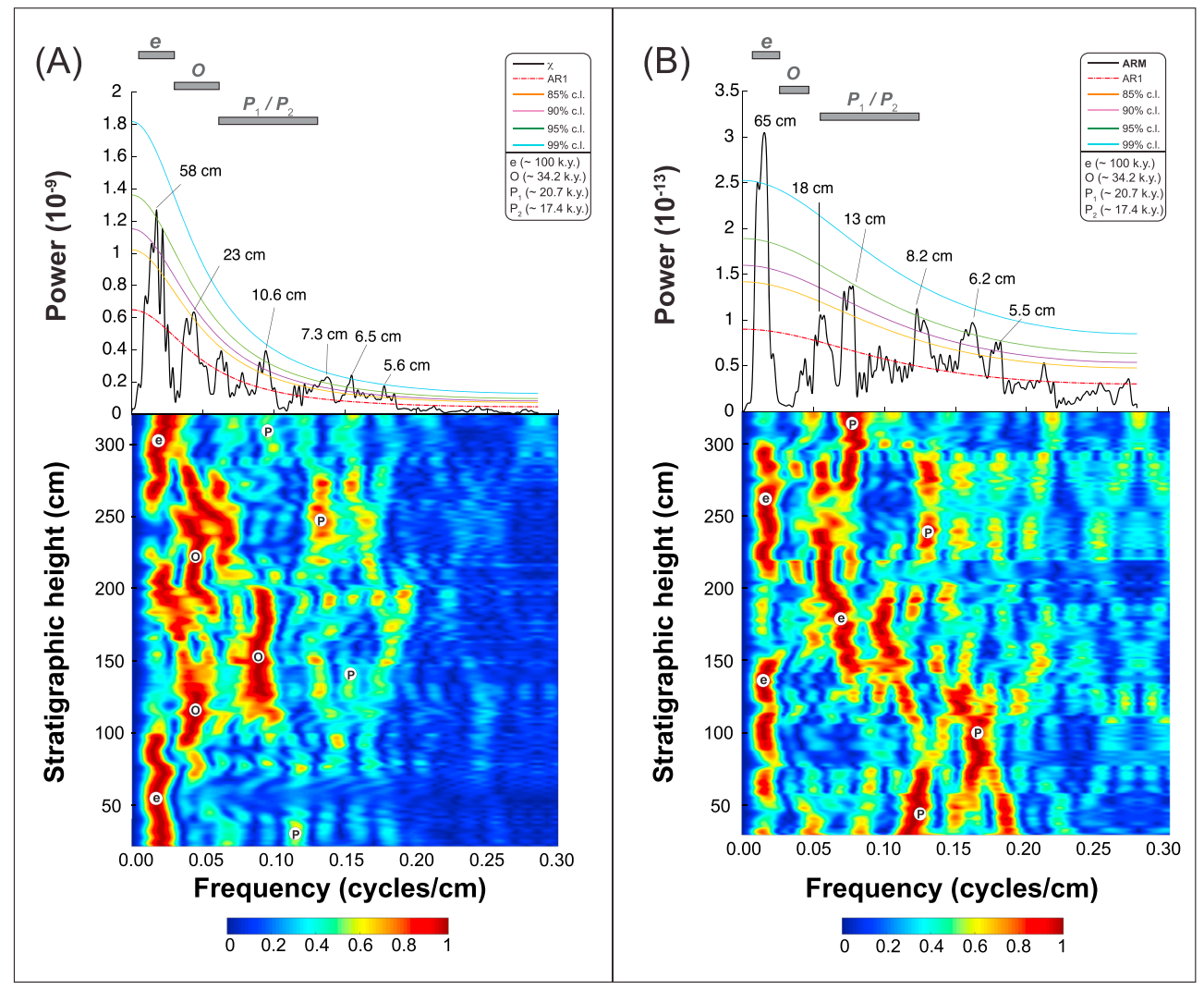

Figure 8. Spectral analysis of the cyclostratigraphic series for (A) $\chi$ and (B) anhysteretic remanent magnetization (ARM). Top: $2 \pi$ multitaper power spectra, with the AR(1) red noise spectral model and $85 \%, 90 \%, 95 \%$, and $99 \%$ confidence levels (c.l.) for null hypothesis testing. Wavelengths of spectral peaks are labeled in $\mathrm{cm}$. Bottom: Evolutionary fast Fourier transform (FFT) spectrograms with a 75-cm sliding window, with each calculated FFT spectrum normalized to 1; e, O, and $\mathrm{P}$ indicate $100-\mathrm{kyr}$ short orbital eccentricity, obliquity, and precession, respectively.

results (Table S2) were converted into VGPs, and a variable cutoff angle procedure (Vandamme, 1994) was used for selecting data. The final cutoff angle was of $24.8^{\circ}$, which removed seven sites.

The mean direction of characteristic remanent magnetization of Mafra rocks, using only the selected directions, is Dec $=144.2^{\circ}$ and Inc $=69.0^{\circ}\left(N=111, R=110.1, k=129.1, \alpha_{95}=1.2^{\circ}\right)$, which results in a paleolatitude of $52.4^{\circ} \mathrm{S}$. The mean direction with inclination shallowing correction $(f=0.97)$ changes to Dec $=$ $144.2^{\circ}$ and Inc $=69.5^{\circ}\left(N=111, R=110.2, k=134.4, \alpha_{95}=1.2^{\circ}\right)$ with paleolatitude of 53.2 ${ }^{\circ} \mathrm{S}$. The final Mafra PP position is $51.9^{\circ} \mathrm{S}, 344.3^{\circ} \mathrm{E}\left(N=111, R=109.0, K=55.9, A_{95}=1.8^{\circ}\right)$. Mafra PP (number 16 in Table S4) is plotted as a star in Figure 9a. The Mafra PP without inclination shallowing correction (named as 16.1 in Figure 9a) is practically the same as the corrected one (16.2). The confidence circle of $95 \%\left(A_{95}\right)$ for the Mafra pole is almost the symbol size and not easily distinguished in the figure.

The set of PPs plotted in Figure 9 and listed in Table S4 from the supporting information was based on the compilation done by Domeier et al. (2012) and some new results from Ernesto et al. (2015), Franco, Ernesto, et al. (2012), and Yokoyama et al. (2014). Poles from 9 to 19 are reverse polarity and are assigned to the Kiaman superchron interval [ 318 to $262 \mathrm{Ma}$; Opdyke \& Channell, 1996]. The PP 18 (Pular and Cas Formations), which have mixed polarities, including a normal polarity record, which, according to Jesinkey et al. (1987), represents a normal event at the base of Kiaman superchron. Mafra PP is inserted in the $A_{95}$ cone of confidence from poles Pular and Cas Formations PP (number 18) and La Tabla Formation PP (number 19). Those poles are from igneous rocks from Chile (Jesinkey et al., 1987) and have similar ages.

The stratigraphic correlation between the Mafra and Rio do Sul formations is well constrained in Santa Catarina State. The Rio do Sul Formation positions in the upper portion of Itarare Group and Mafra 


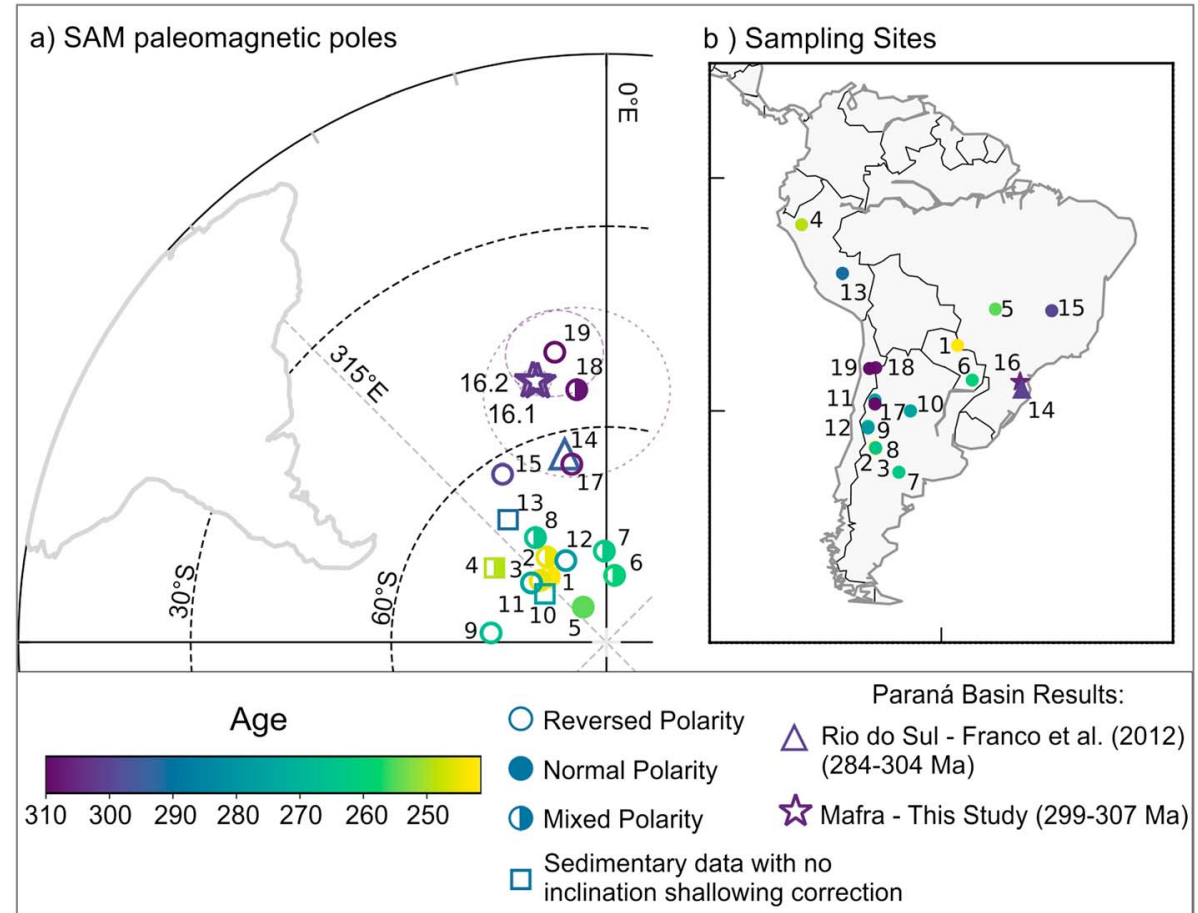

Figure 9. South American paleomagnetic poles. (a) Paleomagnetic poles positions of ages from Carboniferous to Triassic times, where 1-Ernesto et al. (2015); 2, 3, 8-Domeier, Van der Voo, Tomezzoli, et al. (2011); 4-Gilder et al. (2003); 5Yokoyama et al. (2014); 6-Rapalini et al. (2006); 7-Domeier, Van der Voo, Tohver, et al. (2011); 9, 12-Rapalini and Vilas (1991); 10, 11-Geuna and Escosteguy (2004); 13-Rakotosolofo et al. (2006); 14-Franco, Ernesto, et al. (2012); 15-Brandt et al. (2009); 16-this study; 17-Geuna et al. (2010); 18, 19-Jesinkey et al. (1987). The numbering follows the sequence from Table S4 (supporting information). The corrected (16.2) and uncorrected (16.1) Mafra paleomagnetic pole are plotted as stars. The Rio do Sul pole (Franco, Ernesto, et al., 2012) is plotted as a triangle. Empty, full, and half-full symbols are referred to exclusively reversed, exclusively normal, and mixed polarity, respectively. The sedimentary and volcaniclastic results that were originally corrected for the inclination shallowing effect by the authors are plotted in Figure 9a (poles 3 , 14, and 15). The sedimentary poles that did not have any correction are also plotted (squares, PPs number 4, 10, and 13). (b) Site positions of the paleomagnetic poles (following the same numbering, color scale, and type of symbols).

Formation in the middle portion, following the definition of Schneider et al. (1974). As already mentioned in section 2, the age of the Mafra formation is late Pennsylvanian (Kasimovian to Gzhelian). The Rio do Sul formation is younger and corresponds to the Permo-Carboniferous boundary (Gzhelian to Sakmarian, 284.4 to $303.9 \mathrm{Ma}$ ). Recent dating based on $\mathrm{Rb}-\mathrm{Sr}$ of the base of this unit (Lontras shale) indicates a minimum age of $287 \pm 10 \mathrm{Ma}$ (Koester et al., 2016). Conversely, Cagliari et al. (2016) put some more constraints on the ages of these formations as they place the topmost glacial deposits of the Itararé Group at $307.7 \pm 3.1 \mathrm{Ma}$ (Kasomovian-Moscovian), therefore placing the Rio do Sul and Mafra formation being slightly older than this.

The paleomagnetic pole from the Rio do Sul Formation Franco, Ernesto, et al. (2012) is plotted as a triangle and is almost equal to the PP 17 [La Colina pole from Geuna et al., 2010] observed from both sedimentary and volcanic rocks. The Rio do Sul PP would produce a magnetic inclination at Mafra site of $63.9^{\circ}$ corresponding to a paleolatitude of $45.6^{\circ} \mathrm{S}$. This implies a velocity of $3.4 \mathrm{~cm} /$ year toward the north (considering a maximum age difference of $\sim 20 \mathrm{Ma}$; the lowest limit of age from Mafra and the upper limit of age from Rio do Sul) and a velocity of about $6.4 \mathrm{~cm} /$ year. This result is compatible with the velocities of about 6 $\mathrm{cm} /$ year northward between 310 and 290 Ma determined by Torsvik et al. (2012) for Gondwana Supercontinent. After this time interval, the general trend of displacement of Gondwana supercontinent is northward, and the younger paleomagnetic poles gradually plot at higher latitudes, heading toward the geographic pole. After the Pangea breakup, the paleomagnetic poles for the South American plate remained at higher latitudes (Ernesto, 2005 and Font et al., 2009), which means that there is no possibility of the paleomagnetic direction determined by Mafra rocks be a younger overprint. 
Field tests such as folding or conglomerate tests might reinforce the primary origin of the magnetization, but none is available for this intracratonic basin. This absence does not mean that the magnetization is not primary. These sediments exhibit no signs of tectonic folding and were certainly not remagnetized by folding effects. Therefore, we consider the characteristic component, identified by thermal demagnetization, as a primary magnetization.

\section{The Record of Paleosecular Variation by Mafra Rocks Compared to GGP Models}

The positive-inclination remanent magnetization of the Mafra section is expected for a primary magnetization, as its age is entirely constrained in the Kiaman superchron interval [ 318 to 262; Opdyke \& Channell, 1996]. According to the cyclostratigraphic analysis (section 8), the Mafra studied section covers more than $800 \mathrm{kyr}$, which ensures a representative sampling of the paleosecular variation. Moreover, the variation of the characteristic magnetization along the stratigraphic sequence does not show any tendency from bottom to top that could be related to age differences (see Figure 4). Considering the long period represented in the deposition of these sediments, the dense sampling of this section, the primary nature of its magnetic remanence, and the small correction of inclination shallowing applied (AARM procedure), we can consider it a reliable and detailed record of a section of the Kiaman geomagnetic field. However, the Mafra record should be considered as a smoothed signal from the geomagnetic field variations, due to the low rate of deposition of the studied section ( $~ 800 \mathrm{kyr}$ for $5.3 \mathrm{~m}$ ); each sedimentary layer represents a time-averaged field of some thousands of years. Therefore, this paleomagnetic data set cannot be considered as a spot reading of the geomagnetic field, and a partial smoothing of geomagnetic variation is anticipated.

Figure 10a shows the resulting distribution of magnetic remanent directions (mean direction per stratigraphic layer) with the expected direction $\left(\mathrm{Dec}=144.3^{\circ}, \mathrm{inc}=69.3^{\circ}\right)$ rotated to the origin (center of stereographic projection). The elongation values with the $95 \%$ bootstrap confidence limits are $E_{\mathrm{M}}=2.08_{1.45}^{3.03}$ for noncorrected Mafra directional data and $E_{\mathrm{M} i}=2.08_{1.44}^{3.13}$ for AARM-corrected data (inclination shallowing correction). The declination of $V_{2}$ (eigenvector associated to intermediate eigenvalue $\tau_{2}$ of $T$ ) with the 95\% bootstrap confidence limits is $\operatorname{Dec}_{V 2}=128.5_{114.4}^{148.0}$, which is compatible with the mean declination (direction of paleomeridian), as predicted by TK03.GAD model. However, the value of elongation is higher and incompatible with that predicted, and the 95\% confidence bound does not intercept the TK03.GAD elongation curve (black dashed line in Figure 10f). As the value is greater than predicted by the model for its inclination value and the elongation is along the paleomeridian direction, there is no flattening correction that recovers an elongation/inclination pair that makes Mafra data set compatible with TK03.GAD model. Moreover, this would be an inappropriate procedure since the data were already corrected by AARM method.

The dispersion of VGPs of the Mafra Formation with 95\% bootstrap confidence limits was $S_{\mathrm{M}}=11.0_{9.9}^{\circ 11.9}$ for uncorrected data and $S_{\mathrm{M} i}=10.9{ }_{9.8}^{\circ 11.8}$ for AARM-corrected data. As we can see in Figure 10g (purple star), this result is lower than that predicted by TK03.GAD (black dashed line, Figure 10g). This result is not surprising as the TK03.GAD model is related to the last five million years when the geomagnetic field shows higher reversal rates, quite different from the behavior during a superchron. We also need to consider that the reduction of scatter can be enhanced by smoothing of the geomagnetic signal implied by the low deposition rate of Mafra rocks. Even so, other paleomagnetic results (both igneous and sedimentary data) from Kiaman times also presented a reduced secular variation for low and medium paleolatitudes. The VGP scatter of intrusive rocks of Oslo Graben (Haldan et al., 2014) and lavas of Bakaly Formation (Bazhenov et al., 2016) are examples of more two different types of rock that recorded the reduced behavior of the paleosecular variation during the Kiaman superchron (dispersion plots are shown in Figure 10g). Moreover, a recent compilation of paleomagnetic data from Kiaman times shows a strong paleolatitudinal dependence of the dispersion (de Oliveira et al., 2018).

The paleomagnetic data sets are usually limited to some tens of sites, and as the elongation is a ratio of two variables, it has a wide probability distribution with higher variance. Therefore, the elongation results commonly have large error bars, even for the longest sections of paleomagnetic data. The number of sites must be high to define this parameter better. Tauxe et al. (2008) recommended more than 100 paleomagnetic sites. 


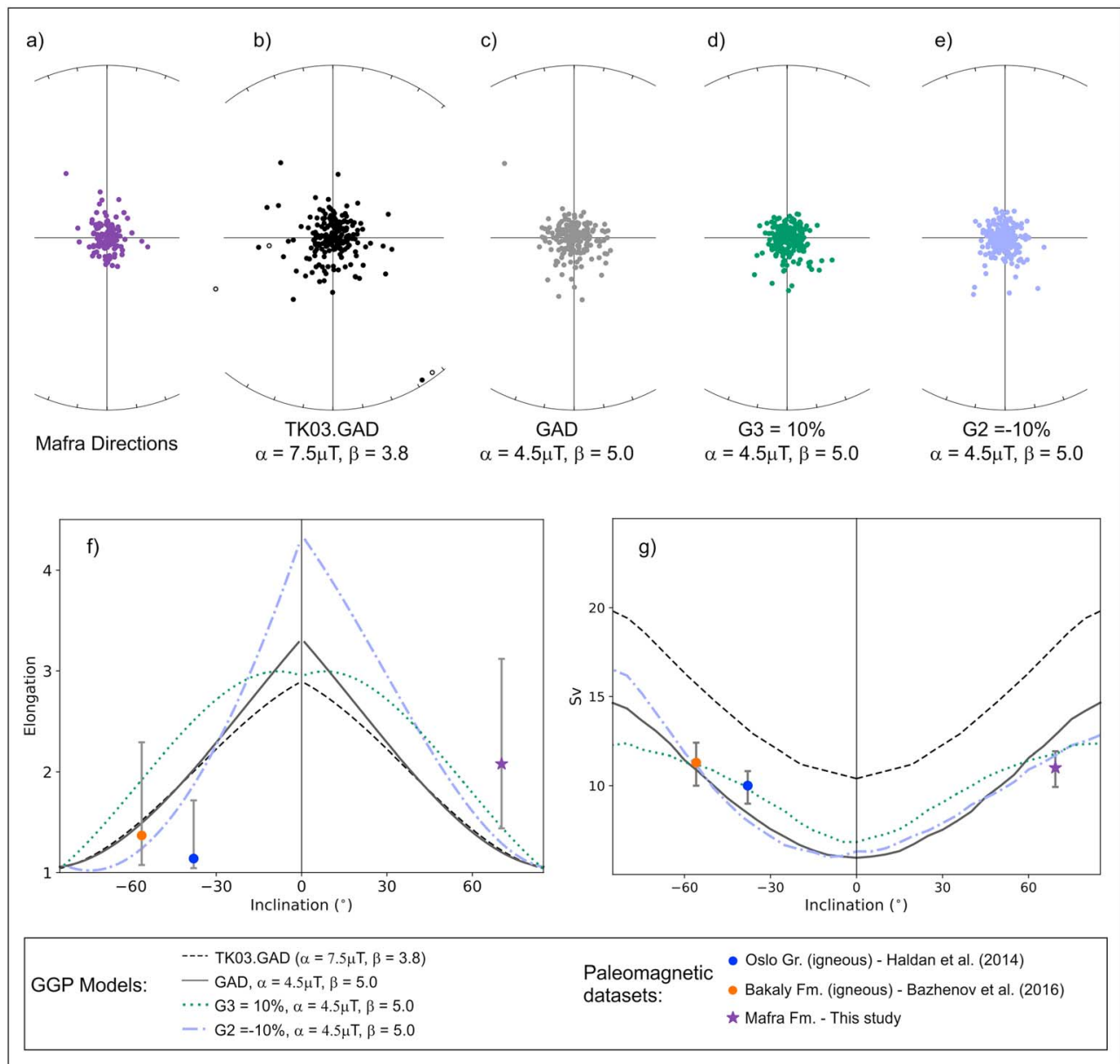

Figure 10. Paleosecular variation from Mafra Formation and Giant Gaussian Process (GGP) models simulations: (a) Mean direction per stratigraphic layer distribution of Mafra Formation, with the expected direction rotated to the origin of stereographic projection; (b) directions of 200 simulations of TK03.GAD model for the same expected inclination $\left(i=69.3^{\circ}\right)$; (c) directions of 200 simulations of a modified version of TK03 model with lower $\alpha$ parameter $(\alpha=4.5 \mu \mathrm{T})$ and higher $\beta$ parameter $(\beta=5.0)$ for the same expected inclination $\left(i=69.3^{\circ}\right)$; (d) the same as (c), but with nonnull octopolar contribution of $10 \%(\mathrm{G} 3=0.10)$; (e) the same as $(\mathrm{c})$, but with a nonnull quadrupolar contribution of $-10 \%$ ( $\mathrm{G} 2=-0.10$ ); (f) elongation of the longest data sets from Kiaman period: purple star denotes this study, blue circle denotes Oslo Graben lavas (Haldan et al., 2014), and orange circle denotes Bakaly Formation (Bazhenov et al., 2016); these results are in Table S5. The curves are elongation results from 10,000 of simulations of GGP models: black dashed line is the original TK03.GAD, fitted polynomial is $E(I)=3.160 \times 10^{-6}|I|$ ${ }^{3}-3.525 \times 10^{-4}|I|^{2}-1.466 \times|I|+2.895$, from Tauxe et al. (2008), the black continuous curve is TK03.GAD model with $\alpha=4.5 \mu \mathrm{T}, \beta=5.0$, fitted polynomial is $E(I)=2.426 \times 10^{-6}|I|^{3}-1.385 \times 10^{-4}|I|^{2}-3.236 \times 10^{-2}|I|$ +3.318 , green dot line has $\alpha=4.5 \mu \mathrm{T}, \beta=5.0$, and $10 \%$ of octopolar contribution, fitted polynomial is $E(I)=4.638 \times 10^{-6}|I|^{3}-8.011 \times 10^{-4}|I|^{2}+1.213 \times 10^{-2}|I|+2.947$, light-purple dash-dot line has $-10 \%$ of quadrupolar contributions fitted polynomial is $E(I)=-1.038 \times 10^{-6} I^{3}+4.426 \times 10^{-4} I^{2}+8.322 \times 10^{-2} I+4.335$, for $I \leq 0$ and $E(I)=4.505 \times 10^{-6} I^{3}-3.777 \times 10^{-4} I^{2}-3.919 \times 10^{-2} I+4.348$, for $I>0$. Simulation results and parameters from these models are in Table S6. (g) Dispersion of virtual geomagnetic poles corresponding to 10,000 simulations of GGP models using the variable cutoff. The colors and line styles follow the same pattern as (f).

The longest igneous sections of paleomagnetic records for Kiaman times are the other two paleomagnetic results shown on Figure 10. The Oslo Graben results (blue circle) are based on 104 paleomagnetic sites, and Bakaly Formation results (orange circle) have 88 paleomagnetic sites. Although their reduced dispersions are in agreement with Mafra result, the elongation results are smaller than the TK03.GAD elongation prediction. The Bakaly Formation mean result plots near the elongation curve predicted by TK03, and considering its error bars, it is compatible with the model. The Oslo Graben result plots far from the model curve 
(almost circular distribution), and its bootstrap confidence limits do not intercept the model curve. The elongation values were obtained with the whole of the available directional data set, without any cutoff, in order to preserve the number of sites.

The GGP model curve is built from the elongation/dispersion results of 10,000 simulations and are not theoretical values. This implies an intrinsic uncertainty contained in the model. As we do not have a direct determination of a theoretical elongation or VGP scatter, in this work, as in other studies (e.g., Tauxe et al., 2008; Tauxe \& Kodama, 2009) and also for inclination shallowing correction, we compared the elongation and also the dispersion value directly with the model curve. We consider the results of 10,000 simulations as a "theoretical" estimate of elongation of directions and VGP scatter.

Ten thousand simulations of modified versions of the GGP model TK03.GAD using a modified function from PMAGPY (mktk03) were done to find the GGP model that best describes Mafra and the igneous results from Oslo Graben and Bakaly Formation. The modified function includes changes to the values of $g_{1}^{0}, \alpha, \beta$, G2, and G3, which are, respectively, the gauss coefficient associated to the mean axial dipolar field, the adjusted parameter proportional to the standard deviations $\left(\sigma_{l}\right)$, the parameter that differentiates symmetric and antisymmetric components, quadrupolar, and octopolar zonal contributions [see the original values on Table 1 from Tauxe \& Kent, 2004]. The first set of simulations were done with the sign of the original $g_{1}^{0} \mathrm{chan}$ ged (original $g_{1}^{0}=-18 \mu \mathrm{T}$, simulated $g_{1}^{0}=+18 \mu \mathrm{T}$ ) for simulating the reversed field. There is no difference between the elongations and dispersion of VGPs from the original TK03.GAD and the reversed version, so we continue to call it TK03.GAD in Figure 10 (dashed black curves). To illustrate the differences between the Mafra data set and the TK03.GAD model, Figure 10b shows 200 directions predicted by TK03.GAD for the same expected inclination $\left(\right.$ inc $=69.3^{\circ}$ ). Figures $10 \mathrm{c}-10 \mathrm{e}$ show directions from modified versions of TK03 model for the same expected inclination.

According to paleosecular variation studies for superchrons (Biggin et al., 2008; de Oliveira et al., 2018; Doubrovine et al., 2019; McFadden et al., 1991), a larger dispersion variation with latitude is expected for superchrons, and an increase in the $\beta$ parameter is reasonable. Therefore, instead of 3.8 from TK03, we used an arbitrarily higher higher $\beta=5.0$. Next, we searched for a model that produced a dispersion curve more compatible with the three available results in a sequence of 40 values of $\alpha$ from 0.4 to 15.0. The model with the least absolute differences (total misfit of $4^{\circ}$ ) in dispersion results had $\alpha=4.5 \mu \mathrm{T}$ for $\beta=5.0$. This model (continuous black line, Figures $10 \mathrm{f}$ and $10 \mathrm{~g}$ ) produces dispersion values close to the results. The elongation of this model is increased for low paleolatitudes. To this model $(\beta=5.0, \alpha=4.5 \mu \mathrm{T})$, we also added different zonal nondipolar contributions (nonnull G2 and G3). The octopolar component (G3=10\%) increases the elongation for both hemispheres (dotted green line model, Figures $10 \mathrm{f}$ and 10g), and the quadrupolar produces an asymmetric result. The contribution of $\mathrm{G} 2=-10 \%$ produces high elongation for the southern hemisphere and low elongation for the Northern Hemisphere (light-purple dash-dot line model, Figures $10 \mathrm{f}$ and 10g).

The sum of absolute differences between the results of elongation and the tested models' curves (Figure 10f) is not so different when we compared the data with TK03 or the other versions of GGP that we ran (GAD, $\alpha=$ $4.5 \mu \mathrm{T}$ and $\beta=5.0 ; 10 \%$ of $\mathrm{G} 3 ;-10 \% \mathrm{G} 2)$. The sum of absolute difference in elongation is reduced from 2.0 for TK03 model to 1.9 for our model (GAD, $\alpha=4.5 \mu \mathrm{T}$ and $\beta=5.0$ ). The smallest difference found was for the GGP version with quadrupolar contribution (1.6 of total absolute difference), because the elongation results are not symmetric and plot nearer to this GGP version. The two data sets from the Northern Hemisphere (Bakaly Formation and Oslo Graben), opposite to the Mafra results, have lower elongation than predicted by the model. However, because of the high error bars associated with the elongation results, and similar misfit for every tested model, we are not able to define the shape of the expected distribution of Kiaman times using only the available elongation results.

Although the elongation results did not help to define the shape of distribution, the dispersion results, even for different types of rocks, consistently do not permit the assumption that the TK03 model is valid for Kiaman times. In addition, if we consider for this time our best fitting GGP model (GAD, $\alpha=4.5 \mu \mathrm{T}$ and $\beta=5.0$ ) for the dispersion, the predicted elongation curve (black continuous curve) will be also different from TK03. This would imply that the inclination shallowing corrections for sedimentary rocks of this age, assuming the TK03 as valid was improper, especially for low paleolatitudes where the elongation is higher. 
It should be noted that perhaps the TK03 model is no longer compatible with the last few million years data because it was fitted to the database available at the end of 1990s. Since then, no new GGP model has been built, but the paleomagnetic database for the recent field has been improved and modified, as we can see in the last compilation made by Cromwell et al. (2018).

These different versions of GGP models were built here only with the intention of speculating what kind of geomagnetic field behavior might represent the available data, so we should also consider that the three data sets have limited number of sites and are from three distinct types of rocks. This limited data set means that any comparisons with the model may be affected by local effects rather than being completely representative of the specific latitude band.

\section{Conclusions}

The paleomagnetic results of the Mafra Formation presented in this study are the largest known section of primary sedimentary data from Kiaman times with AARM inclination shallowing correction. We presented cyclostratigraphic analyses that permitted inference of the time span for the deposition of the Mafra sampling section. The new paleomagnetic pole of reference for South America is compatible with what is expected for the South American plate for this time; furthermore, all remanent magnetizations are reversed and consistent with what we expect from a primary remanence acquired during a reversed superchron. Also, these sediments are completely flat lying, and despite the lack of folding tests, we know that they were definitely not remagnetized by tectonic effects.

This long primary data set together with other two igneous sections is totally incompatible with the VGP scatter predicted by the TK03 GGP model. Because of the way GGP models are built, the dispersion and elongation predictions cannot be dissociated. If we change the parameters of a GGP model, both parameters will alter. In this study, the reduced dispersion produces an increase in elongations mainly near equatorial latitudes.

Recent paleomagnetic studies of the Upper Paleozoic Era adopted the use of the E/I method for correction of sedimentary data (e.g., Brandt et al., 2009; Franco, Ernesto, et al., 2012; Haldan et al., 2009; Lanci et al., 2013). However, no conclusive test had previously been done attesting the validity of TK03.GAD elongation for the Paleozoic Era. This new result is an alert that the indiscriminate use of E/I method may be dangerous for any period over which the method has not been tested.

\section{Acknowledgments}

Comments from two anonymous reviewers improved the paper. This study was supported by the Brazilian funding agency CNPq (308475/2015-1) and in part by the Coordenação de Aperfeiçoamento de Pessoal de Nível Superior-Brasil (CAPES)-Finance Code $88881.186997 / 2018-01$. The data can be found at https://earthref.org/ERDA/ 2391/ (demagnetization data), https:// earthref.org/ERDA/2392/ (rock magnetism data), and in the Tables $\mathrm{S} 1$, S2, S3, S4, S5, and S6 of supporting information.

\section{References}

Bazhenov, M. L., Van der Voo, R., Menzo, Z., Dominguez, A. R., Meert, J. G., \& Levashova, N. M. (2016). Paleomagnetism and dating of a thick lava pile in the Permian Bakaly Formation of eastern Kazakhstan: Regularities and singularities of the paleomagnetic record in thick lava series. Physics of the Earth and Planetary Interiors, 253, 5-20. https://doi.org/10.1016/j.pepi.2016.02.001

Berger, A., \& Loutre, M. F. (1994). Astronomical forcing through geologic time. In: De Boer, P.L., Smith, D.G. (Eds.), Orbital forcing and cyclic sequences. Special Publication of the International Association of Sedimentologists, 19, 15-24. https://doi.org/10.1002/ 9781444304039.ch2

Biggin, A. J., van Hinsbergen, D. J. J., Langereis, C. G., Straathof, G. B., \& Deenen, M. H. L. (2008). Geomagnetic secular variation in the Cretaceous normal superchron and in the Jurassic. Physics of the Earth and Planetary Interiors, 169(1-4), 3-19. https://doi.org/10.1016/j. pepi.2008.07.004

Bilardello, D., \& M. Jackson (2013). What do the Mumpsies do?, IRM Quarterly, Vol. 23, No. 3.

Brandt, D., Ernesto, M., Rocha-Campos, A. C., \& dos Santos, P. R. (2009). Paleomagnetism of the Santa Fe Group, central Brazil: Implications for the late Paleozoic apparent polar wander path for South America. Journal of Geophysical Research, 114, B02101. https:// doi.org/10.1029/2008JB005735

Cagliari, J., Philipp, R. P., Buso, V. V., Netto, R. G., Hillebrand, P. K., Lopes, R. C., et al. (2016). Age constraints of the glaciation in the Paraná Basin: Evidence from new U-Pb dates. Journal of the Geological Society, 173(6), 871-874. https://doi.org/10.1144/jgs2015-161

Chadima, M., and F. Hrouda (2006), Remasoft 3.0: A user-friendly paleomagnetic data browser and analyzer, Travaux Géophysiques, 27, 20-21.

Chadima, M., \& Jelínek, V. (2008). Anisoft 4.2.-Anisotropy data browser. Contributions to Geophysics and Geodesy, 38(Special Issue), 38-41.

Constable, C. G., \& Johnson, C. L. (1999). Anisotropic paleosecular variation models: Implications for geomagnetic field observables. Physics of the Earth and Planetary Interiors, 115(1), 35-51. https://doi.org/10.1016/s0031-9201(99)00065-5

Constable, C. G., \& Parker, R. L. (1988). Statistics of the geomagnetic secular variation for the past 5-My. Journal of Geophysical Research, 93(B10), 11,569-11,581. https://doi.org/10.1029/JB093iB10p11569

Cromwell, G., Johnson, C. L., Tauxe, L., Constable, C. G., \& Jarboe, N. A. (2018). PSV10: A global data set for 0-10 Ma timeaveraged field and paleosecular variation studies. Geochemistry, Geophysics, Geosystems, 19, 1533-1558. https://doi.org/10.1002/ 2017GC007318

de Oliveira, W. P., Franco, D. R., Brandt, D., Ernesto, M., Neto, C. F. D., Zhao, X. X., et al. (2018). Behavior of the paleosecular variation during the Permian-Carboniferous reversed superchron and comparisons to the low reversal frequency intervals since Precambrian times. Geochemistry, Geophysics, Geosystems, 19, 1035-1048. https://doi.org/10.1002/2017GC007262 
Domeier, M., Van der Voo, R., Tohver, E., Tomezzoli, R. N., Vizan, H., Torsvik, T. H., \& Kirshner, J. (2011). New Late Permian paleomagnetic data from Argentina: Refinement of the apparent polar wander path of Gondwana. Geochemistry, Geophysics, Geosystems, 12, Q07002. https://doi.org/10.1029/2011GC003616

Domeier, M., Van der Voo, R., Tomezzoli, R. N., Tohver, E., Hendriks, B. W. H., Torsvik, T. H., et al. (2011). Support for an “A-type” Pangea reconstruction from high-fidelity Late Permian and Early to Middle Triassic paleomagnetic data from Argentina. Journal of Geophysical Research, 116, B12114. https://doi.org/10.1029/2011JB008495

Domeier, M., Van der Voo, R., \& Torsvik, T. H. (2012). Paleomagnetism and Pangea: The road to reconciliation. Tectonophysics, 514-517, 14-43. https://doi.org/10.1016/j.tecto.2011.10.021

Doubrovine, P. V., Veikkolainen, T., Pesonen, L. J., Piispa, E., Ots, S., Smirnov, A. V., et al. (2019). Latitude dependence of geomagnetic paleosecular variation and its relation to the frequency of magnetic reversals: Observations from the Cretaceous and Jurassic. Geochemistry, Geophysics, Geosystems, 20, 1240-1279. https://doi.org/10.1029/2018GC007863

Dunlop, D., \& Ozdemir, O. (1997). Rock magnetism, 573 . New York: Cambridge University Press.edited

Ellwood, B. B., Crick, R. E., El Hassani, A., Benoist, S. L., \& Young, R. H. (2000). Magnetosusceptibility event and cyclostratigraphy method applied to marine rocks: Detrital input versus carbonate productivity. Geology, 28(12), 1135-1138. https://doi.org/10.1130/00917613(2000)28<1135:meacma $>2.0 . c 0 ; 2$

Ellwood, B. B., Lambert, L. L., Tomkin, J. H., Bell, G. L., Nestell, M. K., Nestell, G. P., \& Wardlaw, B. R. (2012). Magnetostratigraphy susceptibility for the Guadalupian series GSSPs (Middle Permian) in Guadalupe Mountains National Park and adjacent areas in West Texas. Geological Society, London, Special Publications, 373(1), 375-394. https://doi.org/10.1144/SP373.1

Ernesto, M. (2005). Paleomagnetism of the post-Paleozoic alkalinemagmatism in the Brazilian Platform: Questioning the mantleplume model. In P. Comin-Chiaramonti, \& C. B. Gomes (Eds.), Mesozoic to Cenozoic alkaline magmatism in the Brazilian Platform, (pp. 689-705). São Paulo: Edusp/Fapesp.

Ernesto, M., Comin-Chiaramonti, P., \& Gomes, C. D. (2015). The Early Triassic magmatism of the Alto Paraguay Province, Central South America: Paleomagnetic and ASM data. Open Geosciences, 7(1), 386-394. https://doi.org/10.1515/geo-2015-0022

Fang, Q., Wu, H. C., Hinnov, L. A., Jing, X. C., Wang, X. L., Yang, T. S., et al. (2017). Astronomical cycles of Middle Permian Maokou Formation in South China and their implications for sequence stratigraphy and paleoclimate. Palaeogeography, Palaeoclimatology, Palaeoecology, 474, 130-139. https://doi.org/10.1016/j.palaeo.2016.07.037

Fisher, R. (1953). Dispersion on a sphere. Proceedings of the Royal Society of London Series a-Mathematical and Physical Sciences, 217(1130), 295-305. https://doi.org/10.1098/rspa.1953.0064

Font, E., Ernesto, M., Silva, P. F., Correia, P. B., \& Nascimento, M. A. L. (2009). Palaeomagnetism, rock magnetism and AMS of the Cabo Magmatic Province, NE Brazil, and the opening of South Atlantic. Geophysical Journal International, 179(2), 905-922. https://doi.org/ 10.1111/j.1365-246X.2009.04333.X

Franco, D. R., Ernesto, M., Ponte-Neto, C. F., Hinnov, L. A., Berquo, T. S., Fabris, J. D., \& Rosiere, C. A. (2012). Magnetostratigraphy and mid-palaeolatitude dispersion of VGPs during the Permo-Carboniferous superchron: Results from Parana Basin (Southern Brazil) rhythmites. Geophysical Journal International, 191(3), 993-1014. https://doi.org/10.1111/j.1365-246X.2012.05670.X

Franco, D. R., Hinnov, L. A., \& Ernesto, M. (2012). Millennial-scale climate cycles in Permian-Carboniferous rhythmites: Permanent feature throughout geologic time? Geology, 40(1), 19-22. https://doi.org/10.1130/g32338.1

Geuna, S. E., Escosteguy, L., \& Limarino, C. Ó. (2010). Paleomagnetism of the Carboniferous-Permian Patquía Formation, Paganzo basin, Argentina: Implications for the apparent polar wander path for South America and Gondwana during the Late Palaeozoic. Geologica Acta, 8(4), 373-397. https://doi.org/10.1344/105.000001578

Geuna, S. E., \& Escosteguy, L. D. (2004). Palaeomagnetism of the Upper Carboniferous-Lower Permian transition from Paganzo basin, Argentina. Geophysical Journal International, 157(3), 1071-1089. https://doi.org/10.1111/j.1365-246X.2004.02229.x

Gilder, S., Rousse, S., Farber, D., McNulty, B., Sempere, T., Torres, V., \& Palacios, O. (2003). Post-Middle Oligocene origin of paleomagnetic rotations in Upper Permian to Lower Jurassic rocks from northern and southern Peru. Earth and Planetary Science Letters, 210(1-2), 233-248. https://doi.org/10.1016/S0012-821X(03)00102-X

Haldan, M. M., Langereis, C. G., Biggin, A. J., Dekkers, M. J., \& Evans, M. E. (2009). A comparison of detailed equatorial red bed records of secular variation during the Permo-Carboniferous Reversed Superchron. Geophysical Journal International, 177(3), 834-848. https://doi org/10.1111/j.1365-246X.2009.04124.X

Haldan, M. M., Meijers, M. J. M., Langereis, C. G., Larsen, B. T., \& Heyer, H. (2014). New palaeomagnetic results from the Oslo Graben, a Permian Superchron lava province. Geophysical Journal International, 199(3), 1554-1571. https://doi.org/10.1093/gji/ ggu351

Halls, H. C. (1976). Least-squares method to find a remanence direction from converging remagnetization circles. Geophysical Journal of the Royal Astronomical Society, 45(2), 297-304. https://doi.org/10.1111/j.1365-246X.1976.tb00327.x

Holz, M., Souza, P. A., \& Iannuzzi, R. (2008). Sequence stratigraphy and biostratigraphy of the Late Carboniferous to Early Permian glacial succession (Itarare subgroup) at the eastern-southeastern margin of the Parana Basin, Brazil. Resolving the Late Paleozoic Ice Age in Time and Space, 441, 115-129. https://doi.org/10.1130/2008.2441(08)

Hu, P. X., Zhao, X., Roberts, A. P., Heslop, D., \& Rossel, R. A. V. (2018). Magnetic domain state diagnosis in soils, loess, and marine sediments from multiple first-order reversal curve-type diagramstaxonomynumbers. Journal of Geophysical Research: Solid Earth, 123, 998-1017. https://doi.org/10.1002/2017JB015195

Irving, E. (1977). Drift of major continental blocks since Devonian. Nature, 270(5635), 304-309. https://doi.org/10.1038/270304a0

Jackson, M. J., Banerjee, S. K., Marvin, J. A., Lu, R., \& Gruber, W. (1991). Detrital remanence, inclination errors, and anhysteretic remanence anisotropy-Quantitative model and experimental results. Geophysical Journal International, 104(1), 95-103. https://doi.org/ 10.1111/j.1365-246X.1991.tb02496.x

Jesinkey, C., Forsythe, R. D., Mpodozis, C., \& Davidson, J. (1987). Concordant late Paleozoic paleomagnetizations from the Atacama Desert: Implications for tectonic models of the Chilean Andes. Earth and Planetary Science Letters, 85(4), 461-472. https://doi.org/ $10.1016 / 0012-821 X(87) 90141-5$

Johnson, C. L., Constable, C. G., Tauxe, L., Barendregt, R., Brown, L. L., Coe, R. S., et al. (2008). Recent investigations of the 0-5 Ma geomagnetic field recorded by lava flows. Geochemistry, Geophysics, Geosystems, 9, Q04032. https://doi.org/10.1029/ 2007GC001696

King, R. (1955). The remanent magnetism of artificially deposited sediments. Geophysical Supplements to the Monthly Notices of the Royal Astronomical Society, 7(3), 115-134. https://doi.org/10.1111/j.1365-246X.1955.tb06558.x

Kirschvink, J. L. (1980). The least-squares line and plane and the analysis of paleomagnetic data. Geophysical Journal of the Royal Astronomical Society, 62(3), 699-718. https://doi.org/10.1111/j.1365-246X.1980.tb02601.x 
Kodama, K. P. (2009). Simplification of the anisotropy-based inclination correction technique for magnetite- and haematite-bearing rocks: A case study for the Carboniferous Glenshaw and Mauch Chunk Formations, North America. Geophysical Journal International, 176(2), 467-477. https://doi.org/10.1111/j.1365-246X.2008.04013.x

Kodama, K. P. (2012). Paleomagnetism of sedimentary rocks: Process and interpretation. Hoboken, NJ: John Wiley \& Sons. https://doi.org/ $10.1002 / 9781118384138$

Kodama, K. P., Anastasio, D. J., Newton, M. L., Pares, J. M., \& Hinnov, L. A. (2010). High-resolution rock magnetic cyclostratigraphy in an Eocene flysch, Spanish Pyrenees. Geochemistry, Geophysics, Geosystems, 11, Q0AA07. https://doi.org/10.1029/2010GC003069

Koester, E., A. K. Scomazzon, L. C. Weinschütz, E. Wilner, L. P. Moutinho, and S. Nascimento (2016), Idade Rb-Sr do folhelho Lontras, Grupo Itararé, Bacia do Paraná, na região de Mafra, SC, Brasil, in Anais do 48o Congresso Brasileiro de Geologia "As geotecnologias e o século XXI" edited, Porto Alegre - Brasil.

Lanci, L., Muttoni, G., \& Erba, E. (2010). Astronomical tuning of the Cenomanian Scaglia Bianca Formation at Furlo, Italy. Earth and Planetary Science Letters, 292(1-2), 231-237. https://doi.org/10.1016/j.epsl.2010.01.041

Lanci, L., Tohver, E., Wilson, A., \& Flint, S. (2013). Upper Permian magnetic stratigraphy of the lower Beaufort group, Karoo basin. Earth and Planetary Science Letters, 375, 123-134. https://doi.org/10.1016/j.epsl.2013.05.0172013.05.017

Latta, D. K., Anastasio, D. J., Hinnov, L. A., Elrick, M., \& Kodama, K. P. (2006). Magnetic record of Milankovitch rhythms in lithologically noncyclic marine carbonates. Geology, 34(1), 29-32. https://doi.org/10.1130/g21918.1

McElhinny, M. W., \& McFadden, P. L. (1997). Palaeosecular variation over the past 5 Myr based on a new generalized database. Geophysical Journal International, 131(2), 240-252. https://doi.org/10.1111/j.1365-246X.1997.tb01219.x

McFadden, P. L., \& McElhinny, M. W. (1988). The combined analysis of remagnetization circles and direct observations in paleomagnetism. Earth and Planetary Science Letters, 87(1-2), 161-172. https://doi.org/10.1016/0012-821x(88)90072-6

McFadden, P. L., Merrill, R. T., McElhinny, M. W., \& Lee, S. H. (1991). Reversals of the earths magnetic-field and temporal variations of the dynamo families, journal of. Geophysical Research-Solid Earth and Planets, 96(B3), 3923-3933. https://doi.org/10.1029/90jb02275

Milani, E. J. (1997). Evolução tectono-estratigráfica da Bacia do Paraná e seu relacionamentocom a geodinâmica fanerozóica do Gondwana sul-oriental. Rio Grande do Sul, Brazil: Universidade Federal do Rio Grande do Sul.

Mudelsee, M. (2014). Climate time series analysis: Classical statistical and bootstrap methods, (2nd ed.). Dordrecht: Springer. 454 pp Opdyke, M. D., \& Channell, J. E. (1996). Magnetic stratigraphy. San Diego, CA: Academic Press.

Opdyke, N. D., \& Henry, K. W. (1969). A test of the dipole hypothesis. Earth and Planetary Science Letters, 6(2), 139-151. https://doi.org/ $10.1016 / 0012-821 x(69) 90132-0$

Quidelleur, X., \& Courtillot, V. (1996). On low-degree spherical harmonic models of paleosecular variation. Physics of the Earth and Planetary Interiors, 95(1-2), 55-77. https://doi.org/10.1016/0031-9201(95)03115-4

Rakotosolofo, N. A., Tait, J. A., Carlotto, V., \& Cárdenas, J. (2006). Palaeomagnetic results from the Early Permian Copacabana Group, southern Peru: Implication for Pangaea palaeogeography. Tectonophysics, 413(3-4), 287-299. https://doi.org/10.1016/j.tecto.2005.10.043

Rapalini, A. E., Fazzito, S., \& Orué, D. (2006). A new Late Permian paleomagnetic pole for stable South America: The Independencia group, eastern Paraguay. Earth, Planets and Space, 58(10), 1247-1253. https://doi.org/10.1186/BF03352620

Rapalini, A. E., \& Vilas, J. F. (1991). Tectonic rotations in the Late Palaeozoic continental margin of southern South America determined and dated by palaeomagnetism. Geophysical Journal International, 107(2), 333-351. https://doi.org/10.1111/j.1365-246X.1991.tb00829.x

Scheidegger, A. (1965), On the statistics of the orientation of bedding planes, grain axes, and similar sedimentological data, US Geological Survey Professional Paper, 525, 164-167.

Schneider, R. L., Mühlmann, H., Tommasi, E., Medeiros, R. A. A., Daemon, R. F., \& Nogueira, A. A. (1974). Revisão estratigráfica da bacia do Paraná. In Anais do 28 Congresso Brasileiro de Geologia (pp. 41-65). Porto Alegre, Brazil: Sociedade Brasileira de Geologia (SBG).

Strauss, B. E., Strehlau, J. H., Lascu, I., Dorale, J. A., Penn, R. L., \& Feinberg, J. M. (2013). The origin of magnetic remanence in stalagmites: Observations from electron microscopy and rock magnetism. Geochemistry, Geophysics, Geosystems, 14, 5006-5025. https://doi.org/ 10.1002/2013GC004950

Strehlau, J. H., Hegner, L. A., Strauss, B. E., Feinberg, J. M., \& Penn, R. L. (2014). Simple and efficient separation of magnetic minerals from speleothems and other carbonates. Journal of Sedimentary Research, 84(11), 1096-1106. https://doi.org/10.2110/jsr.2014.89

Tauxe, L., Banerjee, S., Butler, R., \& Van der Voo, R. (2016). Essentials of paleomagnetism, (4th Web ed., edited). California: California University Press.

Tauxe, L., \& Kent, D. V. (2004). A simplified statistical model for the geomagnetic field and the detection of shallow bias in paleomagnetic inclinations: Was the ancient magnetic field dipolar? Timescales of the Paleomagnetic Field, 145, 101-115. https://doi.org/10.1029/ $145 \mathrm{gm} 08$

Tauxe, L., \& Kodama, K. P. (2009). Paleosecular variation models for ancient times: Clues from Keweenawan lava flows. Physics of the Earth and Planetary Interiors, 177(1-2), 31-45. https://doi.org/10.1016/j.pepi.2009.07.006

Tauxe, L., Kodama, K. P., \& Kent, D. V. (2008). Testing corrections for paleomagnetic inclination error in sedimentary rocks: A comparative approach. Physics of the Earth and Planetary Interiors, 169(1-4), 152-165. https://doi.org/10.1016/j.pepi.2008.05.006

Tauxe, L., Shaar, R., Jonestrask, L., Swanson-Hysell, N. L., Minnett, R., Koppers, A. A. P., et al. (2016). PmagPy: Software package for paleomagnetic data analysis and a bridge to the Magnetics Information Consortium (MagIC) Database. Geochemistry, Geophysics, Geosystems, 17, 2450-2463. https://doi.org/10.1002/2016GC006307

Thomson, D. J. (1982). Spectrum estimation and harmonic analysis. Proceedings of the IEEE, 70(9), 1055-1096. https://doi.org/10.1109/ PROC.1982.12433

Torsvik, T. H., van der Voo, R., Preeden, U., Mac Niocaill, C., Steinberger, B., Doubrovine, P. V., et al. (2012). Phanerozoic polar wander, palaeogeography and dynamics. Earth-Science Reviews, 114(3-4), 325-368. https://doi.org/10.1016/j.earscirev.2012.06.007

Vandamme, D. (1994). A new method to determine paleosecular variation. Physics of the Earth and Planetary Interiors, 85(1-2), 131-142. https://doi.org/10.1016/0031-9201(94)90012-4

Weinschütz, L. C., \& Castro, J. C. D. (2004). Arcabouço cronoestratigráfico da Formação Mafra (intervalo médio) na região de Rio Negro/PR - Mafra/SC, borda leste da bacia do Paraná. Rem: Revista Escola de Minas, 57, 151-156. https://doi.org/10.1590/S037044672004000300003

Wu, H. C., Zhang, S. H., Feng, Q. L., Jiang, G. G., Li, H. Y., \& Yang, T. S. (2012). Milankovitch and sub-Milankovitch cycles of the early Triassic Daye Formation, South China and their geochronological and paleoclimatic implications. Gondwana Research, 22(2), 748-759. https://doi.org/10.1016/j.gr.2011.12.003

Yokoyama, E., Brandt, D., Tohver, E., \& Trindade, R. I. F. (2014). Palaeomagnetism of the Permo-Triassic Araguainha impact structure (Central Brazil) and implications for Pangean reconstructions. Geophysical Journal International, 198(1), 154-163. https://doi.org/ $10.1093 /$ gji/ggu125 
Zhao, X., Heslop, D., \& Roberts, A. P. (2015). A protocol for variable-resolution first-order reversal curve measurements. Geochemistry, Geophysics, Geosystems, 16, 1364-1377. https://doi.org/10.1002/2014GC005680

Zhao, X., Roberts, A. P., Heslop, D., Paterson, G. A., Li, Y. L., \& Li, J. H. (2017). Magnetic domain state diagnosis using hysteresis reversal curves. Journal of Geophysical Research: Solid Earth, 122, 4767-4789. https://doi.org/10.1002/2016JB013683 


\section{Chapter 4}

\section{Giant Gaussian process models of geomagnetic paleosecular variation: a directional outlook}

This chapter presents a manuscript submitted in December/2019 the Geophysical Journal International (Brandt et al., 2019b), which is now under revision. This manuscript contains a new way of characterizing the geomagnetic PSV from directional distributions that can be theoretically predicted from a GGP PSV model. The size of the directional distributions is evaluated along the east-west and north-south axes and is represented by the standard deviations $x_{E}$ and $x_{N}$, which are equal-area coordinates of directional distributions rotated to the vertical ( $\sigma_{E}$ and $\sigma_{N}$ ), revealing not only the distribution shape but also the dispersion. These statistics can be determined by numerical integration of the directional probability density functions (Khokhlov et al., 2001) given by a GGP model.

The directional PSV results of $\sigma_{E}$ and $\sigma_{N}$ from the updated paleomagnetic database of lavas PSV10 (Cromwell et al., 2018) from the last $10 \mathrm{Ma}$ are also presented. The results are compatible with predictions from the TK03 model. Even so, a new model for this time period is presented, which is called BCE19, and fitted using minimum squared differences.

The latitudinal dependence of $\sigma_{E}$ and $\sigma_{N}$ presented to be diagnostic, so it can be used for testing the validity/modeling GGP. Moreover, the latitudinal dependence of $\sigma_{E}$ and $\sigma_{N}$ for a simplified GGP model is symmetric to the Equator and independent of polarity, which allows us to use this type of model for the remote geological past when the polarity and/or paleo-hemisphere are very often unknown.

The application of these new concepts to the Kiaman times is described in Chapter 5 .

Supplementary materials can be found at https://earthref.org/ERDA/2419/. 



\title{
Giant Gaussian process models of geomagnetic paleosecular
}

\author{
variation: a directional outlook
}

\author{
Daniele Brandt ${ }^{1}$, Catherine Constable ${ }^{2}$, and Marcia Ernesto ${ }^{1}$ \\ ${ }^{1}$ Universidade de São Paulo, Instituto de Astronomia, Geofísica e Ciências Atmosféricas, Departamento de \\ Geofísica, 05508-900 São Paulo, SP, Brazil. \\ ${ }^{2}$ Institute of Geophysics and Planetary Physics, Scripps Institution of Oceanography, University of California \\ at San Diego, La Jolla, CA 92093-0225, USA.
}

(Submitted to the Geophysical Journal International, under revision)

\subsection{Abstract}

Assessment of long-term paleosecular variation (PSV) of the geomagnetic field is frequently based on simplified versions of a class of statistical models known as giant Gaussian processes (GGP) used to represent temporal variations in spherical harmonic descriptions of the field. Here we propose a new type of analysis to assess the shape and dispersion of the directional distributions caused by PSV. The quantities analyzed in this study are equal-area coordinates of rotated distributions of paleomagnetic directions, $x_{E}$ (east-westst) and $x_{N}$ (north-southth) and their standard deviations $\left(\sigma_{E}\right.$ and $\left.\sigma_{N}\right)$. These are easy to determine, and can readily be numerically predicted for any GGP model, avoiding the need for the numerous simulations generally used to determine the scatter and/or elongation of directional distributions. Mean predictions of $\overline{x_{N}}$ for a simplified GGP model are different from the expected geocentric axial dipole (GAD) directions, in agreement with inclination differences noted in previous studies. The best estimates for paleomagnetic inclination are the expected directions from the mean of virtual geomagnetic poles (VGPs) calculated using an iterative angular cutoff process. Predictions of $\sigma_{E}$ and $\sigma_{N}$ vary with latitude and are symmetric about the Equator. The N-S direction $\left(\sigma_{N}\right)$ is always larger than E-W $\left(\sigma_{E}\right)$, but the difference decreases from a maximum at the Equator to the poles, where $\sigma_{N}=\sigma_{E}$. A simplified GGP model is used to show that the parameter $\alpha$ (affecting variances in all gauss coefficients) is positively correlated with $\sigma_{E}$ and $\sigma_{N}$ while the $\beta$ parameter, the ratio of dipole to quadrupole family standard deviations, modifies the latitudinal dependence of $\sigma_{E}$ and $\sigma_{N}$. Predictions of simplified GGP models are compared with both numerical simulations and real data spanning the last $10 \mathrm{Ma}$. The latitudinal dependence of the proposed measures of PSV $\left(\sigma_{E}\right.$ and $\left.\sigma_{N}\right)$ provide useful diagnostics for testing the validity of a GGP model. For the past 10 Ma the best fitting GGP model with a mean GAD field set to 
$g_{1}^{0}=-18 \mu T$ has $\alpha=6.7 \mu T$ and $\beta=4.2$. These new directional diagnostics will be used to investigate changes in overall geomagnetic field behavior over other geological time intervals.

Key Words: Paleomagnetic secular variation, paleomagnetism, statistical methods

\subsection{Introduction}

The assessment of the geomagnetic field from Earth's past is possible because a record of the geomagnetic field is preserved in rocks and archaeological artifacts. As we go back in time the paleomagnetic record becomes sparser both geographically and temporally, therefore, statistical models of paleosecular variation (PSV) are used to study the long-term variability of the geomagnetic field. In such models, individual paleomagnetic records from lavas are considered as random spot readings of the geomagnetic field. In this work, we consider only directional paleomagnetic data. Recovery of reliable estimates of field strength is much more challenging (Tauxe and Yamazaki, 2007) so the directions constitute the majority of the data that are available. With the average field structure relative to a geocentric axial dipole (GAD), angular scatter of virtual geomagnetic poles (VGPs) positions, and frequency of polarity reversals provide measurements of the overall directional variation of long-term the geomagnetic field.

Currently, two types of representations are used to describe various aspects of PSV: the G-model (McFadden et al., 1988) and the giant Gaussian process (GGP) type model (Constable and Parker, 1988).

Model $\mathrm{G}$ is based on the following relation between the dispersion of VGPs $(S)$ about the geographic axis and the latitude $(\lambda)$ of the site of the paleomagnetic dataset:

$$
S=\sqrt{a^{2}+b^{2} \lambda^{2}}
$$

Where $a^{2}$ and $b^{2} \lambda^{2}$ are the VGP scatter generated by changes in symmetric and antisymmetric families of geomagnetic spherical harmonic coefficients, respectively, under the assumption that PSV is usually statistically uncorrelated between the two families.

The G-model was first used to explain the VGP scatter of the 0-5Ma of geomagnetic paleosecular variation (McFadden et al., 1988), and, using the GAD hypothesis, it was then applied to paleomagnetic data of older times from Phanerozoic and Proterozoic times (Biggin et al., 2008a; Biggin et al., 2008b; Oliveira et al., 2018; McFadden et al., 1991; Smirnov et al., 2011; Veikkolainen and Pesonen, 2014), which allowed investigation of the 
geomagnetic field over geological time scales, and the possibility of revealing any changes in PSV related to the evolution of Earth's core.

The relationship between the G-model parameters ( $a$ and $b$ ) and reversal frequencies has been used as a proxy for reversal rate, with high values of $b / a$ related to low reversal frequencies, and vice-versa (Biggin et al., 2008b; de Oliveira et al., 2018; McFadden et al., 1991). However, a recent paleosecular variation study for the Cretaceous normal superchron (CNS) and pre-CNS times (Doubrovine et al., 2019) presented an updated high-quality compilation of paleomagnetic directional data from lavas. Their analyses found similar values of $b$ for periods with discrepant reversal frequency: the past $10 \mathrm{Ma}$ (data set PSV10) with reversal rate 4.4-4.8 $\mathrm{Myr}^{-1}$, and two earlier superchrons (CNS and Kiaman) which correspond to tens of million years with no occurrence of reversal, have similar b results $\left(b_{P S V 10}=0.27_{0.19}^{0.31}\right.$; and $\left.b_{C N S}=0.21_{0.05}^{0.26} ; b_{\text {Kiaman }}=0.27_{0.22}^{0.29}\right)$. This is indicative that the ratio $b / a$ is not a reliable proxy for past reversal frequencies. Alternatively, perhaps there is no difference in PSV structure that can be associated with changes in reversal rate and any concomitant changes in the evolving core.

With these considerations in mind, we set out to develop and assess broader diagnostics of PSV that might be sensitive to changes in the geomagnetic field over Earth's history. A potentially useful criterion not encapsulated in Equation (4.1) is the shape of the statistical distributions of either local field directions or their associated VGPs.

It has long been known that geomagnetic PSV produces non-circular distributions of paleomagnetic directions (Creer et al., 1959), whose elongation and dispersion vary with latitude. The GGP are statistical PSV models (Constable and Parker, 1988) that predict directional distribution at any place on Earth and are based on the spherical harmonic description of the geomagnetic field. Therefore, the use of this type of model is an option to follow with directional PSV analysis.

Currently available GGP models CP88 (Constable and Parker, 1988), QC96 (Quidelleur and Courtillot, 1996), CJ98 (Constable and Johnson, 1999) and TK03 (Tauxe and Kent, 2004), have been fitted to data covering the past few million years (0-5 Ma). The most recent of these models, known as TK03, was designed to fit the VGP scatter as a function of latitude of the MM97 database (McElhinny and McFadden, 1997). TK03 is a simplified version of the general GGP formulation, based on a time-averaged GAD field model plus only two additional parameters and predicts latitudinal variation in VGP dispersion compatible with MM97 results. TK03 has already been tested in other earlier geological times (Tauxe and 
Kodama, 2009), and it is currently used as a reference model throughout Earth's history mainly with the use of elongation/inclination method for inclination shallowing correction (Tauxe and Kent, 2004).

A fixed or iterative VGP cutoff angle (Vandamme, 1994) is often imposed in both data analysis and modeling in order to exclude transitional directions. Such a procedure precludes comparison with an exact theoretical prediction for VGP dispersion $S$ (Kono and Tanaka, 1995). To determine $S^{\prime}$ for a specifc GGP model, which is the prediction of VGP scatter with cutoff for a given latitude, thousands of directions/VGPs are usually simulated (Tauxe and Kent, 2004). The resulting prediction of $S^{\prime}$ is an approximation and will be different from a theoretical model value for this latitude, because each set of thousands of simulations are groups of randomly generated samples. Therefore, to avoid imprecision, this type of prediction needs lots of simulations that is time-consuming computationally. In addition to VGP dispersion (Tauxe and Kent, 2004) were pioneers in identifying latitudinal variations in the elongation, $E$, of the directional distributions as a characteristic of the various GGP models. $E$ is the ratio of the intermediate and minimum eigenvalues $\left(E=\tau_{2} / \tau_{3}\right)$ from the “orientation matrix" T (Scheidegger, 1965).

The elongation parameters for TK03 have been used as a reference to test the model's validity in the distant past (Tauxe and Kodama, 2009) and for detecting and / or correcting sedimentary data suffering from inclination shallowing (Tauxe and Kent, 2004). Expected values of $E$ are not exact because they are also predicted using thousands of simulations. Additionally, the summary of the characteristics of the directional distribution provided by $\mathrm{E}$ is limited to how elongated the distribution is, eliminating information about the scale of the directional variability.

In this study, we present a new way of characterizing the geomagnetic PSV from directional distributions that can be theoretically predicted from a GGP PSV model. We use the size of directional distributions along two axes: east-west and north-south, represented by the standard deviations in $x_{E}$ and $x_{N}$, which are equal-area coordinates of directional distributions rotated to the vertical, revealing both the distribution shape and dispersion. These statistics can be determined by numerical integration of the directional probability density functions (Khokhlov et al., 2001). We test whether a recently updated paleomagnetic database of lavas PSV10 (Cromwell et al., 2018) is compatible with predictions from TK03 and explore potential improvements within the model framework. 


\subsection{Predictions of PSV measurements for a simplified GGP model}

The magnetic field $\boldsymbol{B}$, at a $r$ distance from the center of our planet, co-latitude $\Theta$ and longitude $\Phi$, is given by the gradient of the scalar magnetic potential $\Psi(r, \Theta, \Phi)$. The geomagnetic potential produced by an internal source can be described using harmonic functions by the following equations:

$$
\begin{gathered}
\boldsymbol{B}=\left(B_{\Theta}, B_{\Phi}, B_{r}\right)=-\nabla \Psi=\left(-\frac{1}{r} \frac{\partial \Psi}{\partial \Theta},-\frac{1}{r \sin \Theta} \frac{\partial \Psi}{\partial \Phi},-\frac{\partial \Psi}{\partial r}\right) \\
\Psi=r_{a} \sum_{l=1}^{\infty} \sum_{m=0}^{l}\left(\frac{r_{a}}{r}\right)^{l+1}\left(g_{l}^{m} \cos m \Phi+h_{l}^{m} \sin m \Phi\right) P_{l}^{m}(\cos \Theta)
\end{gathered}
$$

Where $B_{\Theta}, B_{\Phi}$, and $B_{r}$ are the orthogonal components of the geomagnetic field parallel to the South, East and vertical (zenith) directions. The geomagnetic field at the Earth surface is given when $r=r_{a}$. The coefficients $g_{l}^{m}$ and $h_{l}^{m}$ are the Gauss coefficients and $P_{l}^{m}(\cos \Theta)$ are the partially normalized Schmidt functions, whose degree $l$ increases (in principle) from 1 to infinity, depending on the complexity of the source. The degree $l$ cannot be zero because the simplest configuration of a magnetic source is a dipole $(l=1)$. The value of $m$ ranges from 0 for a zonal magnetic source (invariant with longitude) to degree $l$.

The GGP models are based on the idea that a giant Gaussian process can describe long term variations of the geomagnetic field (Constable and Parker, 1988). Temporal variations in each Gauss coefficient $\left(g_{l}^{m}, h_{l}^{m}\right)$ follow a normal distribution function, resulting in a statistical fluctuation of the three orthogonal components of the geomagnetic field. These normal distributions are given by a mean value for each coefficient that is the description of the time-averaged field (TAF) and a standard deviation $\sigma_{l}^{m}$ that for most of the available GGPs are constant for $g$ and $h$ of same degree $l$ and order $m$ (note the non-zonal version of CJ98 Constable and Johnson, 1999 is an exception). The TK03 model is a simplified GGP model, it has a mean GAD field and the variances of the Gaussian coefficients for each $l$ and $m$ are determined using only two parameters $\alpha$ and $\beta$ :

$$
\begin{aligned}
& \sigma_{l}^{m^{2}}=\frac{(c / a)^{2 l} \alpha^{2}}{(l+1)(2 l+1)} \text { for } l-m=\text { even }, \\
& \sigma_{l}^{m^{2}}=\frac{(c / a)^{2 l} \alpha^{2} \beta^{2}}{(l+1)(2 l+1)} \text { for } l-m=\text { odd }
\end{aligned}
$$

Where $c / a$ is the ratio of the core radius to that of Earth (0.547).

The TK03 model has the Gauss coefficient correspondent to the axial dipole of $g_{1}^{0}=$ $-18 \mu T$, a fitted $\alpha=7.5 \mu T$ and the dipole family ( $l-m$ odd) coefficients are 3.8 times 
more variable than the quadrupolar $(l-m$ even) ones $(\beta=3.8)$. It is the GGP model that best fits the VGP scatter of the MM97 dataset. Moreover, the simplification that includes a $\beta$ parameter to differentiate the variances from odd and even families allowed the fitting only two parameters, instead of fitting each one of the standard deviations. Despite being a simplified model, the standard deviation for each gauss coefficient follows almost the same trend as earlier models (Figure 4.1). The difference in scale for TK03 largely reflects the selection of a lower average value for $g_{1}^{0}$.

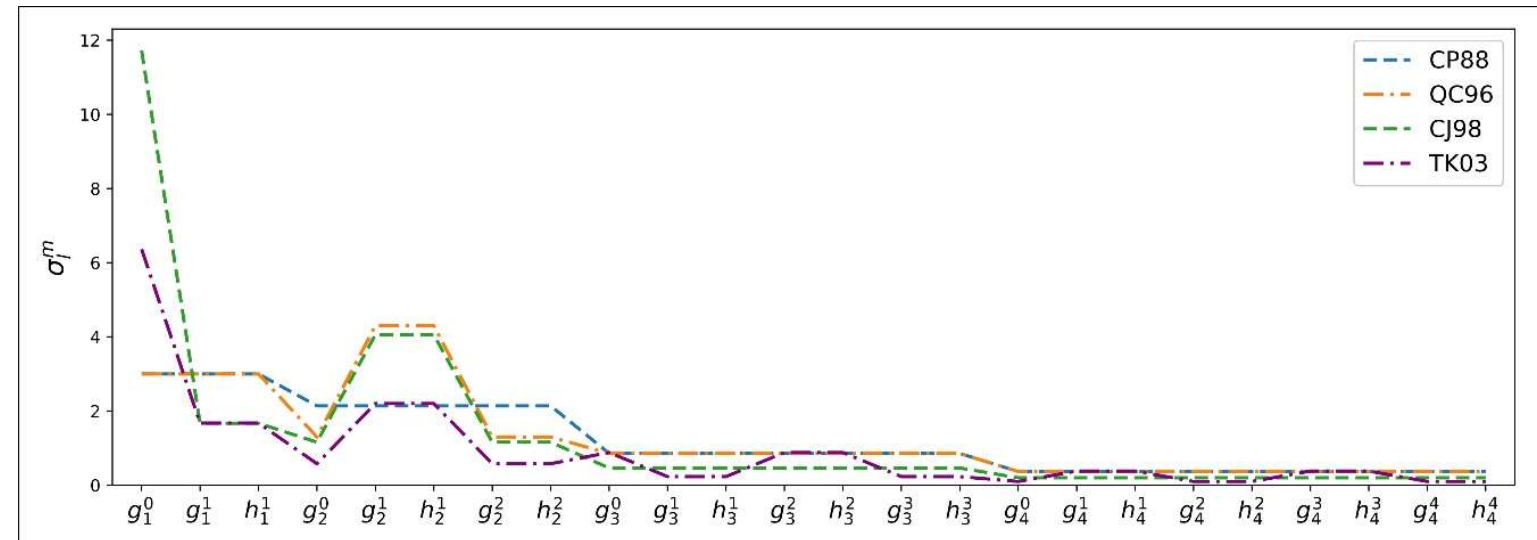

Figure 4.1. Standard deviations for each Gaussian coefficient. Where CP88, QC96, CJ98 and TK03 are GGP models fitted to the last $5 \mathrm{Ma}$ (Constable and Johnson, 1999; Constable and Parker, 1988; Quidelleur and Courtillot, 1996; Tauxe and Kent, 2004).

As the orthogonal components of the magnetic field $\boldsymbol{B}$ are linear combinations of the Gauss coefficients, they are also normally distributed. Therefore, the probability distribution function (pdf) of the magnetic vector at any specific location on Earth is a 3D-Gaussian distribution as follows:

$$
g(\boldsymbol{B})=\sqrt{\frac{\operatorname{det} \boldsymbol{\Lambda}}{(2 \pi)^{3}}} \exp \left[-\frac{1}{2}(\Lambda(\boldsymbol{B}-\boldsymbol{m}), \boldsymbol{B}-\boldsymbol{m})\right]
$$

Here $\boldsymbol{m}$ is the expected value for the magnetic field from TAF and $\boldsymbol{\Lambda}=\operatorname{Cov}(\boldsymbol{B}, \boldsymbol{B})^{-1}$ is the inverse of the covariance matrix of the field at the location.

Since we are interested in unit vectors $(\boldsymbol{u})$ we need to find their pdf by integration across all values of the intensity $\rho$ of the paleomagnetic vectors (Constable and Parker, 1988; Khokhlov et al., 2001, equations are from Khokhlov et al., 2006). A pdf for the directional distribution is given by $s(\boldsymbol{u})$ :

$$
s(\boldsymbol{u})=\int_{0}^{\infty} g(\rho \boldsymbol{u}) d \rho
$$




$$
\begin{aligned}
& s(\boldsymbol{u})=e^{-\frac{1}{2} m^{2}} \cdot \frac{\sqrt{\operatorname{det} \Lambda}}{4 \pi|\boldsymbol{u}|_{\Lambda}^{3}}\left[z \sqrt{\frac{2}{\pi}}+e^{\frac{1}{2} z^{2}}\left(1+z^{2}\right)\left[1+\operatorname{Erf}\left(\frac{z}{\sqrt{2}}\right)\right]\right] \\
& \boldsymbol{u}=\left(x_{n} \frac{\sqrt{1-\left(1-x_{e}^{2}-x_{n}^{2}\right)^{2}}}{\sqrt{x_{e}^{2}+x_{n}^{2}}}, x_{e} \frac{\sqrt{1-\left(1-x_{e}^{2}-x_{n}^{2}\right)^{2}}}{\sqrt{x_{e}^{2}+x_{n}^{2}}}, \pm\left(1-x_{e}{ }^{2}-x_{n}{ }^{2}\right)\right)
\end{aligned}
$$

Here $\boldsymbol{u}$ is a unitary magnetic vector $\boldsymbol{u}=\boldsymbol{B} /|\boldsymbol{B}|$ and it can be described using $x_{e}$ and $x_{n}$ equal area coordinates as given by Equation $4.9 ; \rho$ is the modulus of vector $\boldsymbol{B}$ in spherical coordinates; $|\boldsymbol{u}|_{\Lambda}=\sqrt{(\boldsymbol{u}, \boldsymbol{u})_{\Lambda}}=\sqrt{(\boldsymbol{\Lambda u}, \boldsymbol{u})}$ is the $\Lambda$-norm of $\boldsymbol{u}, z=\frac{(\boldsymbol{m}, \boldsymbol{u})_{\Lambda}}{|\boldsymbol{u}|_{\Lambda}},(\boldsymbol{m}, \boldsymbol{u})_{\Lambda}$ is the $\boldsymbol{\Lambda}$-inner product $(\boldsymbol{m}, \boldsymbol{u})_{\Lambda}$, and $m=|\boldsymbol{m}|_{\Lambda}$. If the distribution is rotated to the origin (vertical), the covariance matrix is also rotated, and the expected field is: $\boldsymbol{m}_{\boldsymbol{r}}=(0,0,|\boldsymbol{m}|)$.

The directional measurements proposed in this study are based on directional distributions rotated to the origin, with the expected field direction in the vertical direction. The N-S distribution is given along the $x_{N}$ axis and E-W along $x_{E}$ axis. The rotated pdf of $s_{r}(\boldsymbol{u})$ of the TK03 model in a positive hemisphere of equal-area projection (Equator and $25^{\circ} \mathrm{N}$ ) are given in Figure 4.2. The expected direction (GAD) is vertical (black cross at the center of the projection). At the top and left of each projection are shown the distributions of $x_{E}$ and $x_{N}$ given by the partial integration of $s_{r}\left(x_{E}, x_{N}\right)$, the colored bars (coral and blue) are the observed $x_{N}$ and $x_{E}$ from 10,000 simulations from TK03 for the same latitude. The distribution at the Equator is symmetric along the N-S $\left(x_{N}\right)$ and E-W $\left(x_{E}\right)$ axis and the distribution of $x_{N}$ is broader than for $x_{E}$. At $25^{\circ} \mathrm{N}$ the distribution is symmetric only along the N-S axis, the $x_{E}$ distribution is a little wider than at the Equator, and $x_{N}$ is thinner, which results in a less elongated distribution. Next, we present the measurements that will help us to quantify such observations and their latitudinal dependence. 


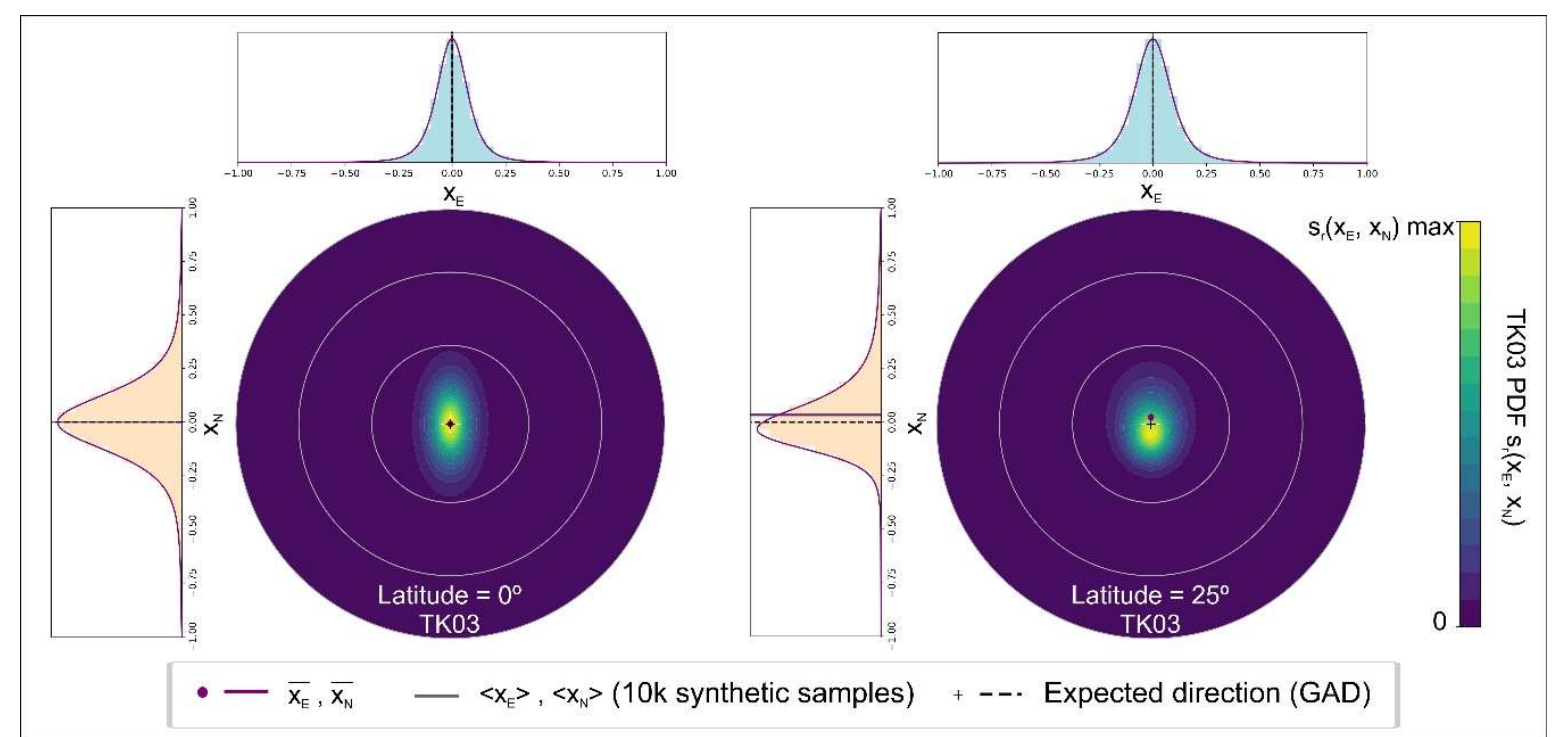

Figure 4.2. Map of the probability density function for unitary vectors $s_{r}(u)$ for the TK03 model at Equator and $25^{\circ} \mathrm{N}$ plotted in a stereographic equal-area projection rotated with the expected GAD direction in the vertical. At the left and top of each projection are shown the distributions of $x_{N}$ and $x_{E}$ equal area coordinates given by the partial integration of $s_{r}(u)$, the colored bars (coral and blue) are the histogram of $x_{N}$ and $x_{E}$ from 10,000 simulations of TK03 for the same latitude. Theoretical mean values $\overline{x_{E}}$ and $\overline{x_{N}}$ are given as purple lines at the histograms and purple circles at the stereographic projections. Expected values of $x_{N}$ and $x_{E}$ (vertical, $\left.x_{E}=0, x_{N}=0\right)$ are shown as dashed lines in the histograms and a black cross in the stereographic projection. Mean values of $\left\langle x_{N}\right\rangle$ and $\left\langle x_{E}\right\rangle$ of the 10,000 synthetic samples generated by the TK03 model are shown as a grey line in the histograms.

\subsubsection{PSV measurements predictions of a simplified GGP model}

The predicted mean values and standard deviation of $x_{E}$ and $x_{N}$ equal area coordinates for rotated distributions can be determined by integrating the pdf $s(\boldsymbol{u})$ using equal-area coordinates $s_{r}\left(\boldsymbol{u}_{\boldsymbol{r}}\right)=s_{r}\left(x_{E}, x_{N}\right)$ :

$$
\begin{aligned}
& \sigma_{E}^{2}=\iint\left(x_{E}-\overline{x_{E}}\right)^{2} s_{r} d x_{E} d x_{N} ; \quad \overline{x_{E}}=\iint x_{E} \cdot s_{r} d x_{E} d x_{N} \\
& {\sigma_{N}}^{2}=\iint\left(x_{N}-\overline{x_{N}}\right)^{2} \cdot s_{r} d x_{E} d x_{N} ; \overline{x_{N}}=\iint x_{N} \cdot s_{r} d x_{E} d x_{N}
\end{aligned}
$$

Because of the complexity of $s_{r}$ a numerical solution is used. A package containing the functions for the calculations of the variances and covariances for a given zonal GGP model, the pdf $s_{r}$, the mean values and the standard deviations are written in Python and is available as a repository at github.com/danielebrandt/BCE19-dirPSV.

For comparing groups of directions with predictions of a GGP model, experimental determination for the mean values and standard deviations $\sigma_{E}$ and $\sigma_{N}$ are calculated using the equations below. Figure 4.3 illustrates how the theoretical and sample-based estimates are done.

$$
\left\langle\sigma_{E}\right\rangle=\sqrt{\frac{\sum_{i=1}^{N}\left(x_{E_{i}}-\left\langle x_{E}\right\rangle\right)^{2}}{N-1}} ; \quad\left\langle x_{E}\right\rangle=\frac{\sum_{i=1}^{N} x_{E_{i}}}{N}
$$




$$
\left\langle\sigma_{N}\right\rangle=\sqrt{\frac{\sum_{i=1}^{N}\left(x_{N_{i}}-\left\langle x_{N}\right\rangle\right)^{2}}{N-1}} ; \quad\left\langle x_{N}\right\rangle=\frac{\sum_{i=1}^{N} x_{N_{i}}}{N}
$$

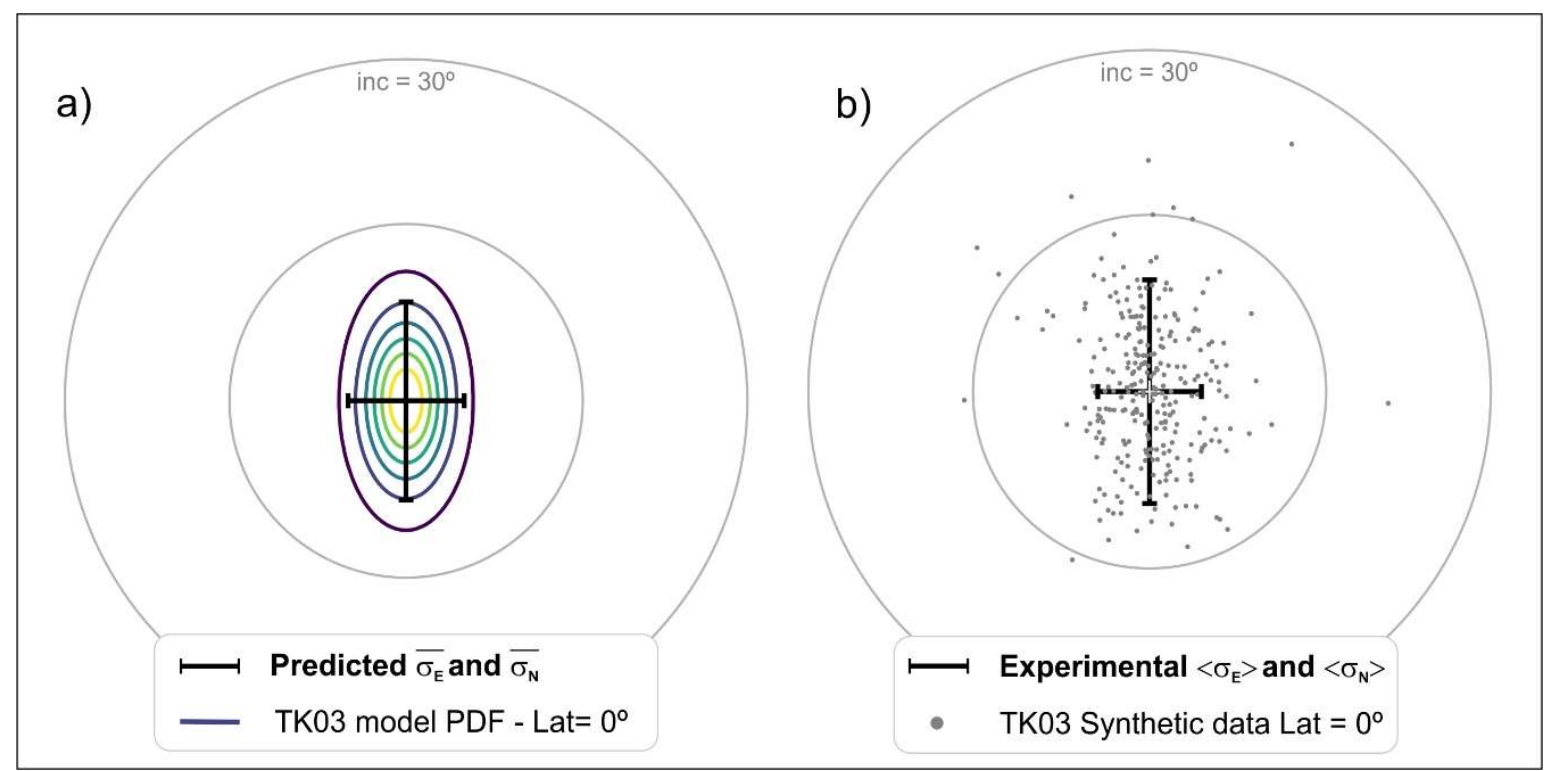

Figure 4.3. Theoretical and experimental determinations of standard deviations of $x_{E}$ and $x_{N}$ equal-area coordinates. a) Equal area projection of the probability density function of the TK03 model (Tauxe and Kent, 2004) at the Equator (iso-probability curves), increasing from purple to yellow, rotated to expected direction. Black lines show the size of the standard deviation of equal-area coordinates $x_{E}$ and $x_{N}$ determined theoretically by Equations 4.10 and 4.11. b) Group of 200 simulations of directions from the TK03 model at the Equator, rotated to expected direction. Black lines show the size of the standard deviation of equal-area coordinates $x_{E}$ and $x_{N}$ determined for this set of artificial data, following Equations 4.12 and 4.13.

The predictions of mean values given by the TK03 model for every $2^{\circ}$ of latitude are shown in Figure 4.4a. The mean $x_{E}$ is always null for any latitude, which means that the declination of the mean direction is equal to the expected for a GAD model (zero). However, the mean $x_{N}$ is not null except at the poles and Equator, which means that the predicted mean direction given by the TK03 model is not co-axial with the expected direction given by the GAD field, there is a difference in inclinations which results from non-symmetric distributions along the meridian. This is an expected result in agreement with (Creer, 1983) - see also Figure 19 of (Johnson and McFadden, 2007). We note that there are always systematic small differences between the simulated and the theoretical predictions of $x_{N}$ that is probably because the limitations of numerical integration used (size of unit area) or due to the truncation on 1 degree, but they are not large enough to be significant and do not occur for other PSV analyzed quantities $\left(x_{E}, \sigma_{E}\right.$ and $\left.\sigma_{N}\right)$. 


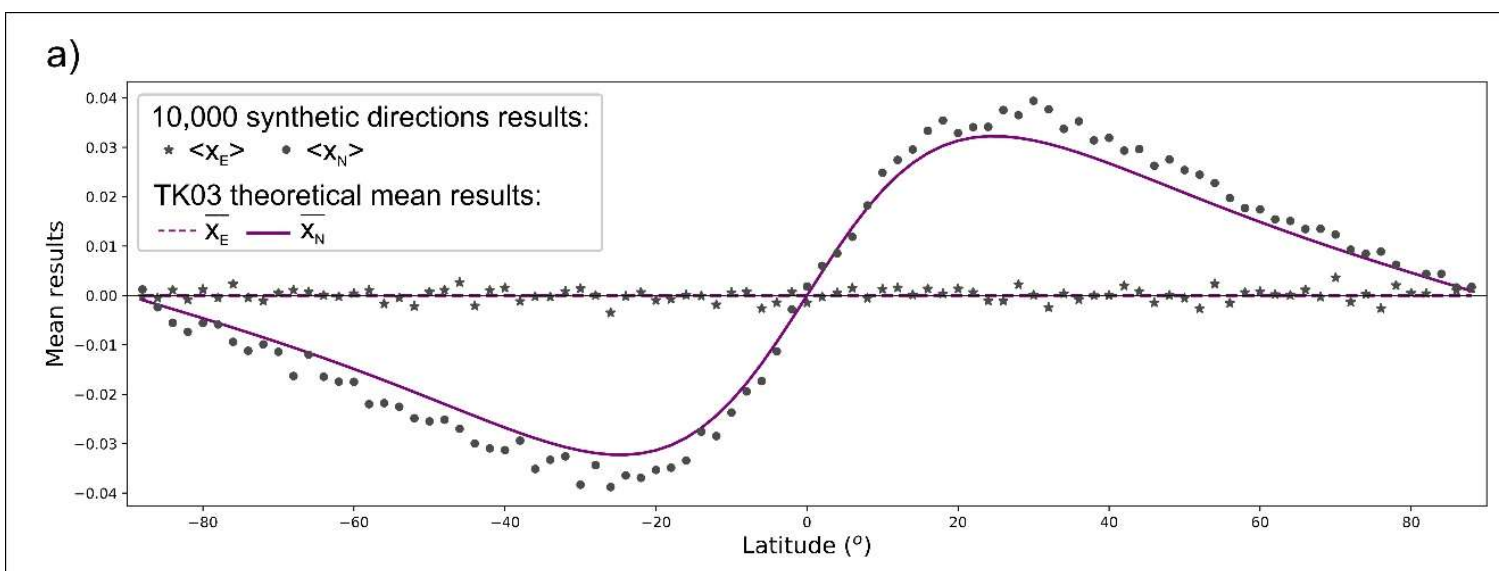

b)

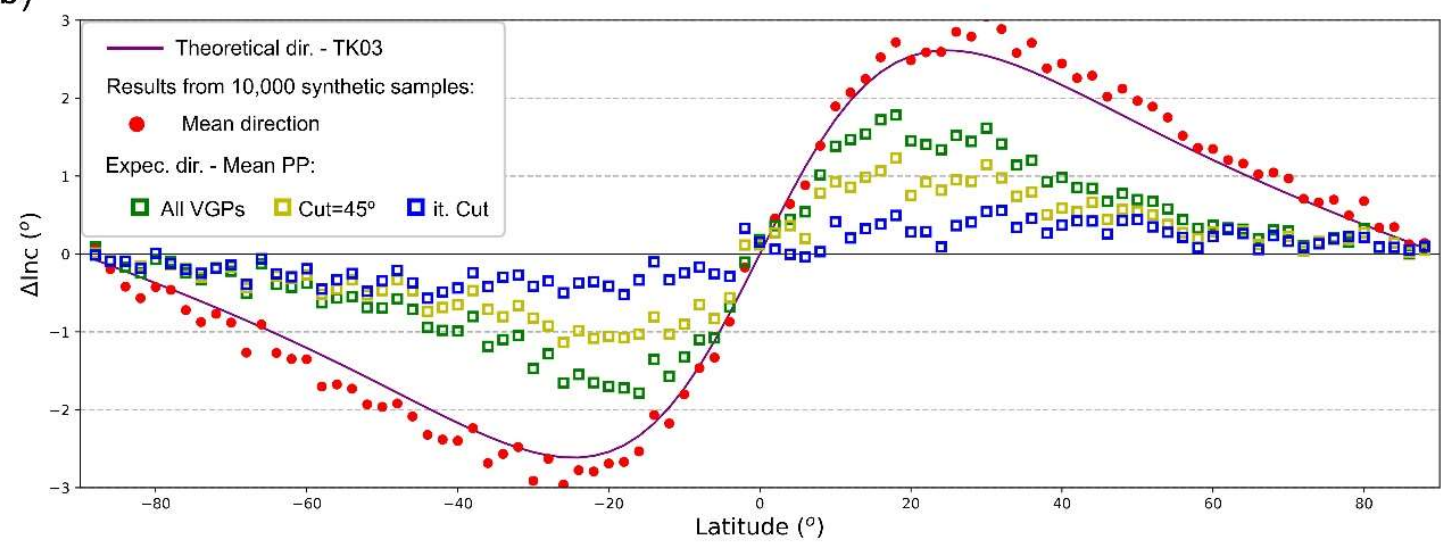

c)

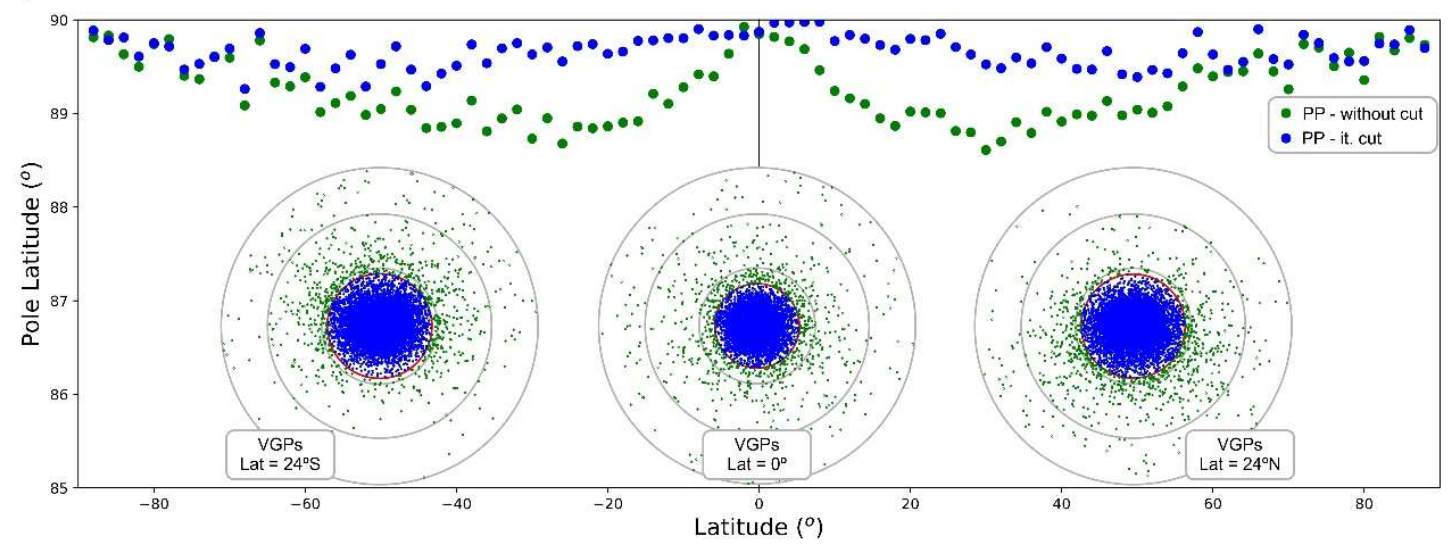

Figure 4.4. a) Theoretical (purple curves) and experimental determinations (results of 10,000 simulations, darkgrey symbols) of mean $x_{E}$ and $x_{N}$ from directional distributions of the TK03 model in $2^{\circ}$ steps of latitudes. $\mathrm{b}$ ) Difference of inclination $(\Delta I n c)$ between the expected direction from GAD and the different ways of determining the magnetic inclination: theoretical mean (purple curve), directional mean in red circles (Fisher, 1953), squares are given by expected directions given by paleomagnetic poles (PP) calculated with all the VGPs (green), using a fixed cutoff angle of $45^{\circ}$, and using an iterative method with variable cutoff angle in blue (Vandamme, 1994). c) Latitude of PPs calculated from 10,000 simulations of the TK03 model for each $2^{\circ}$ of latitude. Green (blue) symbols are PPs calculated without (with) an (iterative) cutoff. Three insets show 10,000 VGPs from TK03 simulations. The red circle is the final cutoff angle of the iterative process (Vandamme, 1994).

The difference between the expected direction (GAD) and different ways of determining the magnetic direction from 10,000 synthetic samples of TK03 model is shown in Figure $4.4 \mathrm{~b}$. The difference $(\Delta \operatorname{Inc})$ between the mean direction (red circles) and the expected GAD 
can be more than $2^{\circ}$ at latitudes around $20^{\circ}$ North and South, but these differences diminish if, instead of using the mean of local field directions, the expected direction from the mean paleomagnetic pole (PP) is calculated (green squares). These differences can be further minimized if a colatitude cutoff angle is used for determining the mean PP (yellow and blue squares). Comparing the iterative cutoff method (Vandamme, 1994), with a fixed $45^{\circ}$ cutoff shows that the iterative cutoff minimizes bias relative to the actual mean PP. The usual application of the Vandamme cutoff is in the estimation of VGP dispersion for PSV studies, but this demonstrates that it could also be important in using unit vectors to estimate mean directions and pole positions.

Figure 4.4c shows the bias in PP latitude calculated using all VGPs and using the iterative cutoff. The PP latitudes predicted by TK03 are consistently low, by as much as 1.5 degrees at about 25-30 degrees latitude. These differences diminish when the cutoff is applied, and the PPs moves to latitudes nearer to the geographic pole. The initial distribution of VGPs is not symmetric with respect to the rotation axis (see the $25^{\circ} \mathrm{N}$ and $25^{\circ} \mathrm{S}$ examples in stereographic projections on Figure 4.4c), but the application of a cutoff criterion forces the distribution of VGPs to be more circular, moving the final mean PP towards the geographic pole. Therefore, although this process excludes important records that characterize the paleosecular variation of the past geomagnetic field, it is efficient when a paleolatitude needs to be determined from the paleo-inclination or a precise paleomagnetic pole is needed. Inclination error cannot be eliminated just by using the mean PP (Behar et al., 2019), it is also necessary to impose a suitable cutoff angle.

The parameters that describe the dispersion and elongation of the directional distributions are the standard deviations of $x_{E}$ and $x_{N}$. Theoretical determinations of $\sigma_{E}$ and $\sigma_{N}$ for the TK03 model are shown for every of $2^{\circ}$ of latitude (Figure 4.5a). Experimental results given by 10,000 synthetic samples are also shown (grey stars and circles).

Both measurements are symmetric with respect to the Equator. The N-S $\sigma_{N}$ decreases from the Equator to the poles, and it is always higher than $\sigma_{E}$, except at the poles where the two are equal. The E-W $\sigma_{E}$ increases from the Equator up to about $30^{\circ}(\mathrm{N}$ and $\mathrm{S}$ ) and smoothly decreases up to the poles.

We can use the ratio $E^{\prime}=\sigma_{N} / \sigma_{E}$ as a measure of how elongated the distribution is along the N-S direction. Figure 4.5b shows $E^{\prime}$ in Northern hemisphere for TK03 as derived from both theoretical calculation and numerical simulation of 10,000 synthetic samples from TK03. Note that $E$ ' differs slightly from the elongation $E$ defined by Tauxe and Kent (2004), 
which is the ratio of the medium and minimum eigenvalues $\left(E=\tau_{2} / \tau_{3}\right)$ from the “orientation matrix" T (Scheidegger, 1965), which is also shown in Figure 4.5b (light grey circles). There is no theoretical determination for $\mathrm{E}$, so it was only calculated by numerical simulation. The elongations $E$ and $E^{\prime}$ follow almost the same tendency of decreasing from the Equator up to the poles, but the original elongation $E$ is generally lower than $E^{\prime}$, and decays faster away from the Equator.

The area given by the product $A_{d i r}=\sigma_{N} \sigma_{E}$ is the overall variability (Rencher and Christensen, 2012), which, in multivariate analysis is given by the measure of the generalized sample variance $A^{2}$ defined as the determinant of the covariance matrix $\left(\Sigma_{x_{E}, y_{N}}\right)$. For a zonal GGP model $x_{E}$ and $x_{N}$ are uncorrelated variables, so the generalized sample variance is the product of the variances $A^{2}=\left|\Sigma_{x_{E}, x_{N}}\right|={\sigma_{E}}^{2}{\sigma_{N}}^{2}$. This measurement shows the overall dispersion of the distributions. The distribution area $A_{\text {dir }}$ of the TK03 model increases slowly from the Equator up to $20^{\circ}$ and, for higher latitudes it continuously decreases towards the poles (Figure 4.5c).

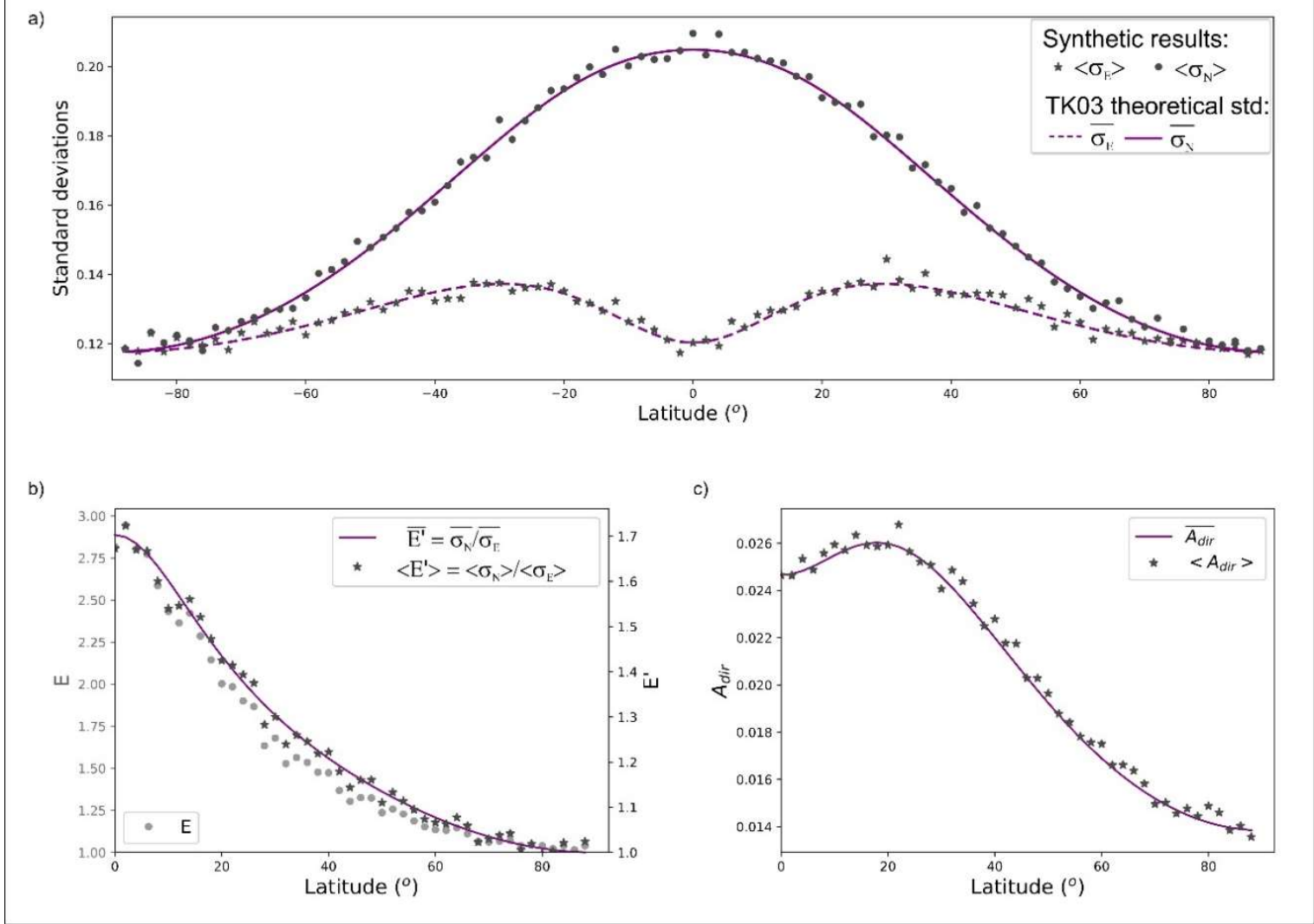

Figure 4.5. Theoretical (purple curves) and experimental determinations (results of 10,000 simulations, darkgrey symbols) from directional distributions of TK03 model in $2^{\circ}$ steps of latitudes. a) Standard deviation for equal area coordinates. a) Elongation $E^{\prime}$ and $E$ (only experimental). e) Distribution area $A_{\text {dir }}$. 
In our simulations from TK03 we consistently present experimental results for 10,000 synthetic samples. This high number of simulations show only minor statistical deviations from the (essentially) exact theoretical predictions using numerical integration of the pdf model. The exact calculations are useful for testing the validity of a GGP model for a real directional paleomagnetic dataset, while the simulations provide a useful background check on the theoretical predictions.

\subsubsection{Modifying Simplified GGP Models}

Simplified GGP models, like TK03, are based on GAD averaged fields with fixed g10, and have only two free parameters that impact directional distributions, namely $\alpha$ and $\beta$. In Figure 4.6 we explore a range of different values for, $\alpha$ and $\beta$ and their effects on the latitudinal structure in $\sigma_{E}, \sigma_{N} \overline{x_{E}}, \overline{x_{N}}, E^{\prime}$ and $A$. Theoretical predictions of TK03 (black, with $\left.g_{1}^{0}=-18 \mu T, \alpha=7.5 \mu T, \beta=3.8\right)$ and a reversed TK03 $\left(g_{1}^{0}=+18 \mu T\right.$, red dashed line) are shown in Figure 4.6 together with those for multiple different values of $\alpha$ (blues) and $\beta$ (greens). Because the average field has a GAD structure, the polarity of the field does not change the results. The prediction of $\overline{x_{N}}$ are of the same sign for reversed and normal versions of the field because it is a result of the distribution rotated to the vertical.

With $\beta=3.8$, held constant, increasing $\alpha$ across the range from 4 to 10 has no effect on the overall mean across all latitudes $\overline{x_{E}}$, which is always zero. However, increasing $\alpha$ produces a systematic increase in the $\overline{x_{N}}$ and standard deviations, and a general decrease in $E^{\prime}$ that is most significant near the Equator, while the overall dispersion $A_{\text {dir }}$ increases.

Increasing $\beta$ (over a range from 1 to 8 ) with fixed $\alpha=7.5 \mu T$, also increases the standard deviations, the mean $\overline{x_{N}}$, variation and $A_{d i r}$, while the elongation $E^{\prime}$ is diminished. However, the latitudinal variation in both the standard deviations and $A_{\text {dir }}$ is significantly different from that obtained by varying $\alpha$. 


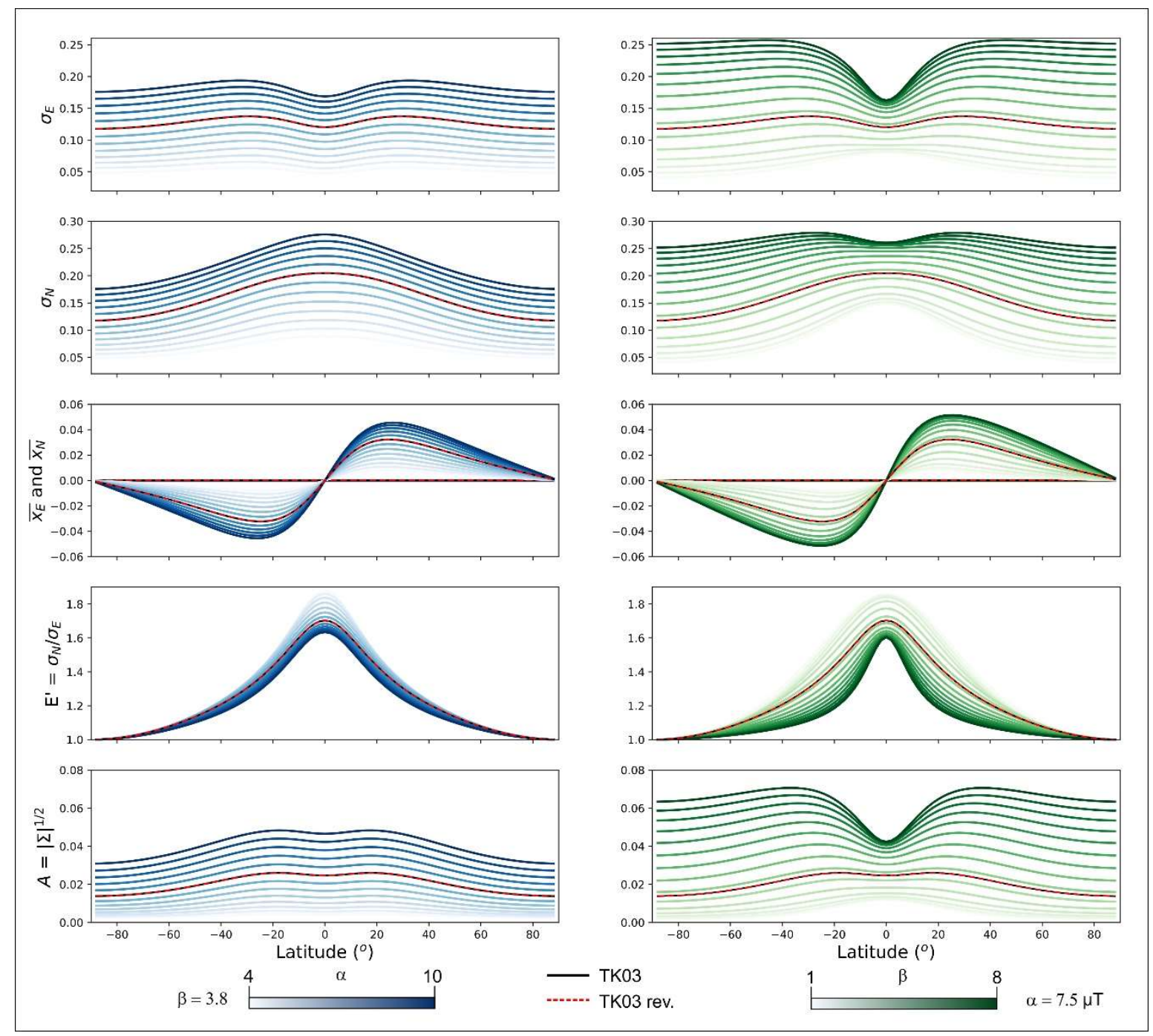

Figure 4.6. Different versions of a simplified GGP model like the TK03 model, with only two free parameters $\alpha$ and $\beta$ were simulated. Simulations results from TK03 (black) and a reversed version TK03 (red dashed line) are shown with different values of $\alpha$ (blue) and $\beta$ (green).

\subsubsection{Assessing directional distributions from the last $10 \mathrm{Ma}$ : Real data}

PSV and TAF studies are mainly based on global compilations of paleomagnetic data from recent lava flows. The latest compilation PSV10 (Cromwell et al., 2018) was done using a selection of the highest-quality paleo-directions recorded over the past $10 \mathrm{Ma}$ and has a greatly improved spatial coverage compared with older versions such as MM97. Because it covers recent ages, the PSV10 database is relatively free of plate tectonics effects, and sample locations can be corrected using the current plate motions for the older data. So, as the primary geographic position is known, the study of recent lavas can involve inclination anomaly determinations as well as non-zonal investigations.

We use the PSV10 database to investigate if PSV directional measurements can be used as a diagnostic for the validity of GGP models, as it is a well-controlled dataset. We know that local variations exist, and more complex TAF models than GAD have been fitted to this 
database (TAF models LN3 and LN3-SC, from Cromwell et al., 2018), showing spatial variation and persistent small non-dipolar components. But the question to be answered in the future is how the general PSV from a specific geological time differs from others, and what these differences might mean in terms of the evolution of the core from ancient times. To date, such questions have only been investigated with type $\mathrm{G}$ models for the ancient past. Our test with the PSV10 database is intended only to answer whether the new directional statistics presented here can be used to test the general validity of a GGP-type model.

The paleomagnetic directions from each geographic site of the PSV10 database were rotated to the origin with the expected direction from GAD in the vertical (Table S4.1). Bins of $10^{\circ}$ of latitude were used to group the paleomagnetic directions forming groups with numbers ranging from 34 up to 411 paleomagnetic directions along latitudes from $80^{\circ} \mathrm{S}$ to $80^{\circ} \mathrm{N}$. Reversed polarity directions were flipped to normal polarity. Three examples of these groups are shown in Figure 4.7b, and for comparison, the prediction of pdf TK03 and 1,000 synthetic data for similar latitudes are also shown (Figure 4.7a). The distribution of directions for $0-10$ and $20-30^{\circ} \mathrm{N}$ seems to be more distributed along N-S direction, while the distribution of $55^{\circ}$ seems to be more circular, following the appearance of what is expected for TK03 at the corresponding latitude (Figure 4.7a). 


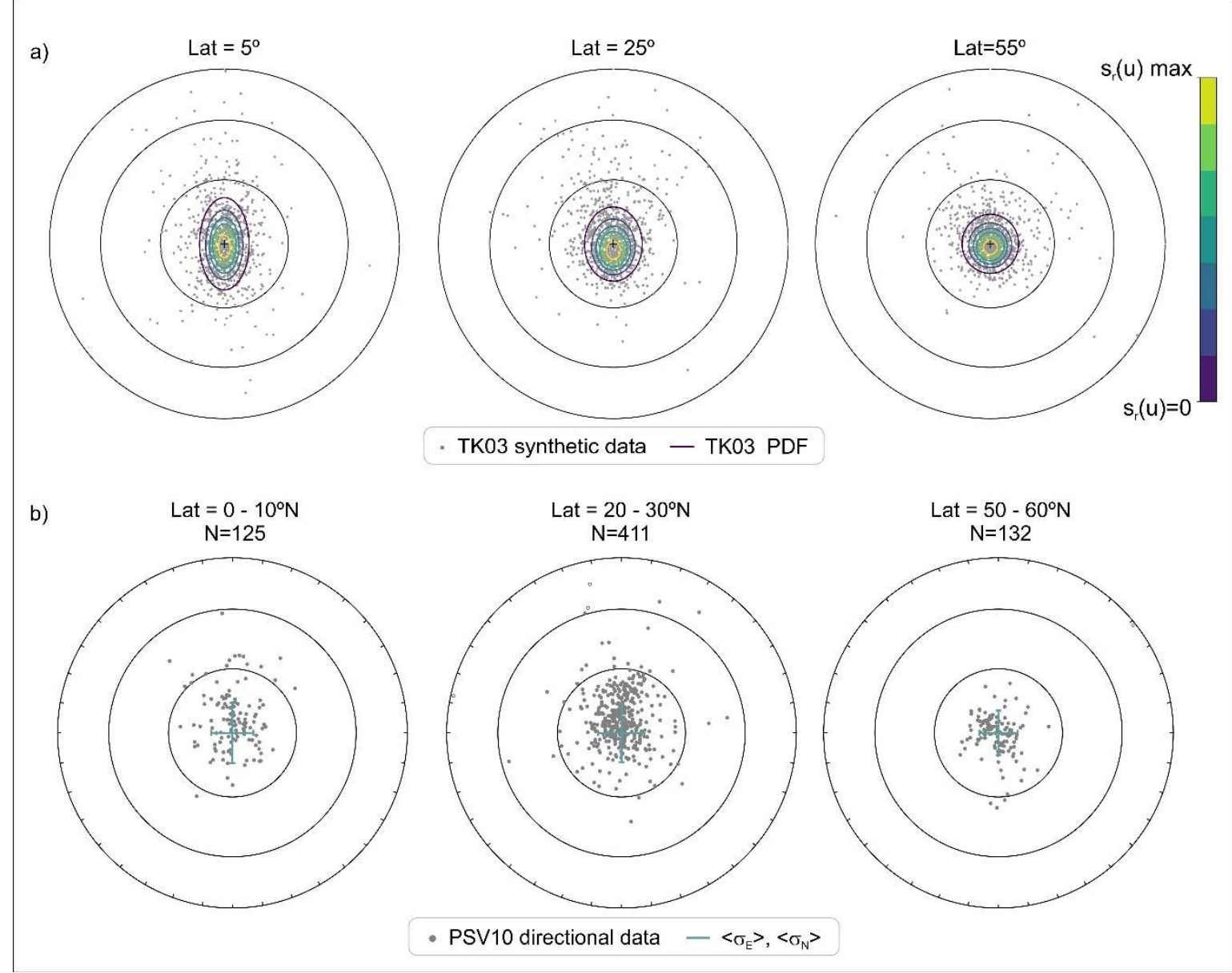

Figure 4.7. Stereographic projections of predictions of the TK03 model and directional data from the last 10 Ma (PSV10, Cromwell et al., 2018). a) Isocurves of the probability density function $s_{r}(u)$ calculated for latitudes 5,25 and $55^{\circ}$ with the expected direction of the field rotated to the center of projection. Grey circles are synthetic directional data produced by simulations of the TK03 model with the expected direction calculated for the corresponding latitude rotated to the origin. b) Directional data from the PSV10 database rotated with the expected direction for the geographic site in the origin and grouped by bins of $10^{\circ}$ of latitudes. Blue lines are the standard deviation calculations for the group of directions.

Calculations of mean values and standard deviations of equal-area coordinates $\left(\sigma_{E}\right.$ and $\sigma_{N}$ ) from directional distributions are given for each group of $10^{\circ}$ of latitude bands in Figure 4.8 (Table S4.2). According to TK03 predictions for a normal polarity field, positive (negative) mean values of $x_{N}$ are expected for northern (southern) hemisphere and null mean $x_{E}$. The PSV10 results of mean $x_{E}$ coordinates are compatible with or nearer to zero than $x_{N}$ results for almost all latitude bins, except for latitudes $20-30^{\circ} \mathrm{S}$ and $60-70^{\circ} \mathrm{S}$. Averages of $x_{N}$ coordinates are mainly positive for both hemispheres with the largest positive values in the range $0-45^{\circ} \mathrm{N}$. 

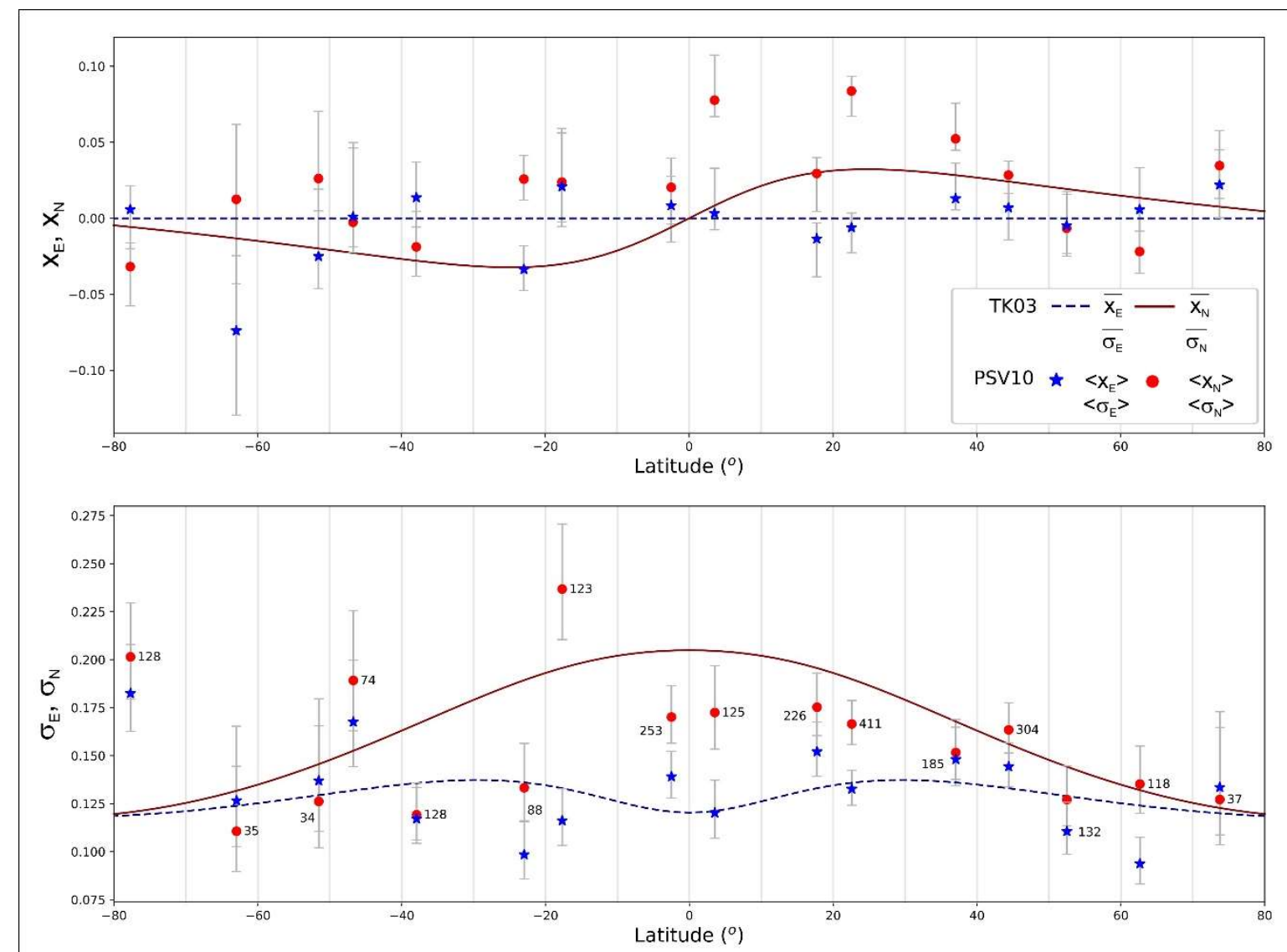

Figure 4.8. Directional PSV measurements for the 0-10 Ma PSV10 database (Cromwell et al., 2018). Symbols are PSV10 results, curves are TK03 predictions, and grey bars are $95 \%$ confidence intervals given by bootstrap re-sampling. a) Mean $x_{E}$ and $x_{N}$ equal-area coordinates from rotated distributions of directions. b) standard deviations of equal-area coordinates $\sigma_{E}$ (dashed/star) and $\sigma_{N}$ (solid/circle).

Standard deviations of the $x_{E}$ coordinate $\left(\sigma_{E}\right)$ are expected to be lower and have less latitudinal variation than $x_{N}$ coordinate. For the majority of results from the PSV10 database $\sigma_{N}$ is greater than $\sigma_{E}$, and follows a smooth variation with latitude, with almost the same trend as TK03 model predictions in the northern hemisphere. The southern latitude bins exhibit a variable and noisy latitudinal variation in $\sigma_{N}$.

The distribution of directional data in PSV10 is hemispherically unbalanced, as there are 1538 northern versus 863 southern hemisphere directions. Thus, the incongruency of southern results might be explained by lower numbers of data or simply local effects. As the main intention of this study is to measure the overall PSV, data from both hemispheres were joined using opposite latitude bins (Tauxe and Kent, 2004). Figure 4.9 shows the results of standard deviations for $10^{\circ}$ latitude bins with northern and southern hemisphere data combined. 


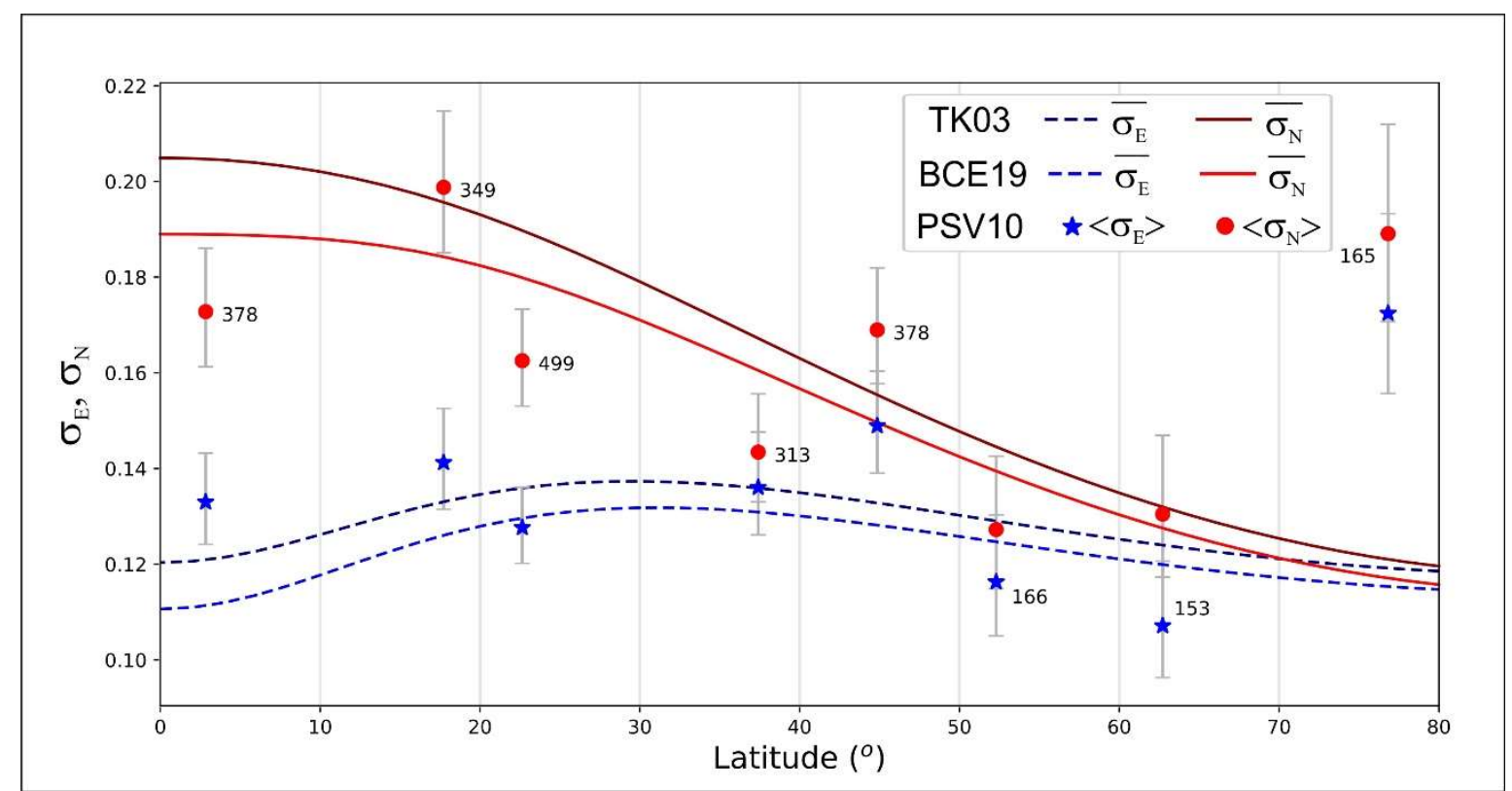

Figure 4.9. Directional PSV measurements for 0-10 Ma PSV10 database (Cromwell et al., 2018) joining opposites hemispheres. Symbols are PSV10 results, curves are TK03 predictions, and grey bars are $95 \%$ confidence intervals given by bootstrap re-sampling. Standard deviations of equal-area coordinates $\sigma_{E}$ (dashed/star) and $\sigma_{N}$ (solid/circle). (Dark) red and blue are predictions by the (TK03 model) minimum GGP model for the last $10 \mathrm{M}$. y (BCE19), theoretical calculations are presented in Table S4.3.

The results show a decreasing $\sigma_{N}$ from the Equator to $70^{\circ}$ latitude, while the persistently smaller $\sigma_{E}$, starting at the Equator is in general agreement with the latitudinal dependence of the TK03 model, exhibiting a slow increase up to mid-latitudes followed by a decreasing trend to $70^{\circ}$. However, the result for the latitude bin of $70-80^{\circ}$ is incompatible with TK03 prediction. It comprises mainly Antarctic data from the McMurdo region (Lawrence et al., 2009). The incompatibility of this dataset with TK03 was originally observed by Lawrence et al. (2009), they declared that the use of GGP models with a flattening trend in VGP dispersion near the poles (e.g. TK03 or CP88) did not appear able to predict the large dispersion at high latitudes as seen in the McMurdo data. (An alternative might be the need for a different TAF model from GAD.) Nevertheless, we consider that at least for latitudes up to $70^{\circ}$ the measurements of standard deviations, $\sigma_{E}$ and $\sigma_{N}$, of equal area coordinates from rotated distributions of the last $10 \mathrm{Ma}$ seems to behave like a simplified zonal GGP model such as the TK03 model.

TK03 is based on a now-obsolete data compilation, so we conducted a search for an improved simplified GGP model that might be more compatible with the PSV10 results. We will call this the BCE19 model and select it on the basis of a minimum residual sum of squares (RSS) misfit to $\sigma_{E}$ and $\sigma_{N}$. For a pre-set mean value of $g_{1}^{0}=-18 \mu T$ (same as TK03), variations in only two parameters were investigated: the $\alpha$ parameter that is related to the variance of all Gaussian coefficients and the $\beta$ parameter, which specifies the ratio 
between the dipolar (odd) and quadrupolar (even) family standard deviations in the Gauss coefficients. The GGP model with the lowest RSS misfit to $\sigma_{E}$ and $\sigma_{N}$ for PSV10 results, for $\alpha, \beta$ parameters varying between 0.01 to 200 , was $\left(g_{1}^{0}, \alpha, \beta\right)$ with $B C E 19_{P S V 10}=$ $(-18 \mu T, 6.7 \mu T, 4.2)$.

The BCE19 model found for the PSV10 data with $g_{1}^{0}, \alpha, \beta=(-18 \mu T, 6.7 \mu T, 4.2)$ has lower overall dispersion $(\alpha)$ than $\operatorname{TK} 03(\alpha, \beta)=(7.5 \mu T, 3.8)$ and the ratio between odd and even families $(\beta)$ persists at about four. PSV10 data from the Equator up to $70^{\circ}$ have a mean distance of 1.37 error bars from the minimum model, which is only a slight improvement over TK03 predictions (1.43 error bars). Therefore, among any simplified zonal GGP model, with only $\alpha$ and $\beta$ as free parameters to adjust, the TK03 model might still be considered adequate to represent the current database. From the range of possible simplified GGP models allowing variations in $\alpha$ and $\beta$ the best least-squares fit would be provided by BCE19.

\subsection{Discussion and Conclusions}

The main behavior of PSV of the geomagnetic field from the distant past has been studied using model $\mathrm{G}$ applied to directional paleomagnetic databases of lava records (Biggin et al., 2008a; Biggin et al., 2008b; de Oliveira et al., 2018; Doubrovine et al., 2019; McFadden et al., 1991; Smirnov et al., 2011) Model G fits the latitudinal dependence of VGP scatter, independently of longitude, and considers a mean GAD field. We have learned from those studies that the PSV (as measured by VGP scatter) of the geomagnetic field has changed significantly over the history of our planet.

The concept of GGP models allows the prediction of a broader range of paleomagnetic observables and has been widely accepted and applied to predict directional distributions. The available models were fitted to the last few million years, but they are probably not valid for the whole history of the core (Brandt et al., 2019a).

Among the available GGP models, the latest one (TK03) is the most simplified, and the best for representing the VGP scatter and the elongation of the directional distribution of the (now outdated) 0-5 Ma database (MM97). In this study, we have presented a new type of PSV statistic based on the shape of the directional pdf (Constable and Parker, 1988; Khokhlov et al., 2001) given by a simplified GGP model like TK03 (Tauxe and Kent, 2004). The PSV parameters using directional distributions proposed in this study are the orthogonal standard deviations $\sigma_{E}$ and $\sigma_{N}$, which can reveal the expected N-S elongation and overall 
dispersion of distribution at any location. As the intention of this work is to define the use of PSV measurements for records of the more ancient geomagnetic field, several simplifications were adopted: a mean GAD field, zonal behavior on average, and only two free parameters $(\alpha, \beta)$ in defining the standard deviations $\sigma_{l}^{m}$ of the individual Gauss coefficients via Equations 4.4 and 4.5.

The simplifications proposed in this study are the same as in the TK03 model (Tauxe and Kent, 2004), and are commonly accepted. To date all available GGP models except for one (CJ98.nz) are zonal (for a given $l$ and $m, \sigma_{l}^{m}$ is the same for $g_{l}^{m}$ and $h_{l}^{m}$ ). The assumption of a mean GAD field is the main hypothesis of paleomagnetism, and it is used in PSV studies of distant times (Biggin et al., 2008a; Biggin et al., 2008b; de Oliveira et al., 2018; Doubrovine et al., 2019; McFadden et al., 1991; Smirnov et al., 2011), as it is essential to determinate the original position (paleolatitude) of paleomagnetic datasets. Nevertheless, it is worth noting that there are small but significant departures from the GAD approximation to the TAF over 0-5 Ma that impact the fit to simplified GGP models at high latitudes.

Our results clearly indicate that for a zonal GGP model for the past, the best way of determining a paleo-inclination or a PP is using an iterative cutoff (Vandamme, 1994). The cutoff angle forces the distribution of VGPs to be circular and at each iteration, the resulting PP goes towards the direction of the geographic pole.

For a zonal GGP model with a GAD mean, the latitudinal dependence $\sigma_{E}$ and $\sigma_{N}$ is symmetric with respect to the Equator and independent of polarity, which allows us to use this model for the geological past when the polarity and/or hemisphere are very often unknown.

If we consider that PSV in the geomagnetic field of the distant past can be emulated by a simplified GGP model, we can imagine that different versions of GGP models may be appropriate for other geological periods of time and use different values of $\alpha$ and $\beta$ to build them. The tests presented in this study show that the isolated increase of either $\alpha$ or $\beta$ will increase both $\sigma_{E}$ and $\sigma_{N}$, but the variation that significantly changes the latitudinal dependence is the modification in $\beta$. For example, suppose that, for a superchron, the PSV from dipolar (odd families) is more important and increases $\beta$, then the elongation $E^{\prime}$ will decrease faster with latitude, than for TK03. This means that, in this case, we would find distributions that are generally more circular than those expected for TK03.

The results of thousands of synthetic samples give the latitudinal dependence of PSV measurements very close to the prediction of the model. Moreover, the results of real data 
(Cromwell et al., 2018) are reasonably compatible with the prediction of a simplified zonal GGP except at high southern latitudes. Therefore, the use of the latitudinal dependence of $\sigma_{E}$ and $\sigma_{N}$ seems to be diagnostic and can be used for further modeling.

Future work, applying this concept of PSV measurements to databases covering older times should be done. A work about the paleosecular variation during the Kiaman superchron is in progress, for which there is an extensive compilation of paleomagnetic data from lavas.

\subsection{Acknowledgment}

D. B. had the support from the Coordenação de Aperfeiçoamento de Pessoal de Nível Superior-Brasil (CAPES)-Finance Code 88881.186997/2018-01. 


\section{Geophysical Journal International}

\section{Decision Letter (GJI-S-19-1092)}

From: lalexander@ras.ac.uk

To: daniele.brandt@iag.usp.br, daniele.paleo@gmail.com

CC: daniele.brandt@iag.usp.br, daniele.paleo@gmail.com,cconstable@ucsd.edu, mernesto@usp.br

Subject: Geophysical Journal International - GJI-S-19-1092

Body: Dear Mrs Brandt

We have now received reviews of your manuscript GJI-S-19-1092 entitled "Giant Gaussian process models of geomagnetic paleosecular variation: a directional outlook". These are appended, together with any additional comments from the editor. Taking these reviews into account, the Editor, Prof. Andrew Biggin, feels that some moderate revision of your manuscript is required, after which Geophysical Journal International will be pleased to give further consideration towards publication.

You now have THREE months in which to submit your revision, but we hope that you will be able to make the necessary revisions well within that time. Your revision is due by 06-Apr-2020. If you do not submit a revised version of your manuscript within three months it will be deemed withdrawn. We would be happy to consider your revised version after that date, but it will be handled as a new submission. In any event, you should quote the reference number of this manuscript.

You should submit your revised version, together with your response to the reviewer's comments via the Geophysical Journal International site https://mc.manuscriptcentral.com/gji. Enter your Author Centre, where you will find your manuscript title listed under "Manuscripts with Decisions." Under "Actions," click on "Create a Revision." Your manuscript reference will be appended to denote a revision.

IMPORTANT: do NOT submit your revised manuscript as a new paper UNLESS you have exceeded the three-month deadline.

We must be in possession of all source files in a .tar file before your paper can be accepted. Please be sure to upload both a file containing your complete manuscript (PDF, PS, WORD etc) and a .tar file containing separate source files of all text (LaTeX etc.), figures (tif, gif, eps, etc.), tables etc. for use by the publisher. Failure to do so will almost certainly result in delays later. Your complete manuscript file should be designated as a Complete manuscript file, including figures and tables (PDF, PS or DOC); your .tar file as Files NOT for review (source files - .zip or .tar.gz).

You will not be able to make your revisions to the originally submitted files of the manuscript held on ScholarOne Manuscripts. Instead, you must delete any original files and abstract you have changed and replace them with your revised files. Check that any requests for colour publication or online-only publication are correct. Proof read the resulting PDF and HTML files that are generated carefully.

When submitting your revised manuscript, you will be able to respond to the comments made by the reviewer in the space provided. You should also use this space to document any changes you make to the original manuscript. In order to expedite the processing of the revised manuscript, please be as specific as possible in your response to the reviewer. Changes to the manuscript should be highlighted (e.g. in bold or colour), to assist the referee and editor. Authors should also upload clean files (remove bold font or track changes) for the publisher, since uncorrected versions of accepted manuscripts are now immediately published online ahead of the proof corrected versions.

Regards,

Dr Louise Alexander

Geophysical Journal International

cc: all listed co-authors.

Editor Prof. Andrew Biggin

Comments to the Author:

Dear Daniele and co-authors

Many thanks for submitting this manuscript to GJI. I am pleased to say that both reviewers see the value in this work and are supportive of its eventual publication though both also have 


\section{Chapter 5}

\section{Properties of the geomagnetic field during the Kiaman superchron: analysis of directional distributions of a new igneous database}

This chapter is devoted to the analysis of the distribution of the paleomagnetic database of the Kiaman superchron following the methodology described in the previous chapter. In order to create a database as large as possible with the existing data, a specific database (the Kiaman database) was created based on site-remanence directions. Details of the adopted procedures for data selection and filtering are giving in the next section, which appears in the form of a manuscript that is being prepared for submission to the Geophysical Journal International, hereafter referred to as Brandt et al. (2020).

The Kiaman database is so far the most complete and largest list of site remanence directions of the Kiaman period. An equivalent database for the same time interval recently presented by Oliveira et al. (2018), which D. Brandt co-authored, is far more limited with only nine datasets due to the very restrictive filtering adopted. The Kiaman database presented here, using more flexible criteria, resulted in a total of 1419 reliable individual igneous directions from 89 datasets of which 60 (977 directions) are of extrusive records. This expanded database was possible by merging directional data from different areas that indicated the same paleolatitude. The data was then merged into paleolatitude bands.

This work presents the latitudinal variation of directional distribution of Kiaman times (following Brandt et al., 2019b), addresses whether this paleomagnetic field is compatible with the accepted TK03 model (Tauxe \& Kent, 2004) or the proposed BCE19 model (Brandt et al., 2019b) and whether a GGP model would be able to describe the PSV behavior of this period of time.

The supplementary materials can be found at https://earthref.org/ERDA/2419/. 



\title{
Properties of the geomagnetic field during the Kiaman superchron: analysis of directional distributions of a new igneous database
}

\author{
Daniele Brandt ${ }^{1}$, Marcia Ernesto ${ }^{1}$, Catherine Constable ${ }^{2}$ \\ ${ }^{1}$ Universidade de São Paulo, Instituto de Astronomia, Geofísica e Ciências Atmosféricas, Departamento de \\ Geofísica, 05508-900 São Paulo, SP, Brazil. \\ ${ }^{2}$ Institute of Geophysics and Planetary Physics, Scripps Institution of Oceanography, University of California \\ at San Diego, La Jolla, CA 92093-0225, USA.
}

(To be Submitted to the Geophysical Journal International)

\subsection{Abstract}

This work presents an extensive directional paleomagnetic database of the Kiaman reversed superchron (Kiaman database) composed of a total of 1419 paleomagnetic directions of igneous rocks corresponding to 89 datasets (paleomagnetic poles). Paleosecular variation (PSV) exhibited by the data is evaluated through analyses of latitudinal variations in both the dispersion of virtual geomagnetic pole (VGP) and the shape dependence of local directional distributions. An N-dependent $A_{95}$ envelope is established for this database to help in assessing the adequacy of the PSV sampling and has maximum and minimum $A_{95}$ limits of $A_{95 \max }=76.6 \mathrm{~N}^{-0.64}$ and $A_{95 \min }=10.3 \mathrm{~N}^{-0.40}$. Using modern standards to filter the Kiaman database based on the quality of demagnetization procedures and directional statistics produces stronger latitudinal dependence of VGP dispersion than including all data regardless of quality. Local directional PSV was characterized by the standard deviations $\left(\sigma_{N}\right.$ and $\sigma_{E}$ ) in north-south and east-west directions in equal-area coordinates of the paleomagnetic directional distributions assigned to paleolatitude bands of width $10^{\circ}$, and with expected direction rotated-to-the-vertical. The latitudinal dependence of $\sigma_{N}$ and $\sigma_{E}$ for the Kiaman database presents two types of behavior: an elongated and more dispersed distribution near the Equator, resembling giant Gaussian process (GGP) models of the recent field; and an almost constant behavior of more concentrated and circular distributions for latitudes above $10^{\circ}$. The latter contrasts strongly with predictions from recent models, which exhibit a steady transition to circular distributions at high latitudes. The use of strict quality controls would exclude all data from the Equator to $20^{\circ}$ latitude, so the equatorial behavior cannot be verified for the highest-quality data analyses. Two GGP models, with parameters $K R S_{m}=\left(\alpha, \beta, g_{1}^{0}\right)=(6.2 \mu T, 3.4,18 \mu T)$ and $K R S_{m}^{\prime}=$ 
(3.6 $\mu T, 6.6,18 \mu T)$, were found, including and excluding the equatorial band data, respectively. Numerical predictions of $\sigma_{N}$ and $\sigma_{E}$, from $K R S_{m}$ and $K R S^{\prime}{ }_{m}$ are a better fit to the Kiaman data than those from other recent models. However, for both Kiaman models, the misfit is larger than expected from the data uncertainties, and systematic in pattern, indicating that a simplified GGP model like the one tested here is not able to describe PSV of the geomagnetic field for Kiaman times. Experimental-noise simulations indicated that the observed misfit may reflect the experimental noise combined with greatly reduced PSV compared to the more energetic recent times.

\subsection{Introduction}

The study of the long-term variations of the Earth's magnetic field is normally performed by building statistical models of the paleosecular variation (PSV). Observations of the paleomagnetic field for any time across the geological timescale, commonly preserve the fundamental hypothesis of paleomagnetism that the average field direction is well described by a geocentric axial dipole (GAD) field and consider the paleomagnetic record to be spot readings providing random samplings of the past geomagnetic field. With these simplifications, quantities such as reversal frequency (e.g. Driscoll and Evans, 2016; Hounslow, 2016), strength of the mean-field (e.g., Tarduno et al., 2006), latitudinal dependence of VGP scatter (e. g. Biggin et al., 2008a; Biggin et al., 2008b; McFadden et al., 1991; Smirnov et al., 2011), and shape of directional distributions (Tauxe and Kodama, 2009) may reveal changing characteristics of the field through geological time.

Superchrons are long periods (tens of million years) of a persistent polarity of the geomagnetic field. Recently, they have been attributed to the collapse of lower mantle superplumes and associated changes in the heat flux at the core-mantle boundary (Amit and Olson, 2015). The regrowth of the plume would again allow field reversals. Three superchrons are recognized in the Phanerozoic: the Cretaceous Normal Superchron (CNS: 84-126 Ma, Ogg, 2012), a 42 My interval of normal polarity; the Moyero Superchron occurred during Ordovician times (Pavlov et al., 2012), and the Permo-Carboniferous Reversed Superchron ( 267-318 Ma; Opdyke and Channell, 1996; Hounslow and Balabarov, 2018) also known as the Kiaman Reverse Superchron.

Superchrons are expected to have a more stable mean dipole field with higher intensities than during times of high reversal frequency (e.g., Tarduno et al., 2006), and this might be expected to have a corresponding effect on measurements of PSV. The latitudinal 
dependence of the VGP scatter $S_{F}$ is defined by the $a$ and $b$ shape parameters in model G (McFadden et al., 1988) in the form:

$$
S_{F}=\sqrt{a^{2}+b^{2} \lambda^{2}}
$$

where $a^{2}$ and $b^{2} \lambda^{2}$ are the VGP scatter caused by quadrupolar (even) and dipolar (odd) families of spherical harmonics contributions, respectively.

Some authors (Biggin et al., 2008b; de Oliveira et al., 2018; McFadden et al., 1991) have claimed stronger latitudinal dependence of $S_{F}$, and lower equatorial $S_{F}$ during superchrons. However, strong latitudinal dependence of $S_{F}$ is also observed for the last few million years and, therefore, this parameter is not a reliable proxy for reversal frequency (Doubrovine et al., 2019).

PSV models based on giant Gaussian processes (GGP) can be used to predict the distribution of directions at any point of the Earth (e.g. CP88, Constable and Parker, 1988; QC96, Quidelleur \& Courtillot, 1996; CJ99, Constable \& Johnson, 1999; TK03, Tauxe \& Kent, 2004; BCE19, Brandt et al., 2019b). Currently, available GGP models for the last few million years were determined using paleomagnetic directions from lava flows which are considered as spot readings of the paleomagnetic field that are randomly distributed in time. In recent times, plate tectonic motions are negligible or can be corrected easily with the currently observed plate displacements (Cromwell et al., 2018). The TK03 model was fitted to the most accurate dataset available at the time of publication (MM97, McElhinny and McFadden, 1997), and agrees with the latitudinal variation of VGP dispersion found in MM97. TK03 is the most simplified version of the GGP models, as it has a mean GAD with an intensity of $g_{1}^{0}=-18 \mu T$ and only two parameters, $\alpha$, and $\beta$, define the whole collection of standard deviations of spherical harmonic Gauss coefficients for every degree $l$ and order $m$ as shown in equations 5.2 and 5.3.

$$
\begin{aligned}
\sigma_{l}^{m^{2}} & =\frac{(c / a)^{2 l} \alpha^{2}}{(l+1)(2 l+1)} \text { for } l-m=\text { even }, \\
\sigma_{l}^{m^{2}} & =\frac{(c / a)^{2 l} \alpha^{2} \beta^{2}}{(l+1)(2 l+1)} \text { for } l-m=\text { odd }
\end{aligned}
$$

Where $c / a$ is the ratio of the core radius to that of the Earth (0.547), and TK03 has $\alpha=$ $7.5 \mu T$ and $\beta=3.8$.

A new simplified GGP model, designated BCE19 (Brandt et al., 2019b), was fitted to an up-to-date directional paleomagnetic database from lavas of the last 10 My (PSV10; Cromwell et al., 2018). The BCE19 model follows the same simplifications (mean GAD, $\alpha$ and $\beta$ parameters) proposed by Tauxe and Kent (2004), but instead of attempting to fit the 
latitudinal variations in VGP scatter, it uses PSV measurements related to directional distributions that can be determined numerically for any given GGP model, thereby avoiding the use of thousands of simulations. The measurements proposed by Brandt et al. (2019b) are $\sigma_{E}$ and $\sigma_{N}$, the standard deviations in equal-area coordinates of rotated-to-the-vertical GAD directional distributions.

An attempt was made by Brandt et al. (2019a) using sediment records to test whether directional predictions of the TK03 model (Tauxe and Kent, 2004) are compatible with the Kiaman times. However, there is a paucity of paleomagnetic data series long enough to properly evaluate the elongation of the directional distributions, resulting in no definitive conclusion about the shapes of directional distributions for the Kiaman. However, it was observed that the TK03 model does not explain the VGP scatter for the analyzed Kiaman data.

Therefore, the main goal of the present work is to investigate the expected directional distributions produced by the Kiaman paleomagnetic field. Accordingly, we present directional analyses following the strategy of Brandt et al. (2019b), together with calculations of $S_{F}$, using a new comprehensive igneous database to determine whether the paleomagnetic field was compatible with either the long-standing TK03 model or the proposed BCE19 model.

\subsection{Methods}

We study the paleosecular variation of the Kiaman geomagnetic field focusing on the directional behavior of the field. A paleomagnetic directional database with data grouped in paleolatitude bands was constructed. VGP scatter associated with the PSV was evaluated, together with shape and scale analyses of directional PSV. New PSV models were fit to the resulting parameters.

\subsubsection{Data Compilation and Selection}

The main tool used in compiling the Kiaman paleomagnetic records was the Global Paleomagnetic Database (McElhinny and Lock, 1996), which contains abundant information about paleomagnetic poles organized in an easily-searchable table. This tool allowed us to find more than $70 \%$ of the references for the paleomagnetic poles used in this work; the remainder came from other global paleomagnetic databases (Magic Database and Pint database) or by bibliographic searching.

The initial criteria used for selecting the datasets were: 
1. Paleomagnetic poles from igneous rocks only;

2. Primary magnetization dating from the same age as the rock studied;

3. Age of the paleomagnetic pole and rock unit compatible with the Kiaman interval;

4. All samples were demagnetized with demagnetization code $D C \geq 2$ (McElhinny and Lock, 1996).

As a second step, tables containing declination and inclination in stratigraphic coordinates of each site were prepared using data taken from the original publication. More information about the reliability of the data, rock type of each site and statistical parameters were also computed. Additional filtering criteria were then applied:

5. Exclusion of sedimentary sites, to avoid inclination shallowing effects or temporal smoothing during remanence acquisition;

6. Exclusion of unreliable sites (e.g. mentioned in the original publication as suspected of having been remagnetized).

7. Only datasets with at least five igneous sites were considered in an attempt to acquire adequate temporal sampling.

8. Further evaluation of whether the dataset distribution sampled the geomagnetic PSV adequately was done using the N-dependent $A_{95}$ envelope (Deenen et al., 2011), as given by the upper and lower limits of the $95 \%$ confidence angle of paleomagnetic poles.

The $A_{95}$ envelope procedure in 8 supposes that a dataset with an $A_{95}$ higher than the maximum limit contains a significant additional contribution to VGP dispersion apart from PSV and should be considered 'unreliable'; while an $A_{95}$ below the lower limit is probably under-representative of the PSV in the geomagnetic field. Deenen et al. (2011) originally proposed limits determined from VGP scatter observed throughout Earth's history. As the PSV during a superchron has been related to a reduction in VGP scatter (Biggin et al., 2008b; Brandt et al., 2019a; Oliveira et al., 2018; Doubrovine et al., 2019; Franco et al., 2012; Haldan et al., 2009; Haldan et al., 2014) the lower limit of $A_{95}$ given by Deenen et al. (2011) may be unrealistic for the time period covered by this database. Therefore, limits of maximum and minimum $A_{95}$ were evaluated for this study based on the newly compiled Kiaman dataset.

To find the proper $A_{95}$ limits to use in this work, we first rotated each data set so that the mean VGP corresponds to the geographic pole. After that, we merged the data from 
northern and southern paleolatitude bands of width $10^{\circ}$. The highest and lowest $K$ (Fisher, 1953 ) for bands with more than 50 VGPs were used to define a new $A_{95}$ envelope, according to the method described by Deenen et al. (2011).

\subsubsection{Merging datasets}

As the size of the Permo-Carboniferous paleomagnetic records from individual studies is not usually large enough to guarantee adequate sampling of PSV, we grouped the directional data according to paleolatitudes thus enlarging the data sets. This helps to improve the directional PSV determinations, as is commonly required for the PSV studies (e.g., Constable \& Parker, 1988; Tauxe \& Kent, 2004; Brandt et al., 2019b). As we considered the most simplified model of the field, zonal and equatorial symmetries are expected, thus, opposite latitudes bands could be joined as done by Tauxe \& Kent (2004) and Brandt et al. (2019b). An expected direction for each dataset (black stars at Figures 5.1a and 5.1b) was calculated from the paleomagnetic pole determined using the iterative cut-off angle of Vandamme (1994). Following the sequence:

1) VGPs are calculated from directions of the dataset;

2) A mean paleomagnetic pole is determined using the VGPs selected using the iterative cut-off angle of Vandamme (1994);

3) An expected direction $\left(D_{\text {exp }}, I_{\text {exp }}\right)$ is calculated from the paleomagnetic pole.

This procedure avoids the effect of asymmetric directional distributions that result in an angular difference between the mean direction and the expected direction (Brandt et al., $2019 b)$. For each dataset, the directions were rotated to take the expected direction to the origin of the projection (with $\operatorname{dec}=0^{\circ}$, inc $=90^{\circ}$ ).

We preferred to use expected directions from GAD to determine the rotation and paleolatitude of the individual datasets instead of using pre-defined paleo-reconstructions (as for example, Gallo et al., 2017; Torsvik et al., 2012) because, among other issues, we would otherwise have to deal with problems such as uncertainties in age (see Table 5.1), best rotation parameters for each tectonic block and each dataset, and using Pangea model A or B (Irving, 1977).

The paleolatitude of each dataset was determined using the GAD equation:

$$
\tan I_{\text {exp }}=2 \tan \lambda \text {, }
$$

where $I_{\text {exp }}$ is the expected inclination and $\lambda$ is the paleolatitude corresponding to the dataset. 


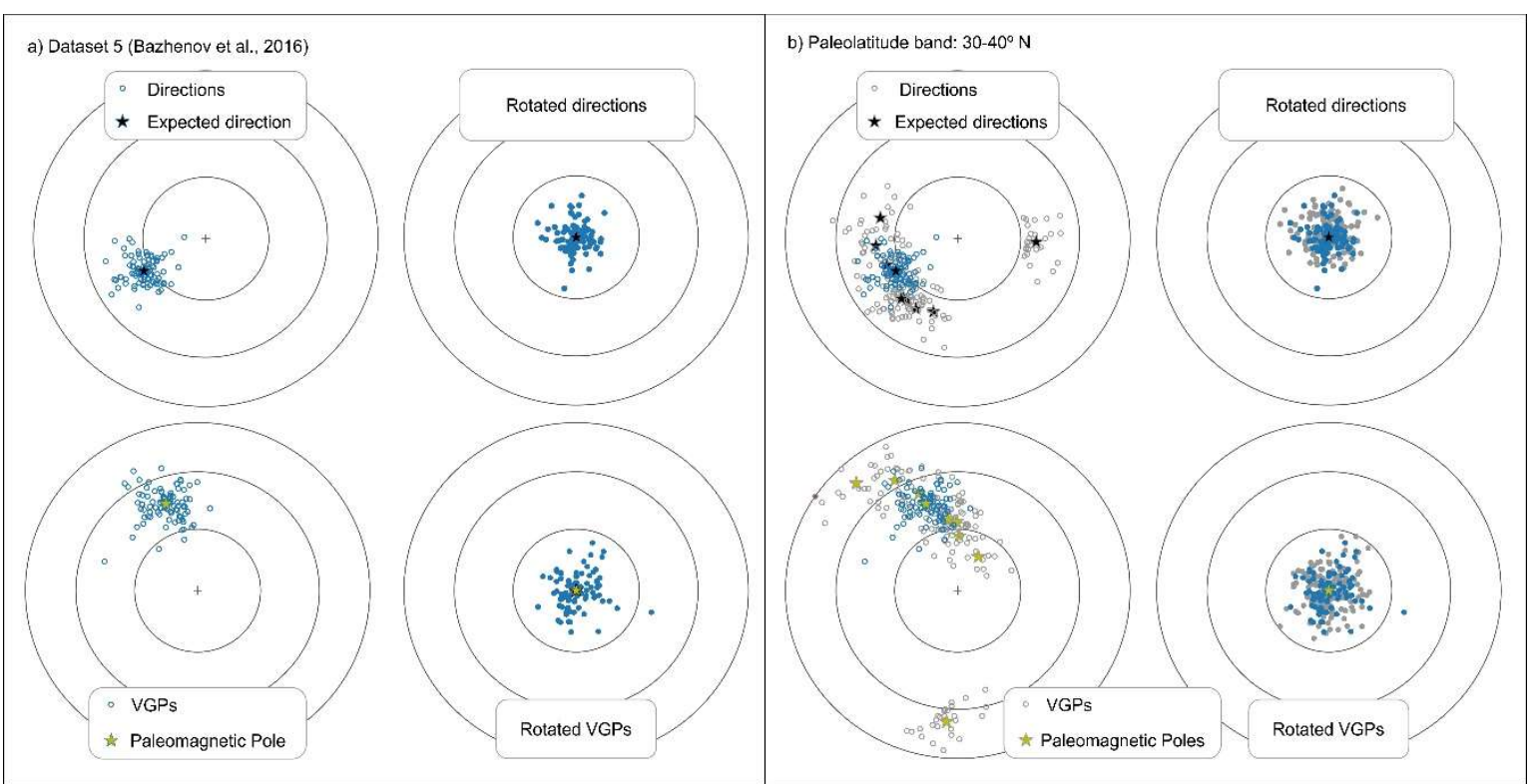

Figure 5.1. Rotation and grouping of directions and VGPs. a) An example of a dataset (Bazhenov et al., 2016). b) Grouping paleodirections and VGPs from the paleolatitude band of 30 to $40^{\circ} \mathrm{N}$.

\subsubsection{VGP Scatter and Model G-type PSV Analysis}

The VGP scatter, $S_{F}$, associated with the paleosecular variation of the field was calculated as follows:

$$
\begin{array}{r}
S_{F}=\sqrt{S^{2}-\frac{S_{w}^{2}}{\bar{n}}} \\
S=\sqrt{\frac{\sum \Delta_{i}^{2}}{N-1}} \\
\frac{S_{w}{ }^{2}}{\bar{n}}=0.335 \overline{\alpha 95}^{2} \frac{2\left(1+3 s i{ }^{2} \lambda\right)^{2}}{\left(5+3 s i i^{2} \lambda\right)}
\end{array}
$$

Where $S$ is the overall dispersion of VGPs and $\frac{s_{w}{ }^{2}}{\bar{n}}$ is the correction associated with the intra-site dispersion $S_{w}$ (McElhinny and McFadden, 1997); $\Delta_{i}$ is the angular difference between each VGP and the paleomagnetic pole; $N$ is the number of sites; $\bar{n}$ is the mean number of specimens and $\overline{\alpha_{95}}$ is the mean $\alpha_{95}$ of the sites in the dataset. For datasets without $\alpha_{95}$ information, a mean value from the whole database was used. The cut-off angle for calcualting the mean was defined using the iterative process of Vandamme (1994). The 95\% confidence limits of $S_{F}$ were determined using 1,000 bootstrapped samples. The shape parameters $a$ and $b$ (Equation 5.1) for type G model (McFadden et al., 1988), for $S_{F}$ versus the paleolatitude $\lambda$, were found using the function "optimize.leastsq" from the "Scipy" Python library for the least squares optimization in non-linear problems. Confidence limits for $a$ and $b$ were found using the lower and upper limits of $S_{F}$ values (in the same way as Biggin et al., 2008a; Oliveira, 2018). 


\subsubsection{Directional distributions - shape and scale of PSV}

To analyze the scatter and elongation of the directional distributions, Brandt et al. (2019b) found statistics that can be numerically predicted for a zonal GGP model. These are the standard deviations $\sigma_{E}$ and $\sigma_{N}$ (Equations 5.8 and 5.9) of equal-area coordinates $x_{E}$ (east-west) and $x_{N}$ (north-south) of the rotated directional distributions:

$$
\begin{aligned}
& \left\langle\sigma_{E}\right\rangle=\sqrt{\frac{\sum_{i=1}^{N}\left(x_{E_{i}}-\left\langle x_{E}\right\rangle\right)^{2}}{N-1}} ;\left\langle x_{E}\right\rangle=\frac{\sum_{i=1}^{N} x_{E_{i}}}{N} \\
& \left\langle\sigma_{N}\right\rangle=\sqrt{\frac{\sum_{i=1}^{N}\left(x_{N_{i}}-\left\langle x_{N}\right\rangle\right)^{2}}{N-1}} ;\left\langle x_{N}\right\rangle=\frac{\sum_{i=1}^{N} x_{N_{i}}}{N}
\end{aligned}
$$

The $95 \%$ confidence limits of $\sigma_{E}$ and $\sigma_{N}$ were determined from 1,000 bootstrapped samples. The representative paleolatitude for each band was determined by the average of the paleolatitudes of the datasets included in the band.

Brandt et al. (2019b) determined that the latitudinal dependence of $\sigma_{E}$ and $\sigma_{N}$ can provide useful diagnostics for the validity of a GGP model, as both shape (elongation) and scale of the distributions vary with location. Therefore, we used them to test existing GGP models for the Kiaman and to search for a new GGP model for this time interval. For a zonal GGP model with a GAD mean, the latitudinal dependence $\sigma_{E}$ and $\sigma_{N}$ is symmetric with respect to the Equator and independent of polarity, which allows us to use this simplified GGP model for the remote geological past when the polarity and/or paleo-hemisphere are very often unknown. We search for the best fitting simplified GGP model $m=\left(\alpha, \beta, g_{1}^{0}\right)$ for Kiaman times, considering a previous mean dipole value of $g_{1}^{0}=18 \mu T$ (as in TK03, but reversed), using least-squares minimization of the misfit between theoretical predictions and directional standard deviations $\left(\sigma_{E}, \sigma_{N}\right)$ estimated from the data.

We used the ratio $E^{\prime}=\sigma_{N} / \sigma_{E}$ as a measure of the elongation of distributions along the $\mathrm{N}-\mathrm{S}$ direction, and the area given by the product $A_{d i r}=\sigma_{N} \sigma_{E}$ to characterize the overall dispersion (following Brandt et al., 2019b). All calculations were done in Python with the help of functions available from the PMAGPY package (Tauxe et al., 2016) and the directional PSV predictions of simplified GGP models derived by Brandt et al. (2019b) and available at github.com/danielebrandt/BCE19-dirPSV.

\subsection{The paleomagnetic database for the Kiaman times}

Flexible criteria were used to build the largest possible directional database for the Kiaman in contrast to the precursory filtering for high-quality data considered in other recent 
compilations (Cromwell et al., 2018; Oliveira et al., 2018; Doubrovine et al., 2019). This procedure resulted in a database with 1419 reliable igneous directions (Table S5.1) corresponding to 89 paleomagnetic poles (datasets) of which sixty (977 directions) are based solely on extrusive rocks. Figure 5.2 shows the sampling site locations and Table 5.1 summarizes the paleomagnetic poles. Below we also consider the effects of adding further quality criteria to filter the data. 
Table 5.1. Compiled Kiaman paleomagnetic results indicating the excluded studies (*) based on the above criteria. More results per datasets in Table S5.2.

\begin{tabular}{|c|c|c|c|c|c|c|c|c|c|c|c|c|c|c|}
\hline NPOLE & Geologic Unit & T. & $N_{i g}$ & Lons $_{S}$ & Lats & $\operatorname{Dec}\left({ }^{\circ}\right)$ & $\operatorname{Inc}\left({ }^{\circ}\right)$ & Plat & $\mathbf{S}_{\mathrm{F}}\left(\mathbf{S}_{\mathrm{FL}}, \mathbf{S}_{\mathrm{FU}}\right)$ & $\operatorname{Age}_{L}$ & Ageu $_{\text {. }}$ & $\operatorname{Rev}$ & DC & References \\
\hline $1^{*}$ & $\begin{array}{c}\text { Alum Mountain } \\
\text { Volcanics }\end{array}$ & E & 18 & 152 & -32.2 & 27.5 & 88.8 & -87.5 & $40.3(33.6,46.2)$ & 270 & 277.5 & 100 & 5 & Shaanan et al. (2015) \\
\hline $2^{*}$ & Bulgonunna Volcanics & $\mathrm{E} / \mathrm{I}$ & 12 & 147.4 & -21 & 203.5 & 79.0 & -68.8 & $28.6(19.1,36.1)$ & 293 & 305 & 100 & 4 & Lackie et al. (1992) \\
\hline 3 & Gerringong Volcanics & $\mathrm{E}$ & 17 & 150.8 & -34.6 & 174.4 & 78.3 & -67.5 & $17.5(13.5,20.8)$ & 264.7 & 265.4 & 71 & 5 & Belica et al. (2017) \\
\hline 4 & Boggabri Volcanics & $\mathrm{E}$ & 6 & 150.1 & -30.6 & 176.5 & 78.2 & -67.2 & $10.8(6.2,13.3)$ & 260 & 299 & 100 & 4 & Klootwijk (2003) \\
\hline 5 & Currabubula F. (W. S. & E & 23 & 150.6 & -31.2 & 233.8 & 77.8 & -66.7 & $20.2(13.1,25.5)$ & 304 & 315 & 100 & 4 & Opdyke et al. (2000) \\
\hline 6 & $\begin{array}{l}\text { Mount Leyshon } \\
\text { Intrusive C. }\end{array}$ & I & 34 & 146.3 & -20.3 & 196.4 & 77.7 & -66.5 & $17.8(14.2,21)$ & 279 & 287 & 100 & 4 & Clark and Lackie (2003) \\
\hline 7 & Lark Hill Formation & $\mathrm{E}$ & 8 & 150.3 & -29.9 & 213.9 & 75.8 & -63.1 & $6.1(1.8,9.8)$ & 306 & 314 & 100 & 4 & Klootwijk (2002) \\
\hline 8 & $\begin{array}{l}\text { Tuckers Igneous } \\
\text { Complex }\end{array}$ & I & 46 & 146.6 & -20.1 & 183.6 & 75.3 & -62.3 & $17.6(13.9,20.6)$ & 283 & 291 & 100 & 4 & Clark and Lackie (2003) \\
\hline 9 & Lago Ranco Granites & I & 7 & 287.7 & -40.2 & 139.0 & 74.7 & -61.4 & $24.5(16.4,31.2)$ & 297 & 307 & 86 & 4 & Beck et al. (1991) \\
\hline 10 & Werrie Basalt & $\mathrm{E}$ & 6 & 150.5 & -31 & 158.3 & 74.5 & -61.1 & $21.8(8.2,31.2)$ & 271 & 299 & 100 & 4 & Lackie and Schmidt (1993) \\
\hline 11 & Rocky Creek & $\mathrm{E}$ & 9 & 150.3 & -30.2 & 203.8 & 73.6 & -59.5 & $18.4(6.8,26.8)$ & 310 & 315 & 100 & 4 & Opdyke et al. (2000) \\
\hline 12 & $\begin{array}{l}\text { Base Currabubula F. } \\
\text { (W. B. }\end{array}$ & $\mathrm{E}$ & 11 & 150.7 & -31.3 & 219.7 & 73.3 & -59.0 & $10.9(4.7,16.1)$ & 302 & 318 & 100 & 4 & Klootwijk (2003) \\
\hline 13 & Werrie Basalt & $\mathrm{E}$ & 9 & 151 & -31.9 & 200.2 & 72.9 & -58.4 & $23.7(15.2,31.4)$ & 260 & 299 & 100 & 4 & Klootwijk (2003) \\
\hline 14 & $\begin{array}{c}\text { Base Currabubula F. } \\
\text { (K. B. }\end{array}$ & $\mathrm{E}$ & 9 & 150.8 & -31.7 & 209.2 & 69.3 & -52.9 & $12(6.9,16.1)$ & 302 & 318 & 100 & 4 & Klootwijk (2003) \\
\hline 15 & $\begin{array}{c}\text { Woniusi F. (Baoshan } \\
\text { Terrane }\end{array}$ & $\mathrm{E}$ & 6 & 99 & 25 & 153.5 & 67.9 & -50.9 & $24.5(20.8,28.9)$ & 273.1 & 280 & 100 & 4 & Xu et al. (2015) \\
\hline 16 & Upper Choiyoi Group & $\mathrm{E}$ & 40 & 291.4 & -34.8 & 169.1 & 66.3 & -48.8 & $12.9(10.6,14.8)$ & 260 & 269 & 53 & 5 & Domeier et al. (2011c) \\
\hline 17 & $\begin{array}{l}\text { Top Currabubula F. } \\
\text { (W. Basin }\end{array}$ & $\mathrm{E}$ & 18 & 150.6 & -31.3 & 243.7 & 65.9 & -48.2 & $10.8(6.9,14.1)$ & 302 & 318 & 100 & 4 & Klootwijk (2003) \\
\hline 18 & $\begin{array}{c}\text { Woniusi Form. Loc } \\
\text { Yongde }\end{array}$ & $\mathrm{E}$ & 6 & 99.2 & 23.9 & 294.9 & 64.2 & -45.9 & $13.5(9.1,16.9)$ & 299 & 318 & 100 & 4 & Huang and Opdyke (1991) \\
\hline 19 & Woniusi Formation & $\mathrm{E}$ & 14 & 99.3 & 25.2 & 241.7 & 63.7 & -45.3 & $21(17.1,24.7)$ & 270.6 & 280 & 100 & 5 & Ali et al. (2013) \\
\hline 20 & Rincon Blanco & $\mathrm{E}$ & 9 & 291.4 & -28.6 & 187.7 & 63.3 & -44.9 & $14.7(7.6,20.5)$ & 271 & 318 & 100 & 4 & Geuna and Escosteguy (2004) \\
\hline 21 & $\begin{array}{c}\text { Woniusi Form. } \\
\text { Baoshan }\end{array}$ & $\mathrm{E}$ & 13 & 99.3 & 25.2 & 208.8 & 61.5 & -42.6 & $17.3(14.8,19.7)$ & 299 & 318 & 100 & 4 & Huang and Opdyke (1991) \\
\hline 22 & Sierra Chica & $\mathrm{E}$ & 35 & 294.5 & -37.9 & 169.0 & 61.3 & -42.4 & $8.7(6.3,10.8)$ & 261 & 264.6 & 89 & 5 & Domeier et al. (2011b) \\
\hline 23 & Tambillos Formation & $\mathrm{E}$ & 16 & 290.5 & -32.2 & 175.6 & 60.9 & -42.0 & $13.4(9.2,17.1)$ & 271 & 285 & 100 & 3 & Rapalini and Vilas (1991) \\
\hline 24 & La Tabla Formation & $\mathrm{E}$ & 10 & 290.7 & -24.5 & 136.4 & 59.1 & -39.9 & $8.8(4.4,10.9)$ & 251 & 318 & 100 & 4 & Jesinkey et al. (1987) \\
\hline
\end{tabular}




\begin{tabular}{|c|c|c|c|c|c|c|c|c|c|c|c|c|c|c|}
\hline 25 & Cas Formation & $\mathrm{E}$ & 10 & 291.5 & -24.4 & 143.8 & 57.0 & -37.6 & $17.4(11.2,23.5)$ & 299 & 318 & 50 & 4 & Jesinkey et al. (1987) \\
\hline 26 & $\begin{array}{c}\text { Panjal Traps of NW } \\
\text { India }\end{array}$ & $\mathrm{E}$ & 14 & 74.9 & 34 & 135.0 & 56.2 & -36.8 & $23.5(16.9,29.4)$ & 286 & 292 & 100 & 5 & Stojanovic et al. (2016) \\
\hline 27 & $\begin{array}{c}\text { Woniusi F. (Baoshan } \\
\text { Terrane }\end{array}$ & $\mathrm{E}$ & 13 & 99 & 24.9 & 232.7 & 55.6 & -36.2 & $16.2(12.6,19.8)$ & 273.1 & 280 & 100 & 4 & Xu et al. (2015) \\
\hline 28 & Takitimu Mountains & $\mathrm{E}$ & 8 & 168 & -46 & 262.6 & 45.7 & -27.1 & $4.5(1.3,8.5)$ & 276 & 284 & 100 & 4 & Haston et al. (1989) \\
\hline 29 & Woniusi Formation & $\mathrm{E}$ & 8 & 99.1 & 24.9 & 124.4 & 45.6 & -27.1 & $7.6(5.3,9.5)$ & 270.6 & 280 & 100 & 5 & Ali et al. (2013) \\
\hline 30 & Portezuelo del Cenizo & $\mathrm{E}$ & 17 & 290.5 & -32.1 & 248.4 & 41.0 & -23.5 & $15(10.5,19.3)$ & 265 & 285 & 100 & 3 & Rapalini et al. (1989) \\
\hline 31 & $\begin{array}{l}\text { Jebel Nehoud Ring } \\
\text { Complex }\end{array}$ & I & 8 & 30.5 & 14.9 & 147.1 & 40.0 & -22.8 & $6.4(2.5,9.4)$ & 278 & 282 & 100 & 4 & Bachtadse et al. (2002) \\
\hline 32 & $\begin{array}{l}\text { Qiangtang Kaixinling } \\
\text { group }\end{array}$ & $\mathrm{E}$ & 14 & 92.4 & 34.1 & 219.8 & 39.9 & -22.7 & $17.7(13.4,21.8)$ & 295 & 298.8 & 64 & 4 & Song et al. (2017) \\
\hline 33 & $\begin{array}{l}\text { South Carolina } \\
\text { Piedmont }\end{array}$ & I & 20 & 278.9 & 36.8 & 160.2 & 22.1 & -11.5 & $11.9(9.3,14.3)$ & 265 & 295 & 100 & 3 & Dooley (1983) \\
\hline 34 & $\begin{array}{l}\text { Middletown } \\
\text { Pegmatites }\end{array}$ & I & 5 & 287.4 & 41.6 & 164.9 & 21.4 & -11.1 & $7.4(4.6,10.3)$ & 252 & 262 & 100 & 2 & De Boer and Brookins (1972) \\
\hline 35 & $\begin{array}{l}\text { H. W-P. Sill and H. } \\
\text { Dyke }\end{array}$ & I & 47 & 357.7 & 54.9 & 188.7 & 4.2 & -2.1 & $8.6(7,10.3)$ & 292 & 297 & 100 & 4 & Liss et al. (2004) \\
\hline 36 & $\begin{array}{l}\text { Cinto Volcanic } \\
\text { Complex }\end{array}$ & $\mathrm{E}$ & 5 & 8.5 & 42.5 & 165.4 & 4.0 & -2.0 & $9.6(4.1,13.5)$ & 251 & 299 & 100 & 2 & Westphal et al. (1976) \\
\hline 37 & $\begin{array}{l}\text { Rotliegendes S. } \\
\text { (Thuringer F. }\end{array}$ & $\mathrm{E}$ & 9 & 10.9 & 50.7 & 194.1 & 1.4 & -0.7 & $14.1(8,19.8)$ & 271 & 299 & 100 & 3 & Mauritsch and Rother (1983) \\
\hline 38 & $\begin{array}{l}\text { Volcanic rocks of } \\
\text { Moissey }\end{array}$ & $\mathrm{E}$ & 7 & 5.6 & 47.3 & 189.8 & 1.4 & -0.7 & $6.2(3.9,8)$ & 276 & 284 & 100 & 4 & Thompson et al. (1986) \\
\hline 39 & Sardinia Dykes & I & 11 & 9.3 & 41.1 & 132.7 & -1.7 & 0.8 & $9.2(5.8,11.9)$ & 251 & 299 & 100 & 4 & Vigliotti et al. (1990) \\
\hline 40 & $\begin{array}{l}\text { NW Sardinia } \\
\text { Ignimbrites }\end{array}$ & $\mathrm{E}$ & 6 & 9 & 41 & 142.3 & -1.8 & 0.9 & $10.3(4.4,14.6)$ & 251 & 299 & 100 & 3 & Zijderveld et al. (1970) \\
\hline 41 & $\begin{array}{c}\text { Holy Island Sill and } \\
\text { Dyke }\end{array}$ & I & 20 & 358.2 & 55.6 & 185.1 & -2.1 & 1.0 & $7.1(4.5,9.2)$ & 292 & 297 & 100 & 4 & Liss et al. (2004) \\
\hline 42 & Pyrenees Andesites & $\mathrm{E}$ & 10 & 1.5 & 42 & 169.4 & -3.0 & 1.5 & $8.9(5.1,12)$ & 271 & 299 & 100 & 3 & Van Dongen (1967) \\
\hline $43^{*}$ & Argyll Dykes & I & 15 & 354.7 & 56.9 & 180.3 & -4.0 & 2.0 & $6.1(3.6,8.1)$ & 316 & 324 & 100 & 3 & Esang and Piper (1984) \\
\hline 44 & $\begin{array}{l}\text { Dykes of Sardinia (C- } \\
\text { E }\end{array}$ & I & 6 & 9.6 & 39.9 & 92.0 & -4.8 & 2.4 & $10.1(4.6,13.6)$ & 289 & 298 & 100 & 4 & Aubele et al. (2014) \\
\hline 45 & $\begin{array}{l}\text { Lower Silesia } \\
\text { Volcanics }\end{array}$ & $\mathrm{E}$ & 12 & 15.5 & 51 & 197.3 & -5.8 & 2.9 & $13.3(9.2,16.7)$ & 271 & 299 & 100 & 2 & Birkenmajer et al. (1968) \\
\hline 46 & SE Sardinia & $\mathrm{E}$ & 27 & 9.5 & 39.8 & 85.2 & -7.7 & 3.9 & $12.7(10.1,15.1)$ & 304 & 312 & 100 & 3 & Edel et al. (1981) \\
\hline 47 & Bolzano Volcanics & $\mathrm{E}$ & 25 & 11 & 47 & 163.8 & -11.8 & 6.0 & $15(11.9,18.2)$ & 271 & 299 & 100 & 2 & Dietzel (1960) \\
\hline 48 & Corsica Dykes & I & 11 & 9 & 41.6 & 134.7 & -12.0 & 6.1 & $8.3(4.4,11.8)$ & 251 & 299 & 100 & 4 & Vigliotti et al. (1990) \\
\hline
\end{tabular}




\begin{tabular}{|c|c|c|c|c|c|c|c|c|c|c|c|c|}
\hline 49 & Bohemian Massif & I & 8 & 12.1 & 49.6 & 200.0 & -12.2 & 6.2 & $9.1(6.3,11.6)$ & 275 & 280 & 100 \\
\hline 50 & $\begin{array}{l}\text { Lower Silesia } \\
\text { Volcanics }\end{array}$ & $\mathrm{I} / \mathrm{E}$ & 8 & 16.5 & 50.5 & 195.4 & -12.9 & 6.5 & $13.4(7.7,18.4)$ & 299 & 307 & 100 \\
\hline $51 *$ & Southern Illinois & I & 6 & 271.6 & 37.5 & 163.1 & -14.9 & 7.6 & $4.3(3,5.1)$ & 260 & 270 & 100 \\
\hline 52 & Black Forest & I & 18 & 8 & 48 & 189.9 & -15.3 & 7.8 & $9.6(6.6,11.9)$ & 271 & 299 & 100 \\
\hline 53 & Scania Dolerites & I & 13 & 13.6 & 55.8 & 199.5 & -15.3 & 7.8 & $10.4(7.5,13.5)$ & 250 & 350 & 100 \\
\hline 54 & $\begin{array}{c}\text { Western Southern } \\
\text { Alps }\end{array}$ & E & 13 & 9.3 & 45.8 & 139.1 & -16.3 & 8.3 & $8(5.8,10.1)$ & 271 & 299 & 100 \\
\hline 55 & Krakow Volcanics & E & 11 & 20 & 50 & 205.2 & -16.9 & 8.6 & - & 271 & 299 & 100 \\
\hline $56^{*}$ & Ny-Hellesund Dykes & I & 10 & 7.8 & 58 & 201.3 & -18.4 & 9.5 & $2.3(0.6,3.9)$ & 272 & 284 & 100 \\
\hline 57 & Exeter Lavas & $\mathrm{E}$ & 7 & 356 & 51 & 193.7 & -19.6 & 10.1 & $7(4.6,8.7)$ & 279 & 291 & 100 \\
\hline 58 & $\begin{array}{c}\text { Lower Collio and } \\
\text { Auccia }\end{array}$ & $\mathrm{E}$ & 5 & 10.2 & 45.8 & 135.6 & -21.8 & 11.3 & $21.3(9.1,31)$ & 271 & 299 & 100 \\
\hline 59 & Ukrainian Shield & I & 19 & 37.9 & 47.4 & 204.4 & -24.5 & 12.8 & $12.6(10.4,14.7)$ & 280 & 285.2 & 100 \\
\hline 60 & $\begin{array}{l}\text { Sakmarian stage } \\
\text { Aksaut River }\end{array}$ & E & 41 & 41 & 43 & 235.3 & -25.1 & 13.2 & $11.9(10.3,13.5)$ & 284 & 295 & 100 \\
\hline $61 *$ & Exeter Lavas & $\mathrm{E}$ & 5 & 356 & 51 & 197.4 & -25.2 & 13.2 & $5.2(2.7,6.8)$ & 281 & 291 & 100 \\
\hline 62 & $\begin{array}{l}\text { Southern Alps } \\
\text { Volcanics }\end{array}$ & E & 7 & 10.5 & 46.2 & 151.4 & -25.9 & 13.6 & $8.5(6.5,10.3)$ & 276 & 284 & 100 \\
\hline 63 & $\begin{array}{l}\text { A. Sill, H. G., St. O. } \\
\text { C. Dyke }\end{array}$ & I & 17 & 358.3 & 55.4 & 198.9 & -26.3 & 13.9 & $11(5.1,15.4)$ & 292 & 297 & 100 \\
\hline 64 & Northern Caucasus & E & 22 & 42 & 43 & 249.2 & -26.5 & 14.0 & $7.9(5.8,10)$ & 270.6 & 299 & 100 \\
\hline 65 & Mauchline Lavas & $\mathrm{E}$ & 5 & 355.4 & 55.5 & 192.4 & -26.7 & 14.1 & $10.3(2.8,14.7)$ & 290 & 305 & 100 \\
\hline 66 & Barra Dykes & I & 9 & 352.5 & 57 & 183.8 & -27.0 & 14.3 & $13.3(8.7,17.5)$ & 251 & 299 & 100 \\
\hline 67 & $\begin{array}{l}\text { Oslo Graben - } \\
\text { Vestfold }\end{array}$ & E & 49 & 10.3 & 59.5 & 201.0 & -36.2 & 20.1 & $9.3(7.7,10.7)$ & 284 & 300 & 100 \\
\hline 68 & Bohuslan Dykes & I & 16 & 11.3 & 58.6 & 194.6 & -37.8 & 21.2 & $14.2(9.5,18.5)$ & 271 & 299 & 100 \\
\hline 69 & Scania melaphyres & I & 8 & 13.7 & 55.7 & 192.1 & -39.2 & 22.2 & $14.1(10.1,17.8)$ & 250 & 285 & 100 \\
\hline 70 & Lunner dykes & I & 25 & 10.5 & 60.3 & 196.8 & -40.1 & 22.8 & $7.5(4.7,10.1)$ & 268.3 & 273.7 & 100 \\
\hline 71 & $\begin{array}{l}\text { Oslo Graben - } \\
\text { Krokskogen }\end{array}$ & $\mathrm{E}$ & 55 & 10.4 & 60 & 208.1 & -40.4 & 23.0 & $9.8(8.3,11.3)$ & 276 & 292 & 100 \\
\hline $72 *$ & Bakalin Formation (B & $\mathrm{E}$ & 8 & 80.7 & 47.5 & 237.0 & -48.1 & 29.2 & $3.8(1.7,5.6)$ & 251 & 260 & 100 \\
\hline 73 & $\begin{array}{l}\text { Harlegiawu and } \\
\text { Karlagang }\end{array}$ & $\mathrm{E}$ & 14 & 86.1 & 46.7 & 166.9 & -48.8 & 29.7 & $12.7(7.7,16.4)$ & 271 & 318 & 100 \\
\hline
\end{tabular}

Soffel and Harzer (1991)

Birkenmajer et al. (1968)

Domeier et al. (2011a)

Konrad and Nairn (1972)

Bylund (1974)

Heiniger (1979)

Birkenmajer and Nairn (1964)

Halvorsen (1970)

Cornwell (1967)

Zijderveld and De Jong (1969)

Yuan et al. (2011)

Solodovnikov (1992a)

Zijderveld (1967)

Muttoni et al. (2003)

Liss et al. (2004)

Bolshakov et al. (1989)

Harcombe-Smee et al. (1996)

Piper (1992)

Haldan et al. (2014)

Thorning and Abrahamsen (1980)

Bylund (1974)

Dominguez et al. (2011)

Haldan et al. (2014)

Levashova et al. (2003)

Li et al. (1991) 


\begin{tabular}{|c|c|c|c|c|c|c|c|c|c|c|c|c|c|c|}
\hline 74 & $\begin{array}{l}\text { Biyoulitie Super } \\
\text { Formation }\end{array}$ & $\mathrm{E}$ & 21 & 79.7 & 40.7 & 222.5 & -49.9 & 30.7 & $9.6(7.4,11.8)$ & 271 & 299 & 100 & 4 & Sharps et al. (1989) \\
\hline 75 & Northern Tien Shan & $\mathrm{E}$ & 7 & 75.5 & 42.5 & 210.2 & -50.1 & 30.9 & $10.1(4.4,14)$ & 251 & 299 & 100 & 3 & Audibert and Bazhenov (1992) \\
\hline 76 & Bakalin Formation (A & $\mathrm{E}$ & 8 & 80 & 47.8 & 265.0 & -50.6 & 31.3 & $8(4.8,10.7)$ & 251 & 260 & 100 & 4 & Levashova et al. (2003) \\
\hline 77 & $\begin{array}{l}\text { Tarim large igneous } \\
\text { province }\end{array}$ & $\mathrm{E}$ & 11 & 79.7 & 40.8 & 221.7 & -51.0 & 31.7 & $13.2(7.9,18)$ & 284.8 & 291 & 100 & 5 & Usui and Tian (2017) \\
\hline 78 & Maitas Formation & $\mathrm{E}$ & 19 & 75 & 48 & 219.3 & -51.3 & 31.9 & $9(5.5,11.6)$ & 251 & 275 & 100 & 4 & Abrajevitch et al. (2008) \\
\hline 79 & Koldar Formation & $\mathrm{E}$ & 15 & 80 & 48 & 285.4 & -51.5 & 32.2 & $12.3(9.1,15)$ & 275 & 305 & 100 & 4 & Abrajevitch et al. (2008) \\
\hline 80 & Molaoba Formation & $\mathrm{E}$ & 12 & 83.1 & 46.1 & 198.0 & -52.3 & 32.9 & $9.7(7.3,12.1)$ & 299.3 & 308.7 & 100 & 4 & Yi et al. (2015) \\
\hline 81 & $\begin{array}{l}\text { Uzbekistan Igneous } \\
\text { rocks }\end{array}$ & $\mathrm{E}$ & 26 & 70 & 41 & 92.5 & -52.4 & 33.0 & $10.8(8.1,13.3)$ & 299 & 318 & 100 & 3 & Solodovnikov (1992b) \\
\hline 82 & Ayaguz Formation & $\mathrm{E}$ & 32 & 80.7 & 47.5 & 249.1 & -53.8 & 34.4 & $13.5(10.4,16.2)$ & 280.7 & 285.3 & 100 & 4 & Menzo (2013) \\
\hline 83 & Bakaly & $\mathrm{E}$ & 88 & 80.7 & 47.5 & 241.8 & -56.5 & 37.0 & $9.9(8.6,11.2)$ & 282.8 & 289.9 & 100 & 4 & Bazhenov et al. (2016) \\
\hline 84 & Junggar Dykes & I & 23 & 83.5 & 45.6 & 186.6 & -56.8 & 37.4 & $19.9(17.1,22.6)$ & 271 & 318 & 100 & 4 & Li et al. (1989) \\
\hline 85 & Liushugou Dykes & I & 7 & 87.8 & 43.8 & 226.0 & -56.8 & 37.4 & $18.5(8.4,26)$ & 271 & 318 & 100 & 4 & Li et al. (1991) \\
\hline 86 & Hoboksar & $\mathrm{E}$ & 16 & 86.6 & 47.2 & 153.7 & -59.5 & 40.3 & $19.8(14.4,24.3)$ & 271 & 318 & 100 & 4 & Li et al. (1991) \\
\hline 87 & Esayoo Formation & $\mathrm{E}$ & 12 & 277.8 & 81.1 & 125.6 & -61.6 & 42.8 & $11.1(7.2,14.3)$ & 271 & 299 & 92 & 3 & Wynne et al. (1983) \\
\hline 88 & $\begin{array}{l}\text { Angara-Vitim } \\
\text { batholith }\end{array}$ & I & 8 & 114.9 & 57.9 & 331.6 & -79.7 & 70.0 & - & 296.1 & 305.9 & 100 & 4 & Shatsillo et al. (2014) \\
\hline 89 & $\begin{array}{c}\text { Mafic dykes - Siberian } \\
\text { Craton }\end{array}$ & I & 5 & 104.1 & 51.8 & 269.4 & -84.5 & 79.1 & $11.7(1.1,19)$ & 271 & 279 & 100 & 5 & Pisarevsky et al. (2006) \\
\hline
\end{tabular}




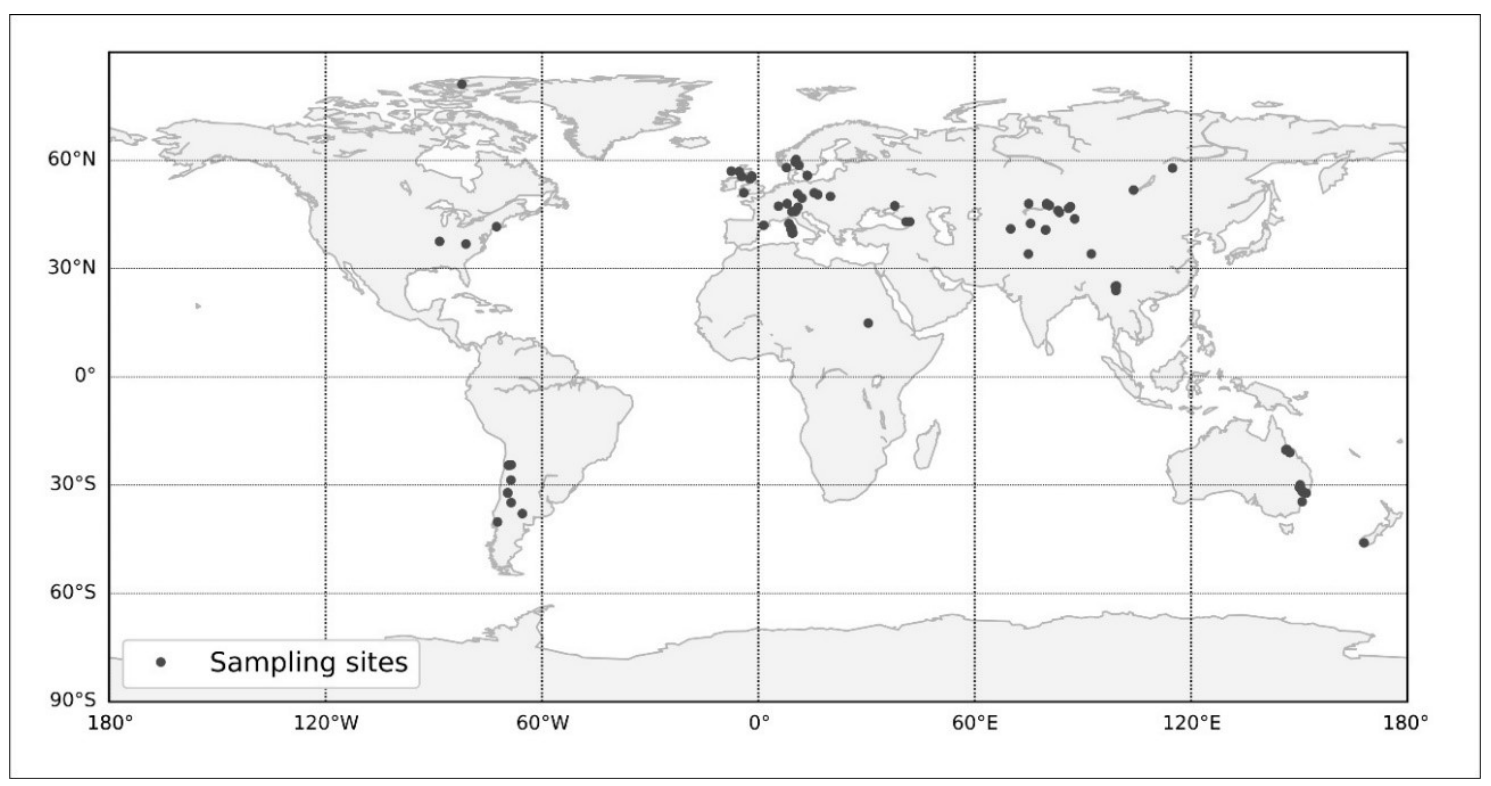

Figure 5.2. Distribution of the paleomagnetic sampling sites selected for the Kiaman database.

As outlined in Section 5.3.1 (criterion 8), the highest and lowest Fisher precision $K$ parameters (Fisher, 1953) were evaluated for latitude bands with more than 50 VGPs, and values for the Kiaman are $K_{\max }=64$ and $K_{\min }=14$. These are both higher than the results given by Deenen et al. (2011) for all ages, and thus produce smaller upper and lower bounds for $A_{95}$ (blue curves on Figure 5.3a). The new $A_{95}$ envelope found (light blue area delimited by blue curves, Figure 5.3a), excludes only 7 datasets ( 74 directions), 5 with limited PSV sampling, and 2 with potentially large scatter from non-PSV sources. These datasets are indicated with asterisks in Table 5.1. The resulting number of directions is reduced from 1419 to 1345 corresponding to $\sim 95 \%$ of the total. Figure $5.3 \mathrm{~b}$ shows the numbers of data remaining as a function of latitude (blue columns) and the filtered data set is given in Table S5.3. As the distribution of $A_{95}$ is more concentrated towards the lower limit, the use of the limits defined by Deenen et al. (2011) instead of ours would mainly exclude datasets with lower $A_{95}$ and larger number of sites (13 datasets or 245 directions). 


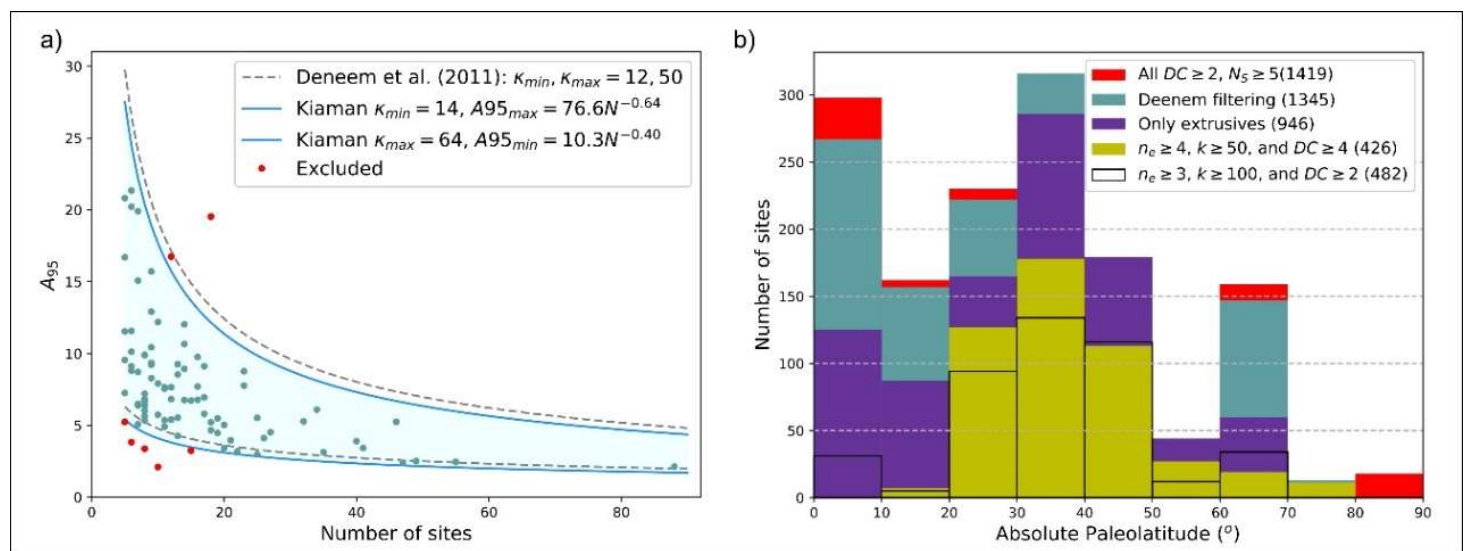

Figure 5.3 a) Filtering the dataset by using the paleomagnetic pole confidence angle $A_{95}$ limits criteria (Deenen et al., 2011). Dashed lines are the $A_{95}$ limits from Deenen et al. (2011) and the blue curves are the limits defined for the Kiaman database. b) Histogram of the paleomagnetic sites per bands of $10^{\circ}$ in latitude and color discrimination of the filtering process. The yellow and empty columns overlap each other in different sizes, see the black like for the limits for empty bars $\left(n_{e}>3\right.$ and $\left.k>100\right)$.

If we consider that extrusive rocks are the best rock type for getting an instantaneous record of the geomagnetic field, as commonly used for PSV studies (e.g., McElhinny and McFadden, 1997), the total number of spot readings is cut to $946(\sim 67 \%$ of the whole database, purple columns in Figure 5.3b), and the range of well-sampled latitudes is reduced from $0-70^{\circ}$ to $0-50^{\circ}$.

Two other filtering procedures can be applied to the Kiaman database: 1) the removal of directions based on less than three specimens and with statistical precision $k$ (Fisher, 1953) less than 100, as implemented by Tauxe and Kent (2004) for the 0-5 Ma lava data; 2) the removal of datasets with DC $<4$ (McElhinny and Lock, 1996), and directions with $n_{e}<4$ and $k<50$, used by Cromwell et al. (2018) for the last 10 Ma lava data. The results after these two filtering processes are shown as empty and yellow bars, respectively, in Figure 5.3b. They resulted in a significant data cut-off leaving only the three consecutive bands of latitudes from $20-50^{\circ}$ with sufficient numbers of directions (approximately 100) for a credible analysis, and representing only a $30^{\circ}$ slice of the hemisphere. Because of the limited size of the Kiaman database, which is much smaller than for 0-10 Ma (Cromwell et al., 2018), we decided to maintain our initial flexible filtering but consider results from the extrusive and intrusive rock data separately for the purpose of comparison. We also evaluate the effects of further imposing the more stringent criteria described here. 


\subsection{VGP scatter and Model G-type results}

The VGP scatter $S_{F}$ associated with the paleosecular variation of the geomagnetic field was determined for each dataset. Data from northern and southern hemispheres are combined. Inter-hemispherical comparisons are not possible as the sampled paleolatitude intervals are not the same for both hemispheres, precluding investigation of any asymmetric behavior of the field. $S_{F}$ values follow a general trend of increasing dispersion with paleolatitude (Figure 5.4), and there appears to be less scatter in the signal across datasets at low paleolatitudes than for medium latitudes. When plotted alone, the extrusive datasets (purple symbols) retain the same dispersion pattern as for the whole database (igneous) that includes the intrusive rocks.

The shape parameters ( $a$ and $b$ ) from model G (McFadden et al., 1988) were calculated for the whole database and for various filtered subsets (Figure 5.4 and Table 5.2). Inserting intrusive records into the analysis does not influence the results significantly, but it is worth considering that the whole dataset includes fewer intrusive than extrusive records; they are also unequally distributed across the latitude bands. It is not evident that the intrusive datasets produce less scatter than the extrusives as might be anticipated from slower cooling; maybe this is a characteristic of the KRS. However, to avoid any possible bias due to the intrusive records we will proceed with analyses using only extrusive records.

Applying cutoffs to the number of sites per study ( $N_{S} \geq 10$ and $N_{S} \geq 20$ ) produces similar results as using only extrusive with lower cutoff $\left(N_{S} \geq 5\right)$. The confidence region based on bootstrap sampling becomes smaller as the $N_{S}$ increases. However, the smaller confidence region could only be a consequence of the reduced available dataset and does not mean an actual improvement of the data selection. The greatest changes in the shape parameters occur when applying a filter based on intra-site statistics (modern filters following Tauxe \& Kent, 2004; and Cromwell et al., 2018), where the equatorial VGP dispersion $a$ values are the lowest, and the latitudinally dependent $b$ values are the highest. 
Table 5.2. Results of shape parameters for Kiaman databases using different filtering processes.

\begin{tabular}{|c|c|c|c|c|c|c|}
\hline Kiaman database filtering & $\mathrm{N}_{\mathrm{d}}$ & $\mathrm{N}_{\mathrm{s}}$ & $\mathrm{N}_{\mathrm{sv}}$ & $a$ & $\boldsymbol{b}$ & Reference \\
\hline All igneous & 82 & 1345 & 1327 & $10.5_{7.1}^{13.5}$ & $0.21_{0.12}^{0.27}$ & This study \\
\hline Only extrusives & 57 & 946 & 938 & $10.7_{7.3}^{13.6}$ & $0.20_{0.12}^{0.26}$ & This study \\
\hline Only extrusives $\left(N_{S} \geq 10\right)$ & 35 & 785 & 778 & $11.2_{8.5}^{13.8}$ & $0.19_{0.13}^{0.25}$ & This study \\
\hline Only extrusives $\left(N_{S} \geq 20\right)$ & 13 & 484 & 478 & $10.0_{8.2}^{11.8}$ & $0.19_{0.13}^{0.24}$ & This study \\
\hline Only extrusives $\left(N_{S} \geq 5, n_{e} \geq 3, k \geq 100, D C \geq 2\right)$ & 37 & 426 & 424 & $9.1_{6.3}^{11.7}$ & $0.26_{0.18}^{0.33}$ & This study \\
\hline Only extrusives $\left(N_{S} \geq 5, n_{e} \geq 4, k \geq 50, D C \geq 4\right)$ & 31 & 482 & 479 & $8.5_{6.6}^{10.3}$ & $0.29_{0.19}^{0.37}$ & This study \\
\hline Igneous rocks $\left(N_{S} \geq 10, D C \geq 4\right)$ & 9 & 336 & 331 & $9.4_{7.5}^{10.9}$ & $0.27_{0.22}^{0.29}$ & (Oliveira et al., 2018) \\
\hline
\end{tabular}
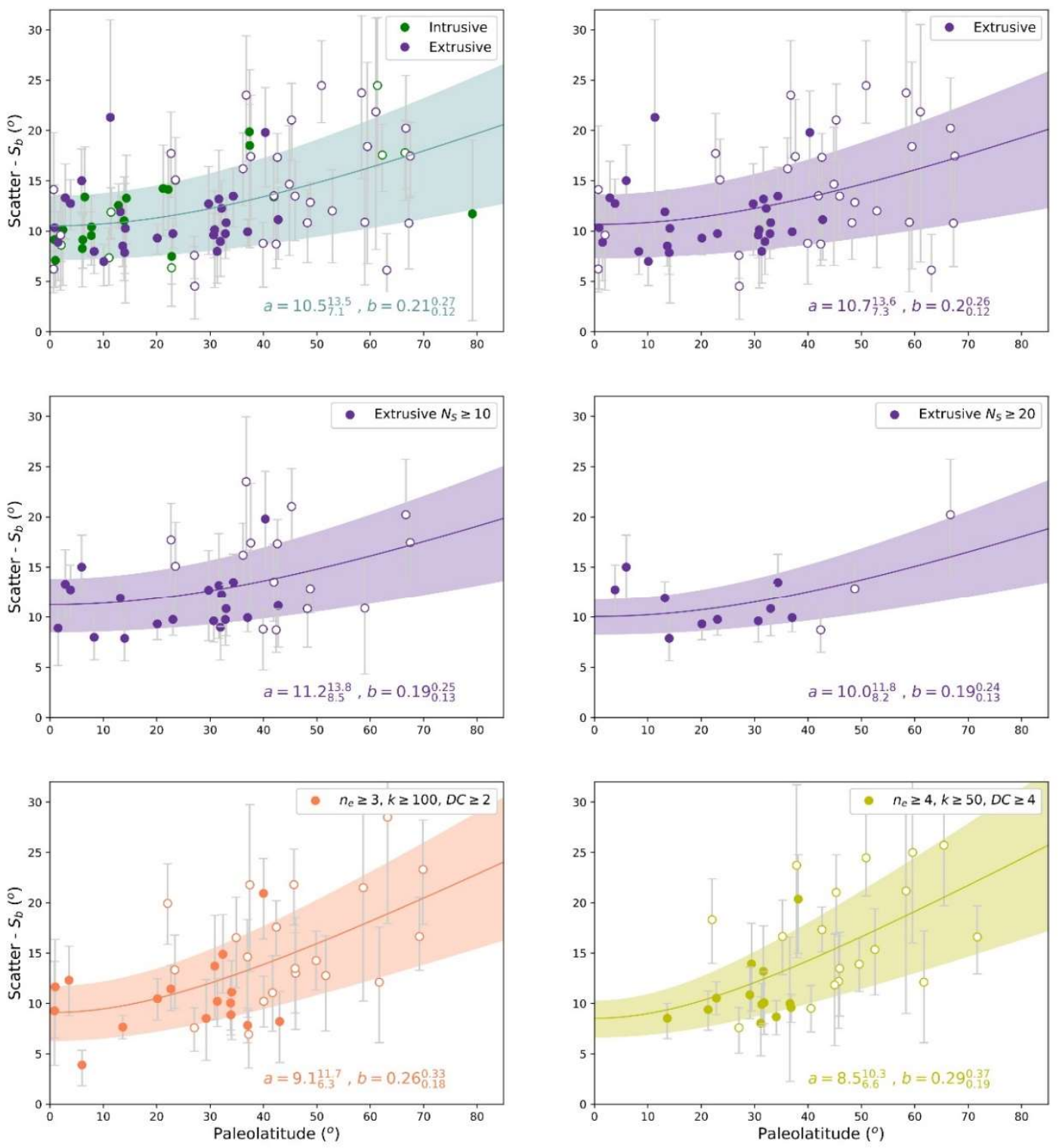

- Southern hemisphere

- Northern hemisphere

Figure 5.4. VGP scatter results per dataset. Closed (open) symbols are northern (southern) hemisphere data. Green: intrusive; purple: extrusive; coral: extrusive database filtered using $n_{e} \geq 3, k \geq 100, D C \geq 2$ (as Tauxe and Kent, 2004); and yellow: extrusive filtered using $n_{e} \geq 4, k \geq 50, D C \geq 4 ; a$ and $b$ are the fitted shape parameters from model $\mathrm{G}$. 


\subsection{Shape and scale of directional PSV during Kiaman times}

In contrast to the VGP scatter results, which were determined for each dataset, the directional PSV results are related to directions grouped using the latitude bands as described in section 2.2. This procedure was adopted considering that all igneous units within a given latitude band should have sampled the same overall behavior of the geomagnetic field during the Kiaman superchron.

Figure 5.5 shows the stereograms of directions rotated with the expected direction at the origin for eight latitude bands from 0 to $70^{\circ}$, with data from the southern (blue) and northern (green) hemispheres merged. The majority of the data from latitudes 0 to $40^{\circ}$ comes from the northern hemisphere, while those for the bands 40 to $70^{\circ}$ data are essentially from the southern hemisphere. The most elongated distribution is the equatorial (paleolatitude from 0 to $10^{\circ}$ ), and the few southern directions belonging to this group seem to follow the same tendency. For the other latitude bins in both hemispheres, distributions seem to display a more circular shape. 


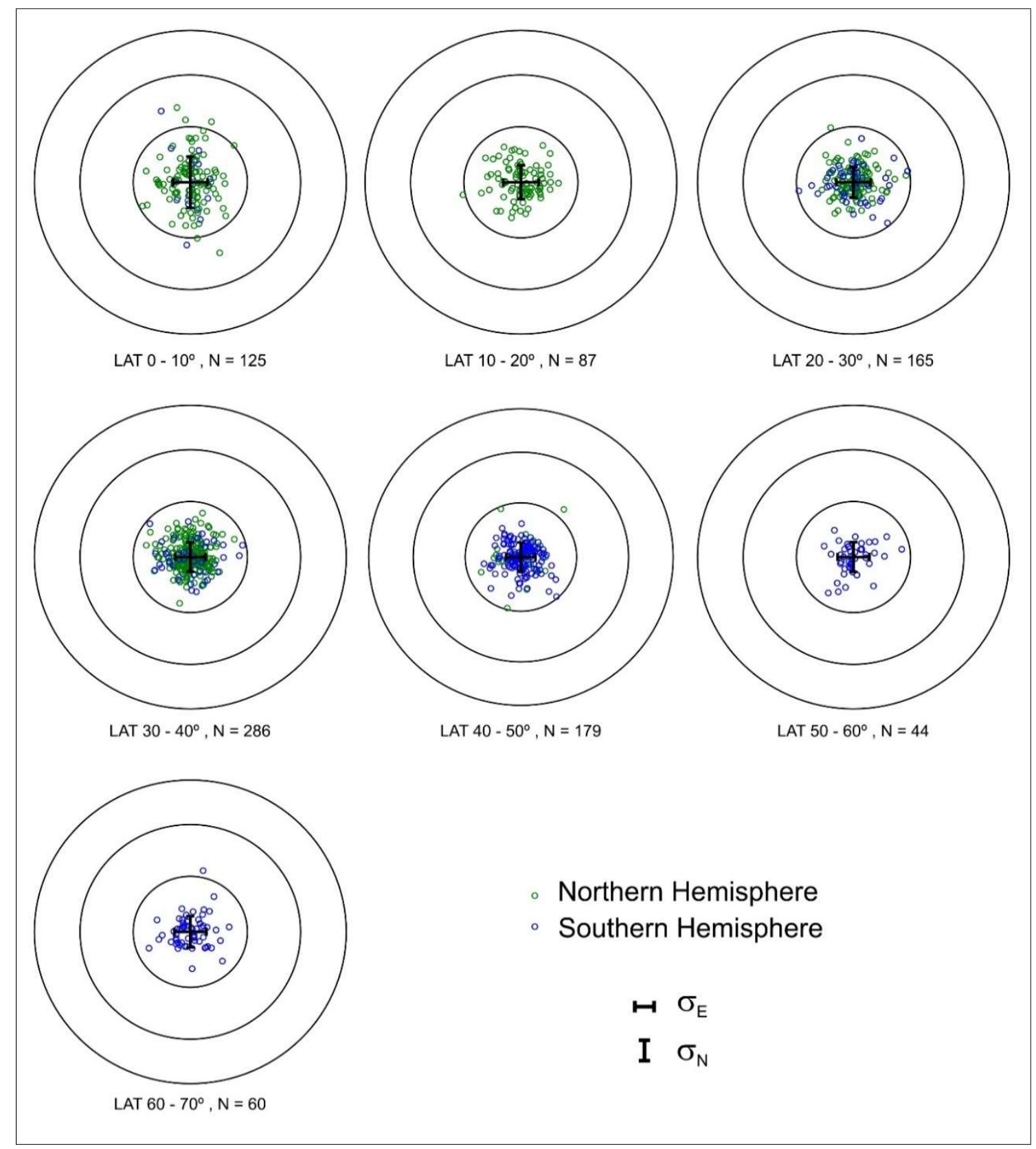

Figure 5.5. The paleomagnetic Kiaman database considering only extrusive rocks; blue (green) is related to southern (northern) hemisphere data. Circles are directions rotated with the expected direction from each dataset at the origin $\left(\mathrm{dec}=0^{\circ}, \mathrm{inc}=90^{\circ}\right)$. From the left top to bottom are bands of paleolatitudes from 0 to $70^{\circ}$. The black lines show the $\sigma_{E}$ and $\sigma_{N}$ standard deviations determined for each band.

The directional shape statistics for the Kiaman database are shown in Figure 5.6a. For comparison, the figure also shows the predicted values of $\sigma_{E}, \sigma_{N}, E^{\prime}$, and $A_{\text {dir }}$ determined for TK03 and the recent BCE19 model (Brandt et al., 2019b).

The Kiaman results show consistently lower overall variability $A_{\text {dir }}$ than the TK03 and BCE19 models at all latitudes. Values for $\sigma_{N}$ totally disagree with the TK03 prediction and the values are consistently lower, and $\sigma_{E}$ is also lower and incompatible 
with the TK03 prediction in almost all latitude bands. The more recent GGP model BCE19 has lower values of $\sigma_{E}, \sigma_{N}$, and $A_{d i r}$ than TK03, but the only latitude band from the Kiaman results that agree with the more recent field is the equatorial band. If the TK03 model is taken as a reference for the last few million years, the same cannot be said in relation to the Kiaman time interval. Likewise, BCE19 does a poor job overall of describing the Kiaman data.
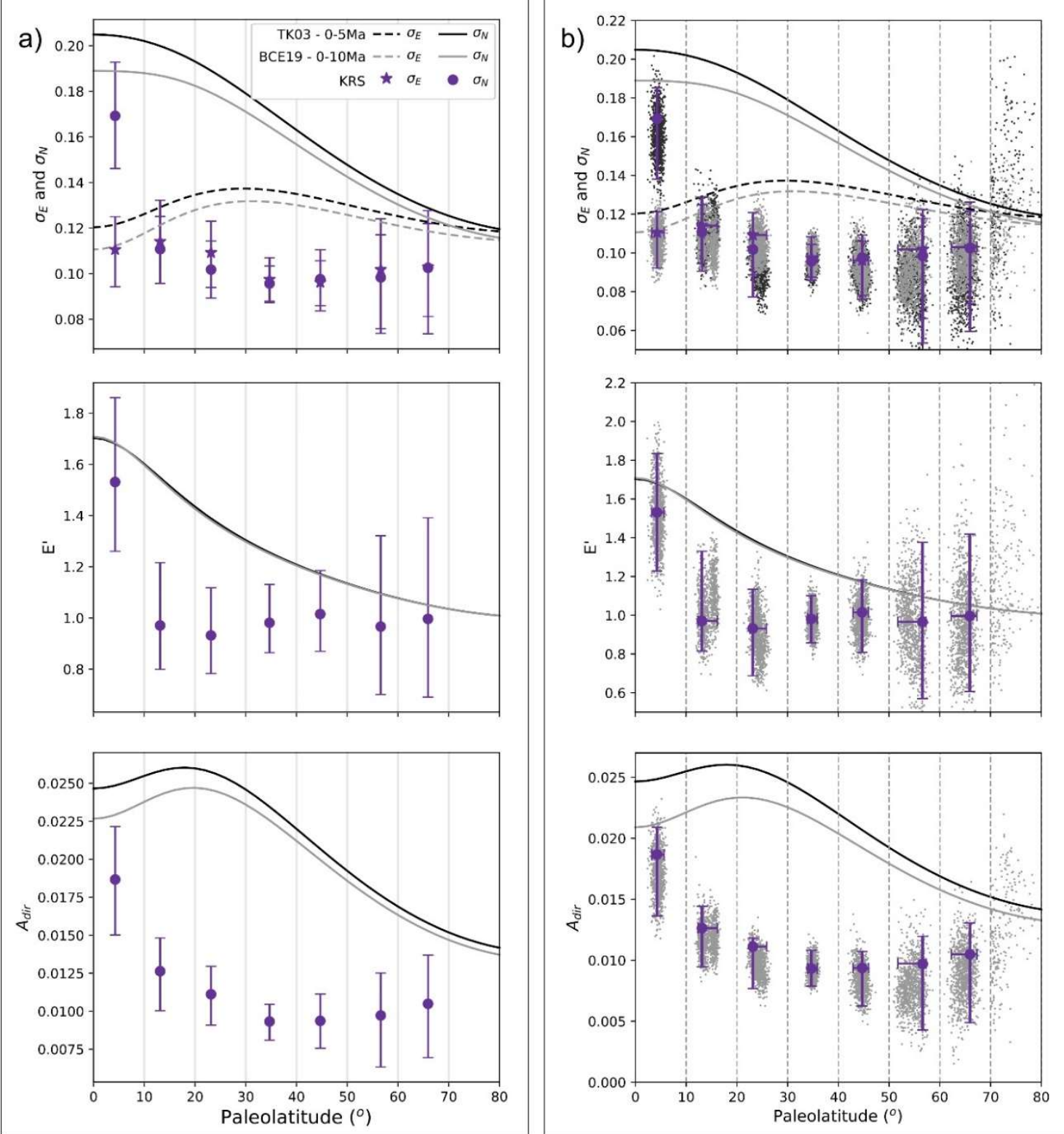

Figure 5.6. a) Directional PSV results using $10^{\circ}$ bands of paleolatitude from Kiaman reverse superchron (KRS) database; $\sigma_{E}$ and $\sigma_{N}$ are the standard deviation for the $x_{E}$ and $x_{N}$ equal-area coordinates from rotated distributions; $E^{\prime}=\sigma_{N} / \sigma_{E}$ is the distribution elongation in the N-S direction, and $A_{d i r}=\sigma_{E} \sigma_{N}$ is the overall variability of the distributions. Black (grey) curves are the predicted values of $\sigma_{E}, \sigma_{N}, E^{\prime}$, and $A_{\text {dir }}$ by the TK03 (BCE19) GGP models. b) black $\left(\sigma_{N}\right)$ and light grey $\left(\sigma_{E}, E^{\prime}, A_{\text {dir }}\right)$ dots correspond to 1,000 results from the bootstrap random re-sampling of the data distribution. Colored bars show resulting $95 \%$ confidence intervals. 


\subsubsection{Reliability of PSV directional results}

The results presented in the last section reveal distinct properties of the geomagnetic field during the Kiaman. The shape and dispersion of the direction distributions all over the globe are quite different from those observed for the past 10 million years (Brandt et al., 2019b), which are basically compatible with the models TK03 and BCE19. It is important to assess the reliability of the results in the older Kiaman context. In contrast to the PSV10 (Cromwell et al., 2018), the Kiaman results are based on the direction distributions of the paleo-reconstructed datasets as described in Section 3. Ill-determined declinations (paleo-meridians) may contribute to a circular distribution of the merged directional data, and inaccurate determination of the expected inclinations may cause the dataset to fall into an incorrect paleolatitude band. These particular sources of error are absent from the PSV10 results. Moreover, the filtering applied to the Kiaman database is less rigorous than the criteria used for PSV10. Thus, it is worth testing whether the results obtained for the Kiaman superchron arise from the way the dataset was constructed.

In this section, we introduce some further filtering and a re-sampling procedure to test the consistency of the results we obtained. We applied two more stringent cutoff limits based on the number of sites $\left(N_{S} \geq 10\right.$ and $\left.N_{S} \geq 20\right)$, and filtering procedures for within-site statistics (Cromwell et al., 2018; Tauxe and Kent, 2004). The results are in Figures 5.6b, and 7. Each dataset was randomly re-sampled by the bootstrap method 1,000 times to test the impact of uncertainty in paleolatitude determinations, and consequently the corresponding assignment to latitude bands. The re-sampling may displace a dataset from one initial band to a neighboring band. Each re-sampling run produced the same number of data as the original data, that is, 946 extrusive directions distributed in seven latitude bands (Figure 5.6b), represented by the small symbols in the figure, along with the bars delimiting the $95 \%$ confidence limits of the resampled distribution.

The resampling process broadened the paleolatitude intervals for each latitude band. However, even with this variation in paleolatitude intervals determinations, the procedure did not reveal any different behavior for the Kiaman results, from that previously observed. PSV results from the Kiaman data maintain the low standard deviations in the N-S direction $\left(\sigma_{N}\right)$, with the elongation of the distributions close to 1 and the overall 
variability smaller than predicted by the models for recent data for latitudes higher than $10^{\circ}$.

Filtering of the datasets to $N_{S} \geq 10$ reduced the total number of directions by $15 \%$, while the condition of $N_{S} \geq 20$ removed $48 \%$ (Figure $5.7 \mathrm{a}$ ). The use of the filters based on intra-site statistics, $D C \geq 4$ with $n_{e} \geq 4$ and $k \geq 50$ and $n_{e} \geq 3$ and $k \geq 100$ (yellow and orange symbols, respectively, in Figure 5.7b) drastically reduced the number of data (Tables S5.5 and S5.6).

Results for bands that are now poorly populated have lost precision, as indicated by the wider confidence bars. Here again, the standard deviation in N-S direction $\left(\sigma_{N}\right)$ is smaller than, and incompatible with, the prediction of models TK03 and BCE19. The elongation is still nearly 1 , and the overall variability diverges from the recent models for latitudes higher than $10^{\circ}$. Considering that a larger number of sites in any given study may imply a better determination of paleolatitudes and paleo-meridians, we might expect that filtering out sites with a low number of observations would result in better estimates for the N-S and E-W distributions. However, Figure 5.7 shows that the main characteristics of the PSV previously reported for the Kiaman database are preserved, with no overall improvement in fit to TK03 or BCE19. The use of the most restrictive filters produces wider confidence limits, due to the depleted number of data, but the results are essentially the same. Note that when we applied the filter from Cromwell et al. (2018) all data from the 0 to $20^{\circ}$ bands were rejected preventing evaluation of whether the more dispersed and elongated PSV distributions at equatorial latitudes can be confirmed for high-quality data. 

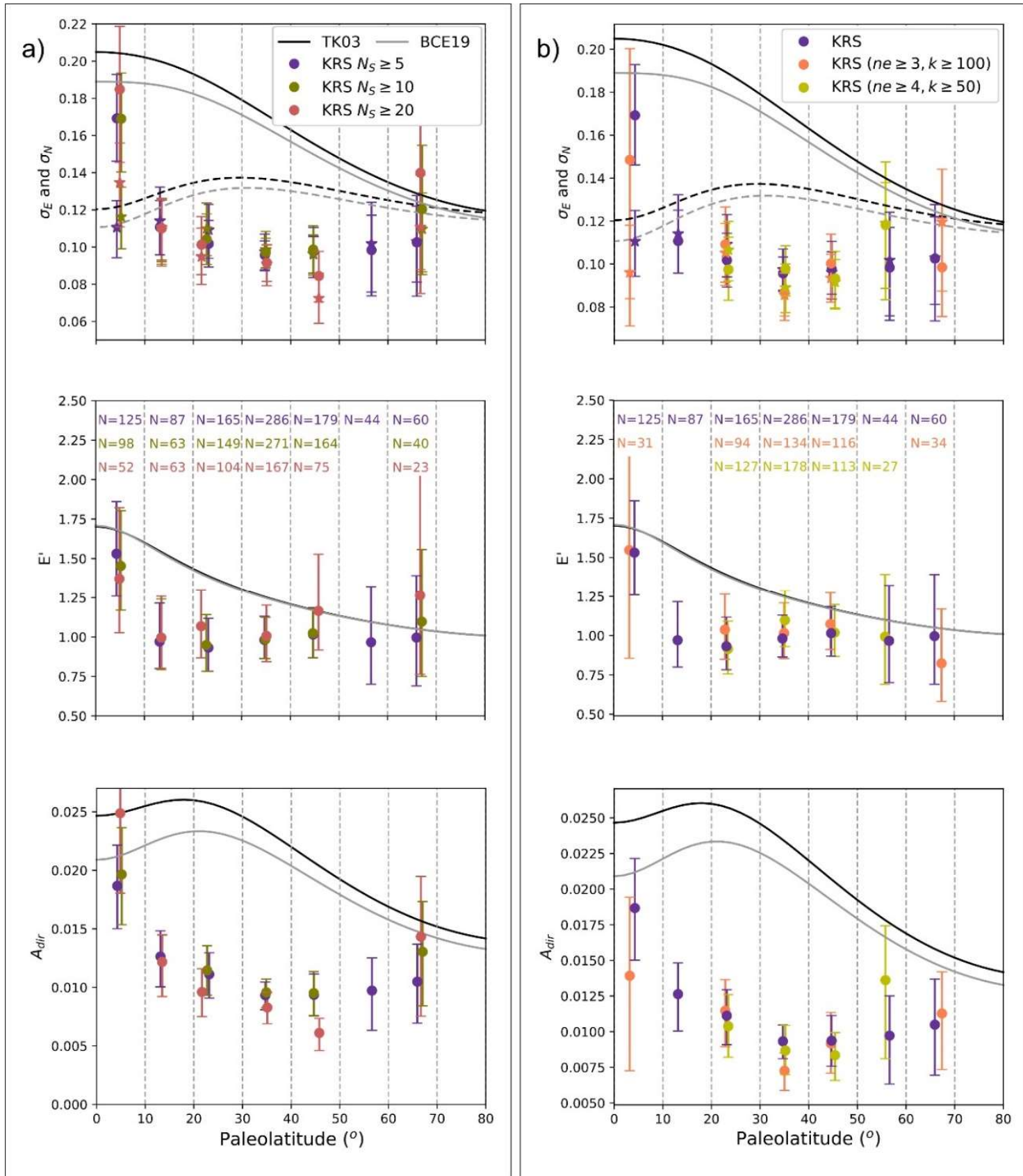

Figure 5.7. Directional paleosecular variation results using $10^{\circ}$ of absolute paleolatitude of the KRS database (extrusive rocks only). Black and grey curves are the prediction from TK03 and BCE19 GGP models, of the standard deviation in $x_{E}$ and $x_{N}$ directions from equal-area projections of rotated distributions of directions $\left(\sigma_{E}, \sigma_{N}\right)$, elongation $E^{\prime}=\sigma_{N} / \sigma_{E}$, and overall variability $\left.A_{d i r}=\sigma_{E} \sigma_{N}\right)$. Stars are $\sigma_{E}$, and circles are $\sigma_{E}$. Left: other cutoff limits of the number of sites: $N_{S} \geq 10$ (dark blue) and $N_{S} \geq$ 20 (olive green). Right: Other types of high-quality filtering data using the intra-site statistics $n_{e} \geq 3$ and $k \geq 100$ (orange); $D C \geq 4, n_{e} \geq 4$ and $k \geq 50$ (yellow).

\subsection{What was the geomagnetic field like during the Kiaman superchron?}

The paleomagnetic directional database presented in this study is so far the most complete and largest list of site remanence directions for the Kiaman period. The database for the same time interval recently presented by Oliveira et al. (2018) is far more 
limited comprising only nine datasets due to the very restrictive filtering adopted. Our new Kiaman database, using more flexible criteria, resulted in a total of 1419 reliable individual igneous directions from 89 datasets of which 60 (977 directions) are derived from extrusive rocks. After application of a modified N-dependent $A_{95}$ envelope 1345 directions (946 extrusive data) remained.

The directional shape and scale analyses applied to the merged datasets using $10^{\circ}$ paleolatitude bands present two distinctive behaviors: elongated and more disperse distributions near the Equator similar to the predictions for the TK03 and BCE19; and an essentially constant behavior of more concentrated and circular distributions for latitudes in the range $10^{\circ}$ to $70^{\circ}$. There are no systematic differences in age that could explain the distinction between the Equatorial data and those from other latitudes. The only difference detected is that the quality of most of the Equatorial data cannot survive the more restrictive filtering processes (Figure 5.3).

We searched for simplified GGP models for the extrusive members of the Kiaman database in two situations, including and discarding the equatorial band, but without another restrictive filtering. We used the least-squares minimization of differences between theoretical predictions and data results of directional standard deviations $\left(\sigma_{E}\right.$, $\sigma_{N}$ ), to determine the $\alpha$ and $\beta$ for a given $g_{1}^{0}=18 \mu T$ (Figure 5.8) of the best fit GGP model. 


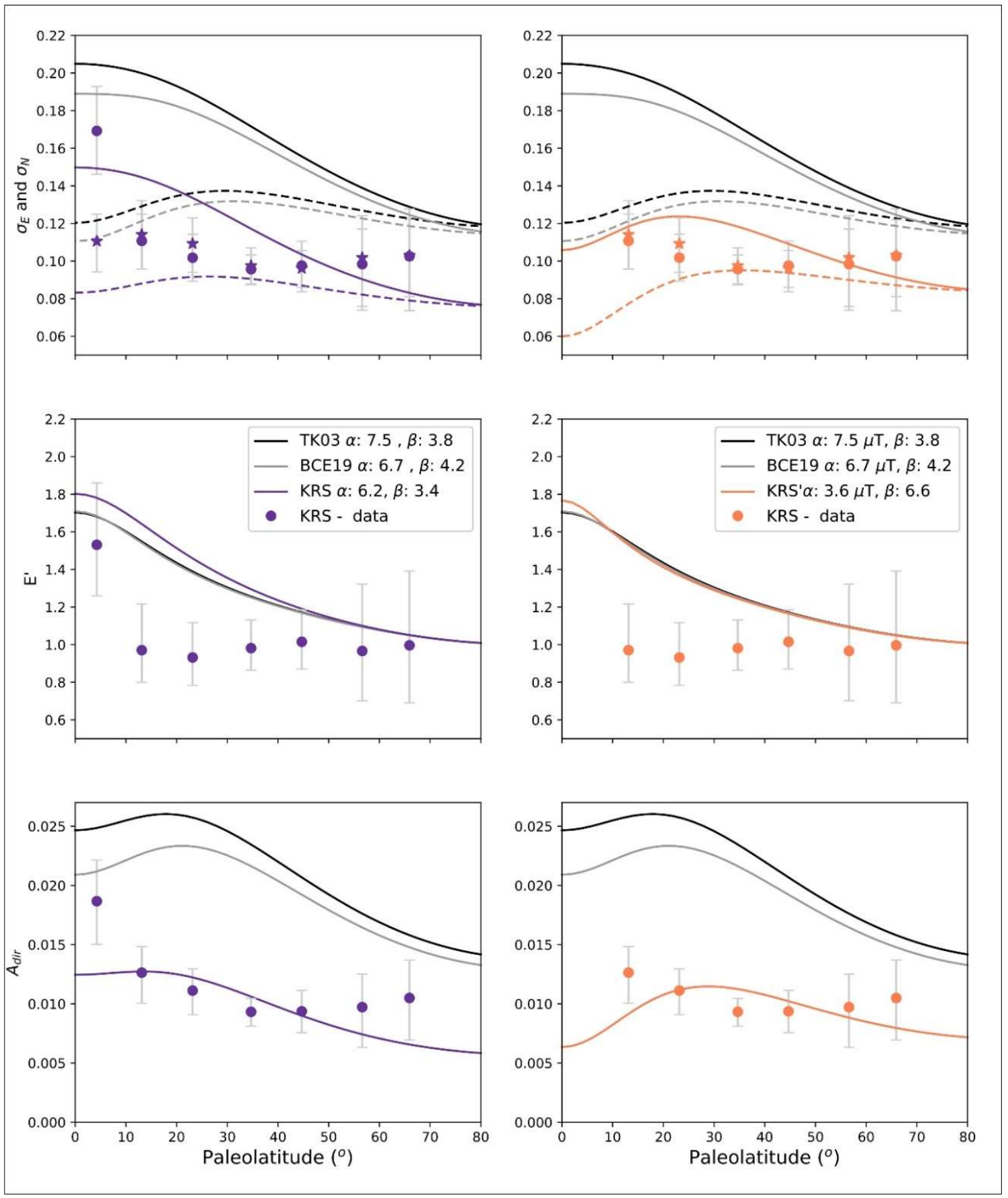

Figure 5.8. Directional PSV results using $10^{\circ}$ bands of paleolatitude from the KRS database, where $\sigma_{E}, \sigma_{N}$ are the standard deviation in $x_{E}$ and $x_{N}$ equal-area coordinates from rotated distributions, $E^{\prime}=\sigma_{N} / \sigma_{E}$ is the elongation of distribution along the N-S direction, and $A_{d i r}=\sigma_{E} \sigma_{N}$ is the overall variability of the distributions. Black (grey) curves are the predicted values of $\sigma_{E}, \sigma_{N}, E^{\prime}$, and $A_{\text {dir }}$ predicted by the TK03 (BCE19) GGP models. Only extrusive results are shown as purple symbols. Orange symbols are KRS results without the equatorial band. Grey bars are the $95 \%$ confidence intervals given by bootstrap resampling. Purple and orange curves are the best fit models fitted to the KRS database with and without the equatorial band, respectively.

The minimum misfit model found for the Kiaman reversed superchron (KRS) database including the equatorial band, $K R S_{m}=\left(\alpha, \beta, g_{1}^{0}\right)=(6.2 \mu T, 3.4,18 \mu T)$, has on average normalized absolute deviation misfit of 2.5 to the data. If the equatorial 
band is excluded, the minimum model, $K R S^{\prime}{ }_{m}=(3.6 \mu T, 6.6,18 \mu T)$, has on average normalized absolute deviation misfit of 1.9. These values are lower than the mean distances between the Kiaman results and BCE19 (5.0 error bars) and TK03 (6.6 error bars) models. However, the results for $\sigma_{E}$ from the Kiaman database lie more than 1 error bar of distance on average above the GGP model $K R S_{m}$ (purple curves), while the $\sigma_{N}$ results are always less than predicted by the model. The same systematic differences occur with the model $K R S^{\prime}{ }_{m}$ constructed from the Kiaman data excluding the equatorial band. However, in this case, the distances are less than one error bar and can be considered more compatible with a simplified GGP model. In both cases the compatibility with the overall variability, $A_{d i r}$, is better than with the distribution shapes.

The high result for $\beta=6.6$ found by the $K R S^{\prime}{ }_{m}$ model means that the PSV variation of dipole family components is more important than in other GGP models found for the last few million years $(\beta=3.8$ TK03 and $\beta=4.2$ BEC19). A strong average dipolar contribution might be expected during superchrons: Tarduno et al. (2006) found high intensities of the dipolar field. McFadden et al. (1991), Biggin et al. (2008) and Oliveira et al. (2018) found strong latitudinal dependence of VGP scatter, which would seem to imply higher variability in the dipole family than in the quadrupole family. In a recent paper, Brandt et al. (2019a) tested higher $\beta$ values and smaller $\alpha(\beta=5, \alpha=4.5 \mu T)$ for simplified GGP models to produce high latitudinal dependence of VGP scatter aiming to explain the VGP scatter found for long paleomagnetic data sequences from the Kiaman period. High dipole strength and variability combined seem somewhat counterintuitive, but we should keep in mind that $\beta$ reflects the ratio of the dipole to quadrupole family variations, not the absolute value which is determined by $\alpha$.

Although model $K R S^{\prime}{ }_{m}$ has some characteristics expected for a superchron, the misfit to the Kiaman results are pretty large and systematic. We can observe this in Figure 5.8, where the data do not follow the predicted trends. The small, circular and constant distribution of directions for latitudes higher than $10^{\circ}$ is not observed in the directional paleosecular variation results of the last few million years. The directional analysis results of $\sigma_{E}$ and $\sigma_{N}$ for PSV10, the current paleosecular database for the last 10 My (Brandt et al., 2019b, Figure 5.9), follow a gradual trend from the Equator to the poles, agreeing with the numerical prediction of the simplified GGP models TK03 and BCE19. The only latitude band in which these models do not adequately represent real paleomagnetic data 
for the last $10 \mathrm{My}$ is the high latitude band of $70-80^{\circ}$, which is mostly composed of paleomagnetic directions from the McMurdo region, Antarctica (Lawrence et al., 2009).

The comparison between Kiaman and PSV10 results is somewhat unrealistic, as the PSV10 database is more than twice the size of the Kiaman database in terms of the number of directions. But if we consider the same filtering for both databases the size of the Kiaman database diminishes by half. The inclusion of low-quality data could be expected to increase overall variability. So, if we imagine that the suppressed variation behavior of the Kiaman results includes additional sources of scatter besides unremoved experimental errors, this would suggest that the true Kiaman paleosecular variation was even lower than the results presented here, and the paleomagnetic field activity of that time was even more subdued.

Our numerical predictions from GGP models so far only include geomagnetic variations. To minimize experimental noise, the mean of specimen directions is commonly used, but the effect of ill-determined mean directions will increase the standard deviations $\sigma_{E}$ and $\sigma_{N}$. The impact is simulated in Figure 5.9. Mean directions for three synthetic samples generated using various values for precision, $k$, (Fisher, 1953) and directions predicted by the GGP model ('spot readings' of geomagnetic field) were produced 10,000 times at every $5^{\circ}$ of latitude. These simulations (Figure 5.9) show increases in determinations of $\sigma_{E}$ and $\sigma_{N}$, which are greater for more disperse sites (lower $k$, light grey curves). This effect is less important for PSV of the geomagnetic field over the past few million years (BCE19; Figure 5.9) than for a quiet field like the plausible $K R S^{\prime}{ }_{m}$ model for Kiaman times. The increase in intra-site dispersion reduces the elongated shape of the geomagnetic PSV, and the results for $\sigma_{E}$ and $\sigma_{N}$ become larger and more similar. This effect is perhaps best visualized in the plots of elongation $E^{\prime}$ (Figure 5.9) which diminishes with the loss of precision and is more significant for the $K R S^{\prime}{ }_{m}$ model than for the BCE19. Therefore, if the Kiaman geomagnetic field was working like a GGP model, the small and circular determinations we have presented in this study could be explained by the result of experimental noise combined with a greatly reduced paleosecular variation of the geomagnetic field. 


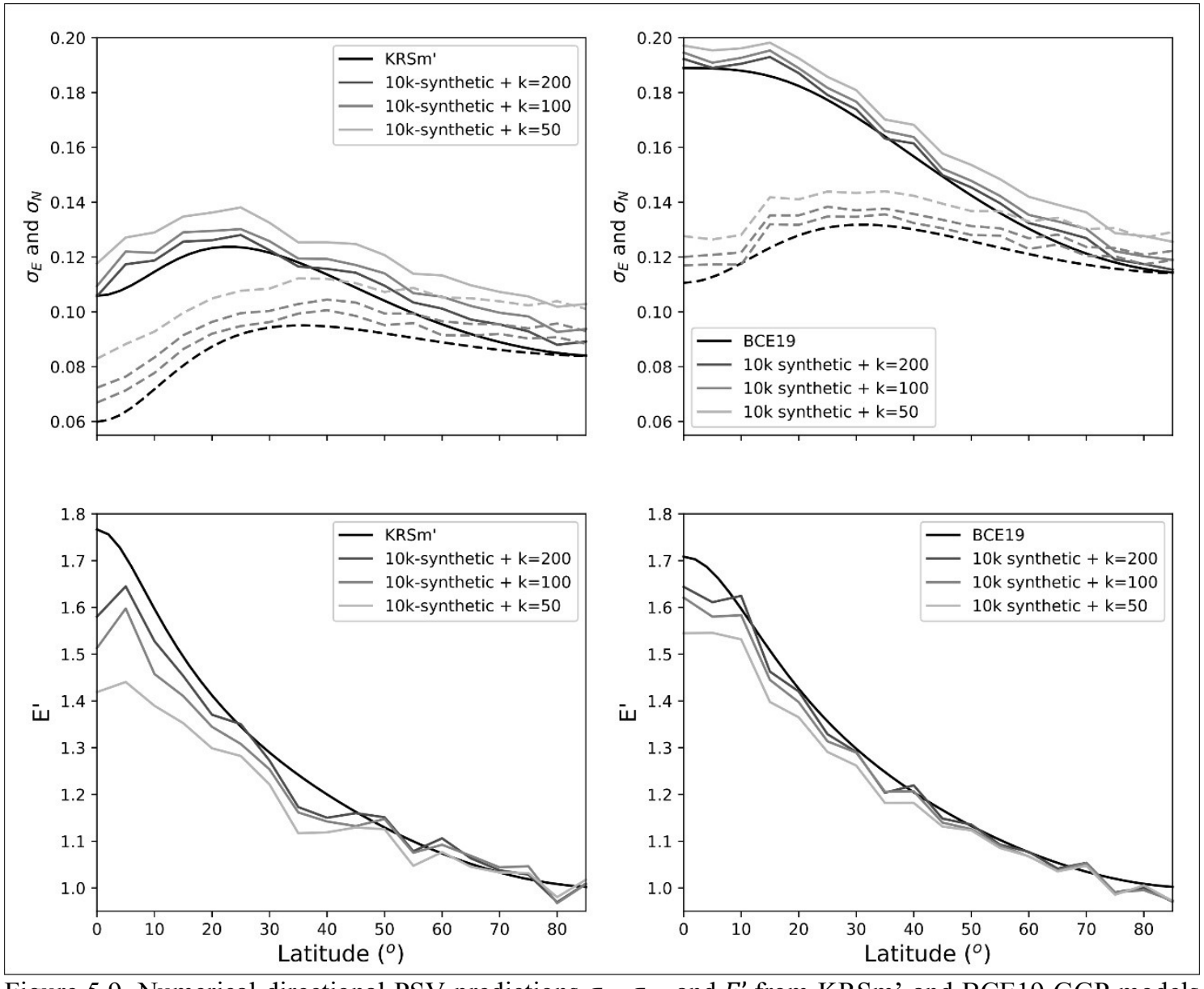

Figure 5.9. Numerical directional PSV predictions $\sigma_{E}, \sigma_{N}$, and $E^{\prime}$ from KRSm' and BCE19 GGP models (black curves) and the result of 10,000 of simulations (greyscale). For each directional simulation from the GGP model (a spot reading of the geomagnetic field), three synthetic samples were generated using various precisions, $k$ (Fisher, 1953), and a Fisher mean direction was calculated from them.

\subsection{Conclusions}

The Kiaman igneous database is the most complete list of site directions for the Kiaman period (267-318 Ma).

The Kiaman superchron geomagnetic variation is marked by low PSV variation, revealed by distributions of directions that are approximately circular, concentrated, and essentially invariant for latitudes higher than $10^{\circ}$. This is completely different from what is predicted by recent GGP models. Simplified GGP models that could be representative of this singular behavior were found using least-squares fit to $\sigma_{E}$ and $\sigma_{N}$, but these attempts were not completely successful. This indicates that either the Kiaman geomagnetic behavior cannot be explained by a simplified GGP model (Tauxe \& Kent, 2004), or, since the Kiaman geomagnetic field is much less variable than recent times, common experimental noise becomes important enough to significantly affect the results.

In the extreme case of very low paleosecular variation during the Kiaman it is possible that data uncertainty could dominate both shape and scale directional analyses 
and VGP scatter analyses. Therefore, for future work, we recommend that if the intention is to study the minutiae long term variations of this time period, the experimental procedures need to produce more accurate results (higher number of specimens per site and k) than are currently available and better determinations of uncertainty to estimate the effect of it in the overall PSV distributions.

\subsection{Acknowledgment}

D. B. had the support from the Coordenação de Aperfeiçoamento de Pessoal de Nível Superior-Brasil (CAPES)-Finance Code 88881.186997/2018-01. 



\section{Chapter 6}

\section{Main Conclusions}

Superchrons are long periods of tens of million years of a unique polarity of the geomagnetic field, which are expected to have a more stable mean dipole field with higher intensities than those for higher reversal frequency times (e. g., Tarduno et al., 2006). The PSV of superchrons measured by the VGP scatter $S$ is also expected to be different from recent times (Biggin et al., 2008b; de Oliveira et al., 2018; McFadden et al., 1991). Even though, the TK03 model is currently used to perform the shallowing correction to the magnetization of sedimentary formations, based on the application of the E/I method (e.g., Brandt et al., 2009; Franco et al., 2012; Haldan et al., 2009; Lanci et al., 2013). Considering that the PSV of a superchron is less scattered than the recent field but with the same shape, then the use of the elongation $E$ is not incorrect. However, the expected distributions of directions of a superchron were still not known. This thesis is a contribution to address this issue in various ways.

The first step was to get new paleomagnetic data from a long section of sedimentary rocks with age inserted in the Kiaman superchron (Chapter 3). The paleomagnetic data from the Mafra Formation is so far the longest known section of Kiaman magnetization with AARM inclination shallowing correction. Its paleomagnetic pole is a reference pole for South America and is compatible with other igneous poles with absolute radiometric dating. When applied to the paleomagnetic results of the Mafra Formation (Chapter 3), the $\mathrm{E} / \mathrm{I}$ method proved to be inadequate, despite the Mafra dataset satisfying all conditions required for the method: more than 100 results with good stratigraphic control. Other two long igneous sequences of Kiaman age (Haldan et al., 2014; Bahzenov et al., 2016) also gave disparate results. The elongation $E$ results presented high uncertainties, while the VGP dispersion $S_{F}$ of the Mafra results and those two sections were similar and totally incompatible with the predictions of the TK03 model. Therefore, an investment in simulations of different versions of GGP was performed. Due to the way the GGP models are built, $S_{F}$ and $E$ predictions cannot be dissociated. If the parameters $\alpha, \beta$ of a GGP model change, both $E$ and $S_{F}$ change too. The simulations of different versions of GGP models showed that if the Kiaman geomagnetic field is described by a simplified GGP model with $S_{F}$ compatible with the Kiaman results, it produces more elongated 
distributions of directions at Equatorial latitudes. This new result has strong implications for the use of the E/I method and must be seen as a cautionary alert to the indiscriminate use of the method to correct supposed inclination shallowing for time intervals over which the method has not been tested.

Because the comparisons of elongation made in this study were not conclusive, the directional distribution for the Kiaman remained an open question. One of the difficulties in solving this problem is that there are few Kiaman sections (mainly of igneous nature) long enough to perform the necessary tests. According to Tauxe et al. (2008), the minimum number of independent records to evaluate elongation is 100-150, and datasets of this size are difficult to achieve. Therefore, a new paleomagnetic database based on paleomagnetic results from igneous rocks to assure more fidelity in the record of the geomagnetic field (Chapter 5), accompanied by a new methodology of analyses based on directional distributions (Chapter 4), was furtherly done.

The new type of PSV statistic developed in this work (Chapter 4) is based on the shape and scale of directional distributions. The PSV parameters are the orthogonal standard deviations $\sigma_{E}$ and $\sigma_{N}$ of equal-area coordinates $\left(x_{E}\right.$ and $\left.x_{N}\right)$ from rotated distributions with the expected direction in the vertical, which can be predicted by numerical integration of the directional pdf (Constable and Parker, 1988; Khokhlov et al., 2001) given by a simplified GGP model as the TK03 (Tauxe and Kent, 2004). Simulations with thousands of synthetic samples were done to test whether the numerical determinations could be good estimates. The simulations revealed a latitudinal dependence of the PSV measurements $\sigma_{E}$ and $\sigma_{N}$ very close to and randomly distributed around the numerical predictions, so the differences could be explained only by the random effect of the Monte Carlo approach. Moreover, the results using real data (PSV10 database of Cromwell et al., 2018) are reasonably compatible with the prediction of a simplified zonal GGP when both hemispheres of data are joined, except at high latitudes. Therefore, the use of the latitudinal dependence of $\sigma_{E}$ and $\sigma_{N}$ for latitudes lower than $70^{\circ}$, seems to be diagnostic and can be used for modeling. According to the numerical prediction presented in this study, for a zonal GGP model with a GAD mean, the latitudinal dependence $\sigma_{E}$ and $\sigma_{N}$ is symmetric with respect to the Equator and independent of polarity, which allows the use of this model for the geological past when the polarity and/or hemisphere are unknown. 
The results of GGP simulations also presented in Chapter 4 clearly indicate that for a zonal GGP model for the geological past, the best way of determining a paleoinclination or a paleomagnetic pole is using an iterative cutoff (Vandamme, 1994). This method came to replace the subjective procedure of eliminating the transient data due to reversals or excursions of the geomagnetic field which tend to enhance the scatter in a paleomagnetic dataset, but do not represent the characteristic PSV scatter.

A new simplified GGP model, the BCE19 with $g_{1}^{0}, \alpha, \beta=(-18 \mu T, 6.7 \mu T, 4.2)$, was fitted to the most up-to-date directional paleomagnetic database from lavas of the last 10 Ma (PSV10; Cromwell et al., 2018). The BCE19 model follows the same simplifications (mean GAD, $\alpha$ and $\beta$ parameters) proposed by Tauxe and Kent (2004), but instead of fitting the model according to the latitudinal VGP scatter, PSV measurements from directional distributions $\sigma_{E}$ and $\sigma_{N}$ were used.

The Kiaman database of this work (Chapter 5) is the most complete list of directions per site for this superchron and it revealed a small PSV variation characterized by approximately circular directional distributions $\left(\sigma_{E} \sim \sigma_{N}\right)$, and tight for latitudes higher than $10^{\circ}$. This behavior completely differs from what is predicted by the recent GGP models. Simplified GGP models that could be representative of this singular behavior were found using the minimization of squared differences of $\sigma_{E}$ and $\sigma_{N}$, but the misfit between the models and the data is higher than the uncertainties. This may be an indication that the Kiaman geomagnetic behavior cannot be explained by a simplified GGP model (Tauxe \& Kent, 2004). Alternatively, the Kiaman geomagnetic field is much less variable than the recent field and, consequently, the usual experimental noise that affects the paleomagnetic data represents a much stronger influence for the Kiaman PSV results. In the extreme case of very low paleosecular variation during the Kiaman, the data uncertainty could dominate both the VGP scatter and the shape and scale directional analyses. Therefore, if the intention is to study the minutiae long scale variations of that period, besides longer series of directional paleomagnetic results, future works will need more accurate experimental procedures increasing the number of analyzed specimens per site and getting higher precision $(k)$. It becomes obvious that much more effort in obtaining good quality data from the Kiaman superchron, as well as from other superchrons, is still necessary to get a good representation of these particular field states. 



\section{References}

Abrajevitch, A., Van der Voo, R., Bazhenov, M.L., Levashova, N.M., McCausland, P.J.A., 2008. The role of the Kazakhstan orocline in the late Paleozoic amalgamation of Eurasia. Tectonophysics 455, 61-76.

Ali, J.R., Cheung, H.M.C., Aitchison, J.C., Sun, Y.D., 2013. Palaeomagnetic reinvestigation of Early Permian rift basalts from the Baoshan Block, SW China: constraints on the site-of-origin of the Gondwana-derived eastern Cimmerian terranes. Geophysical Journal International 193, 650-663.

Amit, H., Olson, P., 2015. Lower mantle superplume growth excites geomagnetic reversals. Earth and Planetary Science Letters 414, 68-76.

Aubele, K., Bachtadse, V., Muttoni, G., Ronchi, A., 2014. Paleomagnetic data from Late Paleozoic dikes of Sardinia: Evidence for block rotations and implications for the intraPangea megashear system. Geochemistry Geophysics Geosystems 15, 1684-1697.

Audibert, M., Bazhenov, M.L., 1992. Permian paleomagnetism of the northern Tien-shan and its tectonic implications. Tectonics 11, 1057-1070.

Bachtadse, V., Aubele, K., Muttoni, G., Ronchi, A., Kirscher, U., Kent, D.V., 2018. New early Permian paleopoles from Sardinia confirm intra-Pangea mobility. Tectonophysics 749, 21-34.

Bachtadse, V., Zanglein, R., Tait, J., Soffel, H.C., 2002. Palaeomagnetism of the Permo/Carboniferous (280 Ma) Jebel Nehoud ring complex, Kordofan, Central Sudan. Journal of African Earth Sciences 35, 89-97.

Bazhenov, M.L., Van der Voo, R., Menzo, Z., Dominguez, A.R., Meert, J.G., Levashova, N.M., 2016. Paleomagnetism and dating of a thick lava pile in the Permian Bakaly formation of eastern Kazakhstan: Regularities and singularities of the paleomagnetic record in thick lava series. Physics of the Earth and Planetary Interiors 253, 5-20.

Beck, M.E., Garcia, R.A., Burmester, R.F., Munizaga, F., Herve, F., Drake, R.E., 1991. Paleomagnetism and geochronology of late paleozoic granitic-rocks from the Lake District of Southern Chile - implications for accretionary tectonics. Geology 19, 332335.

Behar, N., Shaar, R., Tauxe, L., Asefaw, H., Ebert, Y., Heimann, A., Koppers, A.A.P., Ron, H.G., 2019. Paleomagnetism and Paleosecular Variations From the PlioPleistocene Golan Heights Volcanic Plateau, Israel. Geochemistry Geophysics Geosystems 20, 4319-4335.

Belica, M.E., Tohver, E., Pisarevsky, S.A., Jourdan, F., Denyszyn, S., George, A.D., 2017. Middle Permian paleomagnetism of the Sydney Basin, Eastern Gondwana: Testing Pangea models and the timing of the end of the Kiaman Reverse Superchron. Tectonophysics 699, 178-198.

Biggin, A.J., Strik, G., Langereis, C.G., 2008a. Evidence for a very-long-term trend in geomagnetic secular variation. Nature Geoscience 1, 395-398.

Biggin, A.J., van Hinsbergen, D.J.J., Langereis, C.G., Straathof, G.B., Deenen, M.H.L., 2008b. Geomagnetic secular variation in the Cretaceous Normal Superchron and in the Jurassic. Physics of the Earth and Planetary Interiors 169, 3-19.

Birkenmajer, K., Grocholski, A., Milewic, J.z., Nairn, A.E.M., 1968. Palaeomagnetic studies of Polish rocks II The upper Carboniferous and lower Permian of the Sudetes., pp. 435-474. 
Birkenmajer, K., Nairn, A.E., 1964. Palaeomagnetic studies of Polish rocks. I. The Permian igneous rocks of the Kraków District and some results from the Holy Cross Mountains, in: Nairn, A.E. (Ed.). In Annales Societatis Geologorum Poloniae, pp. 225244.

Bolshakov, A.S., Solodovnikov, G.M., Vinogradov, Y.K., 1989. Paleointensity of the geomagnetic-field in the Early Permian. Izvestiya Akademii Nauk Sssr Fizika Zemli, 70-78.

Brandt, D., Ernesto, M., Rocha-Campos, A. C., dos Santos, P. R., 2009. Paleomagnetism of the Santa Fe Group, central Brazil: Implications for the late Paleozoic apparent polar wander path for South America, Journal of Geophysical Research-Solid Earth, 114, 19, doi:10.1029/2008jb005735.

Brandt, D., Ernesto, M., Constable, C., Franco, D.R., Carlos Weinschutz, L., de Oliveira Carvalho Rodrigues, P., Hinnov, L., Jaqueto, P., Strauss, B.E., Feinberg, J., de Paiva Franco, P.V., Zhao, X., 2019a. New Late Pennsylvanian Paleomagnetic Results From Paraná Basin (Southern Brazil): Is the Recent Giant Gaussian Process Model Valid for the Kiaman Superchron? Journal of Geophysical Research: Solid Earth 124, 62236242.

Brandt, D., Constable, C., Ernesto, M. 2019b (under review) Giant Gaussian process models of geomagnetic paleosecular variation: a directional outlook. Submitted to Geophysical Journal International.

Brandt, D., Ernesto, M., Constable, C. 2020 (in preparation). Properties of the geomagnetic field during the Kiaman superchron: analysis of directional distributions in a new igneous database.

Bylund, G., 1974. Palaeomagnetism of dikes along the southern margin of the Baltic Shield. Geologiska Föreningen I Stockholm Förhandlingar, pp. 231-235.

Clark, D.A., Lackie, M.A., 2003. Palaeomagnetism of the Early Permian Mount Leyshon intrusive complex and tuckers igneous complex, North Queensland, Australia. Geophysical Journal International 153, 523-547.

Constable, C.G., Johnson, C.L., 1999. Anisotropic paleosecular variation models: implications for geomagnetic field observables. Physics of the Earth and Planetary Interiors 115, 35-51.

Constable, C.G., Parker, R.L., 1988. Statistics of the geomagnetic secular variation for the past 5 My. Journal of Geophysical Research-Solid Earth and Planets 93, 1156911581.

Cornwell, J.D., 1967. Palaeomagnetism of Exeter lavas Devonshire. Geophysical Journal of the Royal Astronomical Society 12, 181-\&.

Creer, K., 1983. Computer synthesis of geomagnetic palaeosecular variations. Nature $304,695$.

Creer, K.M., Irving, E., Nairn, A.E.M., 1959. Palaeomagnetism of the Great Whin Sill. Geophysical Journal of the Royal Astronomical Society 2, 306-323.

Cromwell, G., Johnson, C., Tauxe, L., Constable, C., Jarboe, N., 2018. PSV10: A Global Data Set for 0-10 Ma Time-Averaged Field and Paleosecular Variation Studies. Geochemistry, Geophysics, Geosystems.

De Boer, J., Brookins, D.G., 1972. Paleomagnetic and radiometric age determination of (Permian) pegmatites in Middletown district (Connecticut). Earth and Planetary Science Letters 15, 140-\&.

de Oliveira, W.P., Franco, D.R., Brandt, D., Ernesto, M., Neto, C.F.D., Zhao, X.X., de Freitas, F.B.V., Martins, R.S., 2018. Behavior of the Paleosecular Variation During the Permian-Carboniferous Reversed Superchron and Comparisons to the Low 
Reversal Frequency Intervals Since Precambrian Times. Geochemistry Geophysics Geosystems 19, 1035-1048.

Deenen, M.H.L., Langereis, C.G., van Hinsbergen, D.J.J., Biggin, A.J., 2011. Geomagnetic secular variation and the statistics of palaeomagnetic directions. Geophysical Journal International 186, 509-520.

Dietzel, G.F.L., 1960. Geology and Permian paleomagnetism of the Merano region, province of Bolzano, N. Italy. Ph.D. thesis, Utrecht University.

Domeier, M., Van der Voo, R., Denny, F.B., 2011a. Widespread inclination shallowing in Permian and Triassic paleomagnetic data from Laurentia: Support from new paleomagnetic data from Middle Permian shallow intrusions in southern Illinois (USA) and virtual geomagnetic pole distributions. Tectonophysics 511, 38-52.

Domeier, M., Van der Voo, R., Tohver, E., Tomezzoli, R.N., Vizan, H., Torsvik, T.H., Kirshner, J., 2011b. New Late Permian paleomagnetic data from Argentina: Refinement of the apparent polar wander path of Gondwana. Geochemistry Geophysics Geosystems 12.

Domeier, M., Van der Voo, R., Tomezzoli, R.N., Tohver, E., Hendriks, B.W.H., Torsvik, T.H., Vizan, H., Dominguez, A., 2011c. Support for an "A-type" Pangea reconstruction from high-fidelity Late Permian and Early to Middle Triassic paleomagnetic data from Argentina. Journal of Geophysical Research-Solid Earth 116.

Domeier, M., Van der Voo, R., Torsvik, T.H., 2012. Paleomagnetism and Pangea: The road to reconciliation. Tectonophysics 514, 14-43.

Dominguez, A.R., Van der Voo, R., Torsvik, T.H., Hendriks, B.W.H., Abrajevitch, A., Domeier, M., Larsen, B.T., Rousse, S., 2011. The similar to 270 Ma palaeolatitude of Baltica and its significance for Pangea models. Geophysical Journal International 186, 529-550.

Dooley, R.E., 1983. Paleomagnetism of some mafic intrusions in the South-Carolina piedmont .1. Magnetic systems with single characteristic directions. Physics of the Earth and Planetary Interiors 31, 241-268.

Doubrovine, P.V., Veikkolainen, T., Pesonen, L.J., Piispa, E., Ots, S., Smirnov, A.V., Kulakov, E.V., Biggin, A.J., 2019. Latitude Dependence of Geomagnetic Paleosecular Variation and its Relation to the Frequency of Magnetic Reversals: Observations From the Cretaceous and Jurassic. Geochemistry Geophysics Geosystems 20, 1240-1279.

Driscoll, P.E., Evans, D.A.D., 2016. Frequency of Proterozoic geomagnetic superchrons. Earth and Planetary Science Letters 437, 9-14.

Edel, J.B., Montigny, R., Thuizat, R., 1981. Late paleozoic rotations of Corsica and Sardinia - new evidence from paleomagnetic and K-Ar studies. Tectonophysics 79, 201-223.

Esang, C.B., Piper, J.D.A., 1984. Paleomagnetism of the carboniferous e-w dike swarm in Argyllshire. Scottish Journal of Geology 20, 309-314.

Fisher, R., 1953. Dispersion on a sphere. Proceedings of the Royal Society of London Series a-Mathematical and Physical Sciences 217, 295-305.

Franco, D.R., Ernesto, M., Ponte-Neto, C.F., Hinnov, L.A., Berquo, T.S., Fabris, J.D., Rosiere, C.A., 2012. Magnetostratigraphy and mid-palaeolatitude VGP dispersion during the Permo-Carboniferous Superchron: results from Parana Basin (Southern Brazil) rhythmites. Geophysical Journal International 191, 993-1014.

Gallo, L.C., Tomezzoli, R.N., Cristallini, E.O., 2017. A pure dipole analysis of the Gondwana apparent polar wander path: Paleogeographic implications in the evolution of Pangea. Geochemistry Geophysics Geosystems 18, 1499-1519. 
Geuna, S.E., Escosteguy, L.D., 2004. Palaeomagnetism of the Upper CarboniferousLower Permian transition from Paganzo Basin, Argentina. Geophysical Journal International 157, 1071-1089.

Gilder, S., Chen, Y., Sen, S., 2001. Oligo-Miocene magnetostratigraphy and rock magnetism of the Xishuigou section, Subei (Gansu Province, western China) and implications for shallow inclinations in central Asia. Journal of Geophysical Research: Solid Earth, 106(B12), pp.30505-30521.

Haldan, M.M., Langereis, C.G., Biggin, A.J., Dekkers, M.J., Evans, M.E., 2009. A comparison of detailed equatorial red bed records of secular variation during the Permo-Carboniferous Reversed Superchron. Geophysical Journal International 177, 834-848.

Haldan, M.M., Meijers, M.J.M., Langereis, C.G., Larsen, B.T., Heyer, H., 2014. New palaeomagnetic results from the Oslo Graben, a Permian Superchron lava province. Geophysical Journal International 199, 1554-1571.

Halvorsen, E., 1970. Palaeomagnetism and the age of the younger diabases in the NyHellesund area, S. Norway. Norsk Geologisk Tidsskrift, pp. 157-166.

Harcombe-Smee, B.J., Piper, J.D.A., Rolph, T.C., Thomas, D.N., 1996. A palaeomagnetic and palaeointensity study of the Mauchline lavas, south-west Scotland. Physics of the Earth and Planetary Interiors 94, 63-73.

Haston, R.B., Luyendyk, B.P., Landis, C.A., Coombs, D.S., 1989. Paleomagnetism and question of original location of the Permian Brook-Street terrane, New-Zealand. Tectonics 8, 791-801.

Heiniger, C., 1979. Paleomagnetic and rockmagnetic properties of the Permian volcanics in the western southern Alps. Journal of Geophysics-Zeitschrift Fur Geophysik 46, 397-411.

Hounslow, M.W., Balabarov, Y.P. 2016. A geomagnetic polarity timescale for the Permian, calibrated to stage boundaries. Geological Society, London, Special Publications, 450, 61-103. doi:10.1144/sp450.8

Hounslow, M.W., 2016. Geomagnetic reversal rates following Palaeozoic superchrons have a fast restart mechanism. Nature Communications 7.

Huang, K.N., Opdyke, N.D., 1991. Paleomagnetic results from the upper carboniferous of the Shan-Thai-Malay block of western Yunnan, China. Tectonophysics 192, 333344.

Irving, E., 1977. Drift of major continental blocks since Devonian. Nature 270, 304-309.

Jesinkey, C., Forsythe, R.D., Mpodozis, C., Davidson, J., 1987. Concordant late Paleozoic paleomagnetizations from the Atacama Desert: implications for tectonic models of the Chilean Andes. Earth and Planetary Science Letters 85, 461-472.

Johnson, C.L., McFadden, P.L., 2007. The time-averaged field and paleosecular variation. Geomagnetism.

Khokhlov, A., Hulot, G., Carlut, J., 2001. Towards a self-consistent approach to palaeomagnetic field modeling. Geophysical Journal International 145, 157-171.

Khokhlov, A., Hulot, G., Bouligand, C., 2006. Testing statistical palaeomagnetic field models against directional data affected by measurement errors. Geophysical Journal International, 167(2), pp.635-648.

Klootwijk, C.T., 2002. Carboniferous palaeomagnetism of the Rocky Creek Block, northern Tamworth Belt, and the New England pole path. Australian Journal of Earth Sciences 49, 375-405.

Klootwijk, C.T., 2003. Carboniferous palaeomagnetism of the Werrie Block, northwestern Tamworth Belt, and the New England pole path. Australian Journal of Earth Sciences 50, 865-902. 
Kono, M., Tanaka, H., 1995. Mapping the Gauss coefficients to the pole and the models of paleosecular variation. Journal of Geomagnetism and Geoelectricity 47, 115-130.

Konrad, H.J., Nairn, A.E.M., 1972. Palaeomagnetism of Permian rocks of Black Forest, Germany. Geophysical Journal of the Royal Astronomical Society 27, 369-\&.

Lackie, M.A., French, D.H., Clark, D.A., 1992. Magnetic mineralogy of felsic volcanics of the Conway-Bimurra area, northeast Queensland: relationships to aeromagnetic anomalies and hydrothermal alteration.

Lackie, M.A., Schmidt, P.W., 1993. Remagnetisation of strata during the Hunter-Bowen orogeny. Exploration Geophysics, pp. 269-274.

Lanci, L., Tohver, E., Wilson, A., Flint, S., 2013. Upper Permian magnetic stratigraphy of the lower Beaufort Group, Karoo basin. Earth and Planetary Science Letters, 375, pp.123-134.

Larson, R.L., Olson, P., 1991. Mantle plumes control magnetic reversal frequency. Earth and Planetary Science Letters, 107(3-4), pp.437-447.

Lawrence, K.P., Tauxe, L., Staudigel, H., Constable, C.G., Koppers, A., McIntosh, W., Johnson, C.L., 2009. Paleomagnetic field properties at high southern latitude. Geochemistry Geophysics Geosystems 10.

Levashova, N.M., Degtyarev, K.E., Bazhenov, M.L., Collins, A.Q., Van der Voo, R., 2003. Permian palaeomagnetism of East Kazakhstan and the amalgamation of Eurasia. Geophysical Journal International 152, 677-687.

Li, Y.P., Sharps, R., McWilliams, M., Li, Y.G., Li, Q., Zhang, W., 1991. Late paleozoic paleomagnetic results from the Junggar block, northwestern China. Journal of Geophysical Research-Solid Earth 96, 16047-16060.

Li, Y.P., Sharps, R., McWilliams, M., Nur, A., Li, Y.G., Li, Q., Zhang, W., 1989. Paleomagnetic results from late paleozoic dikes from the northwestern Junggar block, northwestern China. Earth and Planetary Science Letters 94, 123-130.

Linder, J., Gilder, S.A., 2012. Latitude dependence of the geomagnetic secular variation S parameter: A mathematical artifact. Geophysical Research Letters, 39(2).

Liss, D., Owens, W.H., Hutton, D.H.W., 2004. New palaeomagnetic results from the Whin Sill complex: evidence for a multiple intrusion event and revised virtual geomagnetic poles for the late Carboniferous for the British Isles. Journal of the Geological Society 161, 927-938.

Mauritsch, H.J., Rother, K., 1983. Paleomagnetic investigations in the Thuringer forest (GDR). Tectonophysics 99, 63-72.

McElhinny, M.W., Lock, J., 1996. IAGA paleomagnetic databases with access. Surveys in Geophysics 17, 575-591.

McElhinny, M.W., McFadden, P.L., 1997. Palaeosecular variation over the past 5 Myr based on a new generalized database. Geophysical Journal International 131, 240-252.

McFadden, P.L., Merrill, R.T., McElhinny, M.W., 1988. Dipole quadrupole family modeling of paleosecular variation. Journal of Geophysical Research-Solid Earth and Planets 93, 11583-11588.

McFadden, P.L., Merrill, R.T., McElhinny, M.W., Lee, S.H., 1991. Reversals o the Earth's magnetic field and temporal variations of the dynamo families. Journal of Geophysical Research-Solid Earth and Planets 96, 3923-3933.

Menzo, Z., 2013. Permian secular variation of the Ayaguz formation in Kazakhstan.

Montanez, I.P., Poulsen, C.J., 2013. The Late Paleozoic Ice Age: An Evolving Paradigm. Annual Review of Earth and Planetary Sciences, Vol 41 41, 629-656. 
Muttoni, G., Gaetani, M., Kent, D.V., Sciunnach, D., Angiolini, L., Berra, F., Garzanti, E., Mattei, M., Zanchi, A., 2009. Opening of the Neo-Tethys Ocean and the Pangea B to Pangea A transformation during the Permian. Geoarabia 14, 17-48.

Muttoni, G., Kent, D.V., Garzanti, E., Brack, P., Abrahamsen, N., Gaetani, M., 2003. Early Permian Pangea 'B' to Late Permian Pangea 'A'. Earth and Planetary Science Letters 215, 379-394.

Ogg, J. G., 2012. Geomagnetic Polarity Time Scale. In F. M. Gradstein, J. G. Ogg, M. G. Schmitz, G. M. Ogg (Eds.), The Geologic Time Scale (pp. 85-113). Boston, MA: Elsevier.

Opdyke, N.D., Channell, J., 1996. Magnetic stratigraphy, International geophysics series v 64. Academic Press, San Diego, pp. 1 online resource (xiv, 346 pages).

Opdyke, N.D., Roberts, J., Claoue-Long, J., Irving, E., Jones, P.J., 2000. Base of the Kiaman: Its definition and global stratigraphic significance. Geological Society of America Bulletin 112, 1315-1341.

Pavlov, V.E., Veselovskiy, R.V., Shatsillo, A.V., Gallet, Y., 2012. Magnetostratigraphy of the Ordovician Angara/Rozhkova River section: Further evidence for the Moyero reversed superchron. Izvestiya-Physics of the Solid Earth 48, 297-305.

Piper, J.D.A., 1992. Paleomagnetic properties of a Precambrian metamorphic terrane the Lewisian complex of the outer Hebrides, NW Scotland. Tectonophysics 201, 1748 .

Pisarevsky, S.A., Gladkochub, D.P., Donskaya, T.A., De Waele, B., Mazukabzov, A.M., 2006. Palaeomagnetism and geochronology of mafic dykes in south Siberia, Russia: the first precisely dated Early Permian palaeomagnetic pole from the Siberian craton. Geophysical Journal International 167, 649-658.

Quidelleur, X., Courtillot, V., 1996. On low-degree spherical harmonic models of paleosecular variation. Physics of the Earth and Planetary Interiors 95, 55-77.

Rapalini, A.E., Vilas, J.F., 1991. Tectonic rotations in the Late Paleozoic continentalmargin of southern South-America determined and dated by paleomagnetism. Geophysical Journal International 107, 333-351.

Rapalini, A.E., Vilas, J.F., Bobbio, M.L., Valencio, D.A., 1989. Geodynamic interpretations from Paleomagnetic Data of Late Paleozoic Rocks in the Southern Andes, in Geophysical Monograph Series: Deep Structure and Past Kinematics of Accreted Terranes,50, pp. 41-57.

Rencher, A.C., Christensen, W.F., 2012. Methods of multivariate analysis, Wiley series in probability and statistics, Third edition ed. Wiley, Hoboken, New Jersey, p. 1 online resource.

Roberts, P.H., Stix, M., 1972. Ac-effect dynamos, by the Buliard-Geflman Formalism. Astronomy and Astrophysics, 18, p.453.

Scheidegger, A., 1965. On the statistics of the orientation of bedding planes, grain axes, and similar sedimentological data. US Geological Survey Professional Paper 525, 164167.

Selkin, P.A., Tauxe, L., 2000. Long-term variations in palaeointensity. Philosophical Transactions of the Royal Society of London. Series A: Mathematical, Physical and Engineering Sciences, 358(1768), pp.1065-1088.

Shaanan, U., Rosenbaum, G., Pisarevsky, S., Speranza, F., 2015. Paleomagnetic data from the New England Orogen (eastern Australia) and implications for oroclinal bending. Tectonophysics 664, 182-190.

Sharps, R., McWilliams, M., Li, Y., Cox, A., Zhang, Z., Zhai, Y., Gao, Z., Li, Y., Li, Q., 1989. Lower Permian paleomagnetism of the Tarim block, northwestern China. Earth and Planetary Science Letters., pp. 275-291. 
Shatsillo, A.V., Fedyukin, I.V., Powerman, V.I., 2014. Paleomagnetism of the Late Paleozoic granites of the Angara-Vitim batholith and the host rocks of the BaikalPatom folded area: tectonic implications. Russian Geology and Geophysics 55, 864880.

Smirnov, A.V., Tarduno, J.A., Evans, D.A.D., 2011. Evolving core conditions ca. 2 billion years ago detected by paleosecular variation. Physics of the Earth and Planetary Interiors 187, 225-231.

Soffel, H.C., Harzer, F., 1991. An upper Carboniferous-lower Permian (280 ma) paleomagnetic pole from the western margin of the Bohemian massif. Geophysical Journal International 105, 547-\&.

Solodovnikov, G.M., 1992a. Paleointensity of the geomagnetic field in the Lower Permian. Izv. Acad. Sci., Phys. Solid Earth., pp. 718-722.

Solodovnikov, G.M., 1992b. Paleostrength of geomagnetic field in Middle-Late Carboniferous. Izv. Phys. Solid Earth., pp. 327-331.

Song, P., Ding, L., Li, Z., Lippert, P.C., Yue, Y., 2017. An early bird from Gondwana: Paleomagnetism of Lower Permian lavas from northern Qiangtang (Tibet) and the geography of the Paleo-Tethys. Earth and Planetary Science Letters 475, 119-133.

Stojanovic, D., Aitchison, J.C., Ali, J.R., Ahmad, T., Dar, R.A., 2016. Paleomagnetic investigation of the Early Permian Panjal Traps of NW India; regional tectonic implications. Journal of Asian Earth Sciences 115, 114-123.

Tarduno, J.A., Cottrell, R.D., Smirnov, A.V., 2006. The paleomagnetism of single silicate crystals: Recording geomagnetic field strength during mixed polarity intervals, superchrons, and inner core growth. Reviews of Geophysics 44.

Tauxe, L., Kent, D.V., 2004. A simplified statistical model for the geomagnetic field and the detection of shallow bias in paleomagnetic inclinations: Was the ancient magnetic field dipolar? Timescales of the Paleomagnetic Field 145, 101-115.

Tauxe, L., Kodama, K.P., 2009. Paleosecular variation models for ancient times: Clues from Keweenawan lava flows. Physics of the Earth and Planetary Interiors 177, 3145.

Tauxe, L., Kodama, K.P., Kent, D.V., 2008. Testing corrections for paleomagnetic inclination error in sedimentary rocks: A comparative approach. Physics of the Earth and Planetary Interiors 169, 152-165.

Tauxe, L., Shaar, R., Jonestrask, L., Swanson-Hysell, N.L., Minnett, R., Koppers, A.A.P., Constable, C.G., Jarboe, N., Gaastra, K., Fairchild, L., 2016. PmagPy: Software package for paleomagnetic data analysis and a bridge to the Magnetics Information Consortium (MagIC) Database. Geochemistry Geophysics Geosystems 17, 24502463.

Tauxe, L., Yamazaki, T., 2007. Paleointensities. Treatise on Geophysics.: Geomagnetism, Vol. 5. Elsevier.

Thompson, J.F.C., Guillaume, A., Daly, L., 1986. Palaeomagnetism of the Permian Volcanic Rocks of Moissey (French Jura): Implications For the Palaeofield and Tectonic Evolution. Geophysical Journal International 86, 103-117.

Thorning, L., Abrahamsen, N., 1980. Palaeomagnetism of Permian multiple intrusion dykes in Bohuslän, SW Sweden. Geophysical Journal International 60, 163-185.

Torsvik, T.H., Van der Voo, R., 2002. Refining Gondwana and Pangea palaeogeography: estimates of Phanerozoic non-dipole (octupole) fields. Geophysical Journal International 151, 771-794. 
Torsvik, T.H., Van der Voo, R., Preeden, U., Mac Niocaill, C., Steinberger, B., Doubrovine, P.V., van Hinsbergen, D.J.J., Domeier, M., Gaina, C., Tohver, E., Meert, J.G., McCausland, P.J.A., Cocks, L.R.M., 2012. Phanerozoic polar wander, palaeogeography and dynamics. Earth-Science Reviews 114, 325-368.

Usui, Y., Tian, W., 2017. Paleomagnetic directional groups and paleointensity from the flood basalt in the Tarim large igneous province: implications for eruption frequency. Earth Planets and Space 69.

Van Dongen, P.G., 1967. The rotation of Spain: palaeomagnetic evidence from the eastern Pyrenees. Palaeogeography, Palaeoclimatology, Palaeoecology, pp. 417-432.

Vandamme, D., 1994. A new method to determine paleosecular variation. Physics of the Earth and Planetary Interiors 85, 131-142.

Veikkolainen, T. and Pesonen, L.J., 2014. Palaeosecular variation, field reversals and the stability of the geodynamo in the Precambrian. Geophysical Journal International, 199(3), pp.1515-1526.

Vigliotti, L., Alvarez, W., McWilliams, M., 1990. No relative rotation detected between Corsica and Sardinia. Earth and Planetary Science Letters 98, 313-318.

Westphal, M., Orsini, J., Vellutini, P., 1976. Le microcontinent corso-sarde, sa position initiale: Donnees paleomagnetiques et raccords geologiques. Tectonophysics, pp. 141157.

Wynne, P.J., Irving, E., Osadetz, K., 1983. Paleomagnetism of the Esayoo formation (Permian) of northern Ellesmere island - possible clue to the solution of the Nares strait dilemma. Tectonophysics 100, 241-256.

Xu, Y., Yang, Z., Tong, Y.-B., Wang, H., Gao, L., An, C., 2015. Further paleomagnetic results for lower Permian basalts of the Baoshan Terrane, southwestern China, and paleogeographic implications. Journal of Asian Earth Sciences 104, 99-114.

Yi, Z., Huang, B., Xiao, W., Yang, L., Qiao, Q., 2015. Paleomagnetic study of Late Paleozoic rocks in the Tacheng Basin of West Junggar (NW China): Implications for the tectonic evolution of the western Altaids. Gondwana Research 27, 862-877.

Yuan, K., Van der Voo, R., Bazhenov, M.L., Bakhmutov, V., Alekhin, V., Hendriks, B.W.H., 2011. Permian and Triassic palaeolatitudes of the Ukrainian shield with implications for Pangea reconstructions. Geophysical Journal International 184, 595 610.

Zijderveld, J.D.A., 1967. The natural remanent magnetizations of the Exeter volcanic traps (Permian, Europe). Tectonophysics, pp. 121-153.

Zijderveld, J.D.A., De Jong, K.A., Van der Voo, R., 1970. Rotation of Sardinia: Palaeomagnetic evidence from Permian rocks. Nature, 226(5249), pp.933-934.

Zijderveld, J.D.A., De Jong, K.A., 1969. Paleomagnetism of some Late Paleozoic and Triassic rocks from the Eastern Lombardic Alps, Italy. Geologie en Mijnbouw, pp. 559-564. 